\title{
ELLIPSOMETRY OF SURFACE LAYERS ON LEAD AND LITHIUM
}

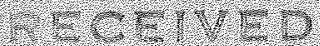 (2)

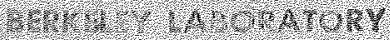 \\ Richard Dudley Peters \\ (M. S. thesis) \\ DEC 22.1978

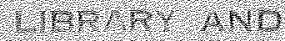

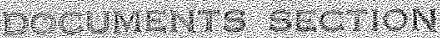 \\ October 1978}

Prepared for the U. S. Department of Energy under Contract W-7405-ENG-48

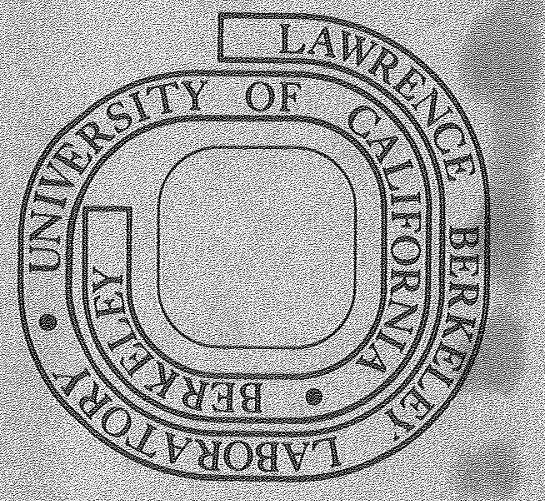

\section{TWO-WEEK LOAN COPY}

This is a Library Circulating Copy which may be borrowed for two weeks. For a personal retention copy, call Tech. Info. Division, Ext. 6782 


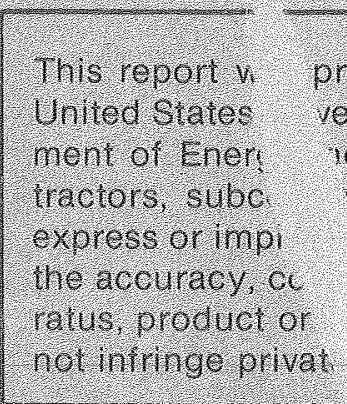

\section{LEGAL NOTICE}

prepared as an account of work sponsored by the vernment. Neither the United States nor the Depart ior any of their employees, nor any of their con ctors, or thetr employees, makes any warranty. jr assumes any legal liability or responsibility for theness or userulness of any Intormation appabss disclosed, or represents that its use woutd phed rights.
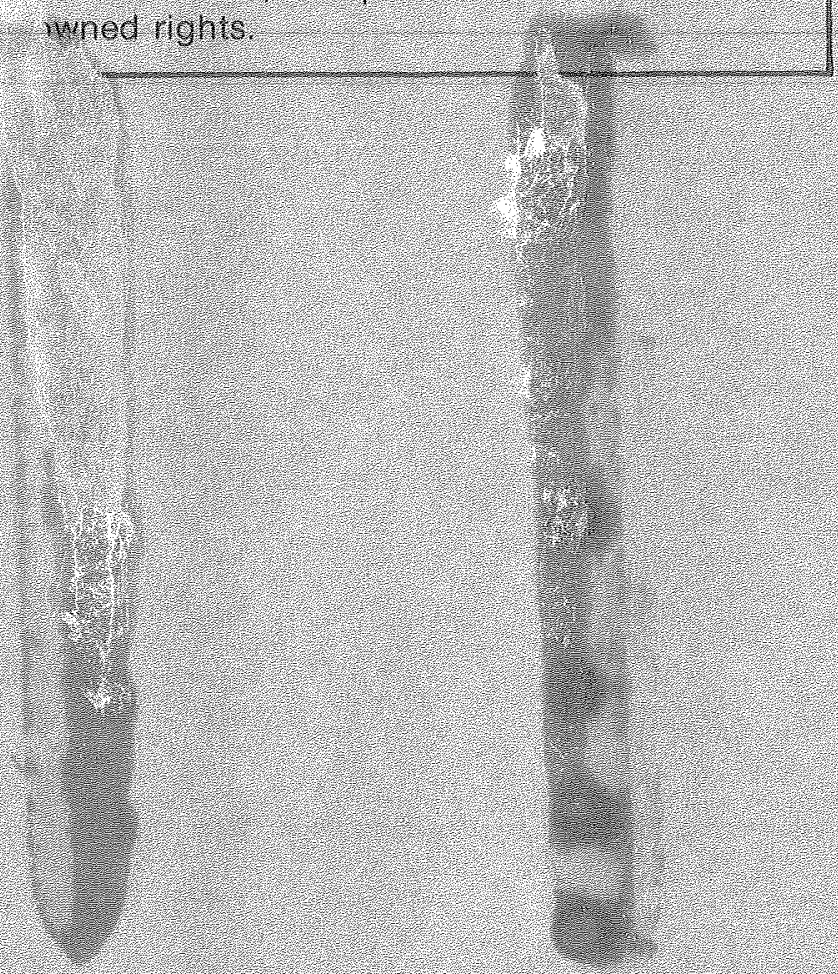
E1Iipsometry of Surface Layers on Lead and Lithium

By

Richard Dudley Peters

Materials and Molecular Research Division, Lawrence Berkeley Laboratory and Department of Chemical Engineering, University of California Berkeley, California, 94720

\begin{abstract}
An automatic self-compensating ellipsometer has been used to study anodic and corrosion films on lead exposed to sulfuric acid and and Ithium to water. Acid concentrations were $1.3,3.1$ and $5 \mathrm{M}$. Anodic current densities for lead ranged from $0.01 \mathrm{~mA} / \mathrm{cm}^{2}$ to $1.3 \mathrm{~mA} / \mathrm{cm}^{2}$ and mass transport conditions included free convection and forced convection. Scanning electron micrographs of the resulting surfaces were also made.

A computer intexpretation of ellipsometer measurements assumes the formation of up to six layers and applies a continuous mass balance. Seven to nine parameters describing the mechanism and structure of surface layers are derived by multidimensional fitting of the measurements. A solution mechanism of film formation on lead is indicated by the dependence of film properties on factors that influence the interfacial concentration of reaction products. A colloidal or polymerized phase of $\mathrm{PbSO}_{4}$ suspended in the solution is postulated on the basis of observed mass balances and interfacial solution refractive indices. Kinetic parameters describing the corrosion of lead, evaluated from ellipsometer measurements, are consistent with those reported in the 1iterature. The lead electrode has now been found to be protected
\end{abstract}


from corrosion during an open circuit potential of $-.6 \mathrm{~V}$ vs $\mathrm{Hg} / \mathrm{HgSO}_{4}$ (basic sulfate). Cathodic reduction of $\mathrm{PbSO}_{4}$ films terminates with the onset of $\mathrm{H}_{2}$ evolution before complete conversion of the sulfate. Changes in kinetic parameters of cathodic electrode reactions which result in preferred $\mathrm{H}_{2}$ evolution are indicated by this observation. The formation of optically absorbing films has been observed in the reaction of lithium with water vapor. 
Dedicated to the memory of my mother. 



\section{ELIIPSOMETRY OF SURFACE LAYERS \\ ON LEAD AND LITHIUM}

\section{Contents}

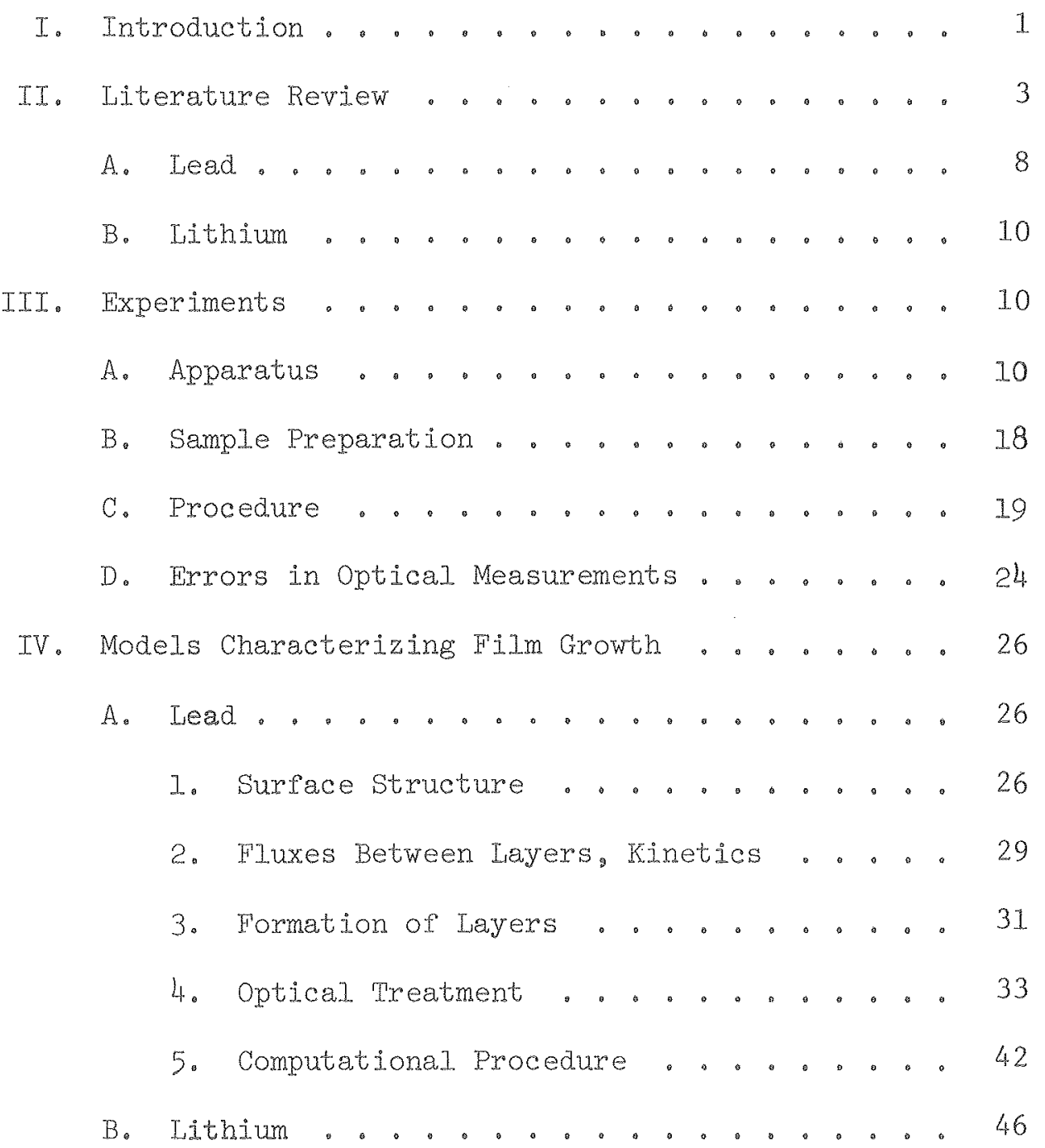


V. Results ................. 47

A. Lead ................ 47

1. Characterization of Surface Layers . . 47

Scanning Electron Micrographs . . . 47 Effect of Experimental Variables . . 47 Shapes of $\psi-\Delta$ - Plots ....... 54

Reproducibility ......... 55

Potential Measurements ...... 60

Trasients During Oxidation ..... 62

Reduction of Anodic Films ...... 65

2. MuItiparameter Model Interpretation... 70

Application of the Model ..... 70

Results of Computations ...... 74

Open Circuit Corrosion ...... 105

B. Lithium ..............., 114

1. Aqueous Electrolyte . . . .... 114

2. Corrosion in Water Vapor ...... 120

VI. Discussion . . . . . . . . . . 123

A. Lead ................. 123

B. Jithium . . . . . . . . . . 128

VII. Conclusions ............... 130

Acknowledgements .............. 133

Appendix A. Relationship Between $i_{C R Y S} \cdot \frac{d L}{d t} \cdots \cdots, 134$

Appendix B. Computex Output .......... 135

References . . . . . . . . . . , . 166 


\section{Introduction}

Surface layers are formed on many metals in electrolytic environments. Understanding the detailed processes in the growth of surface layers and the factors that determine electrode behavior is incomplete. Film formation on two materials of incerest in battery use, lead in sulfuric acid and lithium in water, has been investigated by ellipsometry. This technique allows in situ observation of film growth on metal surfaces in any transparent medium. Simulataneous measurement of current and potential is made and scanning electron micrographs of surface layers are examined.

Measurements of film growth on lead were taken over a range of applied current densities (and at open circuit), electrolyte composition and transport conditions. Electrical and ellipsometer data are interpreted with a multidimensional data fit analysis (44). This method allows determination of 7 to 9 characteristic parameters which describe film structure and the mechanism of film formation. The analysis assumes up to six surface layers and involves use of a continuous mass balance. Discrete crystals are treated optica11y as a homogeneous film. Colloidal or polymerized particles of anodic product which are intermediates in the growth of surface layers are thought to exist during anodization of lead (4), similar to previous findings with silver $(44)$.

Potential transients which occur after interruption of anodic current are measured simultaneously with ellipsometer data in the study of passivation and depassivation of the lead electrode. Reduction of $\mathrm{PbSO}_{4}$ films is also followed by the ellipsometer with 
simultaneous potential measurement. The onset of the $\mathrm{H}_{2}$ evolution and its effect on reduction of anodic product is examined.

The functioning of batteries using lithium anodes in aqueous media crucially depends on the presence of surface layers. Corrosion films on this metal are studied in water vapor since the reaction with aqueous solutions is too vigorous. Partial pressures of about 2 torr are used with an inert carrier gas. The thickness and refractive index of product films and the reaction rate between lithium and water vapor is evaluated from measured ellipsometer data using the computer mode1. 


\section{Literature Review}

Lead

The structural and electrochemical charactexistics of $\mathrm{PbSO}_{4}$ layers formed by anodic oxidation of lead in $\mathrm{H}_{2} \mathrm{SO}_{4}$ solutions have been studied by many authors $(1,2)$. The principal methods employed have been galvanostatic control, potential control, impedance measurements, $x$-ray diffraction and SEM.

The formation of lead sulfate is thought to proceed in at least two steps: first, the dissolution of the lead to $\mathrm{Pb}^{2+}$, and subsequent combination with $\mathrm{SO}_{4}=$ anions to give the solid product (3). Using transient diffusion arguments, Archdale and Haxtison have indicated that $\mathrm{Pb}^{2+}$ is present during lead electrooxidation (4). Another indication of this dissolution mechanism is the presence of large $\mathrm{PbSO}_{4}$ crystals on the anodized lead surface (5). It is inconceivable that such large crystals would form via solid state ionic conduction, particularly in 1ight of the low conductivity of $\mathrm{PbSO}_{4}(6)$. A solution mechanism also explains the relationship between current density and the number density of crystals deposited on the lead. Oxidation at high current gives a high density of small crystals, whereas at low current, fewer crystals are formed, but they are relatively large in size ( 7 ). This indicates that nuclei are being formed from a supersaturated solution of lead sulfate, the degree of supersaturation increasing with current density. Kolthoff and van't Riet have shown that the rate of nuclei formation for $\mathrm{PbSO}_{4}$ crystals indeed depends on the supersaturation of $\mathrm{Pb}^{2+}$ ions ( 8 ). Using potentiostatic control, Fleischmann and Thirsk found that at low current density (less than $0.1 \mathrm{~mA} / \mathrm{cm}^{2}$ ) the initial 
growth is consistent with progressiye nucleation, the number density of nuclei being proportional to time ( 7 )。

Apparently lead sulfate grows from a solution mechanism at discrete centers on the surface. Two types of crystal growth can be imagined. Plumbous ions and $\mathrm{SO}_{4}$ ions may nucleate in the solution forming colloidal or polymerized $\mathrm{PbSO}_{4}$ which diffuses toward and is incorporated into large crystals. Also, it may be possible for the crystal growth to occur heterogeneously, that is, $\mathrm{Pb}^{2+}$ and $\mathrm{SO}_{4}=$ combine on the surface of existing $\mathrm{PbSO}_{4}$ crystals and not in solution.

There has been little discussion of these mechanisms in the literature, probably due to the lack of firm experimental evidence for either case. Archdale and Harrison anodized lead samples which had been previously electropolished (thus having a minimum of sites for heterogeneous nucleation) and concluded that colloidal $\mathrm{PbSO}_{4}$ formed away from the surface, then diffused back and deposited on the surface (4). They postulated a polymerization reaction involving a distribution of particles containing $\mathrm{PbSO}_{4}$ molecules. Using impedance measurements Shaldaev, et a1, hypothesized that a rapid buildup of lead compounds occurs near the surface ( 9 ). Since the solubility of $\mathrm{Pb}^{2+}$ in $\mathrm{H}_{2} \mathrm{SO}_{4}$ is so low $\left(\sim 2 \times 10^{-5} \mathrm{M}\right)$ it is unlikely that this is due to high $\mathrm{Pb}^{2+}$ concentration and it is more likely that this represents suspended $\mathrm{PbSO}_{4}$ particles. Pavlov has derived a relationship describing the distance away from a porous electrode surface at which precipitation of $\mathrm{PbSO}_{4}$ could occur and found qualitative agreement with potential transients observed during galvanostatic oxidation (10). Weininger applied SEM to cycled lead negatives. From the appearance of the deposit he concluded that exystals 
grow by solution transport mechanism (11). SEM studies by Chiku and Nakagima indicate that $\mathrm{PbSO}_{4}$ deposits preferentially on low index planes of the $\mathrm{Pb}$ substrate (12). It is possible that these planes have a moxe favorable surface free energy for the formation of a solid phase from dissolved lons.

Lyzlov, et a1, have applied ellipsometry to passivated lead surfaces in $5 \mathrm{PH}_{2} \mathrm{SO}_{4}$ and conclude that optical responses (several degrees change in polarizer azimuth) resembling thickness decreases are due to removal of an interfacial phase of soluble $\mathrm{Pb}(\mathrm{II})$ compounds (13). However, it is unlikely that soluble $\mathrm{Pb}(\mathrm{Ir})$ would have a measurable effect because of its low solubility. The limit of detection of ellipsometry is for $\triangle \mathrm{C}\left(\mathrm{CuSO}_{4}\right)$ of about .002 $\mathrm{M}$ and this corresponds to .02 degree change in polarizer azimuth (14). Ellipsometer measurement of solution side interfacial refractive index changes are more likely due to removal of colloidal $\mathrm{PbSO}_{4}$ than dissociated $\mathrm{PbSO}_{4}$.

The low solubility of $\mathrm{PbSO}_{4}$ in $\mathrm{H}_{2} \mathrm{SO}_{4}$ solutions leads to the accumulation of solid material at anodized lead surfaces and subsequent isolation of the metal from the electrolyte or passivation ( 2 ). This term has two meanings in lead acid battery literature. When used in conjunction with the sponge lead negative passivation refers to the blockage of pores in the electrode matrix by $\mathrm{PbSO}_{4}$ crystals ( 3 )。 The other context refers to isolation due to adherent coatings of $\mathrm{PbSO}_{4}$ which occurs on lead grids or planar lead surfaces. The latter meaning will be discussed here. 
Passivation is observed potentiostatically as a rapid decay in current if the electrode is held at potentials more positive than the reversible $\mathrm{Pb} / \mathrm{PbSO}_{4}$ value (15). At constant current passivation is signaled by an abrupt shift in potential to more positive values (16). Elucidation of the details of passivation has been the subject of a number of investigations $(2,9,10,13,17-21)$. Galvanostatic techniques lead to the original conclusion that $\mathrm{PbSO}_{4}$ is the only divalent compound formed before attainment of the $\mathrm{PbO}_{2} / \mathrm{PbSO}_{4}$ plateau $(10,22)$. More recently, improved potentiostatic methods and high impedence voltage measurements combined with $x$-ray diffraction techniques have provided evidence for divalent compounds other than $\mathrm{PbSO}_{4}(2)$. Passivation of anodized lead has been explained based on the formation of these compounds identified as $\mathrm{PbO}$ (tetragonal), $\mathrm{PbO}^{\circ} \mathrm{PbSO}_{4}$ and $\mathrm{PbO}^{\circ} 2 \mathrm{H}_{2} \mathrm{O}$ (23). According to Pavlov when the spaces between growing $\mathrm{PbSO}_{4}$ crystals are reduced during oxidation the flux of $\mathrm{SO}_{4}{ }^{2}$ ions to the surface is reduced due to its larger ionic radius. In order to preserve electroneutrality the $\mathrm{pH}$ of the solution at the $\mathrm{Pb}$-film interface becomes alkaline and in this environment intermediate divalent species are stable. Their sudden precipitation results in a continuous dense layer of lead sulfate crystals connected by $\mathrm{Pbo}$ containing compounds which passivate the electrode. Further anodic reaction occurs probably via $\mathrm{O}_{2}{ }^{-}$transport since the metal and solution are no longer directly in contact (24). Tetragonal $\mathrm{PbO}$ and $\mathrm{\alpha}-\mathrm{PbO}_{2}$ are formed at high anodic potentials and since the $\mathrm{PbO}$ is unstable in acid, $\mathrm{PbSO}_{4}$ continues to be produced at the outside of the layer (23). 
Passivation also occurs on lead at open circuit. Samples immersed in $\mathrm{H}_{2} \mathrm{SO}_{4}$ solutions initially exhibit the reversible $\mathrm{Pb} / \mathrm{PbSO}_{4}$ potential, but as time proceeds the potential moves to more noble values. These potentials have been observed to remain for hours or days and indicate the formation of $\mathrm{PbO}^{\circ} \mathrm{PbSO}_{4}$ (2). Lander (25) found that the corrosion rate increases linearly with the square of water activity in solutions of sulfuric acid (corrosion decreases with increasing acid concentration). 
Lithium

Lithium is used as a negative electrode in a high energy density aqueous LiOH electrolyte battery (26). In this cell violent reaction between watex and lithium ( $E=-2.95 \mathrm{~V}$ vS. NHE) is apparently prevented by a layer of precipitated LiOH about $300 \mu$ thick which permits ionic diffusion but inhibits $\mathrm{H}_{2} \mathrm{O}$ diffusion (27). Two types of passivation of the Iithium electrode have been characterized. At high current densities (approximately $100 \mathrm{~mA} / \mathrm{cm}^{2}$ ) in $4 \mathrm{M}$ LiOH solution the rate of film formation. exceeds the dissolution flux from the surface and the electrode becomes mechanically passivated due to isolation from the electrolyte (28). At lower currents a sudden loss of power is observed at $-2.67 \mathrm{y} \mathrm{ys}, \operatorname{NHE}(27)$. This transient or temporary passivation is believed to be caused by the formation of $\mathrm{Li}_{2} \mathrm{O}$ which blocks pores connecting the metal and solution.

The lithium electrode exhibits two reactions, anodic dissolution and corrosion with $\mathrm{H}_{2} \mathrm{O}$ to give $\mathrm{H}_{2}$ gas. Anodic dissolution appears to be controlled by solution side mass transport of lithium hydroxide and the corrosion reaction by external current flow (29). The kinetics of the reaction of $\mathrm{H}_{2} \mathrm{O}$ and lithium has been studied and it is shown that polarization of the $\mathrm{H}_{2}$ evolution reaction is rate limiting ( 30 ). Film properties have been studied in conjunction with reaction between lithium and water vapor (31-33) and to a smaller extent in aqueous electrolyte ( 30 ). Irvine and Lund found that when lithium is exposed to $\mathrm{H}_{2} \mathrm{O}$ vapor of up to 13 torr, initially a thin coherent black film forms at a constant rate. After several hours of exposure the outer portions of the film become hydrated to LiOH. $\mathrm{H}_{2} \mathrm{O}$, and the sublayer of LiOH remains intact. Conversion of Li to LiOH still occurs suggesting 
that the two layers axe permeated by cracks and pores.

Littauer has compared $\mathrm{H}_{2} \mathrm{O}$ vapor formed fllms and those existing in LioH electrolyte ( 30$)$. X-xay analysis of film from aqueous solution show that outer regions consist of hydrous and anhydrous LiOH. Conductivity arguments suggest the film is porous. At the base of the pores adjacent to the metal a thin protective film of LiOH having high conductivity is thought to exist. Littauer proposes a duplex film model whereby an outer porous layer permeated with gas or electrolyte permits mass transport to and from the metal surface. Beneath this layer exists a thin protective and conducting layex adjacent to the metal. This is consistent with the results of Hunderi ( 33 ) who studied vapor deposited lithium films oxidized by water vapor at $10^{-8}$ torr. He applied ellipsometry to lithium hydroxide films up to 30 A thick. Resulting absorption spectra suggest the layer is doped with metal atoms and electronically conducting。 


\section{Expeximental}

\section{A. Apparatus}

Film growth measuxements are conducted using a self-compensating automatic ellipsometer ( 34 ). Fast changes may be continuously monitored since deviations from manual analyzer and polarizer settings are compensated by rotation of the polarized light beam using Faraday cells. The light signal is sensed by a photodetector mounted on the eyepiece of the instrument and is minimized by a null seeking loop controlling analyzer and polarizer Faraday cell magnets. Elliptically polarized light imposed on the sample surface by suitable polarizer rotation is transformed to linearly polarized light and nulled by perpendicular orientation of the analyzer axis. Relative phase $\Delta$ and relative ampli-

tude tan $\psi$ are derived from polarizer and analyzer azimuths respectively. Light at $546.1 \mathrm{~nm}$ is reflected from the sample at an angle of incidence of 75 degrees.

Experiments were performed in an acrylic flow channel having an entrance region of 57 hydraulic diameters, sufficient for stable laminar flow. This cell is fitted with ports which accommodate optical windows, the working electrode holder and counter and reference electrodes (Figure 1). The reference electrode port consists of a hole .025 inches in diameter located immediately upstream from the working electrode. Stainless steel was used as a counter electrode current collector for alkaline electrolytes and platinum for acid electrolytes. The flow channel is securely bolted to an adjustable mount which permits alignment between the specimen (working electrode) and optical components (Figure 2). 
Figure 1. Cell for forced convection experiments.

A. body of flow channel (acrylic resin)

B. observed electrode

C. cylindrical electrode holder

D. electrical connection for observed electrode

E. sealing nut for electrode body (polypropylene)

F. washer (Teflon)

G. O-ring for electrode body (silicone rubber)

H. holder for electrode body (polypropylene)

I. screws to attach observed electrode with holder to flow channel

J. O-ring seal for electrode holder

K. counter electrode

L. sealing material for rectangular counter electrode in round round cavity (epoxy resin)

M. stem for counter-electrode (stainless, silver-soldered)

N. O-ring seal for counter electrode

O. acorn nut with electrical connection for counter electrode (stainless)

P. electrical comection for counter-electrode

Q. cell window (plate glass, 0.25 in. thick, 0.7 in. dia.)

R. O-ring for cell window

S. pressure sleeve for cell window (PvC)

T. sealing nut for cell window (brass)

U. sealing nut for electrical comection feedmthrough

V. o-ring sea1 


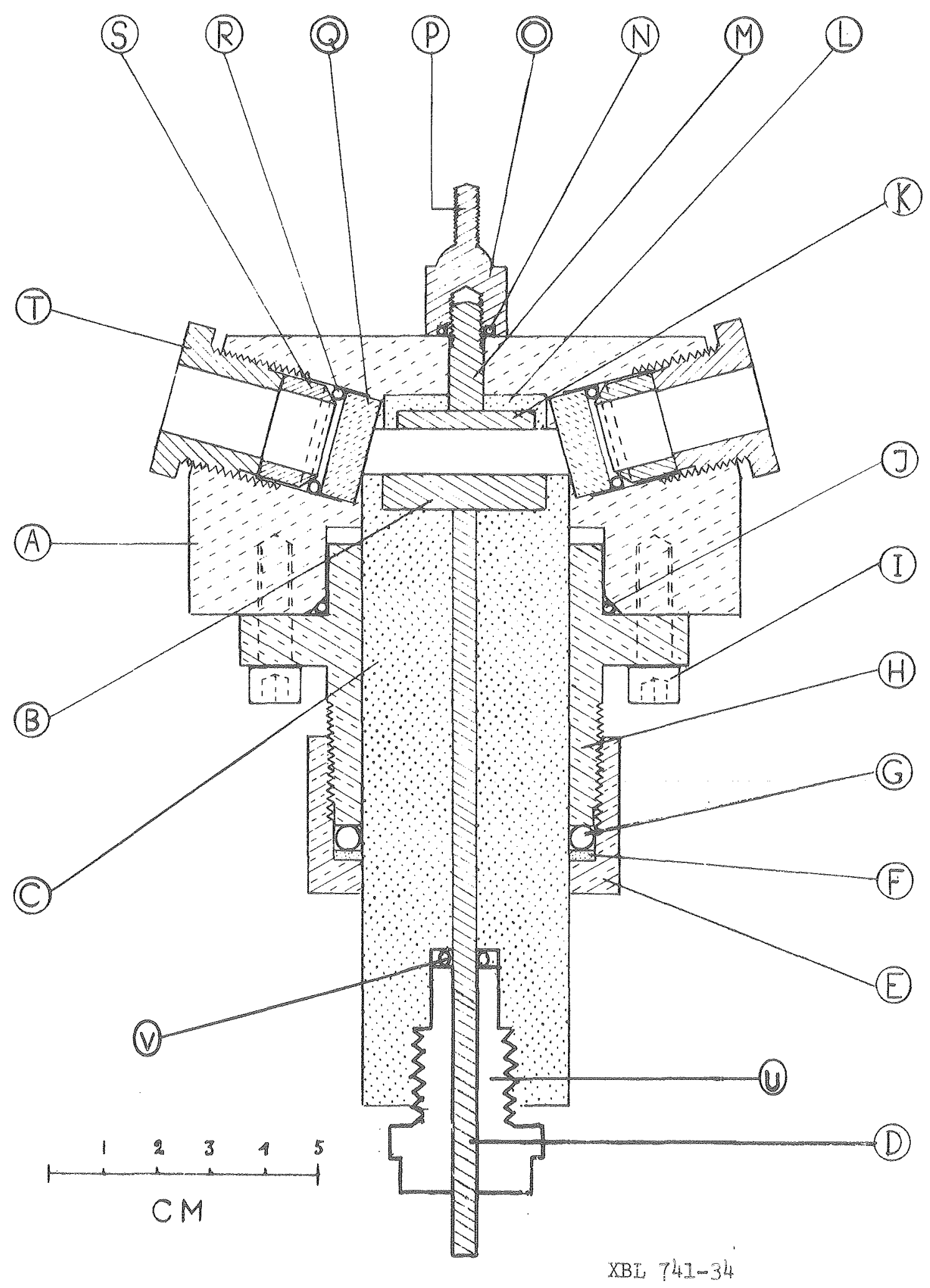

Figure 2. 


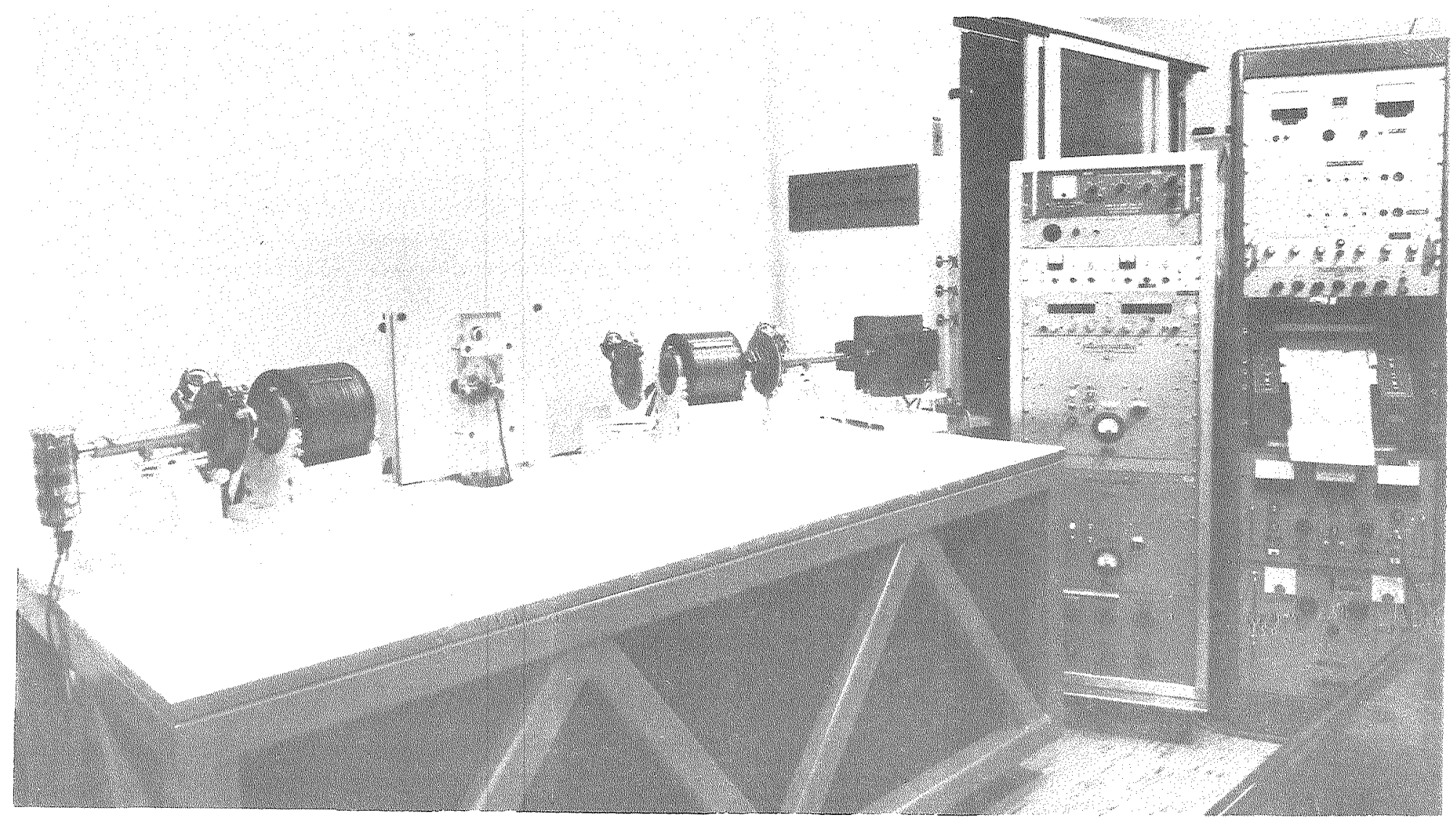

Frigure 2. Ellipsometer arrangement with vertical cell located between optical components mounted on table. Light propagates from roight to lert. Instrument racks at right house Fraraday cell power supplies (lower left rack), Faraday cell controllers (upper left rack), signal amplifiers (uppero roight rack) and the five channel recorder (center right rack). 


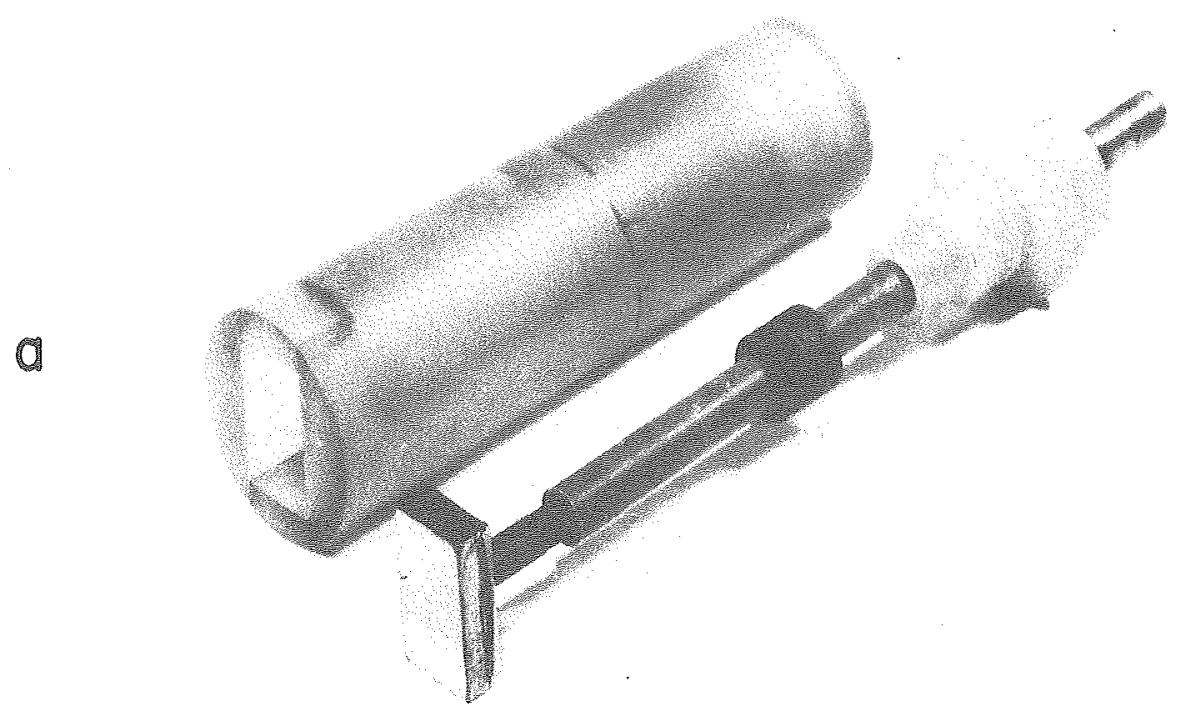

L2cm

b

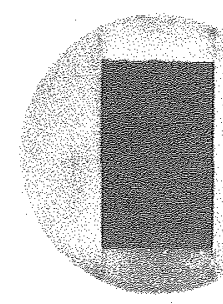

C
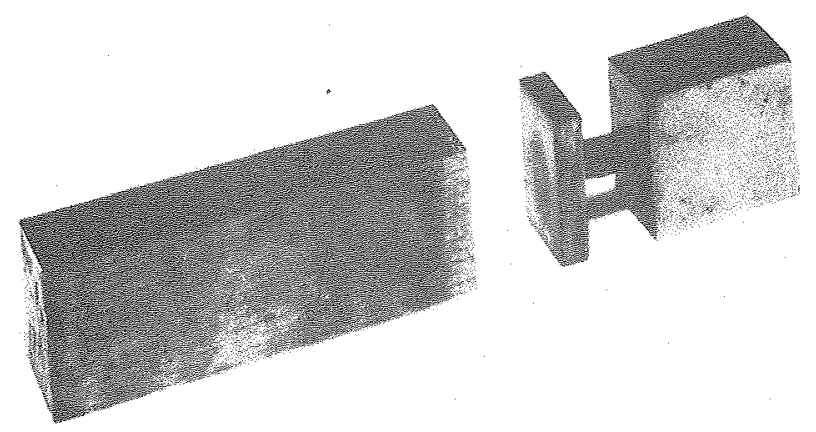

Figure 3.

a) Electrode holder (epoxy) with connecting shaft and mounted electrode. XBB 789-12511.

b) Top view of holder with inserted electrode XBB 789-12513

c) Steel die (left) and pressing support (right) for pressing lead specimen (center) which is mounted on stainless steel backplate attached to threaded stem. Backplate stem and sides of specimen are insulated with $G . E$. insulating lacquer. XBB 789-12511. 
Optically prepared samples are mounted in a cylindrical electrode holder machined from ovenacured epoxy (Figure 3a, b). The electrode holders have an adjustable shaft which allows for positioning of the sample flush with the top surface of the holder. This is necessary in order to minimize hydrodynamic disturbances during convective flow.

Electrolyte is circulated by means of a plumbing network constructed from polypropylene pipe and tubing $\left(1 / 2^{\prime \prime} 1_{0} d_{0}\right)$ with polypropylene and polyvinyl chloride valves and fittings (Figure 4). The electrolyte reservoix is a sealed container except for small openings for input and output of nitrogen. In experiments with lithium, fluid was directed either to the cell or to a standby section using remotely actuated solenoid valves *. A pump with magnetic drive (Gorman Rupp) was used so that only plastic parts contacted the fluid. An ultrasonic flowmeter (Controlatron Series 240 ) measures the electrolyte volume flow rate.

The corrosion reaction between lithium and water vapor was also pexformed in the electrolyte flow cell at atmospheric pressure and at $21^{\circ} \mathrm{C}$. Argon carrier gas was saturated with water vapor using two contacting stages and then diluted with a second stream of argon to control $\mathrm{H}_{2} \mathrm{O}$ partial pressure (Figure 5). Water vapor pressure is calculated using the following expression

$$
\mathrm{p}_{\mathrm{H}_{2} \mathrm{O}}={\stackrel{\mathrm{P}}{\mathrm{H}_{2} \mathrm{O}}} /\left(1+\mathrm{G}_{2} / \mathrm{G}_{1}\right)
$$

$G_{2}$ is the yolume flow rate of the argon dilution stream, $G_{1}$ is the flow rate of the $\mathrm{H}_{2} \mathrm{O}$ saturated argon stream and $\mathrm{P}_{\mathrm{H}_{2} \mathrm{O}}^{\circ}$ is the saturation partial

* Kynar coated brass body 


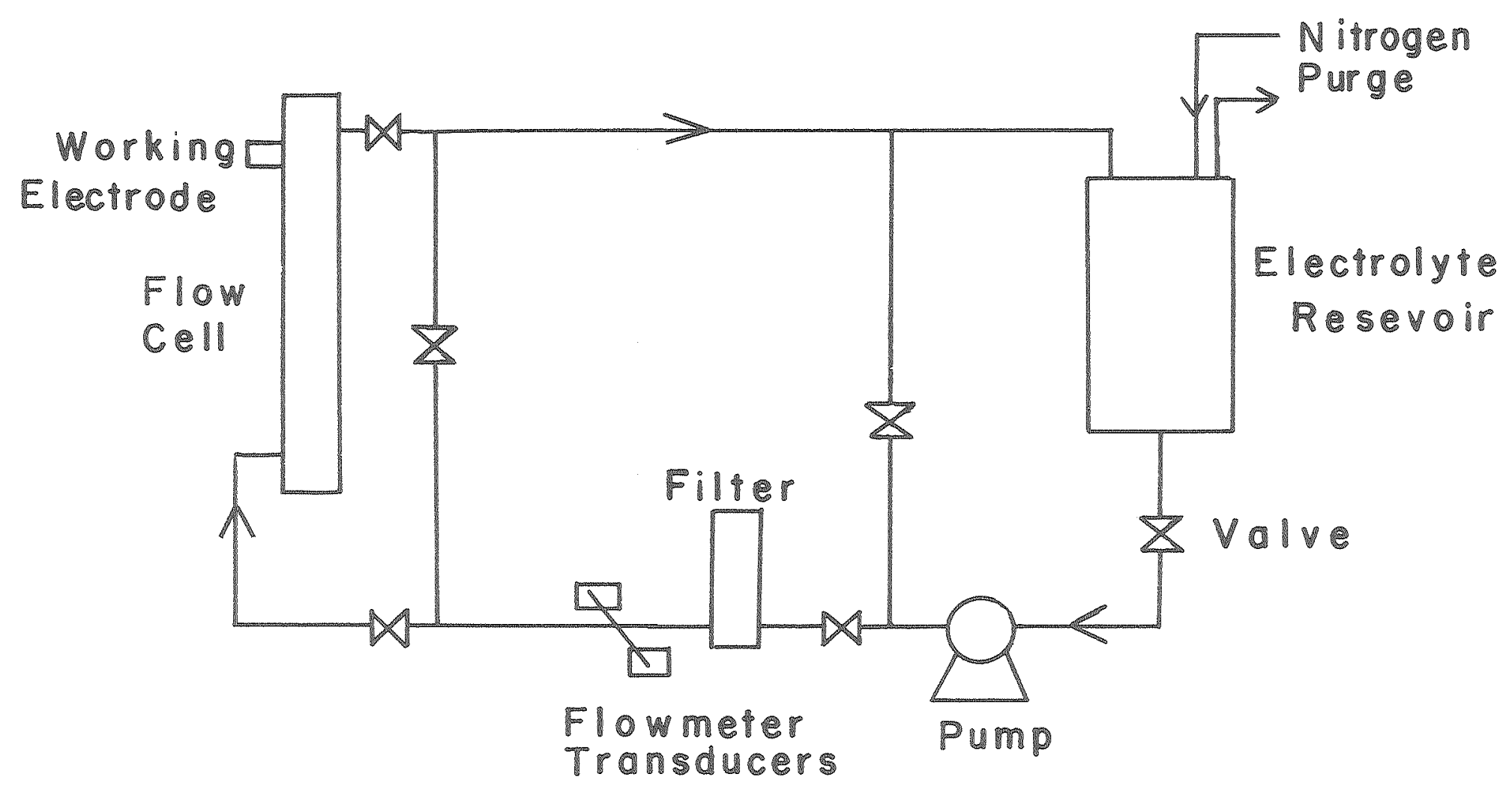

Figure 4.

Electrolyte circulation systen for conducting experiments. Pump capacily, 10 gal. per min。at 15 psi. Filter: Sethco, 60 micron mesh size. Reservoir: 45 liter capacity. 


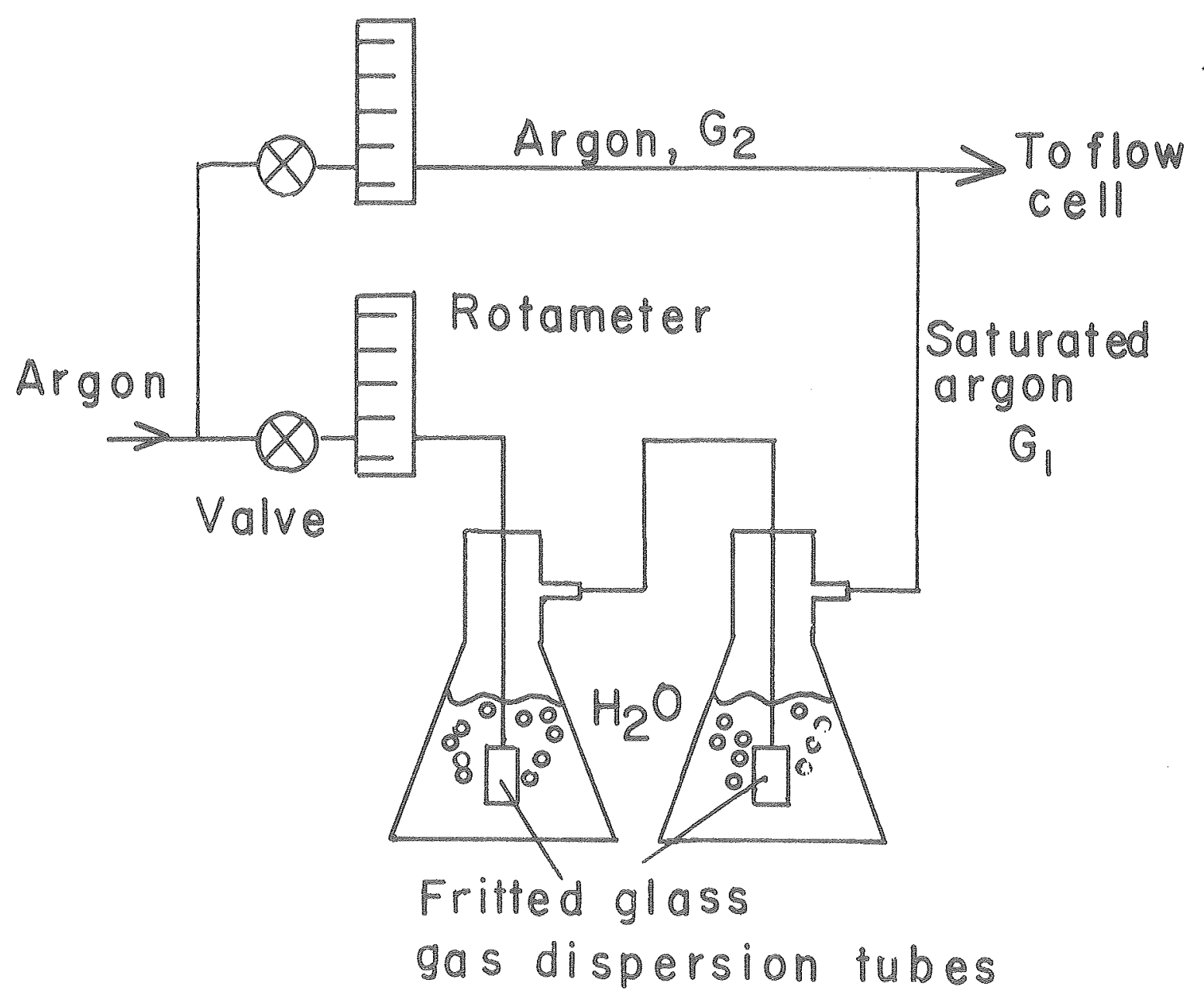

XBL 789-11130

Figure 5. Apparatus for production of argon stream with controlled $\mathrm{H}_{2} \mathrm{O}$ partial pressure. Used for lithium-watex vapor corrosion studies. 
pressure of water in air (assumed the same for argon) at $21^{\circ} \mathrm{C}$.

The electrochemical power supply was a Fluke current/voltage calibrator (Model 非 382A) which provided constant current with an accuracy of $\pm .1 \%$. The electrochemical cell circuit was equipped with a polarity reversed switch, a dumy load resistor for standby operation and a shunt resistor for monitoring current changes. An oscillographic strip chart recorder (Visicorder, Model \# 1108) simultaneously displays the following parameters: rotation of analyzer and polarizer azimuths (deg), cell current (mA), electrode potential (volts), and electrolyte flow rate (gal. per min.). Working electrode potential is measured using a high impedance $\left(10^{9} \mathrm{ohm}\right)$ preamplifier in a recorder channel.

\section{A. Sample Preparation}

\section{Lithium}

High purity rolled lithium sheet (1/8" thick x $51 / 2^{n}$ wide) was supplied by Foote Mineral Company (Exton, PA). Due to its labile nature the metal was handled in an argon filled glove box built in this laboratoxy. Sections $.787^{\prime \prime} \times .787^{\prime \prime}$ (electrode area $4 \mathrm{~cm}^{2}$ ) were cut using a. scalpel and a specially designed cutting jig. The samples were then mounted using conducting silver epoxy onto a stainless steel backplate $\left(.75^{\prime \prime} \times .75^{\prime \prime}\right)$ fitted with a threaded shaft. Methyl ethyl ketone (MEK) was used to chemically polish lithium. This solvent was found to dissolve the metal at a sufficient rate without excessive pitting. Mounted samples were placed in the electrode holder and gently rubbed against microcloth which was continuously wetted with MEK. This was followed by abrasive treatment with fine mesh nylon cloth (Industrial Fabrics 
Corporation, Monodur 非33) which was also soaked with MER. Futher reaction between MEK and lithium is prevented by washing the sample thoroughly with reagent grade hexane. The resulting surface is smooth and diffusely reflectant and it is possible to obtain ellipsometer mea- . surements from the Li in this condition.

Lead

Lead samples of $99.999 \%$ purity were provided by American Smelting and Refining Co, in $1 / 2^{\prime \prime}$ diameter rods. These were rolled to $1 / 8^{\prime \prime}$ thickness and mounted on a stainless steel back plate $\left(.6^{\prime \prime} \times 1.0^{\prime \prime}\right)$ using indium alloy solder (Indaloy 非). The samples were etched in one part nitric acid, one part $30 \% \mathrm{H}_{2} \mathrm{O}_{2}$ and three parts water to remove airformed oxides and then polished by abrasive treatment on common papex towels with acetone as a lubricant. This was followed by thorough rinsing with reagent grade methanol. Finally they were pressed against a highly polished hardened steel die (Figure 3c) in a mold which matched final electrode dimensions, $.6^{\prime \prime} \times 1.0^{\prime \prime}$. This results in a mirror-like reflecting surface, the appearance of which depends on the pressure applied. Best results are obtained when lead samples are pressed for 15-20 seconds at $12-14,000$ psi. Lower pressures result in a surface with streaks remaining from abrasive treatment and higher pressures cause excessive rippling due to cold flow of the lead. All pressing was performed at room temperature.

\section{Procedure}

Anodic film growth experiments were performed at constant current which allows control of the metal dissolution rate. Most experimental 
data were taken in flowing electrolyte of constant velocity. Therefore, steady state transport equations are appropriate. Free convection experiments were performed without electrolyte circulation on the vertically oriented electrodes. Experiments were performed at room temperature.

\section{Lithium}

Polished lithium samples were transferced from the glove box to the flow cell in an argon filled container and then optically aligned. The cell was previously dried with a heated $\left(60^{\circ} \mathrm{C}\right) \mathrm{N}_{2}$ stream and then flushed with argon. Such procedures are necessary in order to prevent aix and water vapor from oxidizing the sample during optical alignment. Anodic current is started when flowing electrolyte makes contact with the lithium electrode (anode) and the stainless steel counter electrode. This completes the circuit between the electrolytic cell and the galvanostat which was previously set in a standby mode. This technique is necessary since it is desirable to minimize the time at which lithium is exposed to solution at open circuit. Anodic film growth may now be monitored by the ellipsometer provided there is sufficient reflected light intensity.

Experiments were performed in aqueous electrolytes with the following compositions: $4.7 \mathrm{M} \mathrm{LiOH}, 10 \mathrm{M} \mathrm{KOH}, 13.6 \mathrm{KOH}$ and $13.6 \mathrm{M} \mathrm{KOH}$ with $0.6 \mathrm{M} \mathrm{LiOH.} \mathrm{Table} \mathrm{I} \mathrm{shows} \mathrm{the} \mathrm{various} \mathrm{current} \mathrm{densities} \mathrm{and} \mathrm{Reynolds}$ numbers used for these solutions and Table II gives their physical properties. Reynolds number is calculated using the average velocity, $\langle v\rangle$, obtained from measured volume flow rate and channel cross sectional area according to

$$
\operatorname{Re}=\frac{4 R_{h} \rho<v>}{\mu}
$$


TABLE I Experimental conditions for Anodic Film Growth on Lithium

$4.7 \mathrm{M} \mathrm{LiOH}$ Applied Current
$\mathrm{mA} / \mathrm{cm}^{2}$

$$
0.0
$$

25

40

$40 \%$

88

$10 \mathrm{M} \mathrm{KOH}$

40

$40 \%$

\begin{tabular}{|c|c|}
\hline & $\begin{array}{l}\text { Reynolds } \\
\text { number }\end{array}$ \\
\hline & 2000 \\
\hline & 2000 \\
\hline & 3200 \\
\hline & 1400 \\
\hline & 2000 \\
\hline $10 \mathrm{M} \mathrm{KOH}$ & \\
\hline & 1700 \\
\hline & 1700 \\
\hline $13.6 \mathrm{M} \mathrm{KOH}$ & \\
\hline & 1000 \\
\hline & 1000 \\
\hline & 1000 \\
\hline & 1000 \\
\hline $\begin{array}{c}13.6 \mathrm{M} \mathrm{KOH} \\
\text { with } 0.6 \mathrm{M} \mathrm{LIOH}\end{array}$ & \\
\hline & 1000 \\
\hline & 1000 \\
\hline & 1000 \\
\hline & 1000 \\
\hline & 250 \\
\hline
\end{tabular}

* Inicial Film Used. 
Aqueous solution

Composition

$\begin{array}{ll}\text { Lithium } & 4.7 \mathrm{M} \mathrm{LiOH} \\ \text { studies } & 10 \mathrm{M} \mathrm{KOH} \\ & 13.6 \mathrm{KOH}, \\ & 13.6 \mathrm{M} \mathrm{KOH} \text { with } 0.6 \mathrm{M} \mathrm{LiOH}\end{array}$

Lead

studies

$$
\begin{aligned}
& \text { Densitty\% } \\
& \mathrm{g} / \mathrm{cm}^{3}
\end{aligned}
$$

$$
1.20
$$

1.37

1.42
Viscosity*
$\mathrm{g} / \mathrm{cm} \mathrm{sec}$

0.016
0.038
0.042

0.016

0.042

.0128

1.350

$3.1 \mathrm{M} \mathrm{H}_{2} \mathrm{SO}_{4}$

$5.0 \mathrm{M} \mathrm{H}_{2} \mathrm{SO}_{4}$
1.080

1.185

1.290
.0179

.0287

1.365

1.380

* Alkaline solution viscosity and density data obtained from Ref. $34, \mathrm{H}_{2} \mathrm{SO}_{4}$ data obtained from Ref. 35. 
$R_{h}$ is the hydraulic radius (35) of the channel (cross sectional area divided by the wetted perimeter, $0.66 \mathrm{~cm}), \rho$ is solution density and $\mu$ is solution viscosity. For $10 \mathrm{M} \mathrm{ROH}$, Re $=48^{\circ}\langle\mathrm{v}\rangle$ where \langle\rangle is in $\mathrm{cm} / \mathrm{sec}$. In some experiments (indicated by $*$ in Table I) and initial protective film of LioH is formed by exposure of the lithium sample to water vapor.

Lead

Smooth reflecting lead specimens were mounted and optically aligned In the empty flow channe1. A two-zone measurement (38) of $\mathrm{A}$ and $\mathrm{P}$ was then performed. Aftex initiation of electrolyte flow cathodic current was immediately started and maintained for several minutes at 0.5 to $1 \mathrm{~mA} / \mathrm{cm}^{2}$. This procedure reduced air-formed oxidation products and inhibited corrosion of the electrode in the acid solution during final alignment. The presence of electrolyte in the cell necessitates minor adjustment in order to maintain the angle of incidence exactly $75^{\circ}$. Automatic ellipsometer measurements started during this cathodizing period. Anodic film growth was conducted at current densities from $.010 \mathrm{~mA} / \mathrm{cm}^{2}$ to $1.3 \mathrm{~mA} / \mathrm{cm}^{2}$ and began when polarity on the electrochemical cell was reversed. Open circuit corrosion measurements began when the cathodic protecting current was interrupted.

Sulfuric acid solutions were used having concentrations of $1.3,3.1$ and $5 \mathrm{M}$ (see Table II). Solutions were prepared from analytical grade acid and distilled water and were deoxygenated with a presaturated stream of $\mathrm{H}_{2}(200-400 \mathrm{ml} / \mathrm{min})$ for several days before use. A fritted glass tube $(2.5 \mathrm{~cm} \times 1.3 \mathrm{~cm})$ was used for gas dispersion in the electrolyte. 
Electrode potentials were measured against an $\mathrm{Hg} / \mathrm{Hg}_{2} \mathrm{SO}_{4}$ reference half cell $\left(-.958\right.$ V vs $\mathrm{Pb} / \mathrm{PbSO}_{4}$ at +.602 Vs NHE). Experiments were ended when nulling orientations of the analyzer and polarizer could no longer be found. This is due to features on the surface (crystals and spaces between them) having dimensions near the wavelength of light (about $1 / 2 \mu)$.

\section{Errors in Optical Measurement}

Imperfections in the optical components of the ellipsometer introduce errors in the measurement of polarization from the sample surface. This leads to variations in the values of $\psi$ and $\Delta$ obtained from four different zones (38). These zones are represented by rotations of components $^{*} 90$ or 180 degrees with respect to each other and ideally result in the same values of $\psi$ and $\Delta$. The imperfections in the ellipsometer in this laboratory have been characterized (39) so that measurements obtained in a single zone during the course of an experiment can be corrected.

The program DCOMPAR is used to produce corrected values of $\psi$ and $\Delta$. The average of initial two or four zone measurements, characteristic parameters describing components in the path of the light beam, and measured values of analyzer and polarizer azimuths (from a single zone) are used as input to the program. Two zone measurements are usually sufficient and are taken in air ${ }^{+}$since lead is quite stable in this environment. Two zone measurements on 1ithium are taken in argon.

\footnotetext{
*Analyzer, polarizer and quarter wave plate

$t_{\text {Air }}(n=1.00)$ measurements are corrected to electrolyte $(n=1.36)$ measurements using Eqs. [18-21].
} 
Surface changes occur relatively fast in electrolyte (roughness and corrosion), even with cathodic protection, and this will reduce accuracy of the average.

Sources of error in the measurement of $\psi$ and $\Delta$ are substitution of two zone measurements in air for measurements in the electrolyte incident medium (even though they are adjusted), experimental exrors in the measurement of optica1 parameters used by DCOMPAR and noise in the recorded signal. Experimental error in the measurement of surface films on lead is taken to be about 1 degree for $\psi$ and $\Delta$. Larger experimental error is allowed for lithiun because of poox reflection even after the polishing treatment. Error in this case is taken to be up to 5 degrees. 
IV. Models Characterizing Film Growth

\section{A. Lead}

Introduction

Scanning electron micrographs indicate that $\mathrm{PbSO}_{4}$ is anodically deposited on lead at low current densities in two types of structures (Figure 6 a,b). In general, large crystals of $\mathrm{PbSO}_{4}$ are visible on the surface ranging in size from 500 to $5000 \AA$. Between these crystals there appears to be a layer of smaller crystals closely adhering to the lead substrate. This situation is similar to anodic film formation on other metals where sublayers and large crystals have been characterized (44). After anodization at high currents the surface appears to be completely covered with small sulfate crystals (Figure $6 c, d$ ). These figures are discussed further in Section V-A.

Smith has developed a general model which incorporates these structures and has applied it to the interpretation of ellipsometer data. obtained from anodically formed films on $\mathrm{Ag}, \mathrm{Cd}$ and $\mathrm{Zn}$. The same model with simplifications is used here to analyze ellipsometer data from oxidized lead surfaces. The model is implemented with an automated computer program which evaluates characteristic parameters (44). The following sections $(1-5)$ were primarily abstracted from Chapter IV of the $\mathrm{Ph}$.D. dissertation of C. G. Smith. Relevant aspects of film growth on lead and a discussion of free convection have been added.

\section{The Surface Structure}

Figure 7 is a schematic of the general model showing layers avail able for the interpretation of film growth data. There are six layers in a11: A roughness layer, the Type II sublayer, the Type I sublayer, 
Figure 6. Scanning ellectron micrographs of anodized lead:

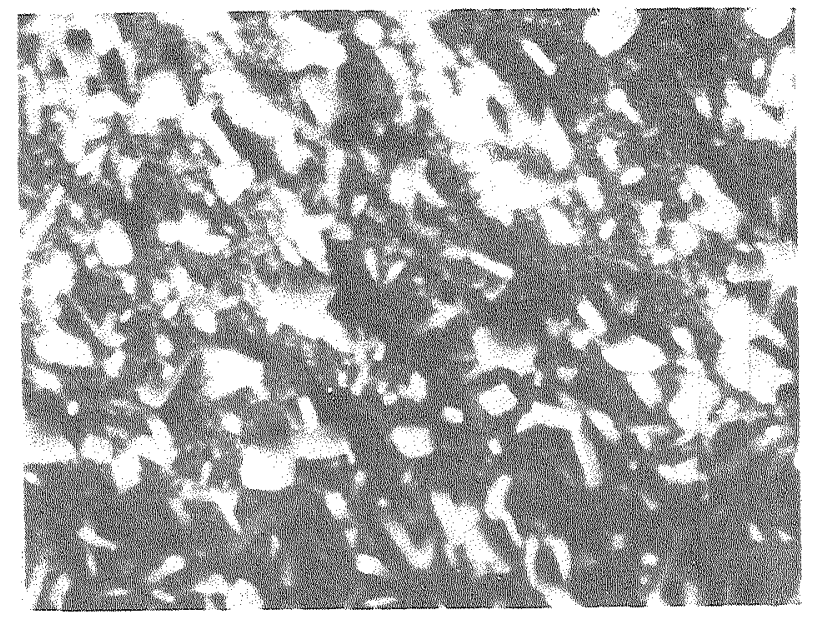

a) $0.052 \mathrm{~mA} / \mathrm{cm}^{2}, 160 \mathrm{~s} 3 \mathrm{M} \mathrm{H}_{2} \mathrm{SO}_{4}$

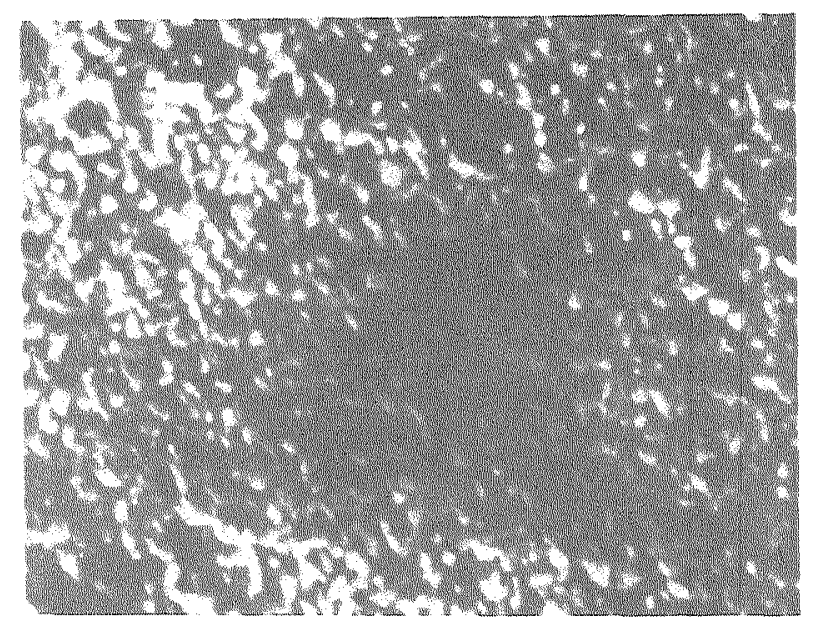

c) $0.388 \mathrm{~mA} / \mathrm{cm}^{2}, 70 \mathrm{~s}, 3 \mathrm{MH}_{2} \mathrm{SO}_{4}$

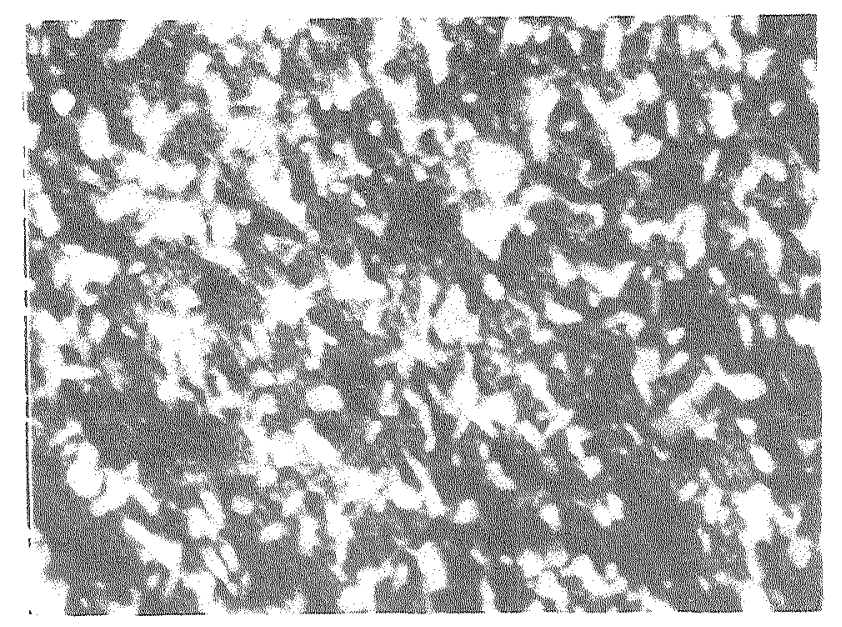

bH $0.26 \mathrm{~mA} / \mathrm{cm}^{2}, 56 \mathrm{~s}_{3} \mathrm{M} \mathrm{H}_{2} \mathrm{SO}_{4}$

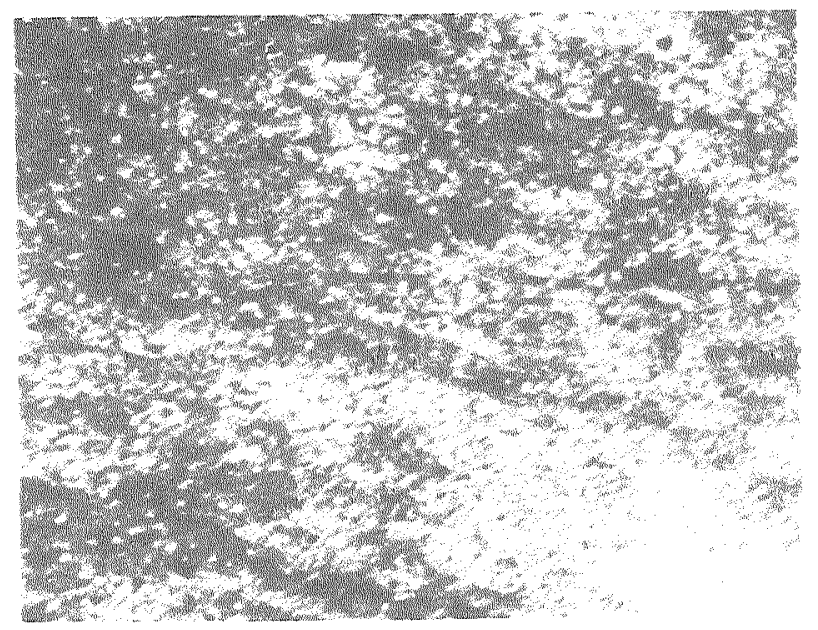

a) $0.517 \mathrm{~mm} / \mathrm{cm}^{2}, 40 \mathrm{~s} 5 \mathrm{MH}_{2} \mathrm{SO}_{4}$ 


\section{Mass Transpor \\ Boundory Layer}

Solubilized Product

Layer

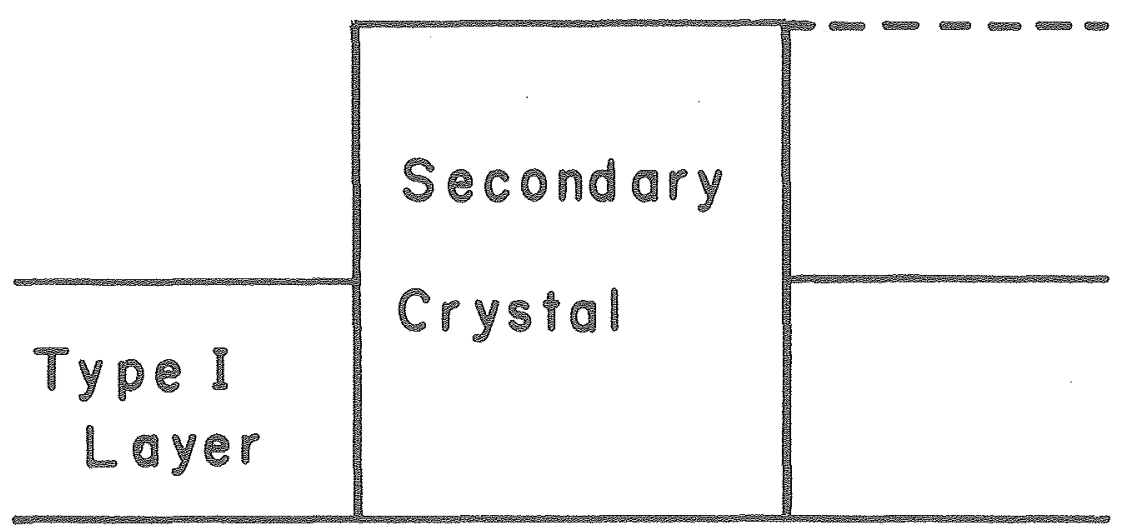

TyPeII Layer

Roughness

Metol
Incliden

Medium

Film 5
骨

3

2

I

Subsirate

XBL 789-11324

Figure 7. Schematic of layers available for modelling corrosion films and anodic films 
secondary crystals, a solution product layer (referred to as the Type I hydrate in the previous work), and the mass transport boundary layer (MTBL). Tye Type $I$ and secondary crystals are the most important features of the interpretation. The Type I layer is thought to form via homogeneous nucleation and subsequent precipitation while the secondary crystals form via heterogeneous nucleation directly onto the growing sites. As previously cited in the literature, there is some evidence for both film growth mechanisms. The Type II film is modelled to be a compact film usually less than 50 A thick. The roughness layer describes substrate roughening due to preferential metal dissolution sites. Since it is necessary to use polycrystalline lead samples, the roughenIng xate can be quite significant. A solution product layer (SPL) accounts for lead compounds which may be colloidally suspended in solution. As already mentioned, several investigators have indicated the possibility of material accumulating in solution away from the electrode surface.

The sequence of film formation begins with dissolution of lead and rapid formation of the Type II film. Not all current is used for film formation as it is possible for $\mathrm{Pb}^{+t}$ to diffuse away ionically or in the form of colloidal particles as $\mathrm{PbSO}_{4}$. The Type II film reaches a limiting thickness and the Type I film and secondary crystals begin forming and continue to grow. Descriptions of symbols used in this chapter and in following chapters are shown in Tables III, IV and TV-a. 2. Fluxes Between Layers, Kinetics

Growth rates of solid $\mathrm{PbSO}_{4}$ are 1 imited by mass transport of soluble species to growth sites or by incorporation of ad-atoms into 
growing crystals. Crystallization kinetics, howeyer, are not understood quantitatively. Formation rates of electrode structures are, therefore, simplified assuming constant ad-atom concentrations and include flux densities which are evaluated by the computational procedure.

The Type II film grows at a constant rate, iIIF, while secondary crystals grow proportional to their surface area $i_{S C}\left({ }^{\approx} i_{C R Y S} A_{S C}[t]\right)$; $i_{I I F}$ and $i_{\text {CRYS }}$ are evaluated parameters. The number density of secondary crystals per unit area is established at $t=0$.

Ionic anodic products enter the MTBL at a flux corresponding to the following current density,

$$
i_{D}=\frac{2 F D\left(C_{S S}-C_{b}\right)}{\delta(t)\left(1-t_{+}\right)}
$$

where $\mathrm{C}_{\mathrm{SS}}$ is the interfacial concentration of $\mathrm{Pb}^{t+}$ and $\delta(\mathrm{t})$ is the $\mathrm{MTBL}$ thickness; $C_{\text {SS }}$ is an evaluated parameter. The boundary layer thickness is calculated using steady state equations for convective flow and transient equations for free convection. Flux entering the SPL is the balance of current remaining after secondary crystal growth and the dissolution flux is accounted for,

$$
\dot{1}_{\mathrm{SPL}}=i-\dot{i}_{\mathrm{D}}-\dot{i}_{\mathrm{SC}}\left(\text { or } \dot{1}_{\text {IIF }}\right)
$$

Materials in the SPL are intermediates in the formation of the Type I film. The Type I entexing flux is a fraction, $f_{R^{\prime}}$ of SPL flux and is independent of the SPI composition (zero order kinetics). Any fraction of total current can produce roughness, $i_{\mathrm{RUFF}}=f_{\mathrm{RUFF}}{ }^{\circ} i_{\mathrm{T}} \cdot$ 
3. Formation of Layers:

Under convective flow and at constant current the boundary layer has a thickness defined by

$$
\delta_{b 1}=\frac{a_{h}}{N u}
$$

where $d_{h}$ is the hydraulic diameter and $\mathrm{Nu}$ is the Nusselt number. For the cell geometry used, the following correlation was applied

$$
N u=1.4\left(\operatorname{ReSc} \frac{d_{h}}{x}\right)^{1 / 3} \operatorname{Re}<3000
$$

where Re is the Reynolds number, $S c$ the Schmidt number and $x$ the distance away from the leading edge of the electrode.

Duxing free convection, the boundary layer thickness initially changes with time. The major contributor in generating solution density changes at the electrode surface is assumed to be depletion of $\mathrm{H}_{2} \mathrm{SO}_{4}$ since the solubility of lead is so low. Steady state free convection is not reached before 300 to $3000 \mathrm{sec}$ (experiments last 200 to $300 \mathrm{sec}$ ) for $\mathrm{H}_{2} \mathrm{SO}_{4}$ concentrations and current densities used. Interfacial acid con centration is thus approximated using the Sand equation (40) for the entire experiment.

$$
C_{0}=C_{b}-\frac{2 i}{n F} \sqrt{\frac{t}{D T}}
$$


The Grashof number is calculated by linearizing tabulated data for density over a short concentration range of interest and applying the following correlation ( 41 )

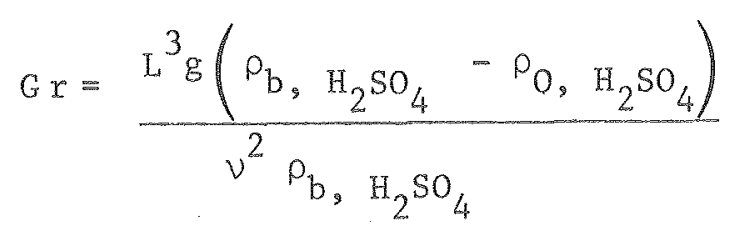

where

$$
\mathrm{P}_{2} \mathrm{SO}_{4}=\mathrm{a} \mathrm{C}_{\mathrm{H}_{2} \mathrm{SO}_{4}}+\mathrm{b}
$$

The appropriate Nusselt correlation is (41)

$$
\mathrm{Nu}=.66(\mathrm{SeGr})^{1 / 4}
$$

and $\delta_{b 1}$ is calculated using $E q \cdot[4]$.

After initiation of current an induction period elapses before the Type II film begins. During this time the steady state interfacial concentration, $\mathrm{C}_{\mathrm{ss}}$, is achieved. The duration of this period, $\mathrm{ss}$, is calculated using a series solution by Rosebrigh and Miller (42) for convection flow and the Sand equation for free convection.

$$
\begin{aligned}
& t_{S S}=\frac{-1}{\alpha} \ln \left[\frac{\pi^{2}}{8}\left(1-\frac{2 F D\left(C_{S S}-C_{b}\right)}{i\left(1-t_{f}\right) \delta_{b 1}}\right)\right], \text { forced convection }[10] \\
& t_{S S}=\left[\frac{2 F D\left(C_{S S}-C_{b}\right)}{1.129 i\left(1-t_{h}\right) D^{1 / 2}}\right]^{2}, \text { free convection }[11]
\end{aligned}
$$


The Type II film grows between $t_{S S}$ and $t_{N U C}$ At $t_{N U C}$, the Type I film and secondary crystals begin. Material enters the SPL starting at $t=0$. Surface roughening also begins at $\hat{t}=0$; however, there is provision for an initial roughness layer. Its growth continues indefinitely independent of the other 1ayers. Table MII shows the times or time periods and appropriate fluxes for all of the layers used.

\section{Optical Treatment \\ a. E11ipsometry Theory}

Linearly polarized light is characterized by a single vector oscillating in a plane parallel to the propagation direction. Elliptically polarized light is a more general case and is described by two orthogonal oscillating vectors which are out of phase and have different amplitudes. Ellipsometry measures the change in phase difference $\Delta$ and change in relative amplitude, tan $\psi$ created between incident and reflected light from reflecting surfaces. The parameters $\psi$ and $\Delta$ are sensitive to incident and substrate refractive indices. If thin optically trans parent films are present, then ellipsometry is also sensitive to their thickness and refractive index. Reflection coefficients $r_{p}$ and $r_{s}$ perpendicular and parallel to the plane of incidence are used to relate incident medium and surface optical properties to $\psi$ and $\Delta$,

$$
\frac{r_{p}}{r_{s}}=\tan \psi e^{i \Delta}
$$

These can be calculated for clean and film-covered surfaces. For clean 


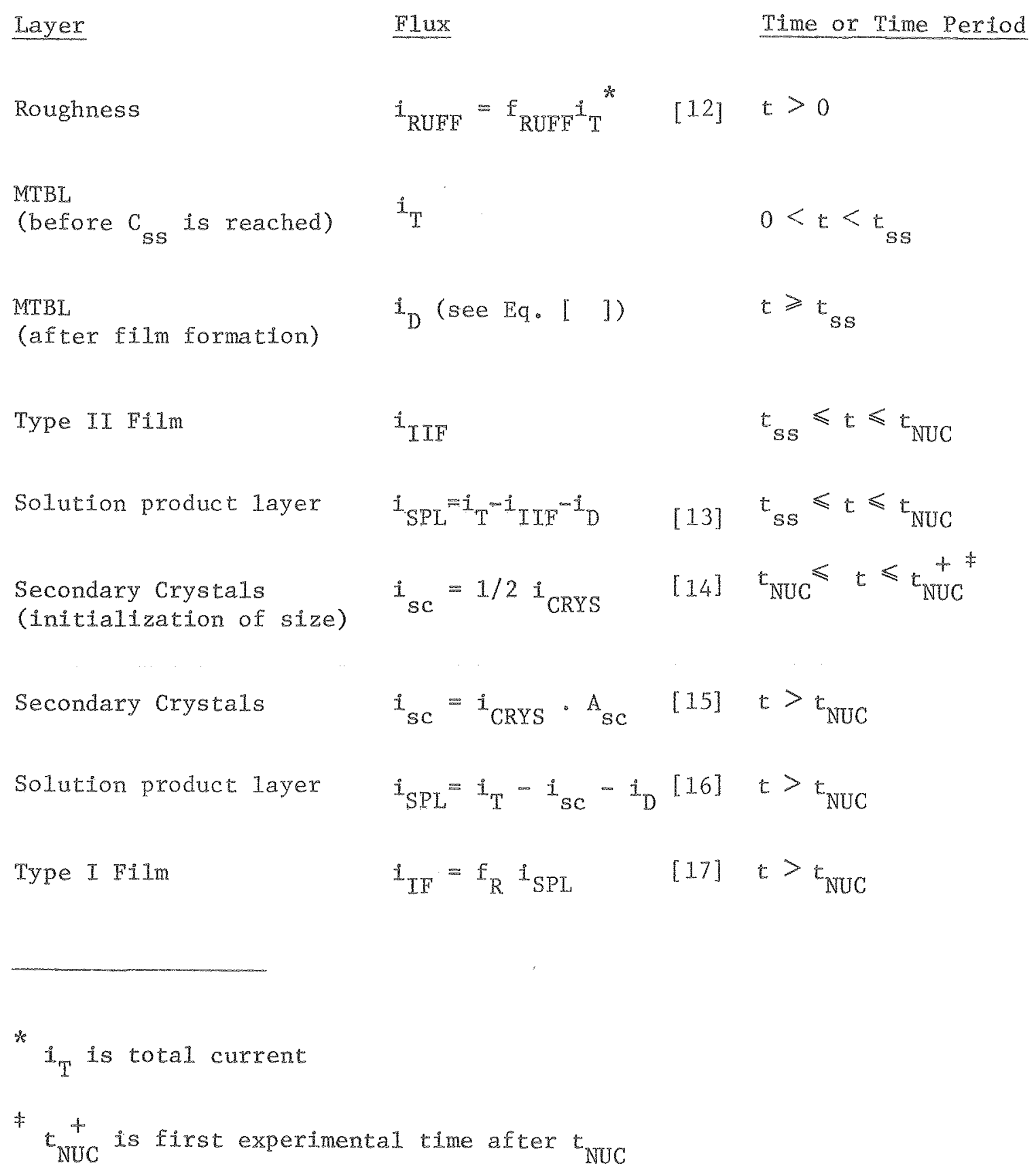


surfaces

$$
\begin{aligned}
& r_{p}=\frac{\tan \left(\phi_{0}-\phi_{\mathrm{m}}\right)}{\tan \left(\phi_{0}-\phi_{\mathrm{m}}\right)} \\
& r_{\mathrm{s}}=-\frac{\sin \left(\phi_{\mathrm{o}}-\phi_{\mathrm{m}}\right)}{\sin \left(\phi_{\mathrm{o}}-\phi_{\mathrm{m}}\right)}
\end{aligned}
$$

where $\phi_{\mathrm{o}}$ is the angle of incidence and $\phi_{\mathrm{m}}$ is the angle of refraction which may be complex. The angle of refraction is determined from Snell's 1aw:

$$
\mathrm{n}_{0} \sin \phi_{0}=\mathrm{n}_{\mathrm{m}} \sin \phi_{\mathrm{m}}
$$

$\mathrm{n}_{\mathrm{o}}$ and $\mathrm{n}_{\mathrm{m}}$ refer to incident medium and substrate refractive indices. If the substrate is a metal then $n_{m}$ can be a complex quantity and is defined as

$$
n_{m}=n-i k
$$

Reflection from surfaces covered with an isotropic homogeneous film is described by overall reflection coefficients which depend on reflection coefficients $r_{1}$ and $r_{2}$ from two interfaces and the phase delay $D$ of light through the film. 


$$
\begin{aligned}
& r_{p}=\frac{r_{1 p}+r_{2 p} e^{-i D}}{1+r_{1 p} r_{2 p} e^{-i D}} \\
& x_{S}=\frac{r_{1 s}+r_{2 s} e^{-i D}}{1+r_{1 s} r_{2 s} e^{-i D}} \\
& D=\frac{4 \pi}{\lambda_{0}} L n_{F} \cos \phi_{F}
\end{aligned}
$$

$\lambda_{0}$ is the wavelength of light in vacuum, $L$ the film thickness, $n_{F}$ the film refractive indes and $\phi_{\mathrm{F}}$ the angle of refraction in the film. The reflection coefficients $r_{1 s}, r_{1 p}$ and $r_{2 s}, r_{2 p}$ are evaluated for the upper and lower interfaces (incident medium-film interface and film-substrate interface, respective1y).

Evaluation of reflection coefficients for the case of multiple films is more complicated.(1.4). First $r_{1 s}, r_{1 p}$ and $r_{2 s}, r_{2 p}$ are evaluated for the substrate and film A interface and are labeled with superscript I (Figure 8). Equations [ $23-25]$ are then used to calculate the first overall coefficients, $r_{s}{ }^{I}, r_{p}{ }^{I}$, which are set equal to bottom coefficients $r_{2 s} I I, r_{2 p}$ II the next sequence. The upper coefficients in this sequence, $r_{1 s} I I, x_{1 p}$ II are evaluated from the boundary between Film $C$ and Film $B$. The procedure is repeated until the top film is reached and the final overall coefficients are obtained.

\section{b. Optical Model}

The structural layers of the surface are treated optically as multiple films on a substrate (Figure 8 ). The thickness of the 


\section{Incident Medium}

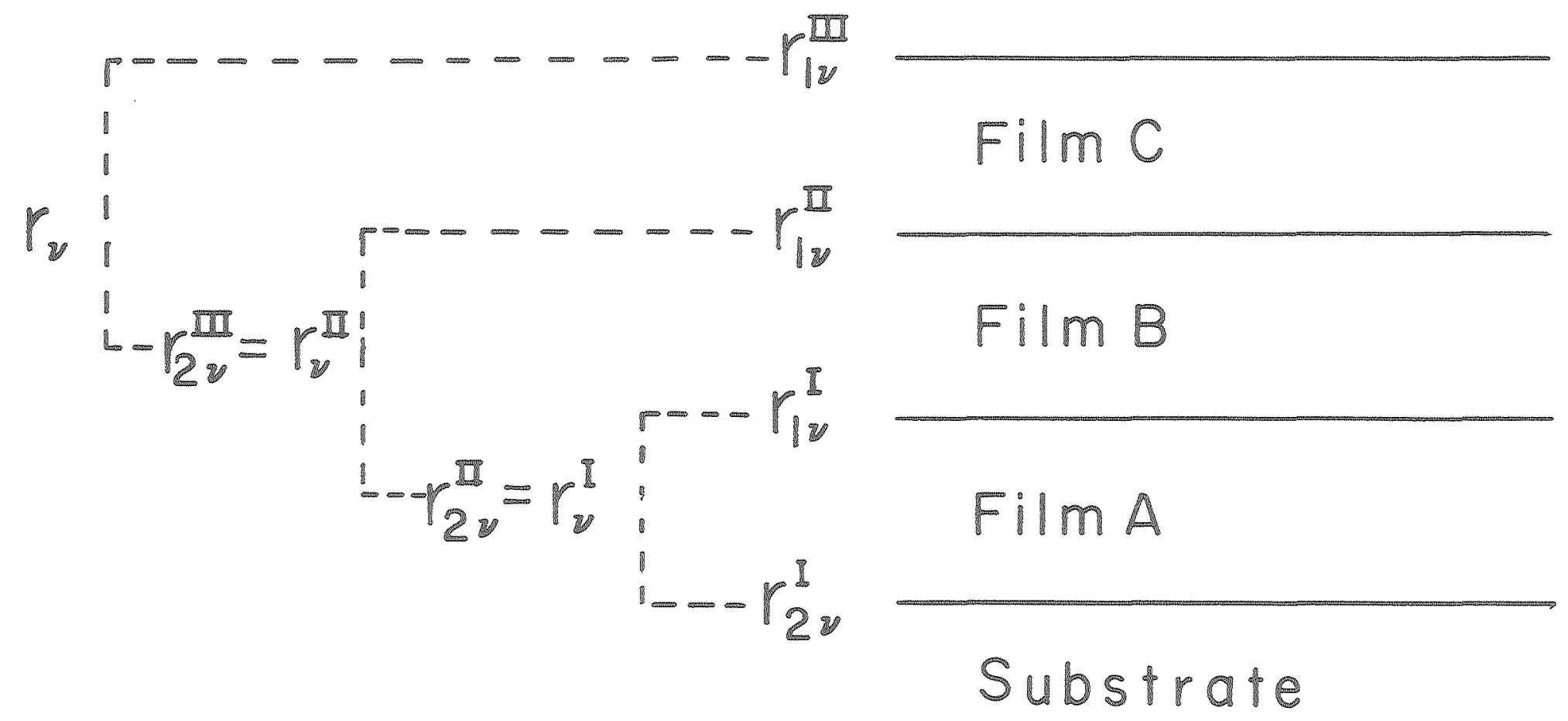

XBL 789-11132

Figure 8. Sequential procedure for evaluating overall reflection coefficients $r,(v$ is either $s$ or $p$ ) for multiple films. Procedure begins by evaluation of individual reflection coefficients labeled with superscript I at the bottom. 
layers is calculated from the yolume of material in each layer per unit superfictal electrode area. Volumes are derived from Faraday"s law (converting current flux to mole flux), molar volume, and porosities. The iteration procedure previously described for multiple films is used to calculate theoretical values for $\psi$ and $\Delta$.

The presence of a MTBL can have an effect on the parameters $\psi$ and $\Delta(14)$. Refractive index variations caused by concentration gradients in the layer alter the effective angle of incidence on the electrode surface. Concentration variations are due to the enrichment of dissolving $\mathrm{PbSO}_{4}$ and the depletion of $\mathrm{H}_{2} \mathrm{SO}_{4}$. As previously mentioned, the Low solubility of $\mathrm{PbSO}_{4}$ prevents it from affecting optical measurements in the boundary layer. At experimentally applied current densities, the change in $\mathrm{H}_{2} \mathrm{SO}_{4}$ concentration is also small. This is evident when $C_{b}-C_{0}$ is calculated using Eq. [2] for representative experimental conditions $\left(i=1 \mathrm{~mA} / \mathrm{cm}^{2}, c_{b}=3 \mathrm{M} \mathrm{H}_{2} \mathrm{SO}_{4}, \mathrm{Re}=500\right.$, one obtains a difference of $.006 \mathrm{M})$. This shift is not below the limits of detection of our instrument under ideal conditions; however, it corresponds to azimuth changes which are well below experimental exror (See Section III-D). Ionic species in the MTBL, therefore, have negligible optical effect for experiments performed on lead.

The SPL (FIIm 5) is treated as an inhomogeneous layer with continuously varying refractive index which extends into the MTBL. No reflection occurs at the boundary between the MTBL and the SPL. The ellipsometer parameters are not sensitive to the SPL thickness; its optical effect is only to change the angle of incidence on layers below. The porosity of this layer $\epsilon_{\text {SPL }}$ decreases linearly with time from $t_{\text {NUC }}$ to $t_{\text {DIFF }}$ corresponding to a transient buildup of material. Its refrac- 
tive index is calculated from

$$
n_{\mathrm{F} 5}=\mathrm{n}_{\mathrm{SPL}}=\left(1-\epsilon_{\mathrm{SPL}}\right) \mathrm{n}_{\mathrm{PbSO}}+\epsilon_{\mathrm{SPL}} \mathrm{n}_{\mathrm{SO} \mathrm{n}}
$$

which represents a volume average of component refractive indices.

Secondary crystals are modelled as cubes. They are combined with the SPL (FIIm 4) to give an effective film refractive index.

$$
\mathrm{n}_{\mathrm{F} 4}=\mathrm{C}_{\mathrm{SC}} \mathrm{n}_{\mathrm{SC}}+\left(1-\mathrm{C}_{\mathrm{SC}}\right) \mathrm{n}_{\mathrm{SPL}}
$$

The optical coverage, $\mathrm{C}_{S C}$, of secondary crystals is based on the actual coverage when viewed along the propagation direction of incident light. Actual coverage is calculated from the number of nucleation sites for secondary crystals and their dimensions. Their refractive index is determined from a volume average of $\mathrm{PbSO}_{4}$ and water (the original nodel assumes hydration water) as in Eq. [26]. The thickness of Film 4 is $\mathrm{T}_{\mathrm{SC}}$ (length of an edge of a crystal) minus the thickness of the Type I film. Treatment of secondary crystals as a homogeneous, isotropic film is rigorous only when $T_{S C}$ is small compared to the wavelength of light $(5461 \AA)$. Their dimensions often exceed $1000 \AA$ as evident from SEM (Figure 6 ) rendering this treatment an approximation. Regrettably, there is no adequate theory for the reflection of light from a surface covered with large distinct crystals.

The Type I film and secondary crystals are combined in the next layer (Film 3) to form an effective refractive index as in Eq. [27 ] above. The porosity of the Type I film $\in_{I F}$ is calculated according to

$$
\epsilon_{I F}=2 / 3 \epsilon_{\mathrm{FO}}+1 / 3 \epsilon_{\mathrm{SPL} .}
$$


This represents the average porosity of the film assuming a parabolic decrease from the top of the film to the bottom. Refractive index of the Type I component is calculated as follows:

$$
\mathrm{n}_{\mathrm{IF}}=\left(1-\epsilon_{\mathrm{IF}}\right) \mathrm{n}_{\mathrm{PbSO}}+\epsilon_{\mathrm{IF}} \mathrm{n}_{\mathrm{SPL}}
$$

The porosity of the Type I phase can decrease linearly with time from $t_{\text {NUC }}$ to $t_{\text {DISS }^{\circ}}$ Ellipsometry of lead anodized in $\mathrm{H}_{2} \mathrm{SO}_{4}$ by Lyzlov has suggested the possibility of $\mathrm{PbSO}_{4}$ deposits becoming more compact with time ( 13$)$.

Since polycrystalline $\mathrm{Pb}$ samples are used, uniform growth of layers on the surface would not be espected. In addition, nucleation of crystals (either in the Type I film or secondary crystals) may occur over a period of time instead of instantaneously. SEM photographs show regions on the surface of enhanced film growth and regions where little or no film formation has yet occurred. These variations are modelled as time dependent coverages of patches containing the secondary crystals and the Type I film. In regions not covered by these structures, reflection occurs only from Film 2 (Type II), Film 1 (roughness) or the bare substrate. The fraction of coverage of the secondary crystal and Type I patches increases parabolically from $t_{\text {NUC }}$ (coverage $=$ COV II) until $t_{\text {DISS }}$ (complete coverage). Before $t_{\text {DISS }}$ the parameter $\mathbb{N}_{0}$ represents the number of secondary crystals per unit area of patches; after t $t_{\text {DISS }}$ it represents the density per unit electrode area.

The refractive index of the Type II film (Film 2) is computed by volume averaging $\mathrm{n}_{\mathrm{PbSO}_{4}}$ and $\mathrm{n}_{\text {soln }}$ as in $\mathrm{Eq} \cdot[26]$. The porosity decreases 
Iinearly with time from $t=0$ to $t=t_{\text {NUC }}$.

The roughness layer (Film 1) is treated as a mixture of metal and $\mathrm{PbSO}_{4}$. Effective refractive index is based on the theory of Garnett (47) which states that the polarizability of a mixture is the volume average of pure component polarizabilities, $\pi_{i}$. Refractive index and $\pi_{i}$ are related as follows:

$$
\pi_{i}=\frac{n_{i}^{2}-1}{n_{i}^{2}+2}
$$

where $\mathrm{n}_{1}$ is complex for the metal component (see $\mathrm{Eq} \cdot[22]$ ). The following expression is used to calculate effective polarizability and hence effective refractive index from Eq. [ 30$]$.

$$
\pi_{e}=\epsilon_{\mathrm{PbSO}_{4}} \pi_{\mathrm{PbSO}_{4}}+\left(1-\epsilon_{\mathrm{PbSO}_{4}}\right) \pi_{\text {substrate }}
$$

where $\in_{\mathrm{PbSO}_{4}}$ is the volune fraction of $\mathrm{PbSO}_{4}$ (porosity) in the roughness layer. If components are dielectric (real refractive index, $k=0$ ), then a simple volume average of refractive indices (as in $\mathrm{Eq},[26],[19]$ is sufficient.

The substrate refractive index is either read from input cards or is calculated from the experimental values for $\psi$ and $\Delta$ at $t=0$ using Eqs. $[18-21]$. Since at $t=0$, the lead is covered with small amounts of $\mathrm{PbSO}_{4}$ and has slightly roughened, the latter method evaluates an effective substrate refractive index. In practice this has been found to be more useful. 
5. Computational Procedure

Experimental data are incerpreted with a sequence of subroutines developed by Smith which are combined with a minimization program (43) which evaluates characteristic parameters describing the model. Subroutines calculate $\psi$ and $\Delta$ based on input variable parameters, known physical constants and experimentally controlled variables. Those parameters which are relevant to modeling anodic growth on lead are presented in Table $I V ;$ there are 37 parameters in a11. The program MINUIT systematically changes these quantities until the error between calculated and experimental optical measurements can no longer be reduced. Generally 7 - 9 parameters are evaluated in a computation; the remaining parameters are fixed, thus becoming input constants. 
TABLE IV Parameters Used For Modelling

\begin{tabular}{|c|c|c|}
\hline $\begin{array}{l}\text { Parametex } \\
\text { as in Program }\end{array}$ & $\begin{array}{l}\text { Symbol } \\
\text { in Text }\end{array}$ & Description \\
\hline CNO & $N_{0}$ & Number density of secondary crystals \\
\hline VCRYS & ${ }^{1} \mathrm{CRYS}$ & $\begin{array}{l}\text { Crystallization rate of secondary } \\
\text { crystals }\end{array}$ \\
\hline VCRYS2 & $i_{I I F}$ & Curxent to the Type II Eilm \\
\hline POREFO & $\epsilon_{\text {FO }}$ & Porosity of the Type I film, time dependent \\
\hline TNUC & $t_{\mathrm{NUC}}$ & $\begin{array}{l}\text { Time, onset of secondary crystals and } \\
\text { Type I film }\end{array}$ \\
\hline TDISS & ${ }^{t}$ DISS & $\begin{array}{l}\text { Time, describing growth of patches } \\
\text { and film compaction }\end{array}$ \\
\hline DSSAT & $D_{S S}$ & Supersaturation of metal cations \\
\hline TDTFE & & Time, minimum porosity of SPL \\
\hline POREF 2 & $\epsilon_{S P L}$ & Porosity of SPL \\
\hline RATF & $f_{\mathrm{R}}$ & Eraction of current to Type I film \\
\hline HYDR & $\epsilon_{\mathrm{SC}}$ & Porosity of secondary crystals \\
\hline FRJEF & $f_{\mathrm{RUFF}}$ & $\begin{array}{l}\text { Rate of void formation in roughness } \\
\text { layer }\end{array}$ \\
\hline POREO & & Porosity of roughness layer \\
\hline TMO & & Initial thickness of roughness layer \\
\hline FPACK & $\epsilon_{\mathrm{FP}}$ & Final porosity of Type I film \\
\hline TNETA & & Mole fraction of metal in patches \\
\hline COVIT & & Initial coverage of patches \\
\hline CURRO & & Applied current density \\
\hline POREI & $\epsilon_{\text {IIE }}$ & Porosity of Type II fIIm \\
\hline
\end{tabular}


TABLE IV-a Additional Symbols

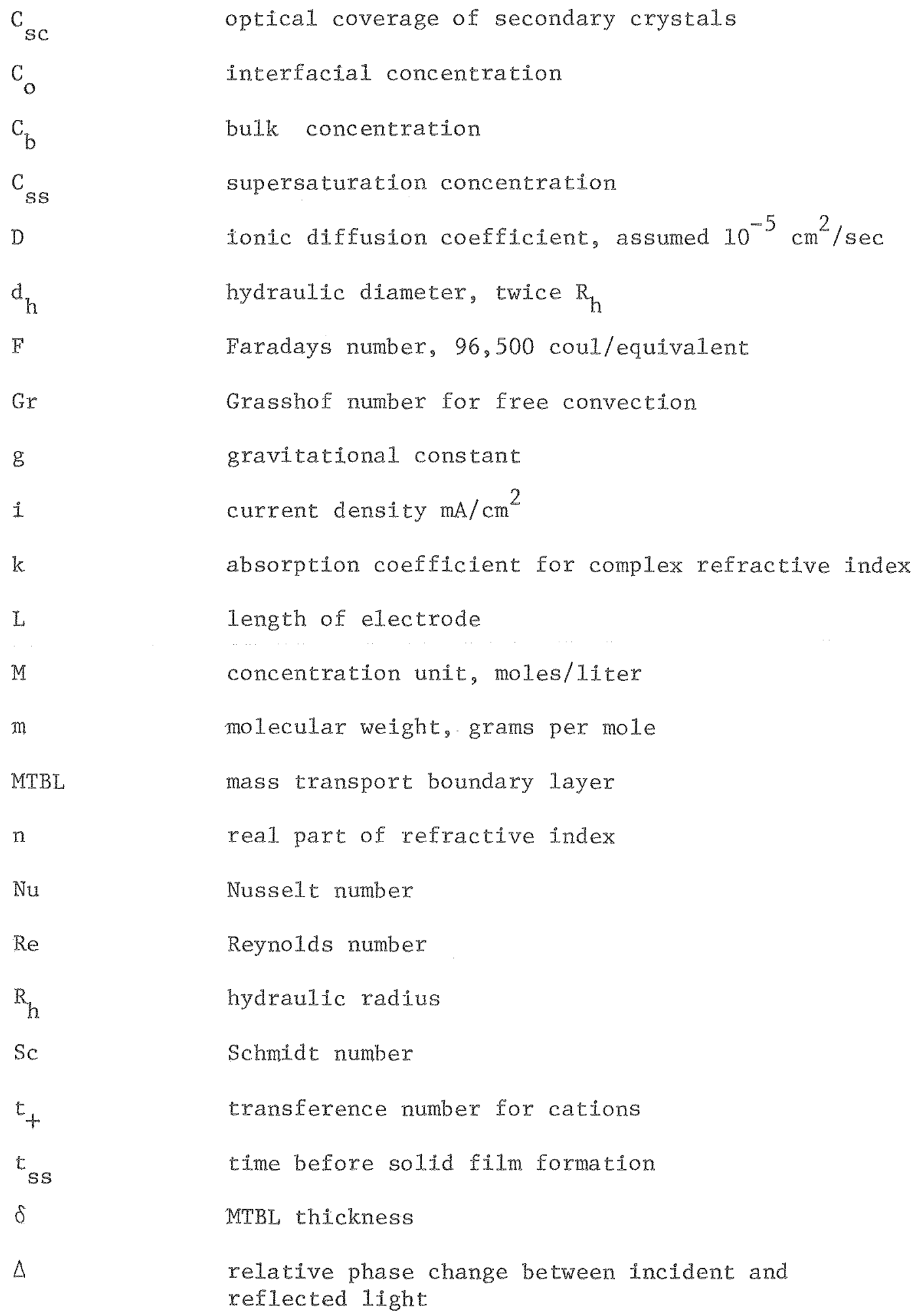


TABLE IV-a (Continued)

$\epsilon_{\mathrm{TF}}$

porosity of Type I film as in Eq. [28]

$\rho$

density

$\pi$

polarizability of compound i

$\psi$

arc tangent of relative amplitude change between incident and reflected light 
B, Lithium

The computer model described in the previous section has been applied to ellipsometer data taken from film formation on a lithium surface corroding in water vapor. Since there is no transport of film material through the gas phase, the dissolution flux and formation of a solubilized product layer does not apply. The model assumes Type I film regions are mixed with lithium metal representing non-stoichiometry of the deposit. The corrosion rate is an evaluated parameter as in the case of open circuit corrosion on lead. 
V. Results

A. Lead

1. Characterization of Surface Layers

Scanning Electron Micrographs

Figure 6c shows the lead electrode surface magnified about 5000x after anodization at $0.388 \mathrm{~mA}$ for $56 \mathrm{sec}$. Crystals are between 1000 and $3000 \AA$ in size and cover roughly $30-40 \%$ of the surface. Using Faraday"s law and the value for molar volume of $\mathrm{PbSO}_{4}\left(48.87 \mathrm{~cm}^{3} / \mathrm{mole}\right)$, the rate of thickness increase per $\mathrm{mA} / \mathrm{cm}^{2}$ of applied current is $25.3 \mathrm{~A} / \mathrm{sec}$. Approximately $600 \mathrm{~A}$ of continuous $\mathrm{PbSO}_{4}$ film would be formed under the conditions specified in Figure 6c. From the sizes and coverage of large crystals the major portion of applied current apparently goes into their formation. Only a small amount of anodic product is expected to be deposited in spaces between these crystals. Figures $6 \mathrm{a}, \mathrm{b}$ and $\mathrm{d}$ show SEM photographs of the surface at other current densities. The sizes of crystals tend to decrease and their number density increases as current density increases (5-10,000 A large and $10-15 \%$ coverage at $0.052 \mathrm{~mA} / \mathrm{cm}^{2}$ in $60 ; 500-1000 \AA$ A large and $50-80 \%$ coverage at $0.52 \mathrm{~mA} / \mathrm{cm}^{2}$ in $6 \mathrm{~d}$ ). Apparent porosity of the surface layer is lower at the higher current densities since voids between crystals are reduced.

\section{Effect of Experimental Variables}

The optical parameters obtained from film growth, relative phase $\Delta$ (degrees), and relative amplitude $\psi$ (degrees), ${ }^{*}$ are generally plotted

$* \psi$ actually represents the arc tangent of the relative amplitude,

$$
\tan \psi\left|\frac{x_{p}}{x_{s}}\right|
$$

where $x_{p}, r_{s}$ are generally complex. 
against each other. Each point along the curye represents a different film thickness or film refractive index (if film properties change with time). Dielectric homogeneous films with constant refractive index give cyclic curves as in Figure 9 which shows calculated $\psi$ vs $\Delta$ for various values of $\mathrm{n}_{\mathrm{f} i \mathrm{Im}}$ on lead substrate. It is apparent that optical measurements are more sensitive as the refractive Index difference between the incident medium $\left(n_{0}=1.365\right)$ and tilm increases. In practice different effective film refractive indices are encountered when solid $\mathrm{PbSO}_{4}$ $(n=1.88)$ forms a porous deposit with the electrolyte $(n=1.3-1.4)$ filling in void spaces in the film. Porosities (E) can be assigned to the refractive index values in Figure 9 using Eq. [26] (replace SPL with $\mathrm{H}_{2} \mathrm{SO}_{4}$ solution). As previously mentioned, higher current densities give higher supersatuxation of lead ions and thus more sites for the nucleation of crystals. Figures 10 and 11 show plots of $\psi$ and $\Delta$ for films grown at different applied current density, and at open circuit. When compared to Figure 9 it appears that higher current densities result in films which are more compact (less apparent porosity) consistent with the idea of a higher population of crystals. Acid concentration has a similar effect on ellipsometer measurements as shown in Figures 12 and 13 . Since the solubility of $\mathrm{PbSO}_{4}$ decreases with increasing $\mathrm{SO}_{4}=$ concentration higher supersaturation is expected at the higher acid concentration. The effect is much more pronounced at the higher current density. Electrolyte flow condition does not influence measurements of $\psi$ and $\Delta$ as markedly as current density and acid concentration. 


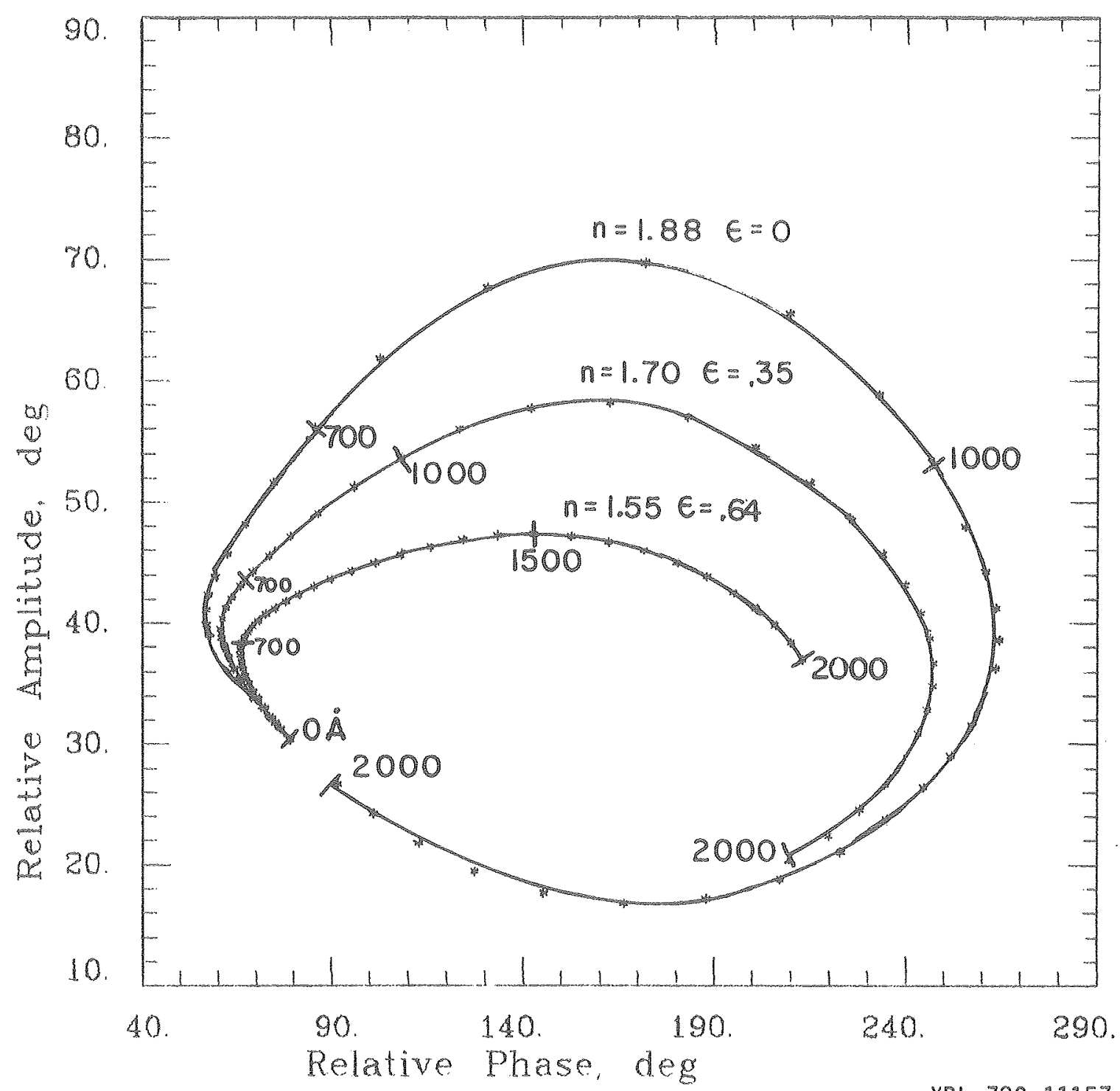

XBL $789-11157$

Figure 9. Computed $\psi-\Delta$ curves for homogeneous isotropic dielectric films. Film properties do not change with thickness. Various refractive indices $(n)$ are obtained by volume averaging $\mathrm{PbSO}_{4}$ refractive index $(\mathrm{n}=1.88)$ with $3.1 \mathrm{M}$ sulfuric acid solution refractive index $(n=1.365)$ as in Eqns [26] and [29]. Porosities ( $E$ ) represent volume fraction of solution. Garnett theory (Eqns. [30], [31]) and volume averaging refractive index give nearly identical results if components are dielectric. Thickness increment between points is $50 \AA$. 


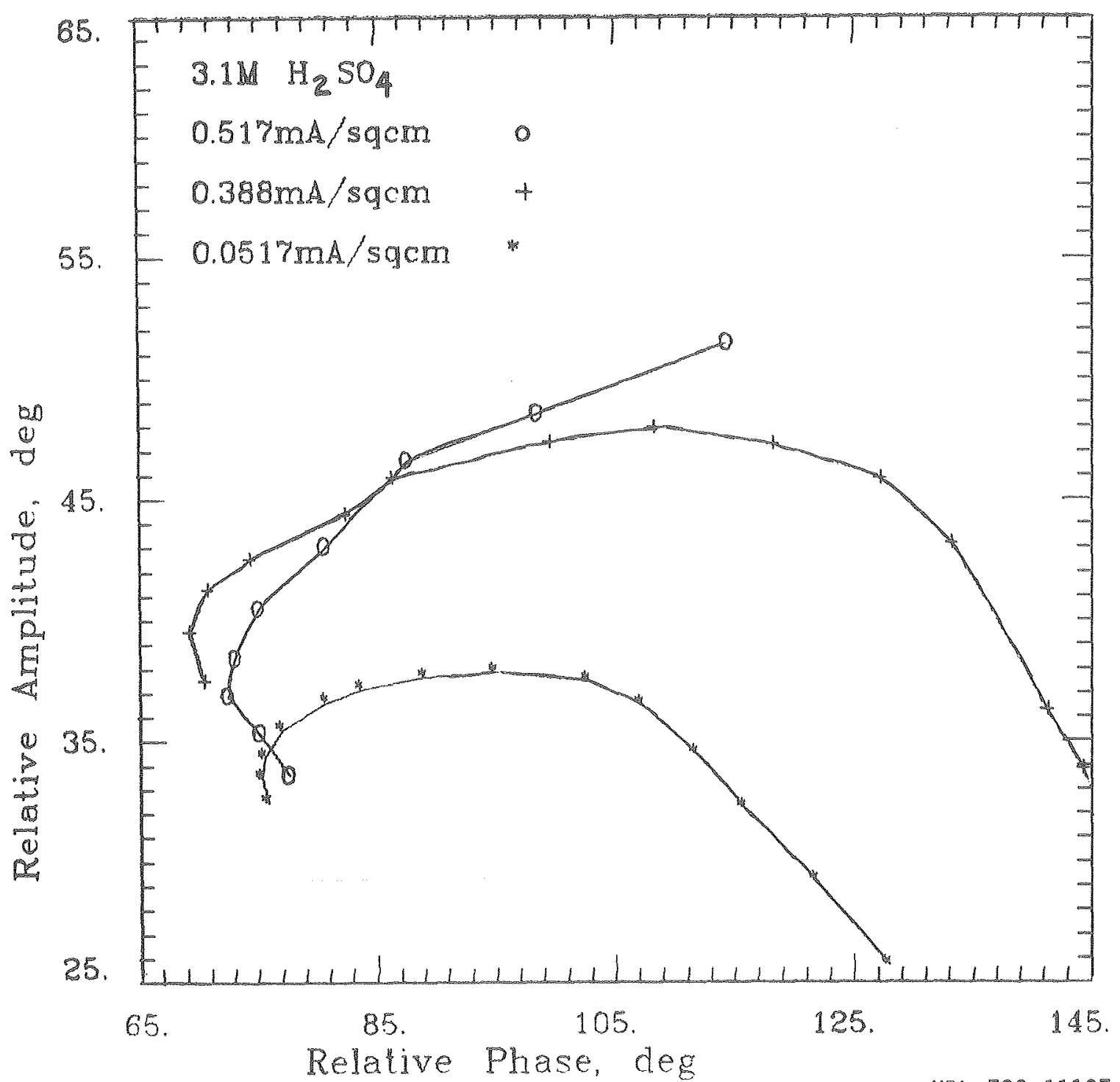

Figure 10. Effect of current density on ellipsometer measurements $\psi$ and $\triangle, 3.1 \mathrm{M}, \mathrm{H}_{2} \mathrm{SO}_{4}{ }^{\circ}$ 


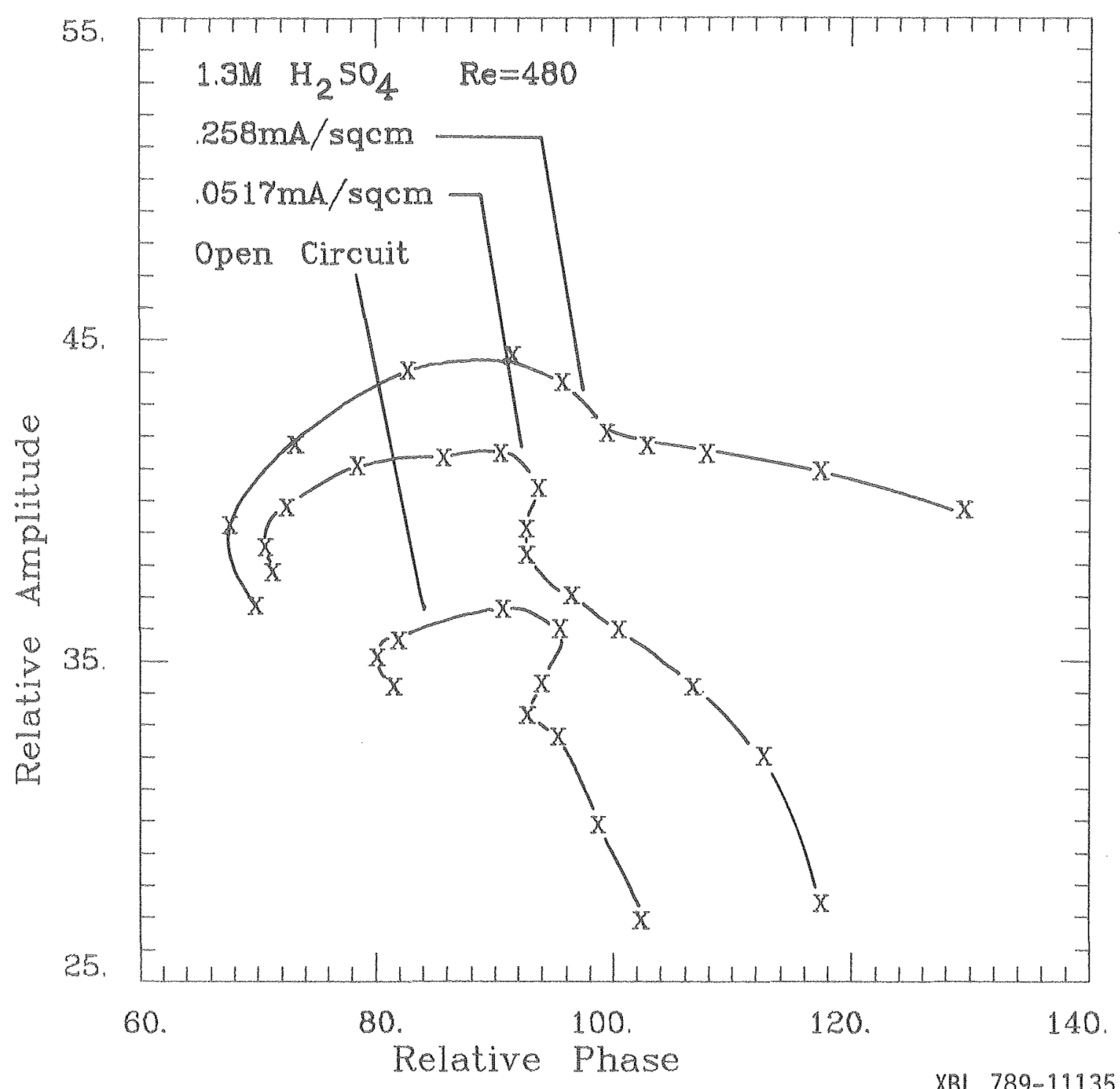

Figure 11. Effect of current density on ellipsometer measurements $\psi$ and $\triangle, 1.3 \mathrm{M} \mathrm{H}_{2} \mathrm{SO}_{4}$. 


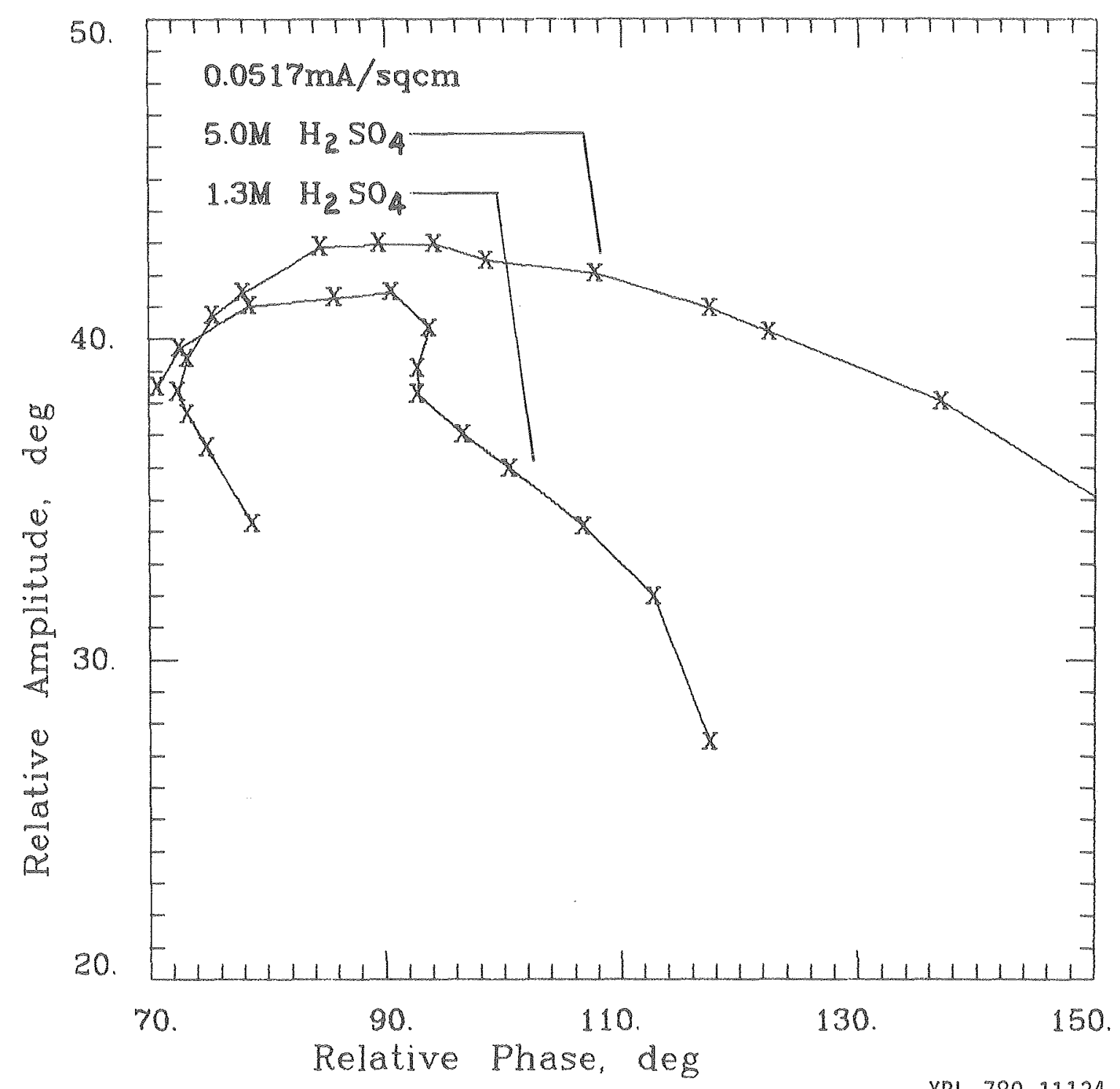

Figure 12. Effect of sulfuric acid concentration on elipsometer measurements, $0.0517 \mathrm{~mA} / \mathrm{cm}^{2}$. 


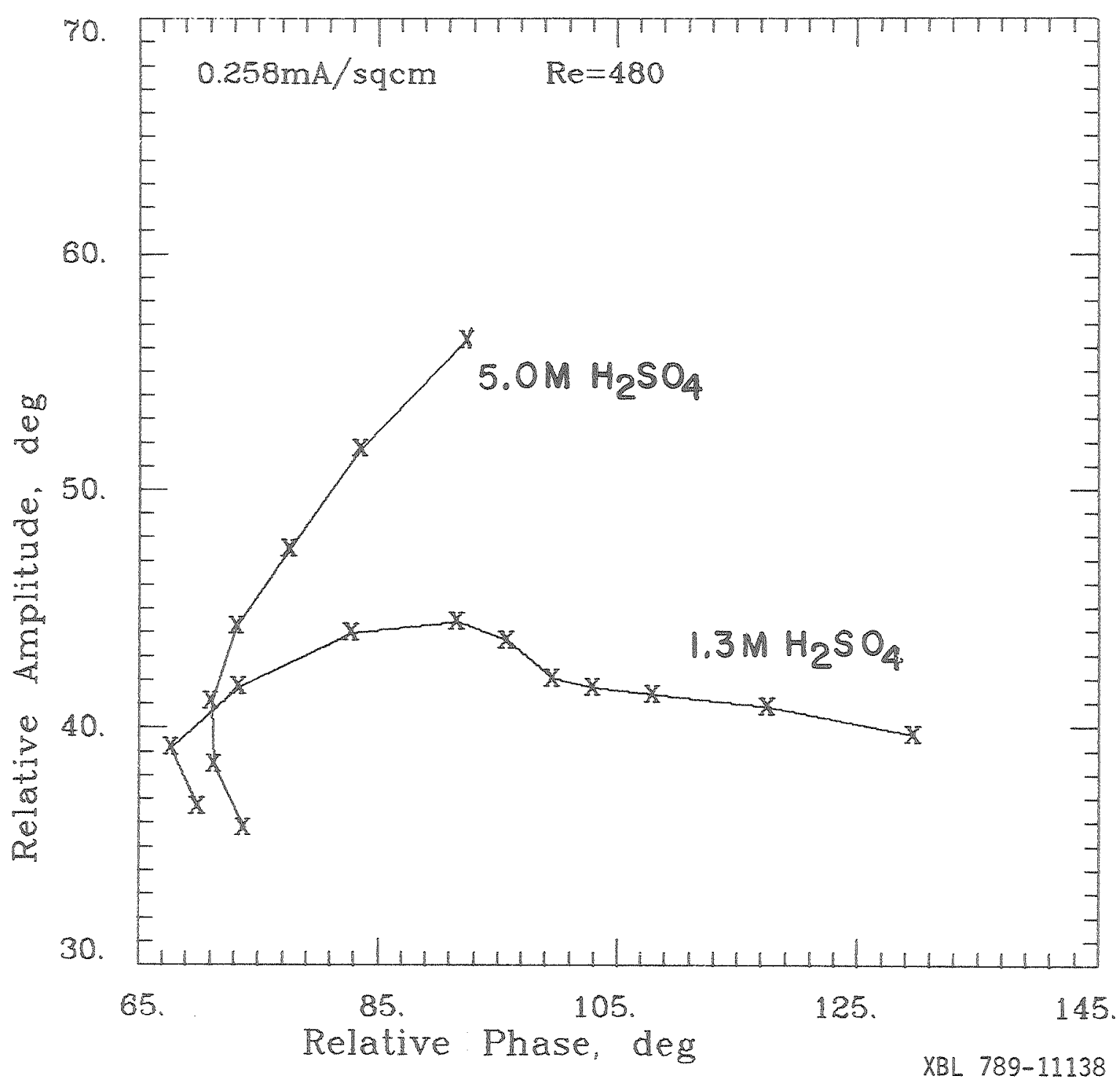

$u_{\omega}^{M}$

Figure 13. Effect of sulfuric acid concentration on ellipsometer measurements, $0.258 \mathrm{~mA} / \mathrm{cm}^{2}$. 
Shapes of $\psi-\Delta$ Plots

When calculated values of $\psi$ and $\Delta$ for single films of constant homogeneous refractive index are compared with experimentally measured values, there are discrepancies in shapes as seen when Figure 9 is compared with Figures 10-13. This is due to effective film refractive index variations as the layers grow.

Refractive index varies with porosity which is expected to change since growing crystals fill in voids making the surface layers more compact with time. Initial decreases in porosity (with little increase in thickness) result in large rises in $\psi$ while changes in $\Delta$ are relatively sma11. This is evident from Figure 9 if points of constant thickness are connected and is illustrated experimentally in Figure 13 ( $5 \mathrm{M}$ data). The structure on the surface can be modelled optically as multiple films as discussed in Section IV. Transient growth of different portions of this structure may cause peculiarities in the shape of $\psi$ vs $\Delta$ plots. The data in Figure 11 for $1.3 \mathrm{M}$ acid show an inflection in the shape of the curves at $\Delta$ near 90 or 100 degrees, the effect becoming more pronounced as current density decreases. This could be explained as large (secondary crystals) increasing in size at this stage of the experiment. From Figure 9 values for $\Delta$ begin to decrease for films where $n>1.7$ at thicknesses of around $1500 \AA$ and,according to SEM photographs, secondary crystals easily reach this dimension. The reversal in direction after this discontinuity to larger values of $\Delta$ may be due to growth of a sublayer (Type I film) not thick enough to cause $\Delta$ to decrease while secondary crystal growth is arrested. 


\section{Reproducibility}

Experiments performed using the same conditions of current density, acid concentration and electrolyte flow are not always reproducible as shown in Figure 14. Surface preparation may largely account for this. Roughness and strain induced from the abrasive treatment and pressing cannot be precisely controlled, thus variations in initial surface condition exist from sample to sample.

Values for $\psi$ and $\Delta$ at the start of anodization show significant variation from one experiment to the next. Ideally, starting points represent clean planar lead; however, certain amounts of roughness and film growth are inevitable from prior handing and from corrosion resulting in initial sample variations. As already mentioned, sample preparation leaves the surface roughened. Exposure to the atmosphere causes slight oxidation of the sample (19). When contacted with the electrolyte, divalent lead is probably converted to deposits of lead sulfate. Corrosion of the sample in the electrolyte also occurs resulting in additional film growth and perhaps more surface roughening. The cathodic treatment which precedes anodic current reduces at least some of the sulfate formed on the surface as shown in Figure 15. Values for $\psi$ and $\Delta$ move toward the lower right during the first cycle (cathodic) indicating the removal of approximately $50 \AA$ of $\mathrm{PbSO}_{4}$ (from single constant refractive index film calculations) in $105 \mathrm{sec}$. At this time the cathodic current was stopped and the optical parameters remained fixed for about $10 \mathrm{~s}$ until anodic current began at $t=115 \mathrm{~s}$. Measured param 


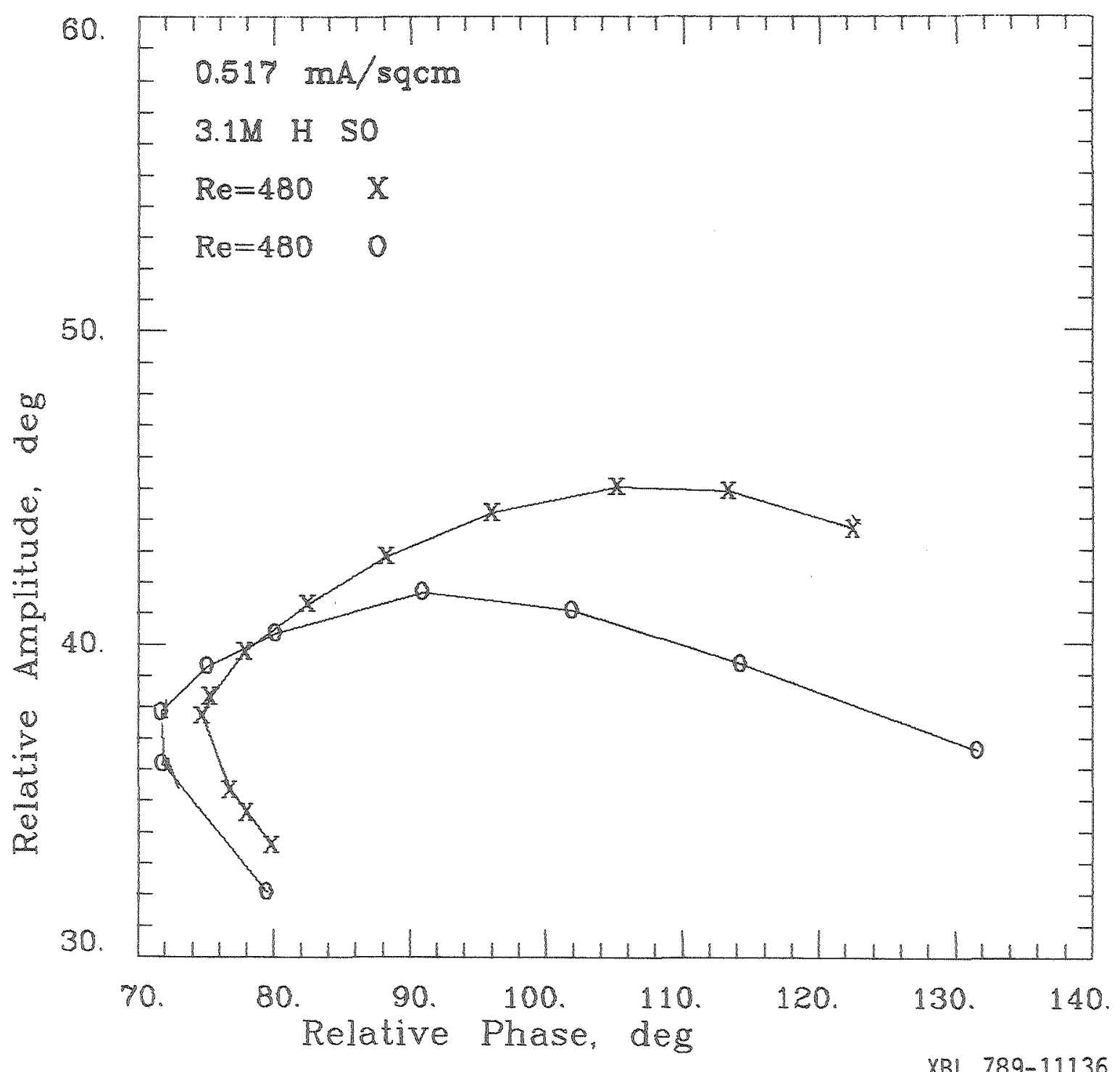

Figure 14. Reproducibility of experimentally measured $\psi$ and $\Delta$ taken at same experimental conditions. 
Figure 15. Ellipsometer measurements taken during cathodic (0 to $105 \mathrm{sec}$ ) and anodic (105 to $140 \mathrm{~s}$ ) applied current.

Cathodic treatment precedes film growth experiments on the lead electrode. Filled in circles are $\psi, \Delta$ pairs which correspond to bare lead optical constants measured by different investigators.

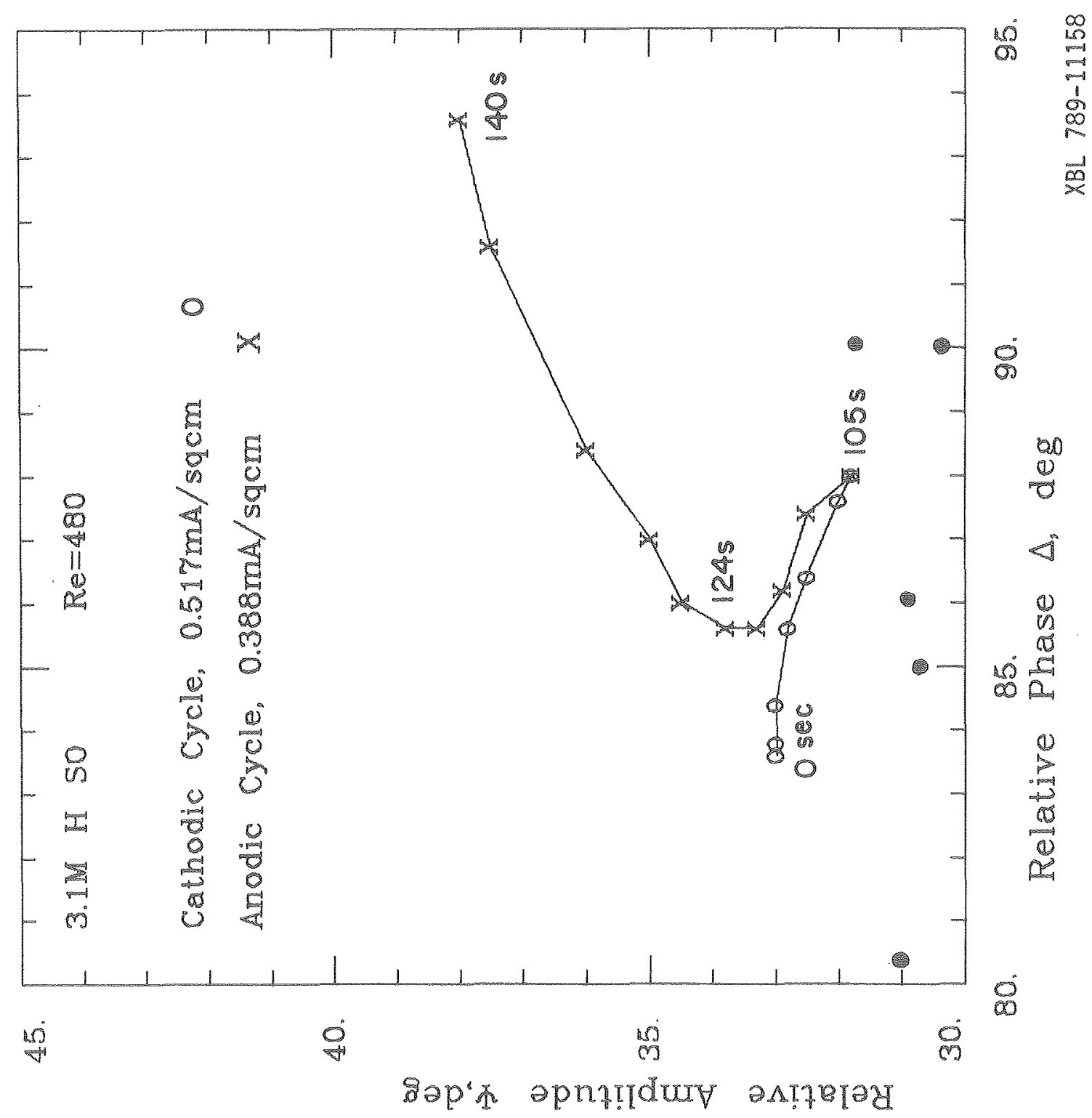


meters then moved back in roughly the same direction at a much higher rate. The cathodic curve is not exactly reproduced in the reversed anodic curve since the morphology of deposits formed by the two processes is different. This figure also indicates values of $\psi$ and $\Delta$ calculated from literature values of the optical constants of lead (see Table $V$ ) using Eqs. [18] to [21]. Literature discrepancies are due to surface roughness and surface layers. Initial $\psi$ and $\Delta$ values In this work compare reasonably well with the literature values.

The cathodic current treatment was found to improve reproducibility since initial deposits of $\mathrm{PbSO}_{4}$ affect the subsequent nucleation of anodic product. Cathodic pretreatment at $.517 \mathrm{~mA} / \mathrm{cm}^{2}$ for periods of longer than about $5 \mathrm{~min}$. was found to be undesirable, resulting in very non-reproducible optical data. This may be due to the adsorption of impurities in the system. 
TABLE Iiterature Values for Lead Refractive Index

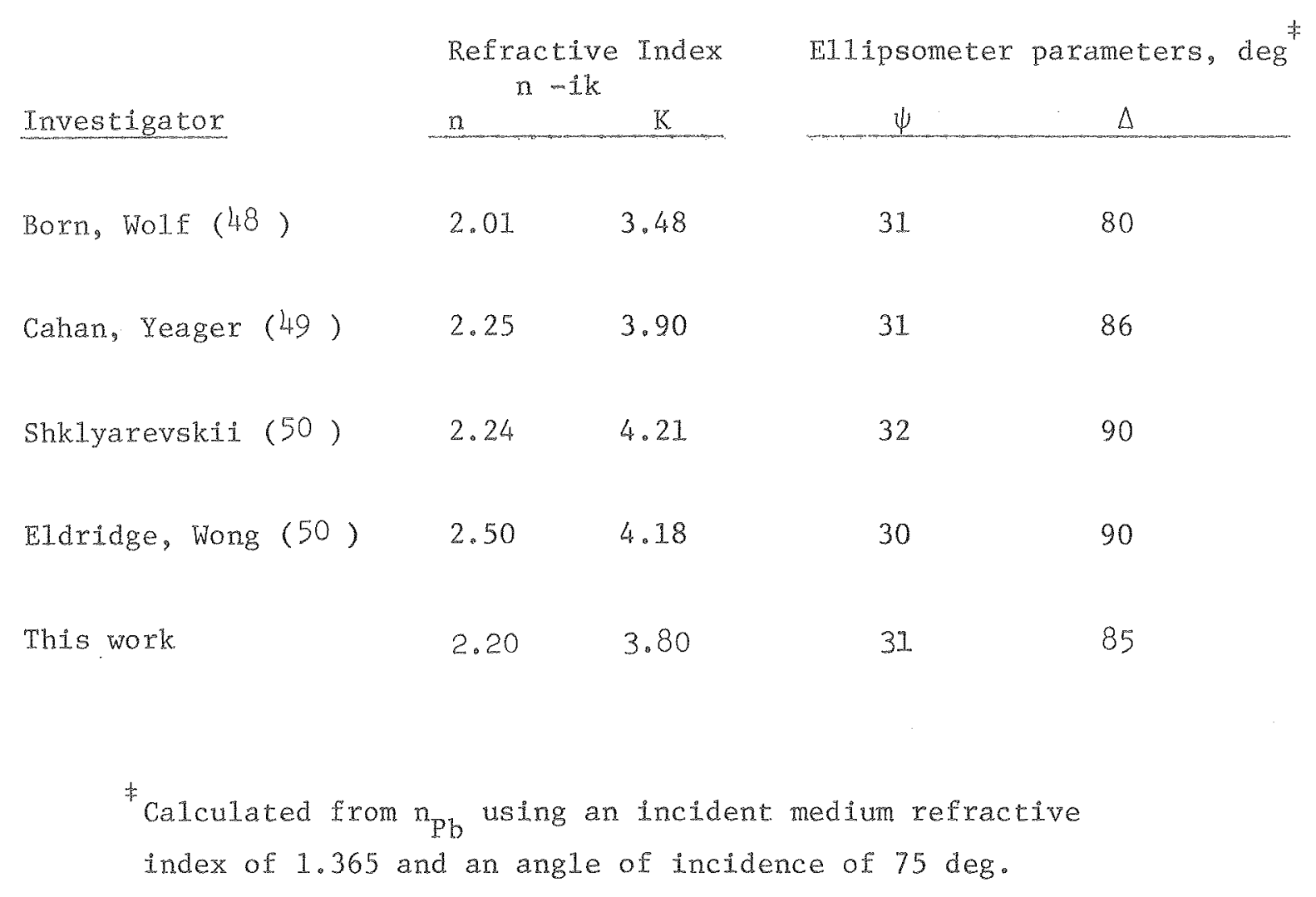


Potential Measurements

Working electrode potential is measured against a mexcurymercurous sulfate reference half cell. The reversible potential between the $\mathrm{Pb} / \mathrm{PbSO}_{4}$ electrode and the $\mathrm{Hg} / \mathrm{Hg}_{2} \mathrm{SO}_{4}$ electrode is -0.958 volts and is independent of electrolyte concentration since both electrodes are exposed to the same solution. Table VI gives reversible potentials for compounds formed on $\mathrm{Pb}$. During cathodic pretreatment measured voltage is usually -1.0 to -1.2 volts corresponding to $\mathrm{H}_{2}$ evolution. This is 400 to $600 \mathrm{mV}$ more negative than the reversible potential, consistent with overpotentials cited in the literature for $\mathrm{H}_{2}$ evolution on $\mathrm{Pb}$. After current is started the potential moves gradually from the reversible value of -.96 volts to about 20 or $30 \mathrm{mV}$ positive near the end of exclusive $\mathrm{PbSO}_{4}$ formation. The formation of new anodic products is signaled by a rapid rise in potencial from -.95 volts to t. 6 volts occurring in a mater of seconds. This is discussed further in the next section.

The 20-30 $\mathrm{mV}$ overpotential observed during anodization is due to IR losses through the film, concentration polarization and activation polarization. The contribution of each of these cannot be determined since the required structural and kinetic details about the electrode are not known. Ohmic losses occur in minute pores between deposits of

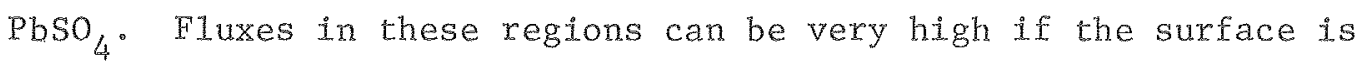
covered by insulating $\mathrm{PbSO}_{4}$. Concentration polarization is due to supersaturation of lead ions, depletion of acid at the surface and $\mathrm{pH}$ gxadients which exist in the film (45). Activation enexgies must be overcome in the transfer of metal atoms from the lattice to the solution. 
TABLE VI Thermodynamic Potentials for the $\mathrm{Pb}-\mathrm{H}_{2} \mathrm{SO}_{4}-\mathrm{H}_{2} \mathrm{O}$ System
(in 1 normal $\mathrm{H}_{2} \mathrm{SO}_{4}$ )

\begin{tabular}{|c|c|}
\hline Electrode & Volts vs $\mathrm{Hg}_{-} \mathrm{Hg}_{2} \mathrm{SO}_{4}$ \\
\hline $\mathrm{PbSO}_{4} / \mathrm{Pb}$ & $=0.958$ \\
\hline $\mathrm{H}_{2} / \mathrm{Pb}$ (cathodic reaction) & -0.602 \\
\hline $\mathrm{PbO} \mathrm{PbSO}_{4} / \mathrm{Pb}$ & -0.745 \\
\hline $3 \mathrm{PbO}^{\circ} \mathrm{PbSO}_{4}{ }^{\circ} \mathrm{H}_{2} \mathrm{O} / \mathrm{Pb}$ & -0.635 \\
\hline $4_{4} \mathrm{PbO}^{\circ} \mathrm{PbSO}_{4} / \mathrm{Pb}$ & -0.562 \\
\hline $\mathrm{PbO} / \mathrm{Pb}$ & -0.437 \\
\hline $\mathrm{O}_{2} / \mathrm{Pb}$ & +0.628 \\
\hline $\mathrm{PbO}_{2} / \mathrm{Pb}$ & +1.05 \\
\hline
\end{tabular}




\section{Transients During Oxidation.}

Formation of new anodic products at the lead electrode is signaled by a sudden rise in potential during constant current oxidation. Optical properties of the surface were measured during potential transients as seen in Figure 16 where values of $\psi, \Delta$ and potential are plotted vs time. Oxidation at the $\mathrm{Pb} / \mathrm{PbSO}_{4}$ plateau occurs for the first $60 \mathrm{~s}$; this data is presented and analyzed as Exp. 121 (Figure 33). The potential then increases rapidy to positive values beginning at point a due to high film resistance and new anodic products. The rate of change of $\Delta$ decreases due to the formation of $\alpha-\mathrm{PbO}_{2}$ which is formed at potentials more positive than 0 volts (23). The volume of $\mathrm{PbO}_{2}$ formed per unit Coulomb is about 1/4 that of $\mathrm{PbSO}_{4}$ (see Table VII). Thickness changes are, therefore, less for $\mathrm{PbO}_{2}$ growth than for $\mathrm{PbSO}_{4}$ growth.

When current is incerrupted at $b$, the potential falls immediately to potentials associated with basic lead sulfates (see Table VII). The same arrest was observed by Pavlov et al ( 23 ) after interruption of anodic current. He postulates that potential remains fixed due to the existence of basic sulfates which block intercrystalline spaces. These compounds are stable at higher $\mathrm{pH}^{\prime}$ s which are established on the surface during anodic current. When current is interrupted basic sulfates dissolve in the strong acid which permeates spaces between crystals. The potential falls back to the $\mathrm{Pb} \mathrm{PbSO}_{4}$ plateau when this material dissipates completely and active metal sites and electrolyte are again in contact. Values for $\psi$ and $\Delta$ are constant between $b$ and $c$ (Figure 16) sincc cor- 

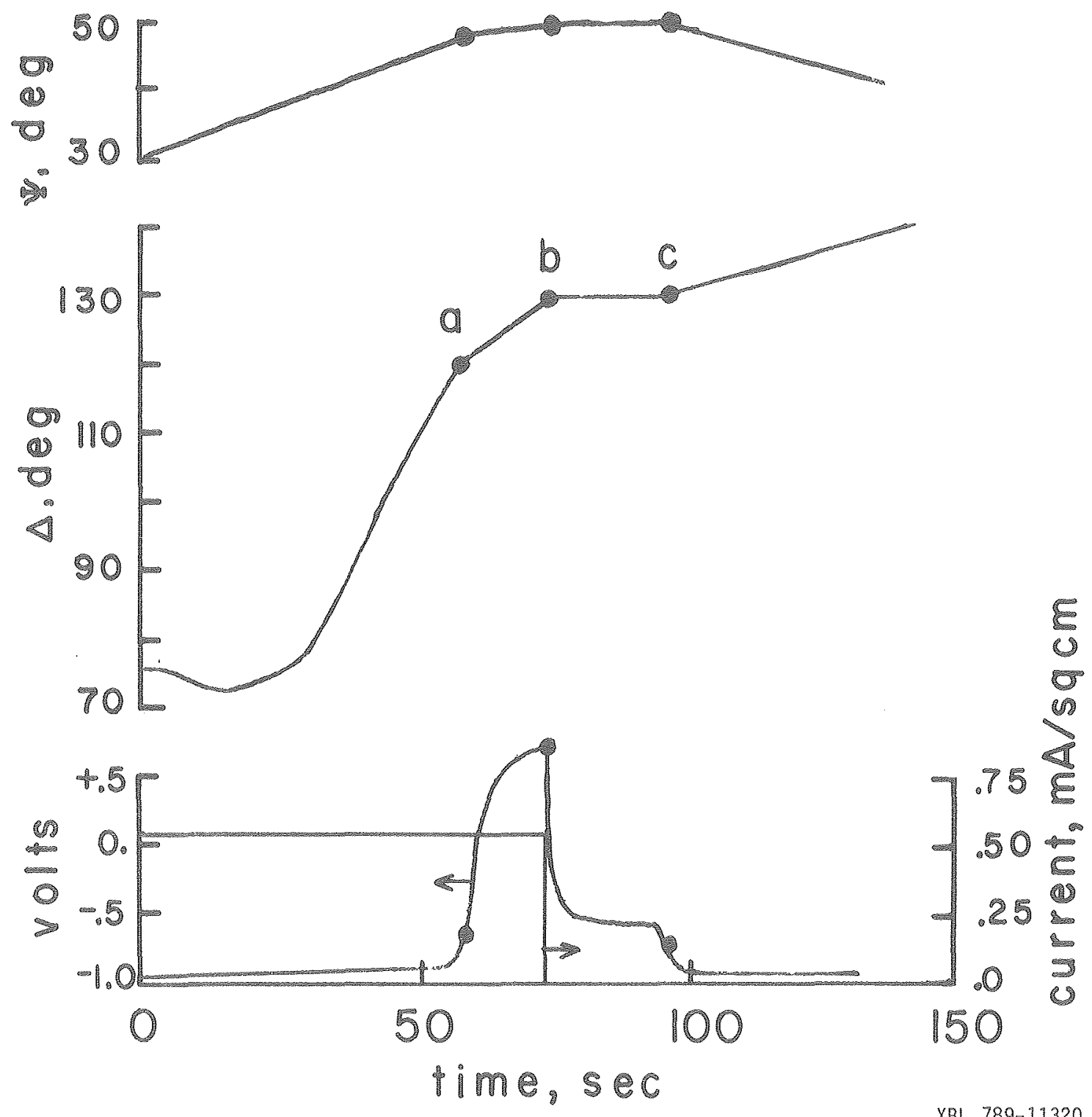

XBL. $789-11320$

Figure 16.

Potential and optical transients observed during $\mathrm{PbO}_{2}$ formation ( $a$ to $b$ ) and passivation ( $b$ to $c$ ). Volts are measured against $\mathrm{Hg} / \mathrm{Hg}_{2} \mathrm{SO}_{4}$ electrode in the same solution ( $3.1 \mathrm{M}_{0} \mathrm{H}_{2} \mathrm{SO}_{4}$ ) as the working electrode. Depassivation occurs at $c$ where $\psi$ and $\Delta$ resume changing after arrest between $b$ and $c$. 
TABLE II Properties for Anodic Film Materials

$$
\frac{\text { Equivalent Volume }}{\left(\frac{\mathrm{M}}{\rho} \frac{1}{\mathrm{nE}}\right), \frac{\mathrm{cm}}{\mathrm{cou} 1}}
$$

$\mathrm{PbSO}_{4}$

$\mathrm{Pbo}_{\text {tet }}$

$\alpha-\mathrm{PbO}_{2}$

$2.53 \times 10^{-4}$

$1.2 \times 10^{-4}$

$6.6 \times 10^{-5}$ *absorption coefficients not axailable
Refractive Index ${ }^{*}$

$$
\text { A/sec per } \mathrm{mA} / \mathrm{cm}^{2}
$$

25.3

1.88

12.0

2.61

0.66

2.23 
rosion of the metal is prevented by the presence of basic sulfates. Open circuit corrosion with film formation begins at $c$ as evident from the increase in $\Delta$ and slight decrease in $\psi$ (such decreases in $\psi$ are typical after $500-1000 \AA$ of film growth). The corrosion product is $\mathrm{PbSO}_{4}$ since the electrode potential is stable near $-.95 \mathrm{~V}$.

Reduction of Anodic Films

Lead sulfate deposits formed during anodic oxidation can be reduced back to lead by driving cathodic current through the electrode. Figure 17 is a scanning electron micrograph of a surface after partial reduction of the anodic film. Crystals are smallex in size than those formed after anodic current at the same current density (compare with Figure $6 \mathrm{~b}$ ), suggesting that material is removed from these crystals during reduction. This observation is consistent with a dissolution mechanism. Figure 19 presents $\psi$ vs $\Delta$ obtained during anodic oxidation at -.95 volts and at +.5 to +.7 volts and during cathodic reduction. Although basic sulfates form at high potentials (more positive than -.4 volts), the principal anodic material is lead sulfate since $\mathrm{PbO}$ is unstable in acid. In addition, the oxidation period at -.95 volts is about 4 times longer than the period at +.5 volts. It was found that when anodic current is interrupted before passivation $\psi$ and $\Delta$ continue to change rather fast indicating $\mathrm{PbSO}_{4}$ film formation due to corrosion. Application of reducing current at this point does not have as large an effect on $\psi$ and $\Delta$ vs time as does reducing the sample after passivation. In the passivated state corrosion is arrested as described in the previous section. From Figure 19 it is seen that the $\psi-\Delta$ 


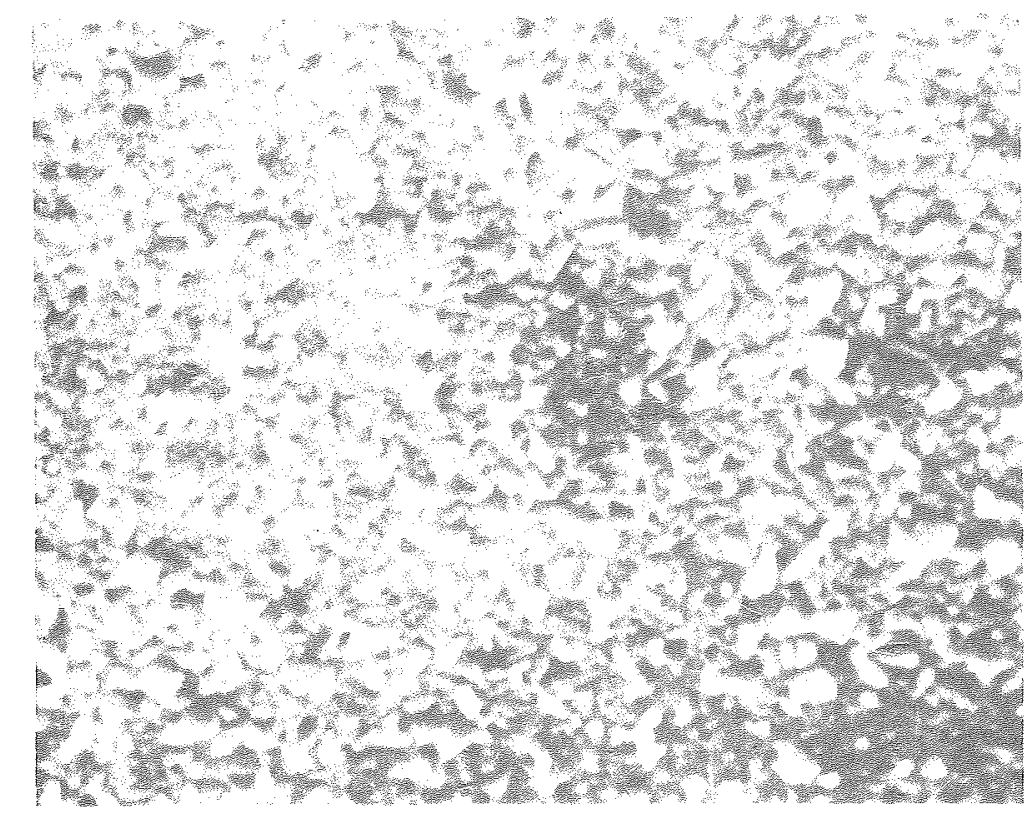

Figure 17. Scanning electron micrograph of lead suraee anodired in $5 \mathrm{MH}, \mathrm{SO}$ at $0.26 \mathrm{~mA} / \mathrm{cm}^{2}$ fom 330 s then reduced at 0.26 $\mathrm{mA} / \mathrm{cm}^{2}$ for $150 \mathrm{~s}$.

\section{$\| \mu$}

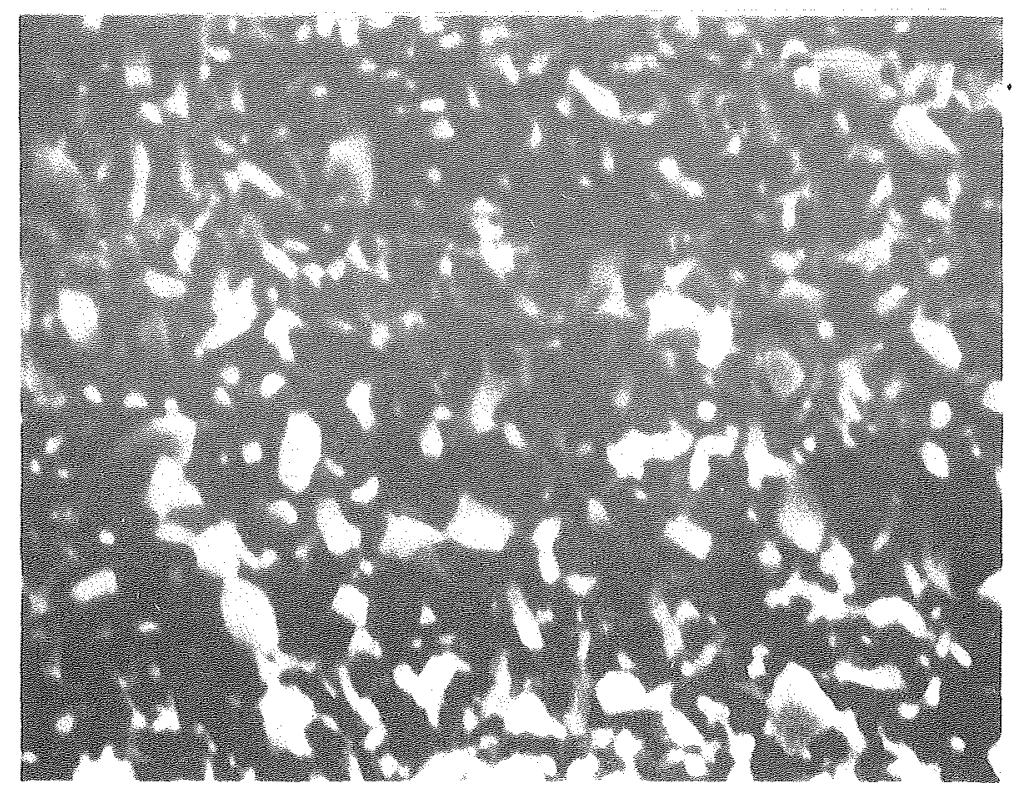

Higure 18. Scaming electron micrograph of lead striace corroded at open circuit rom 250 in $31 \mathrm{M} \mathrm{H}_{2} \mathrm{SO}_{4}$ 


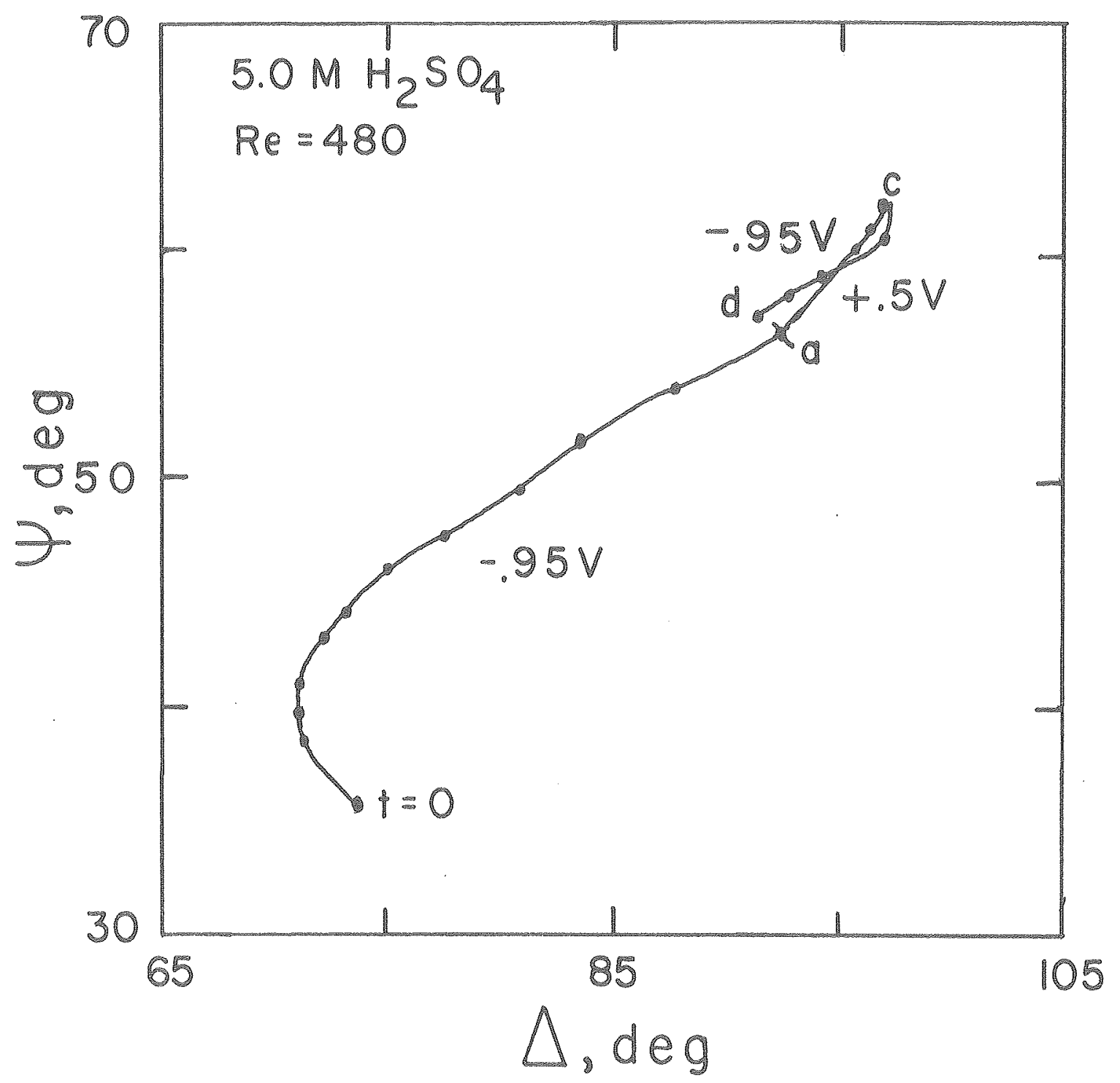

XBL $7810-11928$

Figure 19. Oxidation and reduction of the $\mathrm{Pb} / \mathrm{PbSO}_{4}$ electrode in $5 \mathrm{M} \mathrm{H}_{2} \mathrm{SO}_{4}$ solution and at $\mathrm{Re}=480$. From $t=0$ to $\mathrm{a}$, anodic current $\left(.250 \mathrm{~mA} / \mathrm{cm}^{2}\right)$ at $-.95 \mathrm{~V} \mathrm{vs} \mathrm{Hg} / \mathrm{Hg}_{2} \mathrm{SO}_{4}$. From a to $c$ anodic current $\left(.258 \mathrm{~mA} / \mathrm{cm}^{2}\right)$ at $+.5 \mathrm{~V}$. From c to d cathodic current $\left(.258 \mathrm{~mA} / \mathrm{cm}^{2}\right)$ at $-.95 \mathrm{~V}$. Convection dissolution of solid $\mathrm{PbSO}_{4}$ film is not large enough to exclusively account for changes from $c$ to $d$. Hydrogen evolution begins at d. 
curye is quite similax in sections a to $c$ and sections $c$ to $d$. This indicates that the same structures forming during anodic oxidation are being eliminated during cathodic reduction. The computational procedure is applied to this data in the next section (Figure 27) and the thickness of the deposit at point a is $800 \stackrel{\AA}{\mathrm{A}}(\epsilon=.33)$. This value also approximates the thickness at point $d$.

Figure 20 shows $\psi, \Delta$, potential and current density vs time for the data of Figure 19. Point a corresponds to passivation; at b the anodic current is interrupted and at $c$ reducing current is started. Ellipsometer parameters change slightly between $\mathrm{a}$ and $\mathrm{b}$ due to $\alpha-\mathrm{PbO}_{2}$ formation (as described previously) which occurs above 0. volts. The rate of change in $\psi$ and $\Delta$ is much slower during reduction compared to changes during anodic oxidation up to a. This suggests a lower apparent current efficiency since anodic and cathodic currents have the same magnitude. At point d the potential falls to a plateau of - $1.1 \mathrm{~V}$ signalling the onset of $\mathrm{H}_{2}$ evolution. The ellipsometer parameters stop changing at this point indicating that reduction has terminated even though cathodic current continues. There is an $800 \AA$ layer of material remaining which is not avallable for reduction to lead.

Hydrogen evolution is the only parasitic cathodic reaction expected and does not occur prior to d. The apparent low current efficiency up to d therefore is not due to consumption of current for some reaction other than reduction. It may be due to simultaneous corrosion of freshly deposited $\mathrm{Pb}$. 

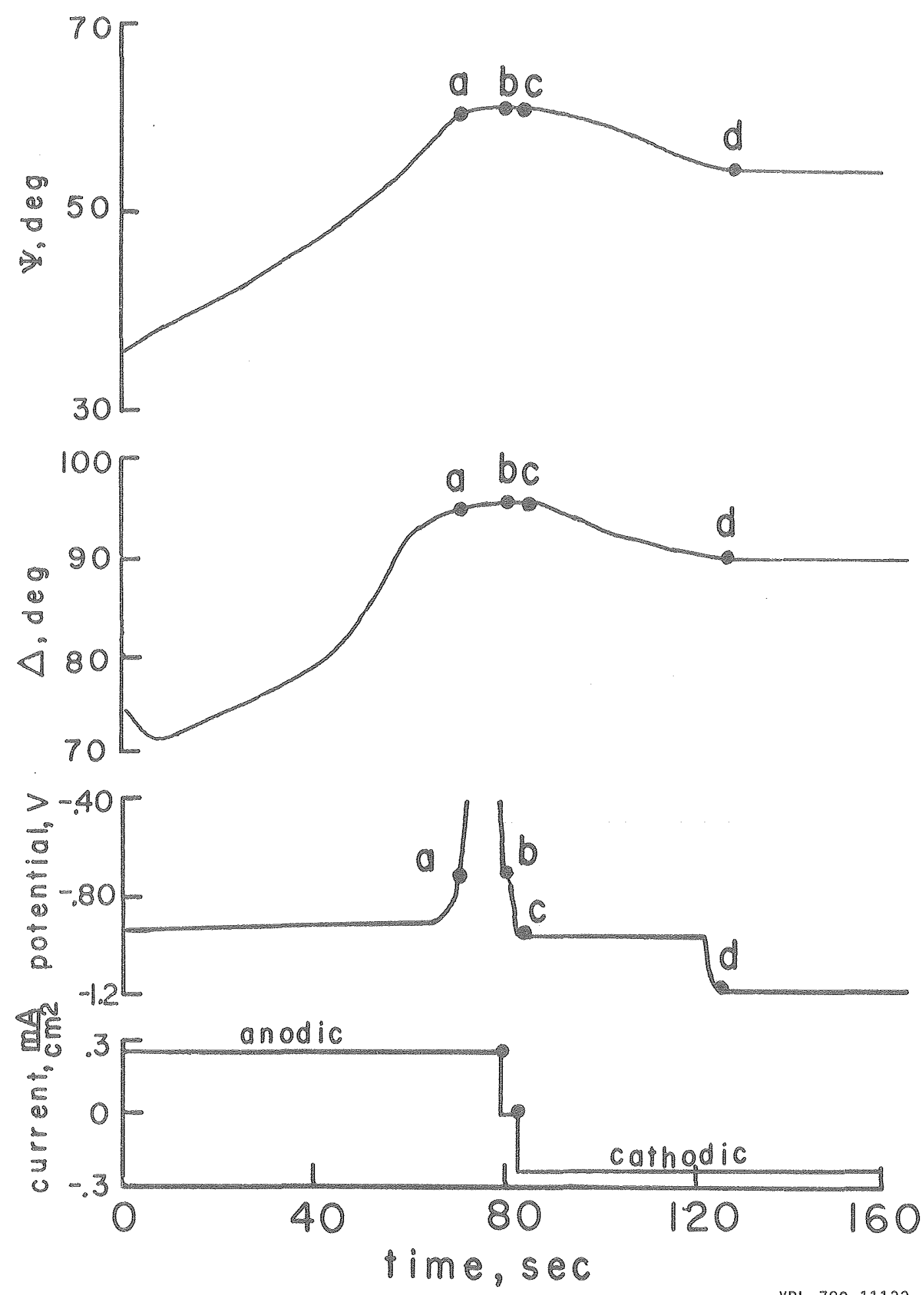

XBL 789.11133

Figure 20. Data of Figure 19 showing transients in $\psi, \Delta$ and potential. a, rise in potential and decrease in rate of change of $\psi$ and $\Delta$ due to $\mathrm{PbO}_{2}$ formation. $\mathrm{b}$, anodic current is interrupted and electrode is at open circuit until c. Cathodic reduction begins at $c_{3} \mathrm{PbSO}_{4}$ reduction continues until d when the potential drops to the hydrogen evolution plateau. 
2. Multiparameter Interpretations, Anodic Film Studies

a. Application of the Mode1

In most cases the use of 6 layers is not necessary in order to reproduce experimental data. It is generally sufficient to use secondary crystals, the Type I film (also referxed to as the primary layer) and the solubilized product layer. The Type II film is used in some high current density $\left(i_{\mathrm{T}} \geqslant .130 \mathrm{~mA} / \mathrm{cm}^{2}\right)$ calculations where formation of an initial compact film is required. Roughness is used in several calculations to qualitatively explain the large decrease in $\psi$ observed near the end of some experiments.

\section{Structura1 Aspects}

As previously mentioned, the model used for the anodic film structure is a:simplified representation. No adequate theory exists for polarization. of light reflected from a surface covered with particles larger than or farther apart than the wavelength of 1ight. At low current densities $\left(.010=.130 \mathrm{~mA} / \mathrm{cm}^{2}\right)$ the lack of rigorous theory presents serious interpretation difficulties since the surface is covered with crystals sometimes exceeding $5000 \AA$ (Figure $6 a, b)$. At higher currents the homogeneous film model better approximates the condition of the deposit on the surface since crystals are smaller and closer together (Figure 6c,d). For current densities of .010 and $.0517 \mathrm{~mA} / \mathrm{cm}^{2}$ secondary crystals referred to in the model will represent the large crystals visible in. SEM photographs. The Type I films will represent proposed sublayers between the large crystals. These sublayers are difficult to observe using ellipsometry since the secondary crystals tend to dominate polari- 
zation of 1ight.

At current densities of $.130 \mathrm{~mA} / \mathrm{cm}^{2}$ and above the secondary crystals and the Type I film in the model are used to represent essentially the same crystalline deposits on the surface instead of representing separate structures (sublayer and large crystals) as in the low current density range. Secondary crystals will represent the larger less numberous crystals and the Type I film will represent the smaller distribution of crystals as visible in Figure $6 \mathrm{c}$, d. In the mode1 secondary crystals grow proportional to their surface area and the Type I film grows at a constant rate. This method is used to distinguish the growth of larger and smaller crystals. Solutions obtained from the computational procedure are improved using these kinetic assumptions (see Figure 29). Calculated dimensions and coverage of larger crystals (secondary crystals) generally do not agree with sizes visible from SEM photographs.

Transient Growth and Material Transport

The computational procedure calculates the time ts at which solid film growth begins (see Eqs, [10] and [1] ]). This represents the time to reach supersaturation of $\mathrm{pb}^{\text {Ht }}$ ions necessary for film growth. This supersaturation is not known; however, measured overpotentials are usually less than $30 \mathrm{miV}$ which corresponds to $\mathrm{pb}^{\text {th }}$ concentrations of less than 10 times solubility $\left(D_{\mathrm{ss}}=10\right)$. The following expression is used to relate the supersaturation ratio $\mathrm{D}_{\mathrm{SS}}\left(\mathrm{C}_{\mathrm{SS}} / \mathrm{C}_{\mathrm{S}}\right)$ to overpotential $\eta$

$$
\eta=\frac{R T}{n F} \ln D_{S S^{\circ}}
$$


Not al1 of the measured overpotential can be attributed to supersaturam tion of $\mathrm{Pb}^{++}$. Thus, $\mathrm{D}_{\mathrm{SS}}$ is less than 10 , and for computational purposes, it has been arbitrarily fixed at 1.1. The time to reach supersaturation $t_{s}$ for free convection and forced convection is generally less than $1 \mathrm{sec}$ even if $D_{\mathrm{ss}}$ is as high as 10 . Essentially there is no induction period before solid $\mathrm{PbSO}_{4}$ formation. This is observed experimentally since $\psi$ and $\Delta$ change immediately after current is initiated.

The parameter $D_{S S}$ also determines the ionic flux $I_{D}$ (Eq. [2]) of $\mathrm{Pb}^{++}$away from the electrode surface. This leaves two parameters $f_{R}$ and $D_{\text {ss }}$ which can determine the effective film current $i_{\text {film }}$. This is apparent from the following flux balance equations which are valid after $t_{\text {NUC }}$ (most of the computation) when the only fluxes contributing to film growth are the Type I fiIm ${ }^{i}$ IF and the secondary crystals $i_{\text {sc }}$

$$
\begin{aligned}
& i_{\text {total }}=i_{f i l m}+i_{\text {remaining in solution }} \\
& i_{f i l m}=i_{S C}+i_{I F} \\
& i_{f i 1 m}=i_{S C}+f_{R}\left(i_{T}-i_{S C}-i_{D}\right.
\end{aligned}
$$

Equation [35] is derived from Eqs. [34], [16] and [17]. Fixing the value of $D_{\text {SS }}$ prevents overspecification of the material balance expression. The parameter $f_{R}$ thus establishes the balance of material used for solid film formation. 
At $t_{\text {NUC }}$ growth of the Type II layer stops and the Type I fiIm and secondary crystals begin. The value of $t_{\mathrm{NUC}}$ is generally fixed to a small value to reduce the number of floating parameters although it affects the initial size of the secondary crystals (Eq.[14]). Numerous trial calculations are performed for each set of experimental data and different values for $t_{\text {NUC }}$ are often attempted. This quantity represents a realistic transition time only for some high current density experiments where growth of a Type II film is indicated.

After $t_{\text {NUC }}$ growth of the Type I film and secondary crystals occurs only in certain regions. These patches increase in coverage from t $t_{\text {NuC }}$ to $t_{\text {DISS }}$ as described earliex. The coverage of secondary crystals before $t_{\text {DISS }}$ refers to coverage in a patch, not per unit superficial electrode area. Also the Type I film decreases in porosity from $t_{\mathrm{NUC}}\left(\in_{\text {IFO }}\right)$ to $t_{\text {DISS }}\left(\in_{\text {IFF }}\right)$. Both of these processes can be due to progressive nucleation of crystals of $\mathrm{PbSO}_{4}$.

The following sections present results of the computer analysis. Reproductions of output from the program are found in the appendix. For each evaluated parameter an error term is calculated which represents the amount the parameter must change in order to alter the average distance between points by 1 degree. This term is an average of positive and negative uncertainty and indicates the sensitivity of computed $\psi$ and $\Delta$ to the evaluated parameter. 
b. Results of Computations

0.010 and $0.0517 \mathrm{~mA} / \mathrm{cm}^{2}(99,144,78,138)$

The results at these current densities are only qualitatively interpreted since light polarization due to large crystals cannot be ana1yzed accurately. Calculated final dimensions of secondary crystals are between 1200 and $2900 \AA$ as indicated on Figures $21-24$ which show experimental and calculated points. These dimensions are about $1 / 2$ as large as the sizes apparent from SEM microphotographs. Dimensions for the Type I film are uncertain since large error terms are associated with porosities of this layer (see Tables VIII, TX).

When applied current density is $0.01 \mathrm{~mA} / \mathrm{cm}^{2}$ the effective current density (Table VIID) is larger than the applied current density since corrosion contributes significantly to the formation of $\mathrm{PbSO}_{4}$. In this calculation the total current becomes an evaluated parameter. Use of a constant current during corrosion is not rigorously correct since the corrosion rate may vary with surface coverage. However, this assumption was adequate to reproduce data and give some idea of the influence of corrosion. Effective current is $.009 \mathrm{~mA} / \mathrm{cm}^{2}$ larger than applied current so that this difference roughly represents the corrosion current. Void spaces between crystals cannot be differentiated from hydration of secondary crystals since the optical theory averages voids and crystals 


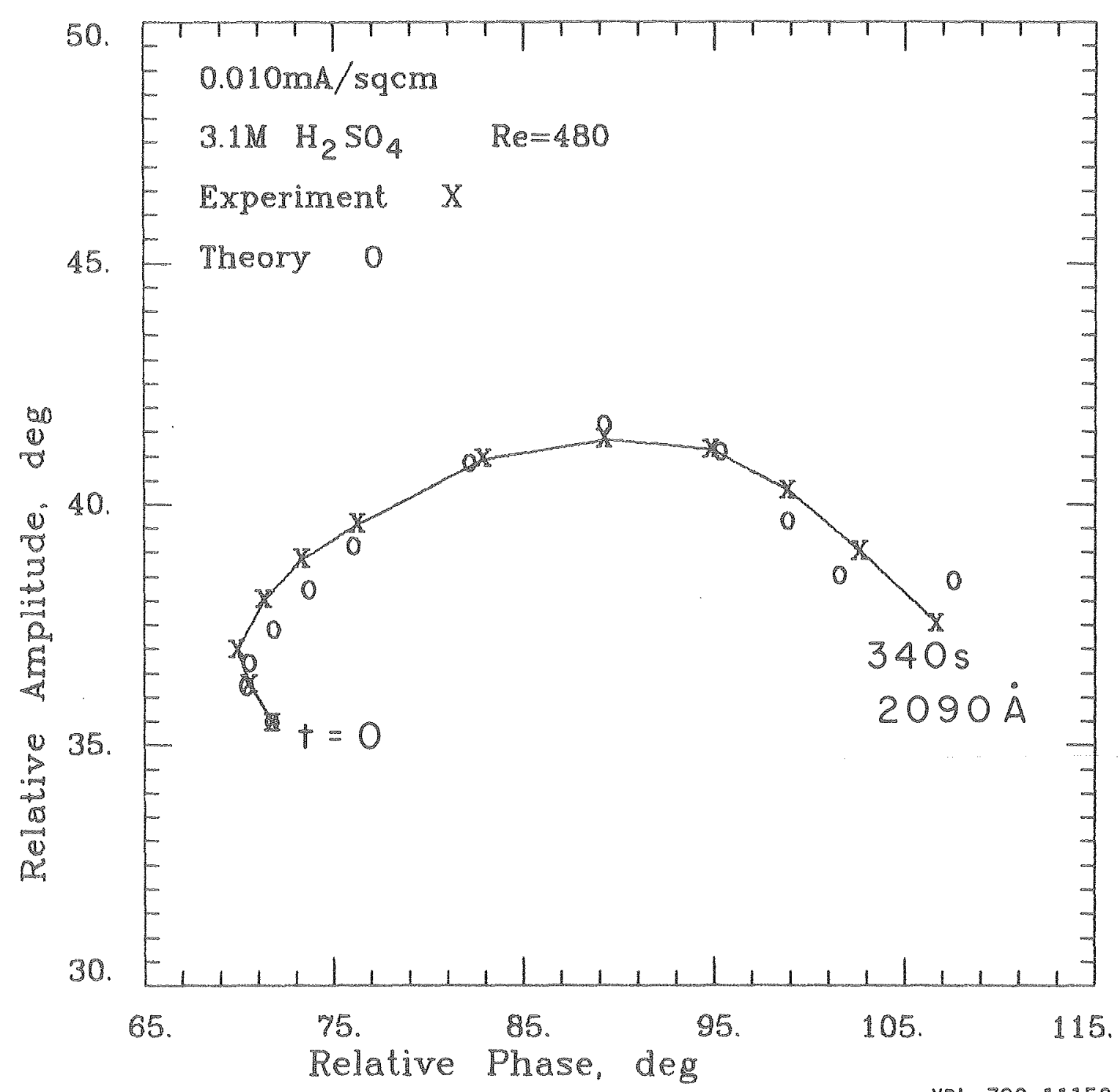

Figure 21. Experiment 99. Experimental and theoretical values of $\psi$ and $\triangle$ obtained from $\mathrm{PbSO}_{4}$ film growth on lead.

Theoretical points are calculated using model described in Chapter IV. Dimension at end point is final size of secondary crystals (coverage of $24 \%$ ). 


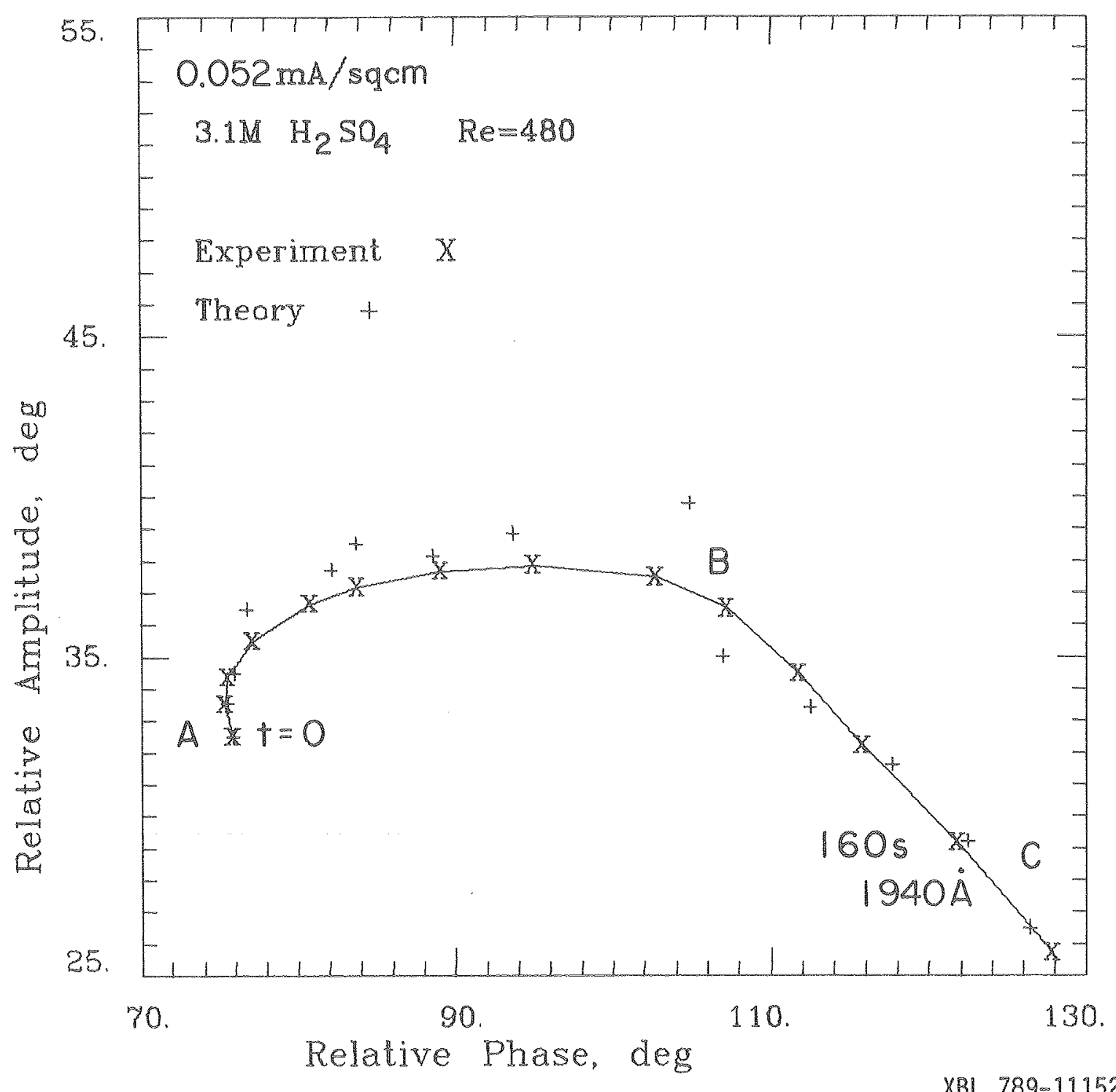

Figure 22. Experiment 78. As in Figure 21, final coverage is 38\%. Theoretical points were calculated in two stages $A$ to $B$ and $B$ to $C$. 


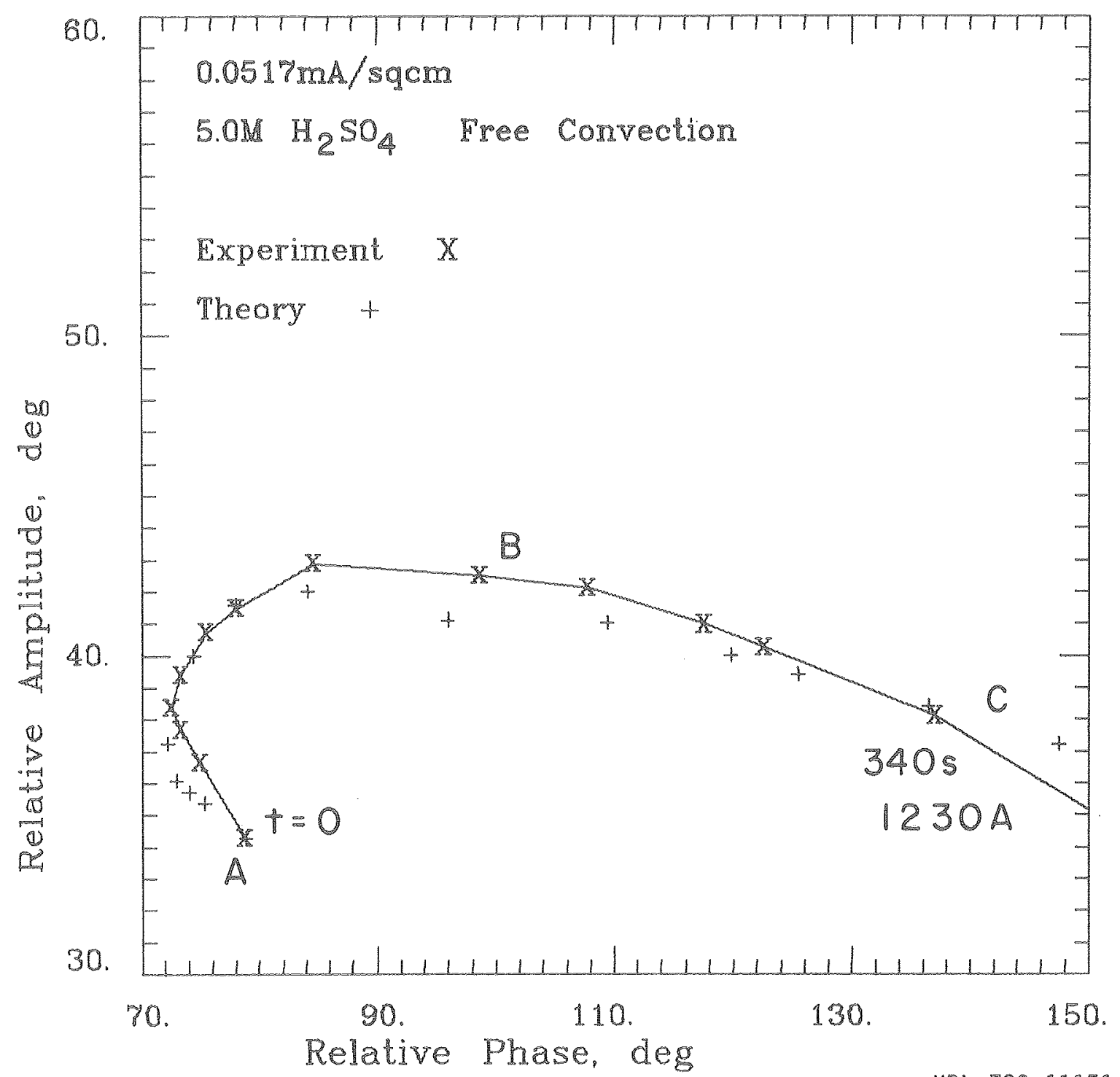

Figure 23. Experiment 138. As in Figure 21, final coverage is $14 \%$. Theoretical points were calculated in two stages, A to $B$ and $B$ to $C$. 


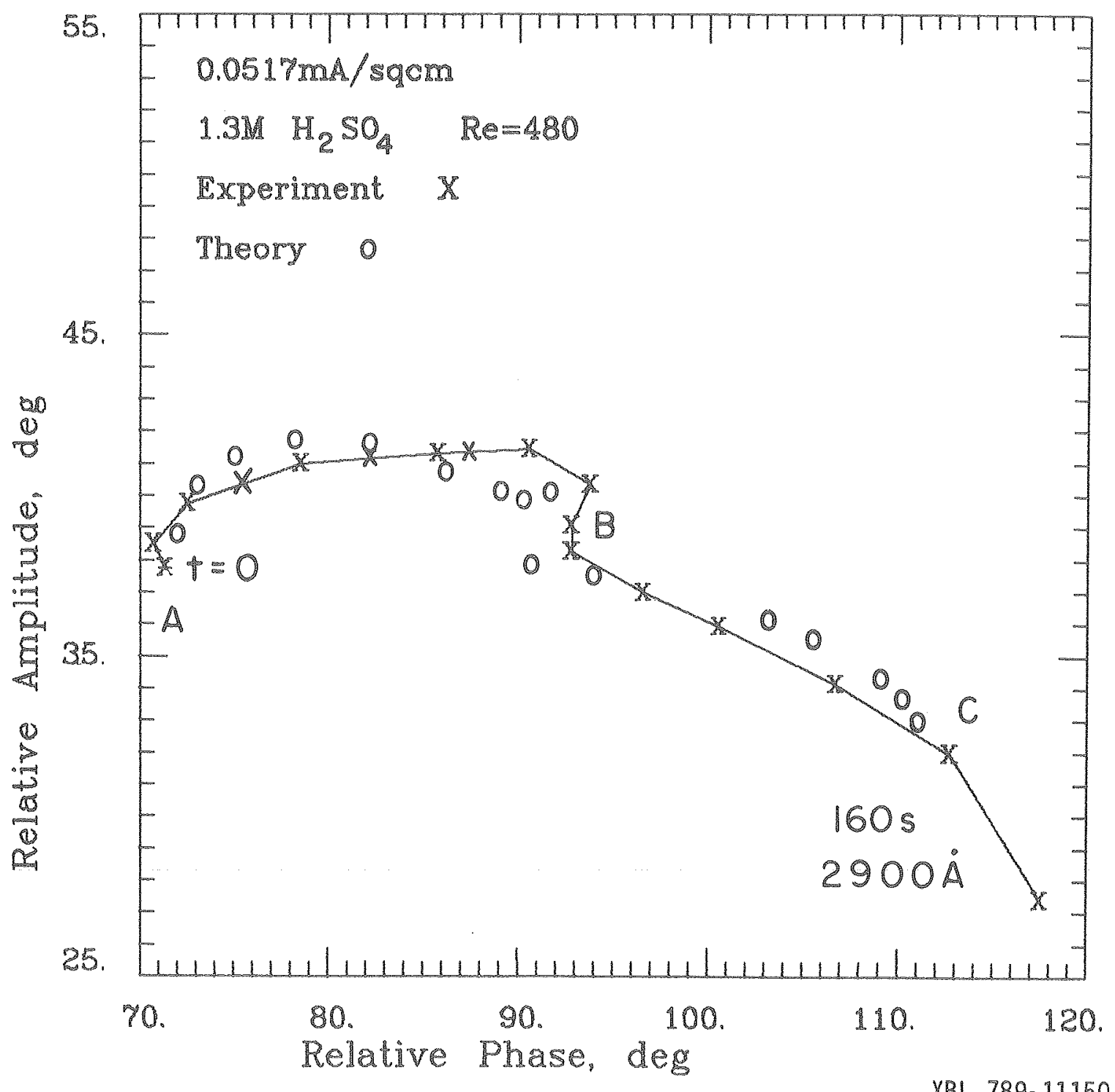

Figure 24. Experiment 144. As in Figure 21, final coverage is $34 \%$. Theoretical points were calculated in two stages, A to $B$ and $B$ to $C$. 
TABLE VIII Evaluated Parameters for Growth of Anodic $\mathrm{PbSO}_{4}$

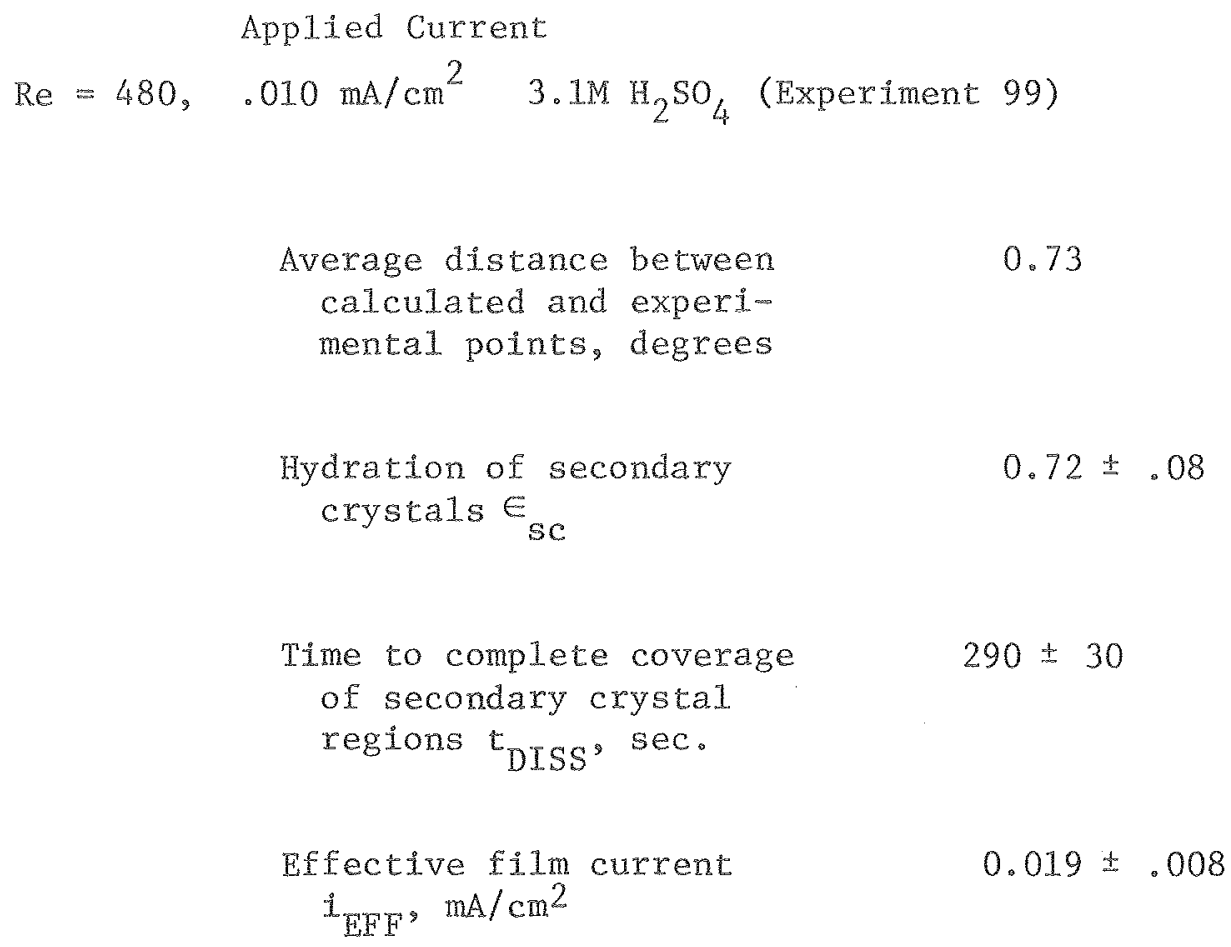




\begin{tabular}{|c|c|c|c|c|c|c|}
\hline EXPERIMENT & \multicolumn{2}{|c|}{78} & \multicolumn{2}{|c|}{144} & \multicolumn{2}{|c|}{138} \\
\hline Acid Concentration $M$ & \multicolumn{2}{|c|}{3.1} & \multicolumn{2}{|c|}{1.3} & \multicolumn{2}{|c|}{5.0} \\
\hline Elow Condition & \multicolumn{2}{|c|}{$\mathrm{Re}=1640$} & \multicolumn{2}{|c|}{$\mathrm{Re}=480$} & \multicolumn{2}{|c|}{ free convecinion } \\
\hline & $\begin{array}{l}\text { initial } \\
\text { points }\end{array}$ & $\begin{array}{l}\text { Final } \\
\text { points }\end{array}$ & $\begin{array}{l}\text { initial } \\
\text { points }\end{array}$ & $\begin{array}{l}\text { Einal } \\
\text { points }\end{array}$ & $\begin{array}{l}\text { initial } \\
\text { points }\end{array}$ & $\begin{array}{l}\text { Final } \\
\text { points }\end{array}$ \\
\hline $\begin{array}{l}\text { Average distance between experimental } \\
\text { and calculated points, degrees }\end{array}$ & 1.4 & 1.6 & 1.36 & 4.70 & 2.5 & 3.3 \\
\hline Hydration of secondary crystals $\in_{\text {se }}$ & $0.30 \pm .17$ & $0.60 \pm .05$ & 0.30 & $0.80 \pm .15$ & $.1 \pm .23$ & 0.20 \\
\hline $\begin{array}{l}\text { Time to complete coverage of secondary } \\
\text { crystal regions toISS }\end{array}$ & $70 \pm 16$ & $250 . \pm 150$ & $43 . \pm 7$ & 250. \pm 100 & $200 . \pm 32$ & $430 . \pm 72$ \\
\hline Final coverage of secondary crystals, \% & 8. & 38. & 7. & 34. & 6. & 14. \\
\hline
\end{tabular}


into the same film. Hydration of secondary crystals $\epsilon_{\mathrm{sc}}$ is large as seen in TableVIII and suggests a large void volume in the deposit. The time to reach complete coverage of secondary crystal regions $t_{\text {DISS }}$ is 290 s. Figure 21 shows good agreement between experimental and theom retical points up to the $(\Delta, \psi)$ coordinates of $(104,38)$. At this point large secondary crystals make analysis of polarization difficult.

Data for Experiments 78, 138 and 144 were analyzed in two stages, segments $\overline{\mathrm{A} B}$ and segments $\overline{\mathrm{BC}}$, since the computational procedure could not find a solution in one calculation (Figures 22-24). The high acid concentration (5 M) and free convection conditions of Experiment 138 (see Table) would be expected to result in a less porous deposit than in Experiments 78 and 144 since supersaturation conceivably is higher. This is qualitatively confirmed by the lower values for $\epsilon_{\mathrm{sC}}$ in Experiment 138 . Values of $\epsilon_{S C}$ are probably influenced by void volume as in Experiment 99 with smaller hydrations representing less void space. There are discrepancies between parameters evaluated for the initial segment $A B$ and final points. BC (Figures 22-24). Values for $\in_{\text {SC }}$ are larger suggesting a more voluminous final deposit. The time $t_{\text {DISS }}$ is much larger for the initial calculation than the final calculation. However, final coverage of. secondary crystals is larger in the second calculation. This suggests progressive nucleation for $200-300 \mathrm{~s}$. Although final coverage of secondary crystals is larger in Experiment 78 and 144, a larger Type I film $(530 \AA$ ) was calculated for Experiment 138 , perhaps due to enhanced concentration of film-forming species.

Roughening of the metal substrate was used to reproduce the decreasing values of $\psi$ towards the end of Experiments 78 and 144 (Figures 22 

TABIE $X$ Results for Experiments at $0.13 \mathrm{~mA} / \mathrm{cm}^{2}$ and 5.0 $\mathrm{M} \mathrm{H}_{2} \mathrm{SO}_{4}$ Electrolyte

\begin{tabular}{|c|c|c|c|}
\hline 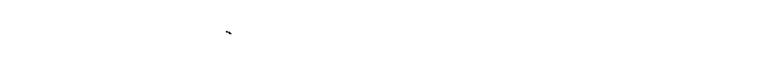 & \multicolumn{3}{|c|}{ Experiment } \\
\hline & \multicolumn{2}{|c|}{134} & \multirow[t]{2}{*}{137} \\
\hline & $\begin{array}{l}\text { initial } \\
\text { points }\end{array}$ & $\begin{array}{l}\text { final } \\
\text { points }\end{array}$ & \\
\hline Flow condition & \multicolumn{2}{|c|}{ free convection } & $\operatorname{Re}=480$ \\
\hline $\begin{array}{l}\text { Average distance between experiment } \\
\text { and theory, degree }\end{array}$ & 1.53 & 2.2 & 2.2 \\
\hline Final porosity of primary layer $\epsilon_{\text {IFP }}$ & $0.69 \pm .04$ & $0.33 \pm .15$ & $0.69 \pm .018$ \\
\hline Hydration of secondary crystals $\epsilon_{S C}$ & $0.50 \pm 0.27$ & $0.11 \pm 0.40$ & $0.47 \pm 0.04$ \\
\hline Growth period $t_{D I S S}$ seconds & $90 . \pm 24$. & $186 . \pm 12 。$ & $132 . \pm 3.0$ \\
\hline
\end{tabular}




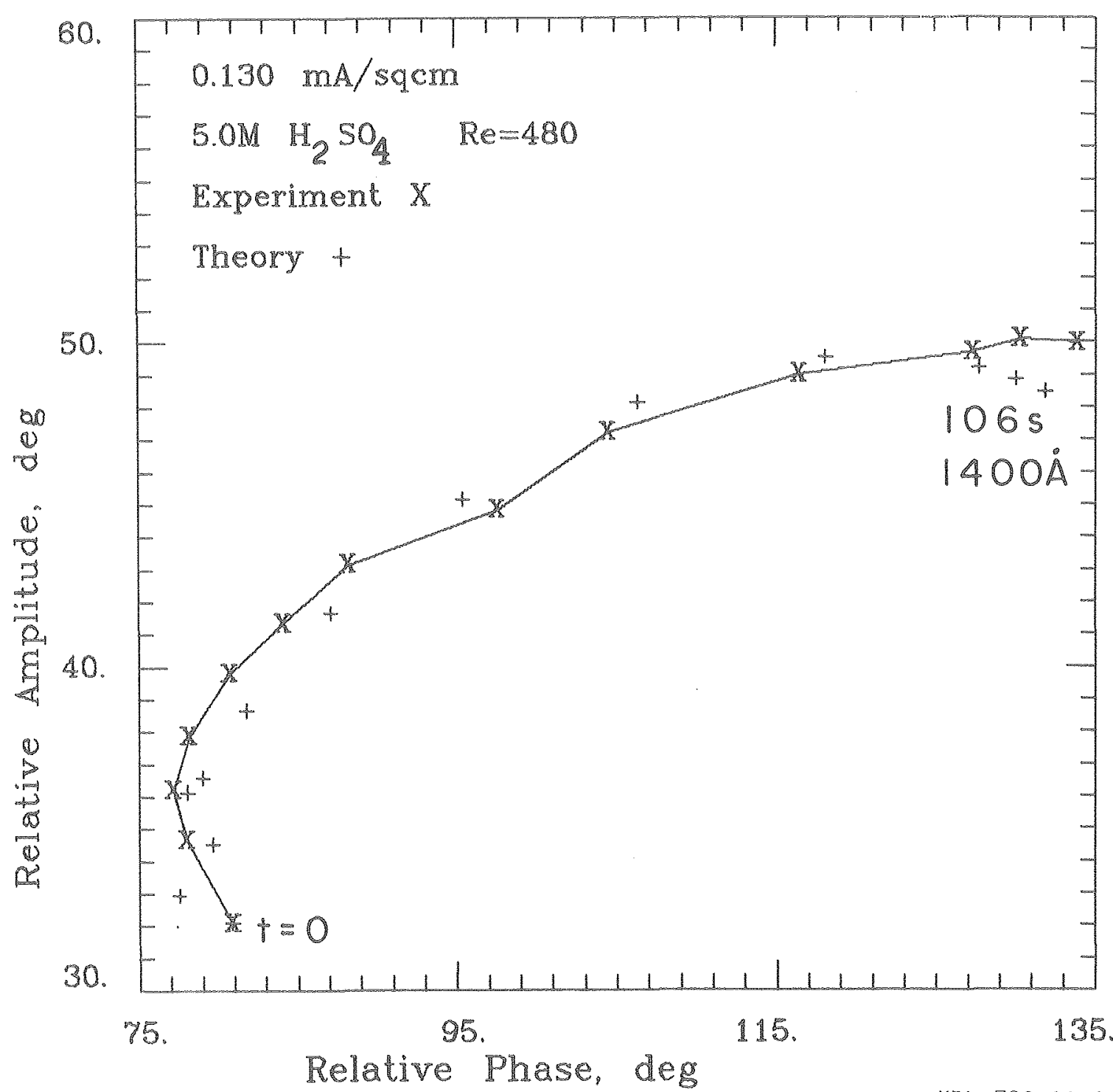

XBL 789-11149

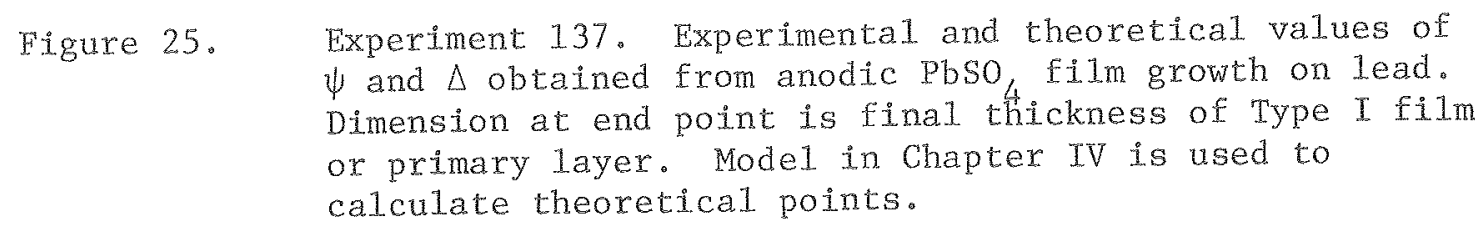




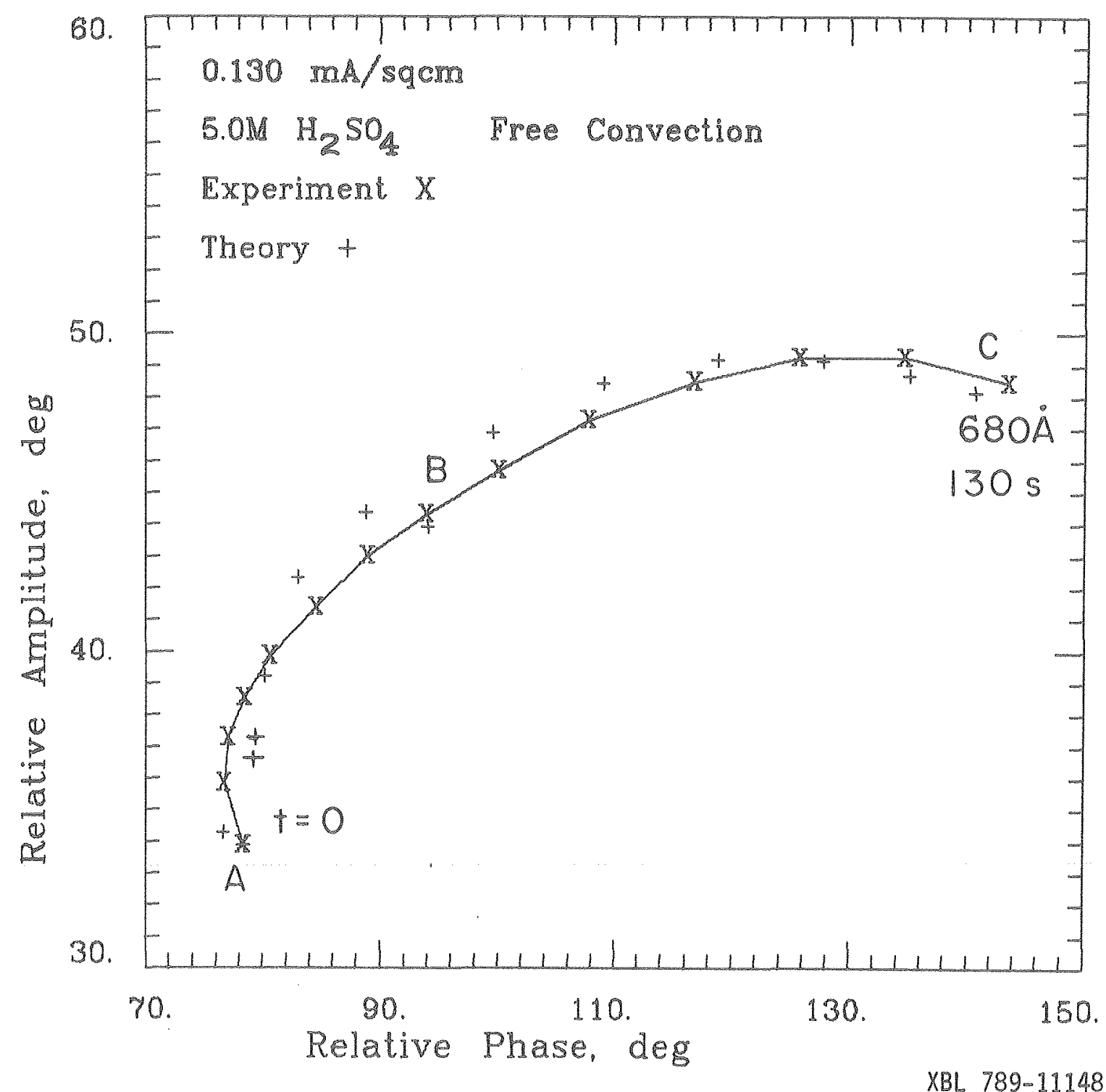

Figure 26. Experiment 134. As in Figure 25, theoretical points were calculated in two stages, $A$ to $B, B$ to $C$. 
and 24 ). No solution could be found using dielectric film refractive indices exclusively (various porosities of secondary crystals) so that introduction of an underlying roughness layer with complex reflective Index became necessary. In Experiment 78 the final roughness layer is $450 \AA$ thick and contains $40 \%$ metal, and in Experiment 144 it is $120 \AA$ thick with $50 \%$ metal. The decrease in $\psi$ and $\Delta$ at point $B$ in Experiment 144 is apparently caused by the growth of large secondary crystals (about $2000 \AA$ ) and the onset of roughening.

$0.130 \mathrm{~mA} / \mathrm{cm}^{2}(134,137)$

Table X compares results of the calculations for these two experiments and Figures 25 and 26 show calculated and experimental points. Expeximent 134 (Figure 26 ) was analyzed in two stages, $\overline{\mathrm{AB}}$ and $\overline{\mathrm{BC}}$. Calculations indicate a more compact deposit for the final part of Exp. 134 (free convection) than for Exp. 137 (Re $=480)$. Higher concentration of film-forming species is expected with free convection than with forced convection. The large uncertainty in $\in_{\text {IFP }}$ (Table $x$ ) for Experiment 134 places upper and lower bounds on its value. The value for $\epsilon_{\text {IFP }}$ is larger in Experiment 137 than in Experiment 134. Initial growth of pacches and decrease in Type I film porosity occur at a faster rate in Experiment 134 since $t_{\text {DISS }}$ is smaller. The large value of $t_{\text {DISS }}$ in the final stage of Experiment 134 accommodates less porosity.

$0.258 \mathrm{~mA} / \mathrm{cm}^{2}(73,131,135,147)$

Evaluated parameters for this current density are presented in Table XI which compares various conditions of electrolyte flow and 
composition. Figures 27 through 30 show calculated and experimental points. It is apparent that maximum $\psi$ values are 10-15 degrees higher in experiments at $5 \mathrm{M} \mathrm{H}_{2} \mathrm{SO}_{4}$ than the experiments at 1.3 and $3.1 \mathrm{M}$. This is due to less film porosity (higher refractive index, see Figure 9 ) caused by higher supersaturation. Experiments in $5 \mathrm{M}$ acid result in lower values of $\epsilon_{\text {TFP }}$ followed by the 3.1 and 1.3 M expeximents as shown in Table XI. Secondary crystal hydration ranges between 0.5 and 0.6 . They are not used in calculations for Experiment 135 and the initial part of Experiment 147. The compaction and growth period $t_{\text {DISS }}$ is between 50 - $100 \mathrm{~s}$ at this current density, shorter than at $0.13 \mathrm{~mA} / \mathrm{cm}^{2}$. The measured time to reach passivation (from potential jump) corresponds to $t_{\text {DISS }}$ within the uncertainty 1 imits for Experiments 131 and 135.

Extensive growth of secondary crystals is derived from the calculations for Exp. 73 (Figure 28). This is optically equivalent to a large primary layer of high porosity since the crystals cover only $12 \%$ of the surface. Enhanced mass transport from the high Reynolds number $(1,640)$ evidently lowers supersaturation, giving a more porous deposit.

The plotted $\psi-\Delta$ curve for Experiment 147 shifts direction abruptly near point $B$ (Figure 30 ) where the second calculation for points $\overline{\mathrm{BC}}$ begins. Growth of large secondary crystals is indicated from the computational procedure for this final portion while the primary layer is relatively constant to the end (point $\mathrm{C}$ ).

Two alternate film growth processes were investigated in calculations for Experiment 131 (Figure 29). Growth of secondary crystals at a rate proportional to their size (Theory I) is preferred to constant growth (Theory II) or absence of secondary crystals (Theory III)。 
TABLE XI Results for Experiments at $0.258 \mathrm{~mA} / \mathrm{cm}^{2}$

\begin{tabular}{|c|c|c|c|c|c|}
\hline Experiment & 73 & 131 & 135 & 147 & \\
\hline Flow condition, $\operatorname{Re}$ & 1640 & 480 & 480 & 480 & \\
\hline Acid concentration, $\mathbb{M}$ & 3.1 & 5.0 & 5.0 & $\begin{array}{l}1.3 \\
\text { initial points }\end{array}$ & final points \\
\hline $\begin{array}{l}\text { Avg distance between Exp。 } \\
\text { and Calc. points, deg. }\end{array}$ & 1.7 & 4.4 & $\mathbb{1} .76$ & 0.84 & 0.95 \\
\hline $\begin{array}{l}\text { Final porosity of primary } \\
\text { Iayer, } \in_{\text {IFP }}\end{array}$ & $0.53 \pm .09$ & $0.41 \pm .04$ & $0.36 \pm .09$ & $0.74 \pm .09$ & $0.66 \pm .02$ \\
\hline $\begin{array}{l}\text { Hydration of secondary } \\
\text { crystals, } \in_{S C}\end{array}$ & $0.59 \pm .05$ & $0.49 \pm .4 \mathbb{1}$ & -- & -- & $0.51 \pm .41$ \\
\hline $\begin{array}{c}\text { Final fractional coverage } \\
\text { of secondary crystals }\end{array}$ & 0.124 & 0.056 & $-\infty$ & -- & 0.059 \\
\hline Growth period, $t_{\text {DISS }}$ sec. & $55 . \pm 5$ & 100 & $93 .+20$ & $44 . \pm 9$ & $75 . \pm 5$ \\
\hline $\begin{array}{l}\text { Time to reach passivation } \\
\text { (measured), sec. }\end{array}$ & 120 & 110 & 70 & -- & 125 \\
\hline
\end{tabular}




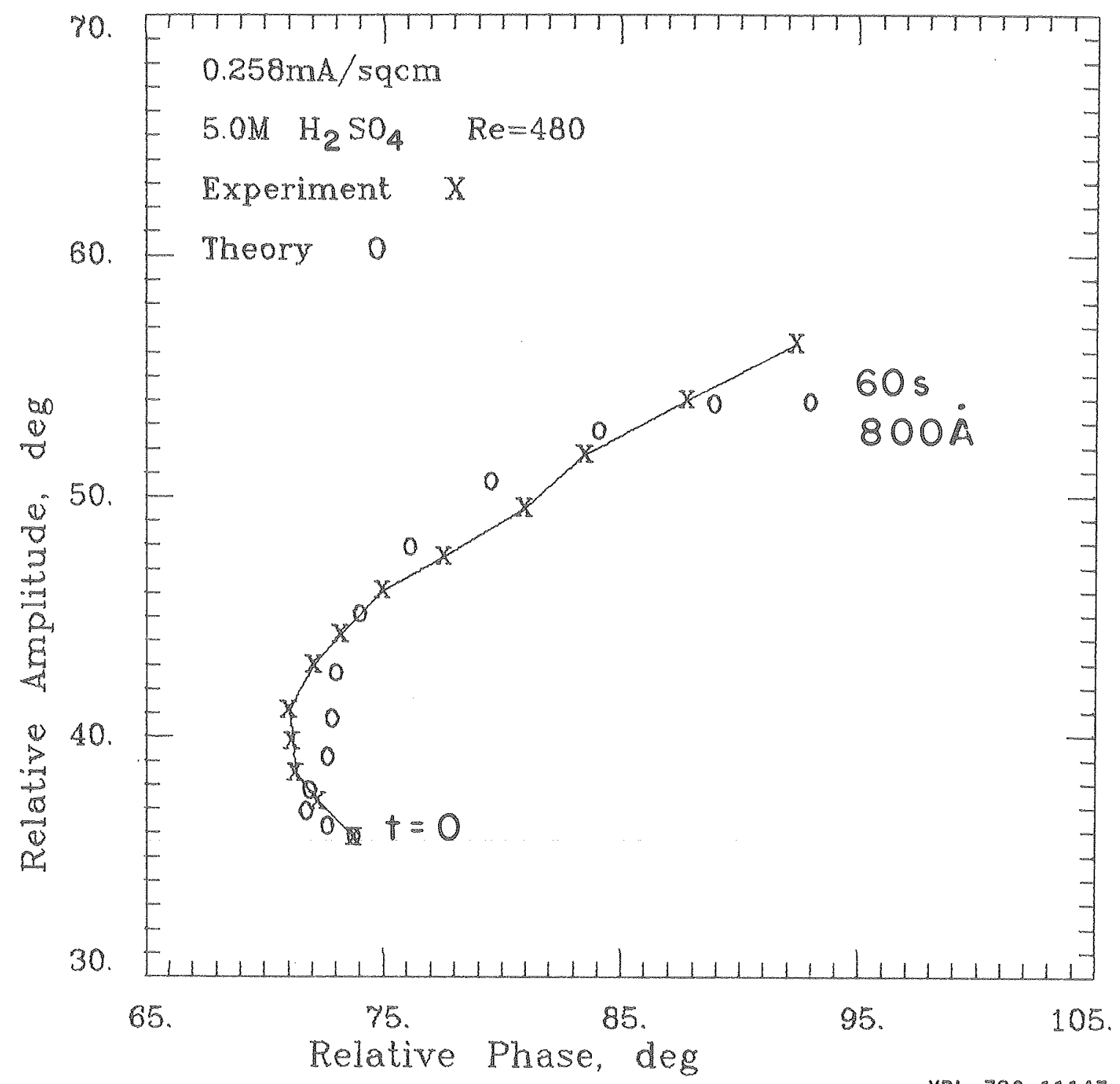

XBL $789-11147$

Figure 27. Experiment 135. As in 25. 


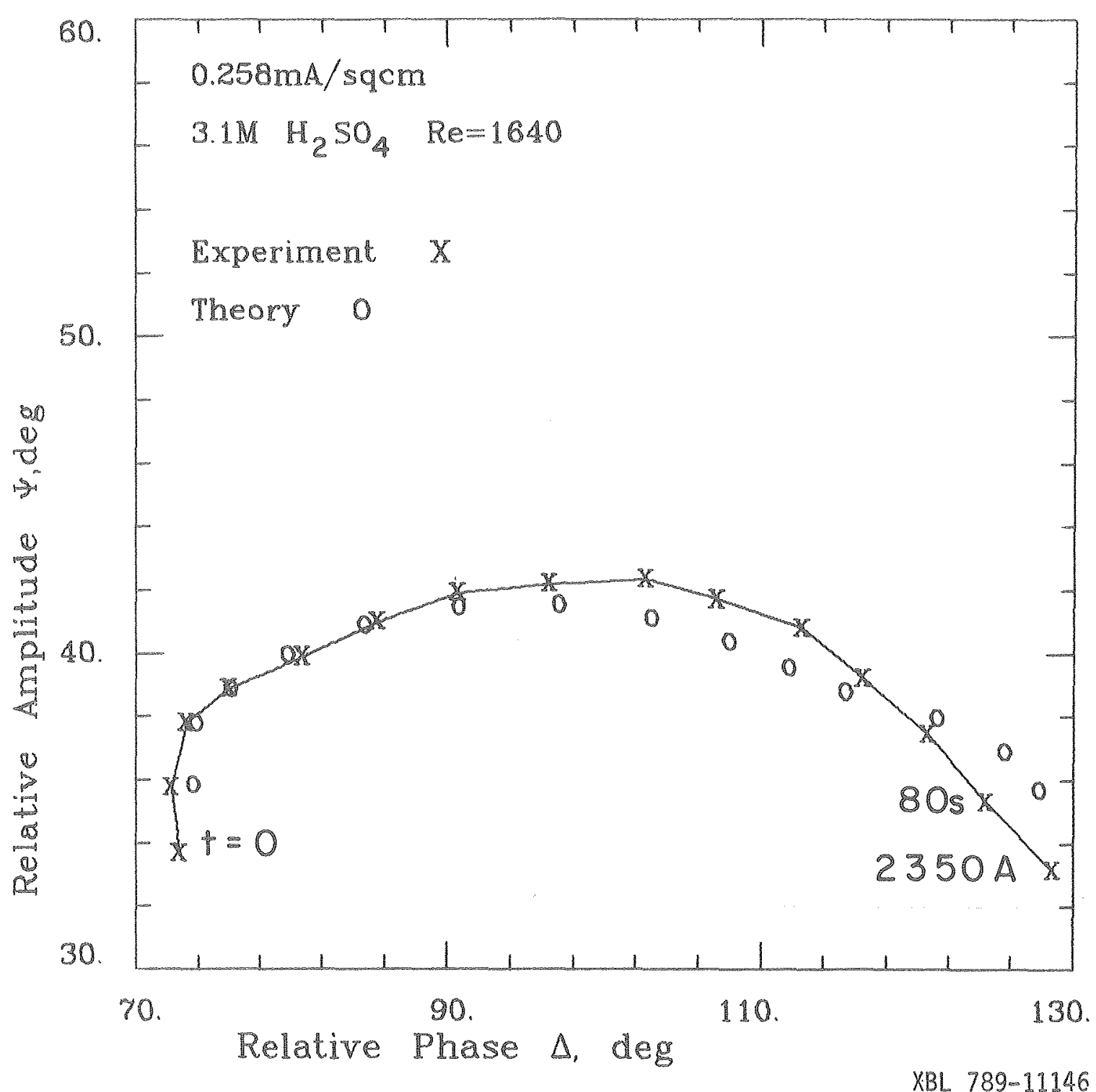

Figure 28. Experiment 73. As in Figure 25. 


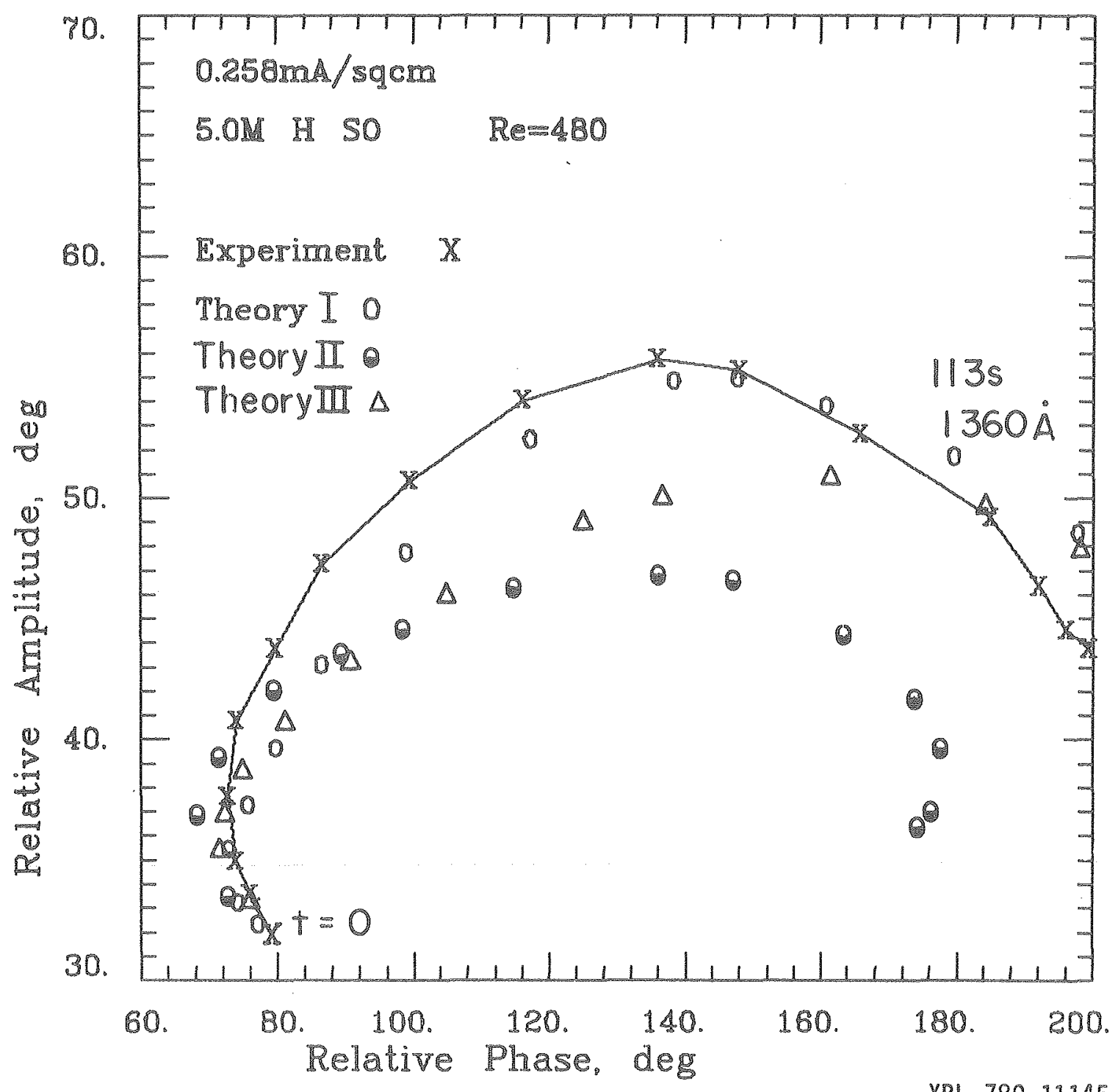

Figure 29. Experiment 131. As in Figure 25. Also shown are curves assuming different types of film growth. Theory I, model as described in Chapter IV utilizing secondary crystals which grow proportional to their surface area and a primary layer. Theory II, constant growth rate of secondary crystals. Theory III, absence of secondary crystals. 


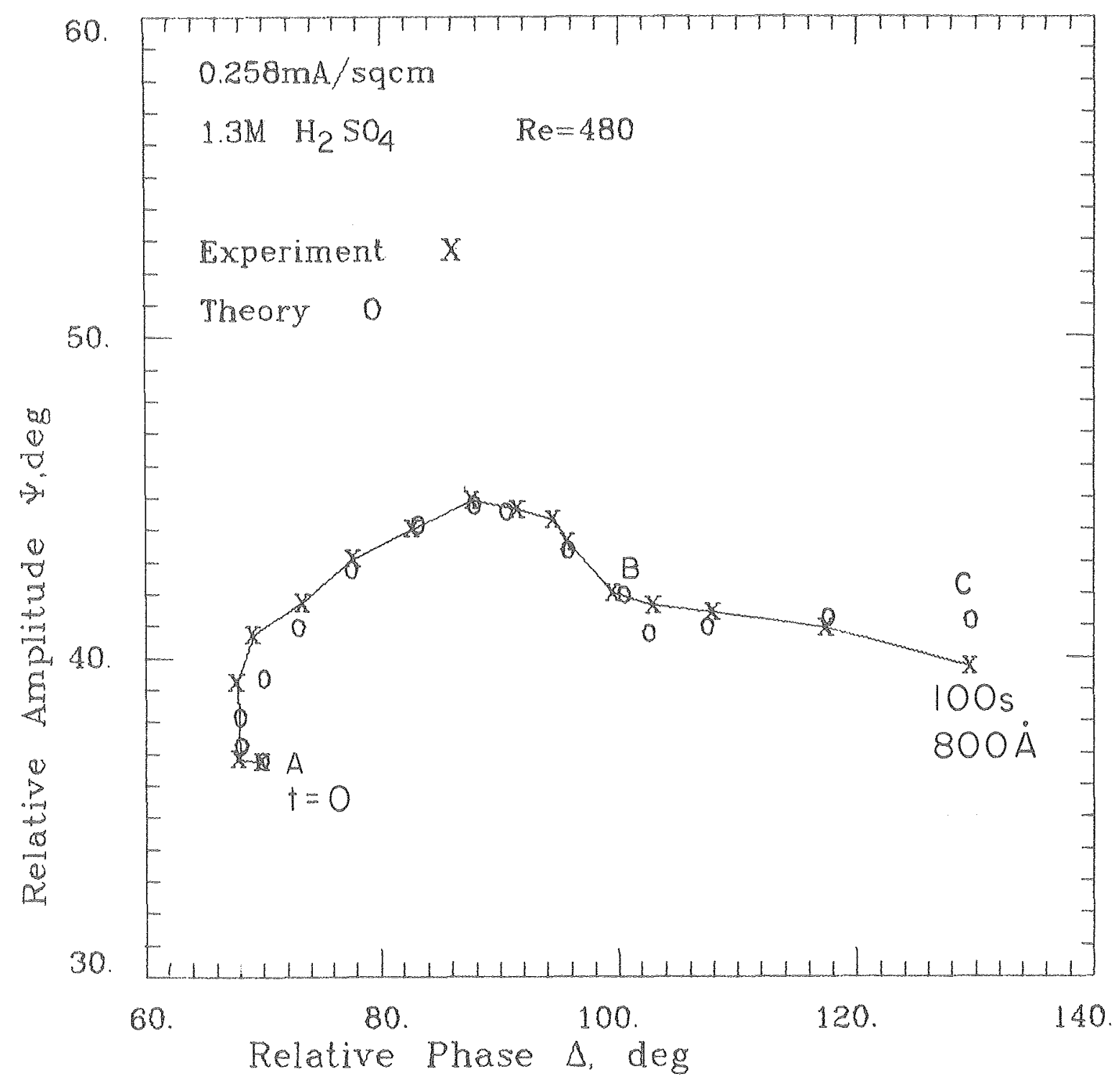

XBL $7810-11927$

Figure 30. Experiment 147. As in Figure 25, theoretical points were calculated in two stages, $A$ to $B$ and $B$ to $C$. 
$0.388 \mathrm{~mA} / \mathrm{cm}^{2}$

Film growth during free convection is compared with forced convection at this current density (Figures 31 and 32 ). Table XII shows that $\in_{\text {TFP }}$ is lower in the convection case. Effective film current is higher for Experiment 126 indicating that less solubilized anodic product remains in solution. The growth rate parameter torss is slightly smallex in the free convection case due to the higher supersaturation which enchances nucleation rates. The data for Exp. 81. (Figire 31) are not sufficiently reproduced by theory without use of secondary crystals. The average distance between calculated and experimental points is 2.2 degrees with them and 5.3 degrees using only the primary layer.

$0.517-1.33 \mathrm{~mA} / \mathrm{cm}^{2}(121,92,89,91)$

Anodic films formed at these high current densities consist of very small closely packed crystals as seen from the SEM photograph in Figure 6d. Very good agreement is found between experimental and theoretical points as seen in Figures 33 through 36 , since small densely packed crystals approach the optical effect of a continuous film. In Experiment 91 (Figure 36 ), the potential reached the $\mathrm{PbO}_{2}$ plateau near the characteristic minimum in $\Delta$ and the experiment was terminated. Table XIII compares results of these experiments. The growth pexiod $t_{\text {DISS }}$ corresponds to measured passivation times. When film-covered regions completely cover the surface, the electrode passivates since transport through the film is inhibited. This does not occur at lower current densities due to a higher porosity of filmecovered regions, Film compaction is assumed to terminate at $t_{\text {DISS }}$ so that yalues of porosity at 


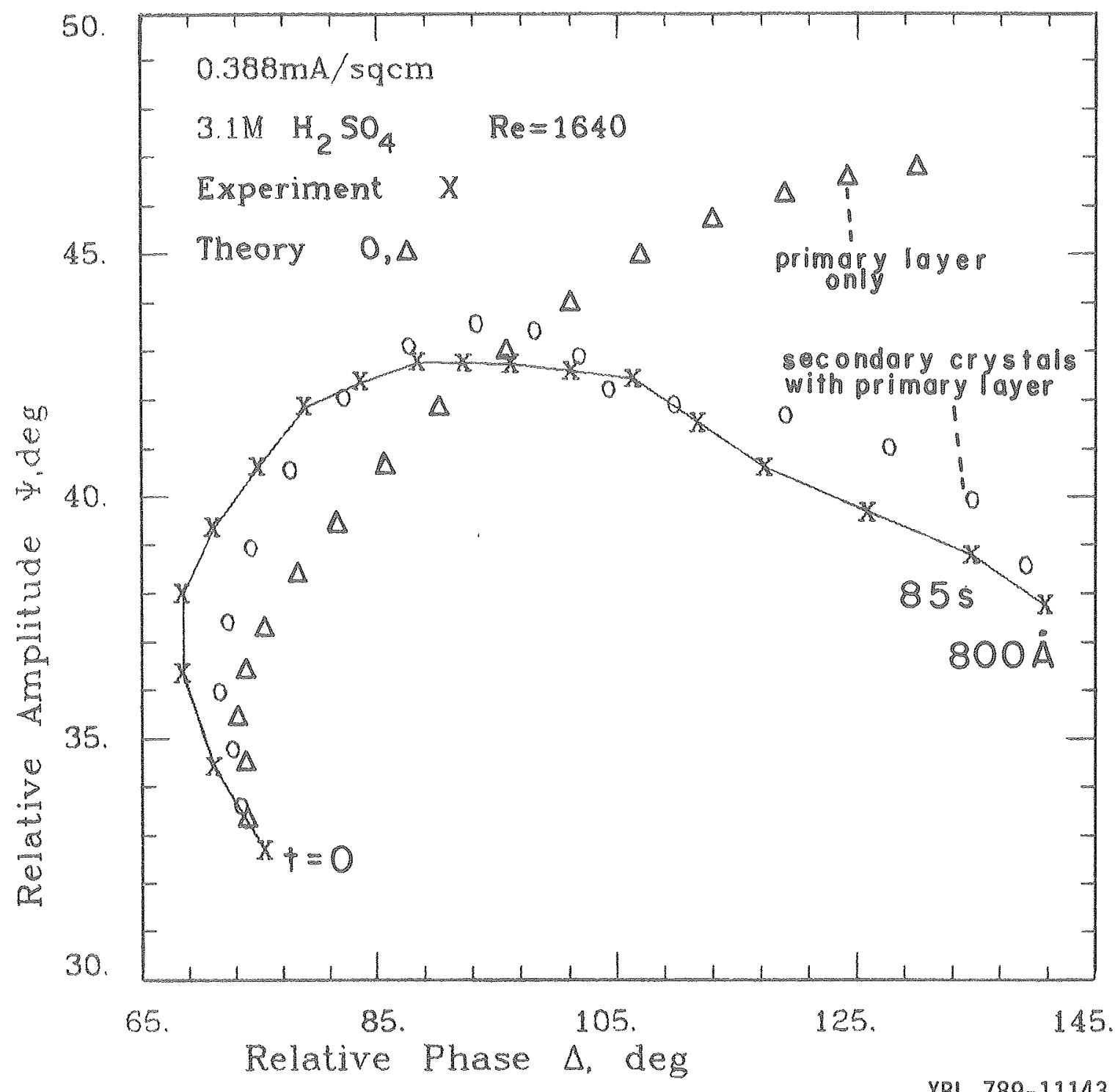

Figure 31. Experiment 81. As in Figure 25. Also shown is calculated curve assuming growth of primary layer (Type I film) only. 


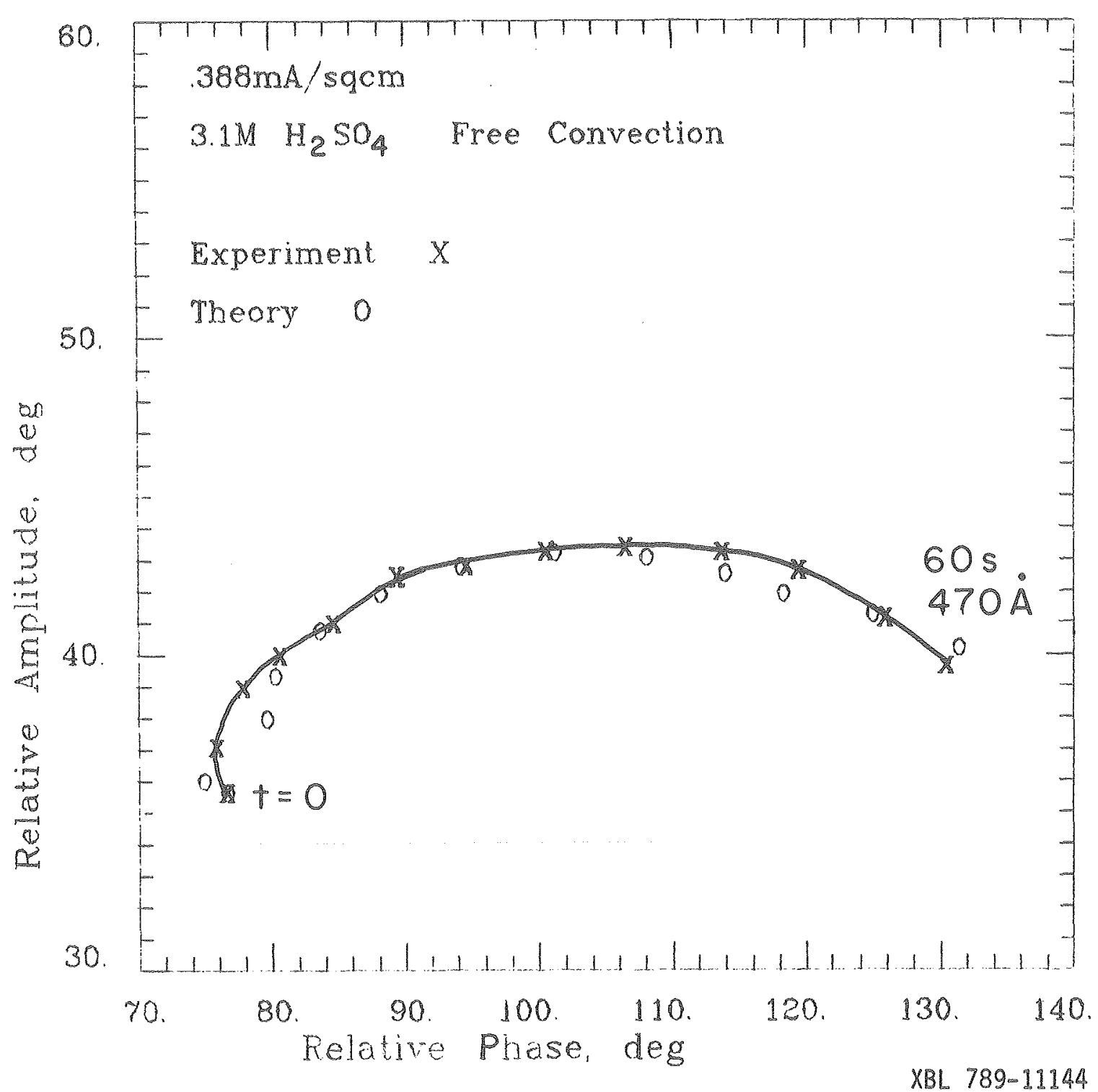

Figure 32. Experiment 126. As in Figure 25. 
TABLE MT Comparison of Results at Different Electrolyte Flow Conditions $\left(0.388 \mathrm{~mA}^{-\mathrm{cm}^{2}}\right.$ and $3.1 \mathrm{M} \mathrm{H}_{2} \mathrm{SO}_{4}$

\begin{tabular}{|c|c|c|}
\hline & \multicolumn{2}{|c|}{ Experiment } \\
\hline & 81 & 126 \\
\hline Flow condition & $\operatorname{Re}=1640$ & Eree convection \\
\hline $\begin{array}{l}\text { Average distance between } \\
\text { Exp. and theory }\end{array}$ & 2.2 & 1.2 \\
\hline $\begin{array}{c}\text { Final primaxy layer } \\
\text { porosity } \in_{\text {IEP }}\end{array}$ & $0.61 \pm 0.37$ & $0.42+0.13$ \\
\hline $\begin{array}{l}\text { Effective film current } \\
\mathrm{mA} / \mathrm{cm}^{2}\end{array}$ & 0.238 & 0.310 \\
\hline Growth period, toISS ${ }^{\text {sec }}$ & $52 .+5$. & $63 .+6$. \\
\hline
\end{tabular}




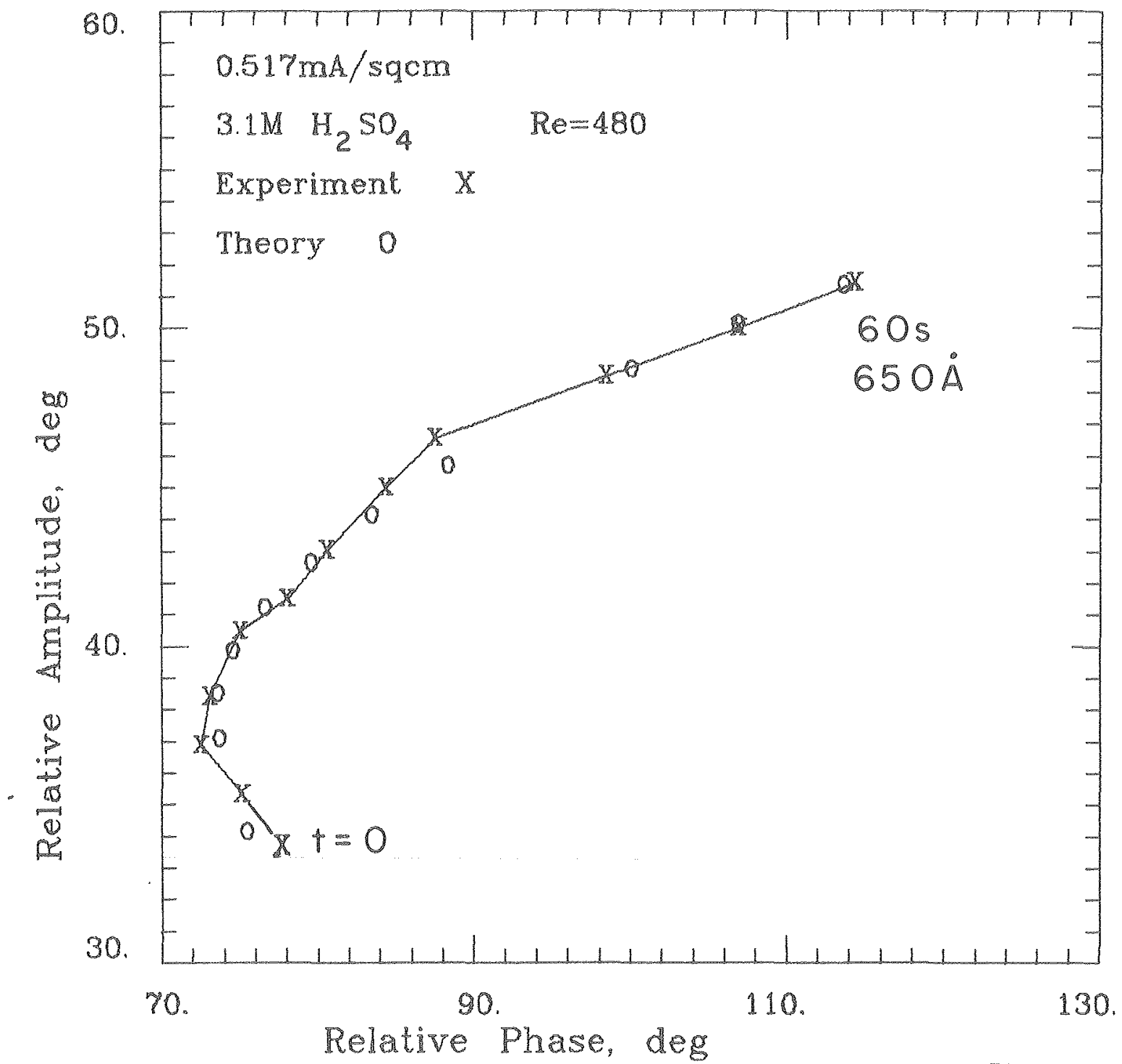

XBL 789-11142

Figure 33. Experiment 121. As in Figure 25. 


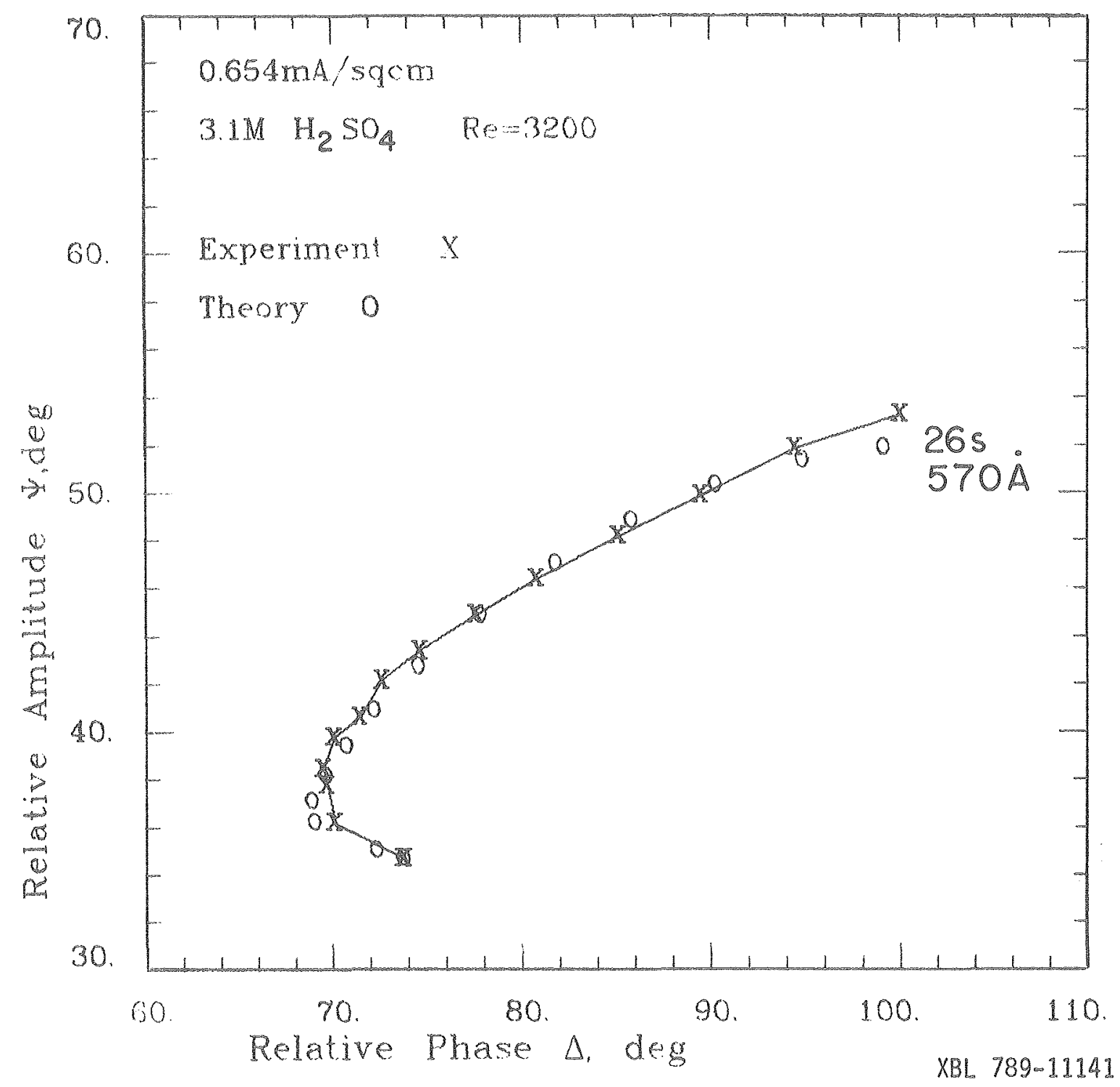

Figure 34. Experiment 92. As in Figure 25. 


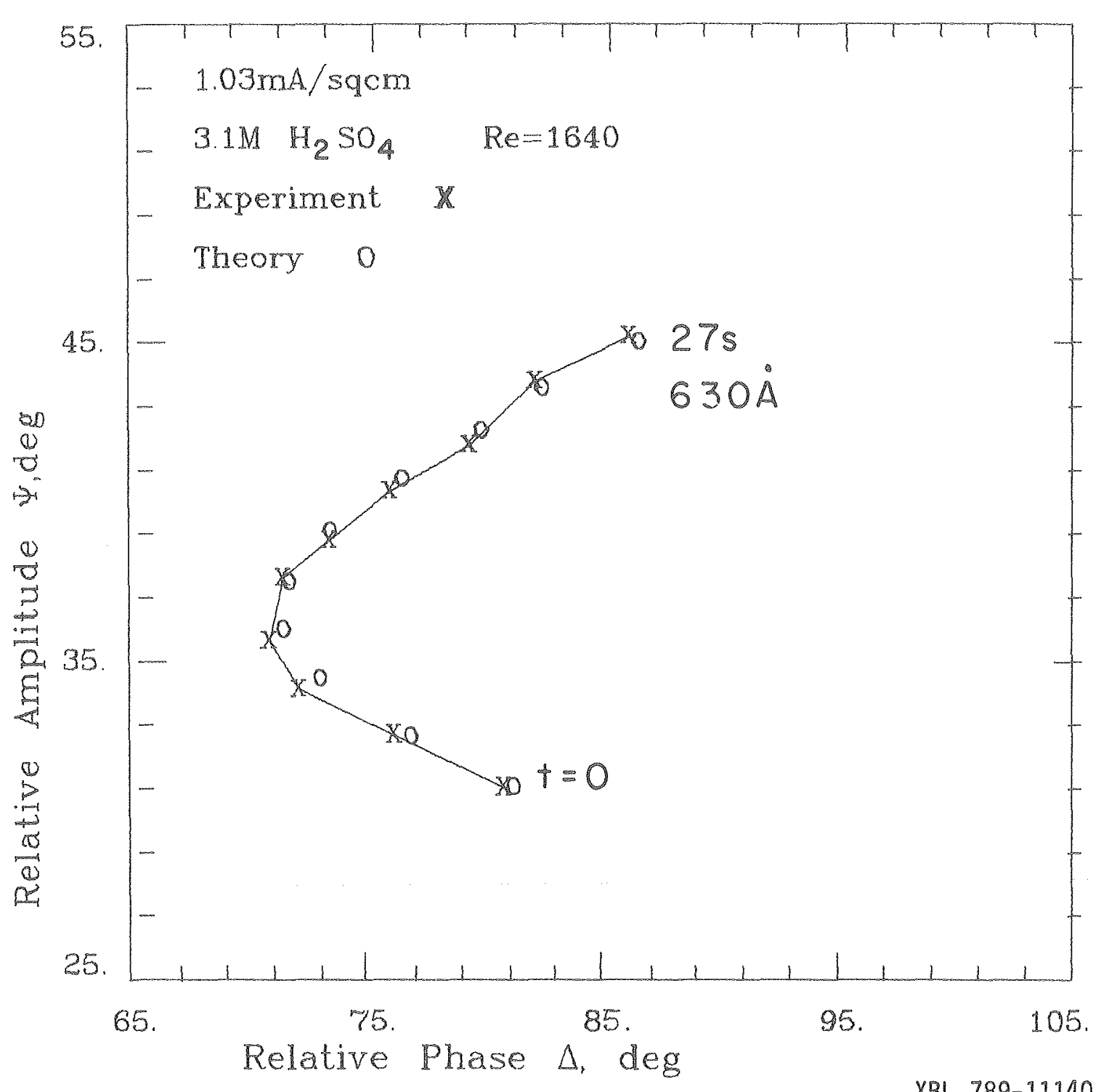

Figure 35. Experiment 89. As in Figure 25 . 


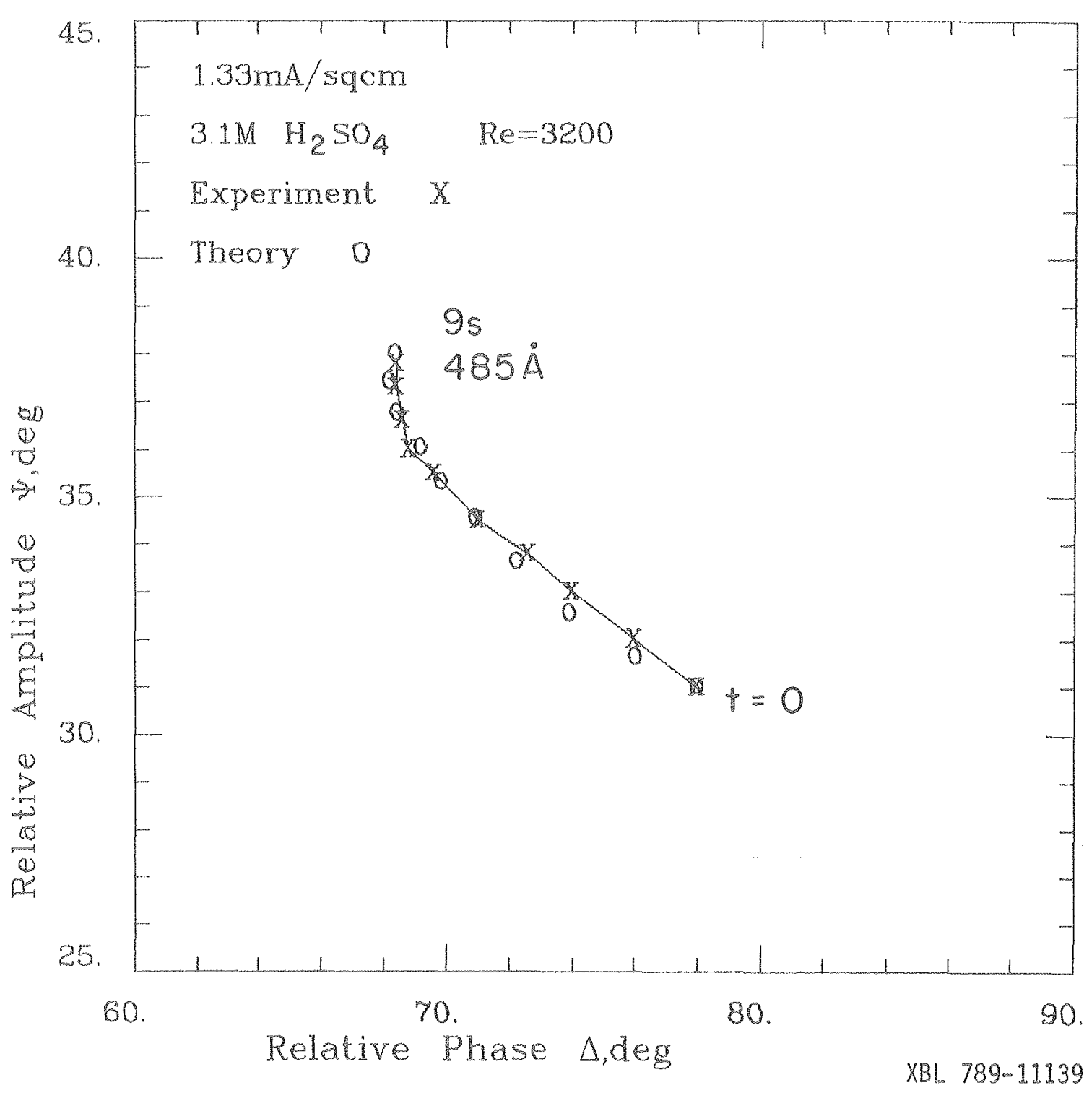

Figure 36。 Experiment 98. As in Figure 25. 
CABLE XIII Results of High Current Density Experiments $3.1 \mathrm{M} \mathrm{H}_{2} \mathrm{SO}_{4}$

Experiment

121

0.517

480

$0.39 \pm 0.10$

porosity $\epsilon_{\text {IFP }}$

Growth period $t_{\text {DISS }}$ sec

Passivation time

(measured) sec

$65 . \pm 22$

60.
92

0.654

3200

$0.30 \pm 0.12$

$0.16 \pm .04$

$0.53 \pm 0.22$

$37 .+3.4$

50 .

28.

$26 . \pm 4$

$6 . \pm .04$ 
passiyation are indicated by $\epsilon_{\text {TFP }}$ For current densities between 0.517 and $1.03 \mathrm{~mA} / \mathrm{cm}^{2}$ porosities at passiyation are $0.30-0,40$. Values of porosity larger than this would not be expected to limit transport of reactants through the film. At the highest current density, $1.33 \mathrm{~mA} / \mathrm{cm}^{2}$, the final porosity is about 0.66. Passivation at this high porosity may be due to formation of a compact sublayer (Type II film). The computational procedure calculates a Type II film 25 A thick and 50\% porous. This value of porosity is not low enough to result in passivation thus the computed value is probably high.

\section{Comparison of Current Densities}

The growth rate constant $i_{C R Y S}$ which controls current to secondary crystaIs (see Eq. [14] in Table III) is plotted with current density in Figure 37. Values of $\dot{I}_{\text {CRYS }}$ and its uncertainty were averaged over the experiments performed at each current neglecting variations in Reynolds number. The data show a roughly linear trend up to $0.65 \mathrm{~mA} / \mathrm{cm}^{2}$ with a slope of 0.19 . Values of ${ }_{\text {CRYS }}$ for currents higher than this have a large uncertainty since secondary crystals and primary layer crystals become indistinguishable,

The growth period tolss and current efficiency $n$ are compared at different current densities in Table XIV. Current efficiency $\left(i_{\text {eff }} / i_{T}\right)$ represents the percentage of applied current forming solid film and decreases as current increases. Transport of material away from the surface probably increases due to higher supersaturation caused by higher currents. Electrolyte flow does not influence current efficiency as strongly as current density. 


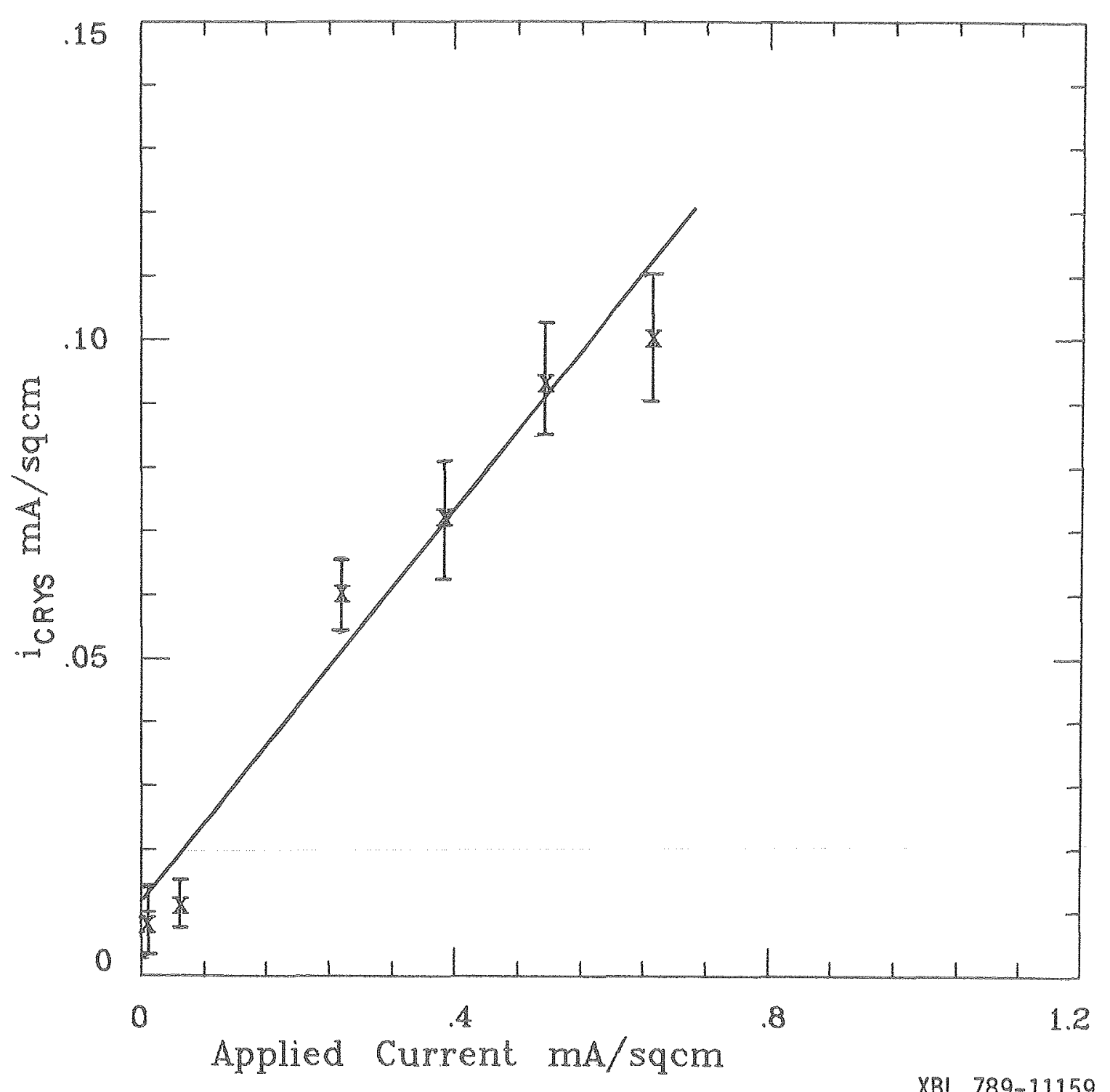

Figure 37. Secondary crystal growth parameter i CRYS (see Eqn. [15], Table III) derived by the computational procedure for various current densities. 
TABLE XIV Variation of Current Efficiency and Growth Time $t_{\text {DISS }}$ with Current Density

\begin{tabular}{|c|c|c|c|}
\hline $\begin{array}{l}\text { Applied Current } \\
\mathrm{mA} / \mathrm{cm}^{2}\end{array}$ & Exp。 & $\begin{array}{l}\text { urrent } \\
\text { iciency } \%\end{array}$ & ${ }^{t}$ DISS ${ }^{\text {sec }}$ \\
\hline 0.010 & 99 & $190 \% \%$ & 300 \\
\hline 0.0517 & $78,138,144$ & -- & $200-400$ \\
\hline 0.130 & 134,137 & $88^{*}$ & $90-180$ \\
\hline 0.258 & $73,131,135,147$ & $81^{*}$ & $45-100$ \\
\hline 0.388 & $80,81,126,127$ & $76^{2 \%}$ & $45-65$ \\
\hline 0.517 & 93,121 & $72^{\%}$ & $40-60$ \\
\hline 0.654 & 92 & 76 & 37 \\
\hline 0.775 & 119 & 61 & 45 \\
\hline 1.03 & 89 & 75 & 26 \\
\hline 1.33 & 91 & 75 & 6 \\
\hline
\end{tabular}

\footnotetext{
Averages

*t* Corrosion
} 
As expected, the growth time toIss decreases with current density. This quantity represents the time required for coverage of exposed substrate regions. At currents above $0.388 \mathrm{~mA} / \mathrm{cm}^{2}, t_{\text {DISS }}$ coincides fairly we11 with passivation of the electrode.

Solubilized product layer (SPL) porosity is an evaluated parameter, but does not show a consistent trend over the range of experimental variables examined. From this porosity the refractive index and composition of the layer is specified. The effective concentration (moles/1iter) of $\mathrm{PbSO}_{4}$ is calculated from the following expression:

$$
C=\left(I-\epsilon_{\mathrm{SPL}}\right) \frac{1000}{\bar{M}}
$$

where $\bar{M}$ is the molar volume of $\mathrm{PbSO}_{4^{\circ}}$. Values of $\epsilon_{\text {SPL }}$ range between 0.95 and 0.99 corresponding to concentrations of $1 \mathrm{M}$ and $0.2 \mathrm{M} \mathrm{PbSO}_{4}$. Dissolved $\mathrm{PbSO}_{4}$ has a solubility of $1.2 \times 10^{-5} \mathrm{M}$ in $3 \mathrm{M} \mathrm{H}_{2} \mathrm{SO}_{4}$ so that concentrations indicated for the SPL evidentIy represent colloidally suspended $\mathrm{PbSO}_{4}$ and not dissociated $\mathrm{PbSO}_{4}$. Refractive index values for these concentrations are 1.387 and 1.368, respectively, as calculated from Eq. [ 26] using a bulk solution refractive index of 1.365 (3.1 $\left.\mathrm{M} \mathrm{H}_{2} \mathrm{SO}_{4}\right)$. Concentrations of the SPL are not precisely decermined since the assumption of volume averaging $\mathrm{PbSO}_{4}$ particles and $\mathrm{H}_{2} \mathrm{SO}_{4}$ solution to obtain effective refractive index is an approsimation. However, the values discussed here provide an order of magnitude estimate and indicate that solubilized concentration can be high compared to the solubility of dissociated $\mathrm{PbSO}_{4}{ }^{\circ}$ 


\section{Open Circuit Corrosion}

When lead is allowed to stand in sulfuric acid for long periods a protective film develops. The initial growth of this layer is investigated here. Lead is converted to $\mathrm{PbSO}_{4}$ by two possible reactions.

$$
\begin{gathered}
\mathrm{Pb}+1 / 2 \mathrm{O}_{2}+\mathrm{H}_{2} \mathrm{SO}_{4} \rightarrow \mathrm{PbSO}_{4}+\mathrm{H}_{2} \mathrm{O} \\
\mathrm{Pb}+\mathrm{H}_{2} \mathrm{SO}_{4} \rightarrow \mathrm{PbSO}_{4}+\mathrm{H}_{2}
\end{gathered}
$$

If the solutions used are completely free of dissolved $\mathrm{O}_{2}$ then $\mathrm{PbSO}_{4}$ formation occurs only by reaction [ 2 ].

Figures 37-39 show experimental and calculated data for $\mathrm{PbSO}_{4}$ films formed from open circuit corrosion at different acid concentrations and flow conditions. A scanning electron micrograph of the corroded surface (Figure 18 ) shows large crystals of $\mathrm{PbSO}_{4}$ from 1000 to 5000 A in size. Results of calculations are shown in Table XV. Current density was an evaluated parameter and is assumed constant.

If the reaction occurs according to [1], then the corrosion rate would be limited by transport of $\mathrm{O}_{2}$ from the bulk solution to the surm face since it is a dilute component. Maximum $\mathrm{O}_{2}$ solubility is about

$3 \times 10^{-4} \mathrm{M}$ for solutions exposed to the atmosphere. Since the electrolyte is purged with $\mathrm{N}_{2}$ the concentration of $\mathrm{O}_{2}$ should be much less than this. The flux of $\mathrm{O}_{2}$ to the surface is proportional to the Nusselt number (Eq. [5]). For the forced convection case (Exp. 148), the Nusselt number is 150 ( $\mathrm{Eq},[5]$ ) and for the free convection case (Exp, 128), it is about 15 (using Eq, [ 7$],[8]$ and [9] and $i=.05 \mathrm{~mA} /$ 
$\left.\mathrm{cm}^{2}, t=100 \mathrm{sec}\right)$. The corrosion rate in Exp. 148 (Table XV) is only about $23 \%$ larger than the rate for Exp. 128 rather than 10 times largex as predicted assuming transport control. Conceivably, dissolution of $\mathrm{PbSO}_{4}$ may be occurring in Exp. 148 to lower the effective film current. How ever, if the surface concentration of $\mathrm{PbSO}_{4}$ is approximately the saturation concentration, then this flux is only .005 mA $/ \mathrm{cm}^{2}$ (from Eq. [ 2 ]). This suggests that corrosion is not transport-limited and occurs by Reaction [2].

The corrosion current decreases with increasing acid concentration (or decreasing water concentration) as seen in Table XV . Landex reported this effect by studying corrosion rates using weight loss measurements. He suggested water as a possible attacking component. Such a mechanism is conceivable if $\mathrm{HPbO}_{2}{ }^{-2}$ is an intermediate.

$$
\begin{array}{ll}
\mathrm{Pb}+2 \mathrm{H}_{2} \mathrm{O} \rightarrow \mathrm{HPbO}_{2}^{-}+3 \mathrm{H}^{+}+2 \mathrm{e}^{-} & {\left[\begin{array}{ll}
3 & ]
\end{array}\right]} \\
\mathrm{HPbO}_{2}^{-}+\mathrm{SO}_{4}=+3 \mathrm{H}^{+} \rightarrow \mathrm{PbSO}_{4}+2 \mathrm{H}_{2} \mathrm{O} & {\left[\begin{array}{l}
4
\end{array}\right]}
\end{array}
$$

Reactions [ 3 ] and [ 4] are listed in reference (51) and when combined give the overall reaction occurring at anodic sites.

$$
\mathrm{Pb}+\mathrm{SO}_{4}=\rightarrow \mathrm{PbSO}_{4}+2 \mathrm{e}^{-}
$$

When this reaction is combined with hydrogen eyolution,

$$
2 \mathrm{H}^{+}+2 \mathrm{e}^{-} \rightarrow \mathrm{H}_{2} \quad\left[\begin{array}{ll}
6 &
\end{array}\right]
$$


TABLE NV Results of Computations for Open Circuit Corrosion

Experiment

Acid Concentration, M

Water Concentration, M

Flow condition

Average distance between

exp. and calc, pts., deg.

Current density $\mathrm{ma} / \mathrm{cm}^{2}$

Hydration of secondary crystals
$148(\mathrm{Eig} \cdot 38)$

1.3

52.8

$\operatorname{Re}=480$

1.2

$0.05+.03$

$0.8+.1$
128 (Fig. 39 )

3.1

49.2

free convection

1.5

$0.04 \pm .002$

$0.7 \pm .1$
143 (Fig. 40 )

final free convection

6.1

$0.03 \div .002 \quad 0.02 \pm .007$

$0.4 \pm .17 \quad 0.55 \pm .08$ 


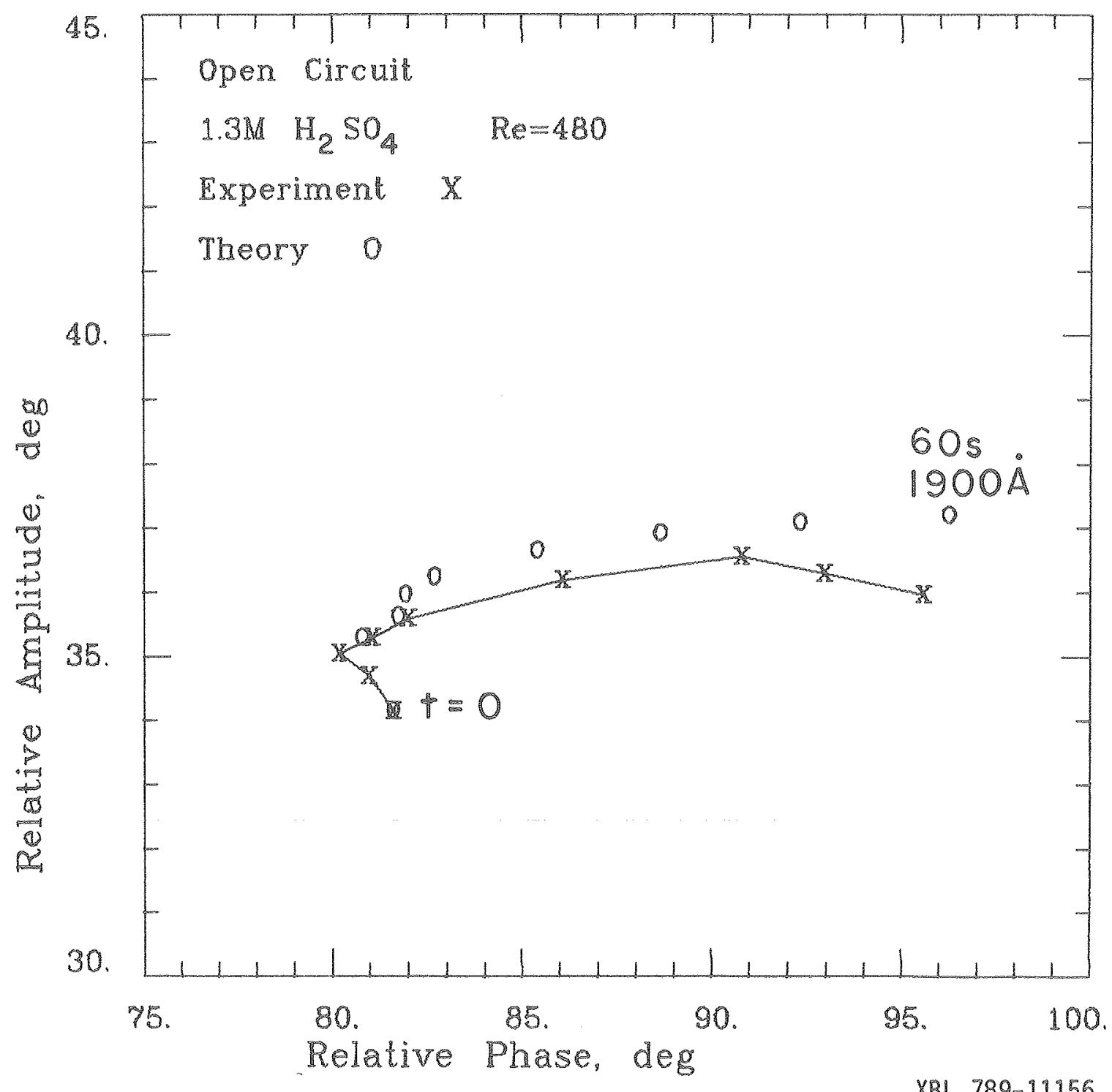

Figure 38. Experiment 148. Experimental and calculated values of $\psi$ and $\Delta$ obtained from corrosion of lead in sulfuric acid. Dimension at end point is size of secondary crystals (coverage of $12.3 \%$ ). 


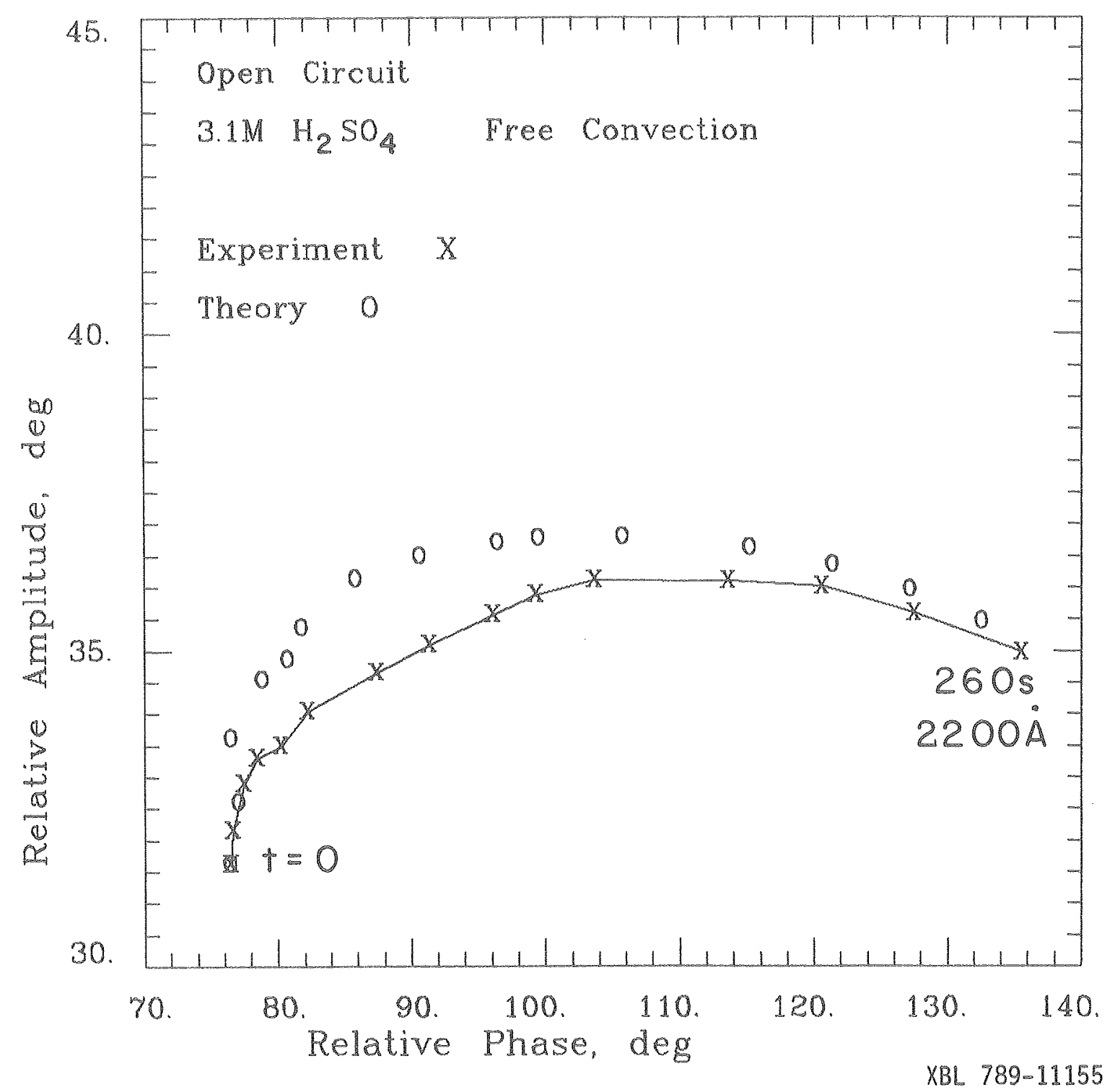

Figure 39. Experiment 128. As in Figure 38, Final coverage is 29\%。 


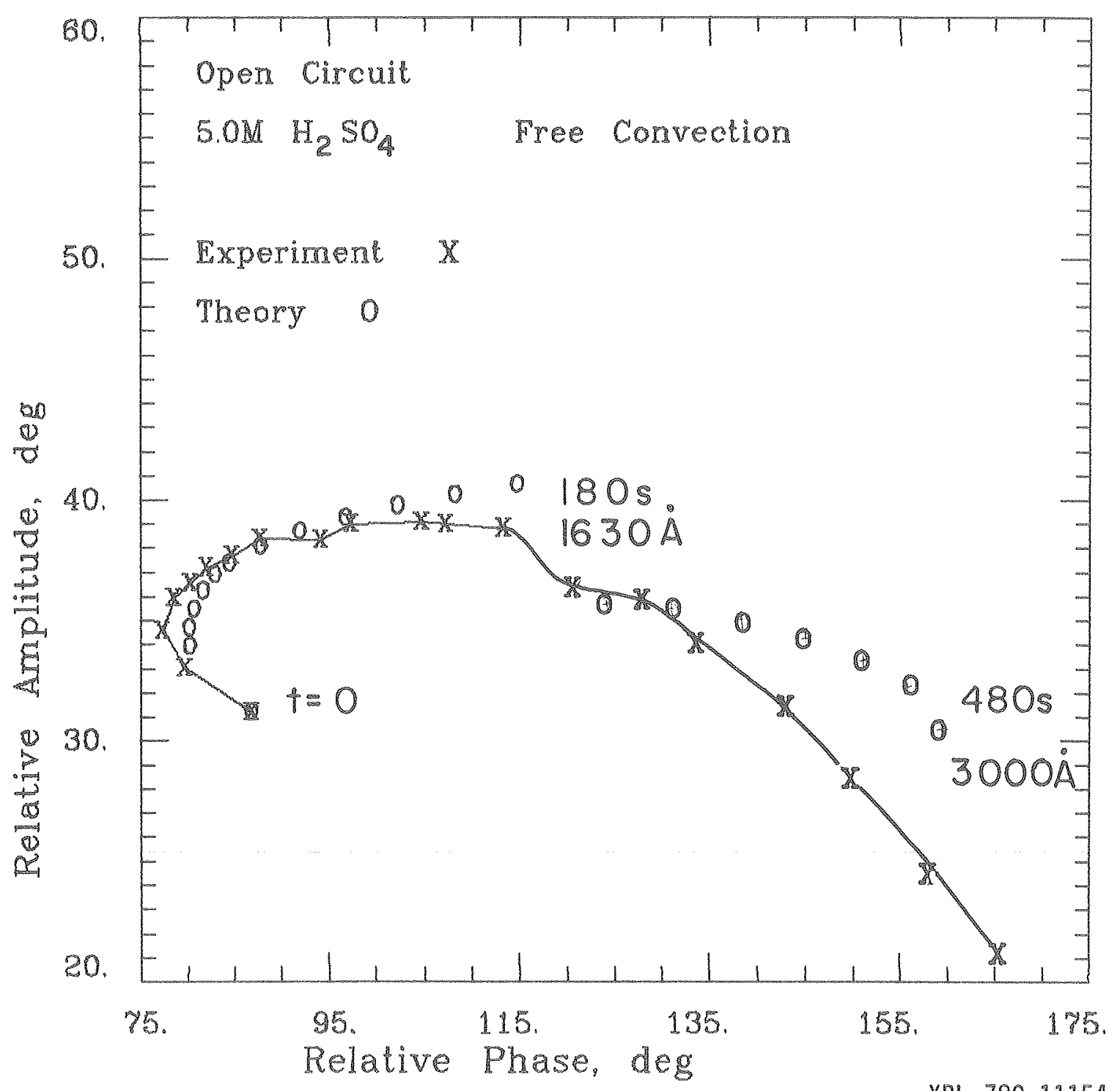

Figure 40. Experiment 143. As in Figure 38, final coverage is $17.4 \%$. Computations were performed in two stages, 0 to $180 \mathrm{~s}$ and $180 \mathrm{~s}$ to $480 \mathrm{~s}$. 
reaction [ 2] is obtained. Since reaction [ 3 ] is only favored at high pH's, such conditions would have to exist on the surface in order for this mechanism to apply.

From reaction [ 3 ] the expected dependence of corrosion rate on water concentration is

$$
i=\mathrm{K} \quad \mathrm{C}_{\mathrm{H}_{2} \mathrm{O}}^{2}
$$

Evaluated corrosion rate $i$ is plotted $\mathrm{vs}_{\mathrm{H}_{2} \mathrm{O}}^{2}$ in Figure 41 and a straight Iine is obtained through points to the origin (which is also a data point). Lander found the same dependence comparing corrosion rates (obtained at various constant potentials) with the square of water activity. His experiments were performed over periods of hours and show a constant corrosion of $0.046 \mathrm{~mA} / \mathrm{cm}^{2}$ in $1.1 \mathrm{M} \mathrm{H}_{2} \mathrm{SO}_{4}$ at $-0.9 \mathrm{~V}$ (vs $\mathrm{Hg}_{2} / \mathrm{Hg}_{2} \mathrm{SO}_{4}$ ). This compares favorably to the rate found in this work under similar conditions (Experiment 148, the potential is that of lead at open circuit, $-.950)$.

Hydration for secondary crystals is rather high indicating large void volume and tends to decrease with increasing acid concentration. In Exp. 148 (Figure 37) polarization of reflected light was not measureable after only $60 \mathrm{~s}$, probably due to reflection from large crystals (larger than indicated by calculation) which scatter 1ight. Experiment 143 (Figure 39) was analyzed in two stages, 0 to $180 \mathrm{~s}$ and $180 \mathrm{~s}$ to $480 \mathrm{~s}$. At $t=180 \mathrm{~s}$ $\psi=38, \Delta=115)$ the value for $\psi$ decreases abruptly. The calculation for

tis activity coefficients are assumed unity 


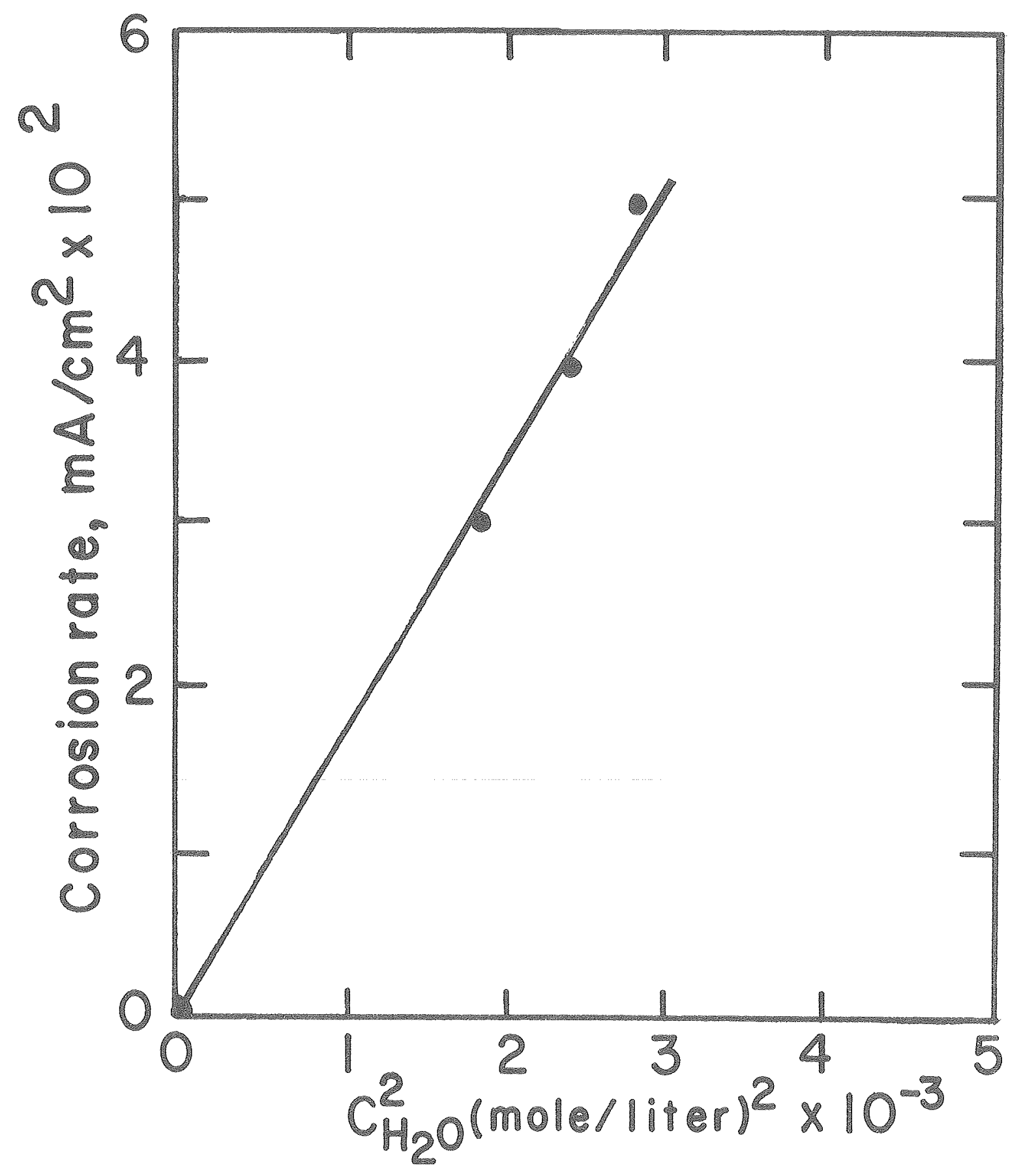

XBL 789-11323

Figure 41 . Corrosion rate of lead (rate of $\mathrm{PbSO}_{4}$ formation) vs. the square of water concentration in sulfuric acid solutions. 
points between $t=180$ and $t=480$ suggest this is due to growth of large secondary crystals which have a final dimension of $3000 \AA$. 


\section{B. Lichium}

1. Aqueous Electrolyte

When the lithium electrode makes contact with the solution, a corrosive reaction begins immediately according to:

$$
\mathrm{Li}+\mathrm{H}_{2} \mathrm{O} \rightarrow \mathrm{LiOH}+1 / 2 \mathrm{H}_{2}
$$

with the rate dependent on water activity (30). Experiments performed in $4.7 \mathrm{M}$ LiOH (near battery electrolyte composition) exhibited extremely violent film growth in the first several seconds after exposure to electrolyte and initiation of current due to relatively high water activity. During this initial period, hydrogen evolution, surface roughening and rapid film growth can be visually observed through cell windows. After three to five seconds a black film develops with rough morphology and the $\mathrm{H}_{2}$ evolution subsides since this film now protects the metal. Anodic dissolution of the lithium, according to [8] and [9] occurs simultaneously with the corrosion reaction and contributes to film formation:

$$
\begin{aligned}
& \mathrm{Li}+\mathrm{OH}^{-} \rightarrow \mathrm{LiOH}+e^{-} \\
& \text {[ } 8 \text { ] } \\
& \mathrm{LiOH} \rightleftharpoons \mathrm{Li}^{+}+\mathrm{OH}^{-}
\end{aligned}
$$

Water activity is lowered in $10 \mathrm{M} \mathrm{KOH}, 13.6 \mathrm{M} \mathrm{KOH}$ and $13.6 \mathrm{M} \mathrm{KOH}$ with $0.6 \mathrm{M}$ LiOH solutions and the initial corrosion reaction appears greatly reduced. However, $\mathrm{H}_{2}$ gas evolution and surface roughening still 
occur. An electrolyte of $13.6 \mathrm{M} \mathrm{KOH}$ with $0.6 \mathrm{M}$ LiOH was found to be near the saturation limit of LiOH. This solution was used in order to enhance the precipitation of LiOH at the electrode interface and thus more rapidly form a protective layer. Higher current densities used for this electrolyte also contributed to enhanced protective film formation by maintaining a high interfacial concentration $C_{0}$ Eq. [36] is used to establish the relationship between $i_{T}$ and $C_{0}\left(C_{b}\right.$ is the bulk concentration of LiOH):

$$
\frac{i_{T}}{n F}=N_{L I O H}=\frac{D\left(C_{o}-C_{b}\right) N u}{d_{h}}
$$

This applies when all of the LiOH generated according to [8] goes into convective diffusion flux. The $C_{0}$ calculated from this does not necessarily represent the actual $C_{0}$ since the processes occurring on the electrode surface are complicated by turbulence from bubble generation, unsteady state diffusion, and generation of LiOH from the corrosion reaction. However, if an interfacial concentration calculated for a given current density is not reached, then the dissolution flux is less than $i_{\mathrm{T}} / \mathrm{nF}$, and film formation must occur in order to maintain a mass balance. IE a high enough current density is used then calculated $\mathrm{C}_{0}$ can reach and exceed the solubility of the dissolution product. Table XV gives values of surface concentration predicted from Eq. [38 ] for representative experimental conditions. Values of solubility of LiOH are estimated, based on the solubility product of LiOH (35). 
TABLE XVI Interfacial LiOH Concentrations Predicted from Steady State Correlation

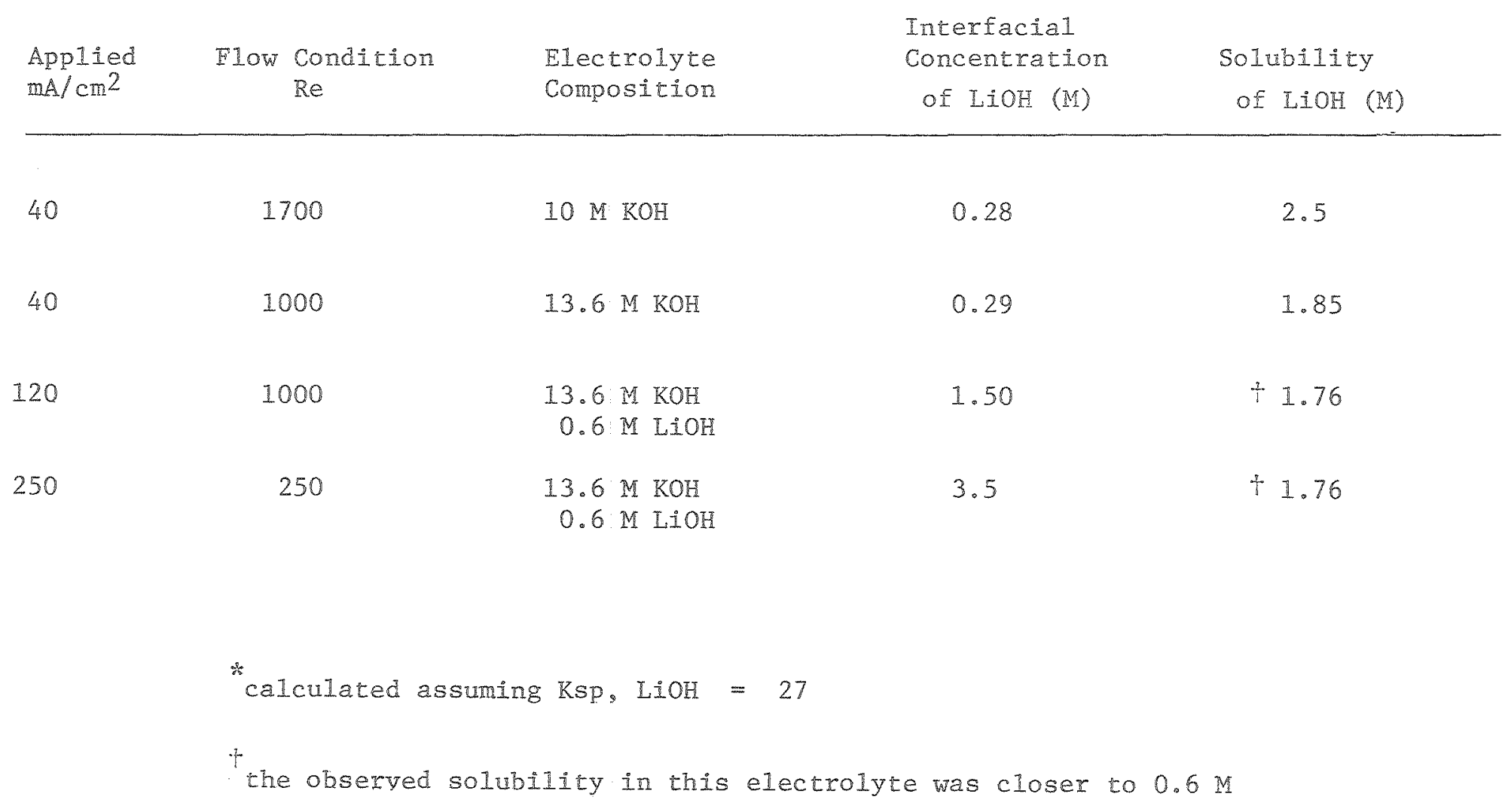




$$
\mathrm{K}_{\mathrm{Sp}}=\left[\mathrm{Li}^{+}\right]\left[\mathrm{OH}^{-}\right]=27
$$

where activity coefficients have been neglected. At the highest current density $\left(250 \mathrm{~mA} / \mathrm{cm}^{2}\right)$ in Table XV the interfacial concentration of LiOH is roughly twice that of the solubility limit of LiOH for that solution. If the solubility is exceeded then precipitation is expected.

In all of the experiments described above, the reflected light intensity was not sufficient for anodic film growth measurement. When clean metal makes contact with electrolyte the spontaneous hydrogen evolution and surface roughening disperse the specular beam. The reaction subsides; however, the rough film which forms is non-reflecting.

In some experiments (denoted by an asterisk in Table I), an initial protective film was formed on the metal by reaction with water vapor according to Reaction [7]. Prior to introduction of solution to the cell, the 1ithium was exposed to a stream of argon containing 1.5 to 3.5 torr of water vapor for periods of several minutes. During this time, optical changes on the surface were observed using the ellipsometer. The solution was then introduced to the cell and current initiated. At $40 \mathrm{~mA} / \mathrm{cm}^{2}$ in $13.6 \mathrm{M} \mathrm{KOH}$ the transition from gas phase to electrolyte was measured. Several seconds of subsequent anodic film growth was also monitored as shown in Figure 42 (from point $c$ to point d).

The shift in $\psi$ and $\Delta$ at point $b$ is due to the increase in incident medium refractive index from 1.00 (gas phase) to 1.39 (solution phase). The ellipsometer parameters are now less sensitive to film thickness since the difference in refractive index between the incident medium 

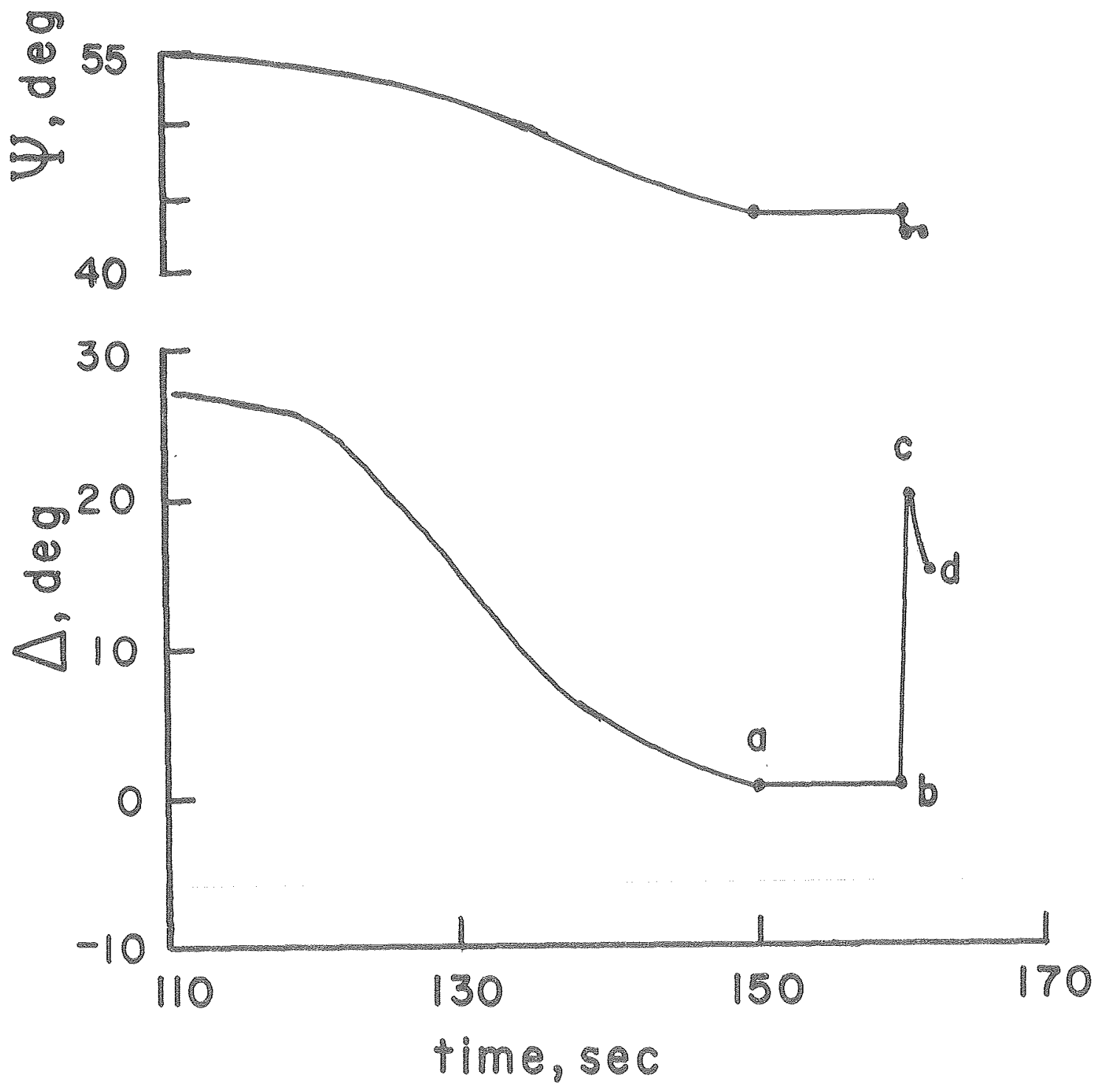

XBL 789-11322

Figure 42. Change in optical parameters $\psi$ and $\Delta$ during water vapor corrosion and exposure of the sample to potassium hydroxide electrolyte. From $t=110$ to a, corrosion in 2 tor $\mathrm{H}_{2} \mathrm{O}$ vapor. a to $\mathrm{b}$ corrosion is stopped, sample is exposed to pure argon. At $b$ the sample is exposed to electrolyte and anodic current of $40 \mathrm{~mA} / \mathrm{cm}^{2}$ is initiated, ellipsometer parameters jump to values at $c$. From $c$ to d measurements in aqueous electrolyte are obtained. At d reflection from the surface is scattered due to rough morphology. 
and film has been reduced. This is clearly evident in the case of $\Delta$ which reverses direction; however, the change in $\psi$ is less profound and doesn't move back as expected. 


\section{Corrosion in Water Vapor}

Scanning electron micrographs of the lithium surface corroded at at $\mathrm{H}_{2} \mathrm{O}$ partial pressure of 2 torr for 120 seconds is shown in Figure 43 . Deposits of LioH are visible with details on the order of $1 \mu$. At the highest magnification, cracks in the layer are visible and perhaps extend to the metal surface. The corroded surface has a black appearance, and since LiOH is a white crystal, this may indicate non-stoichiometry or doping of the LiOH deposit with Li metal. Such a layer would have a complex refraction index due to light absorption.

Figure zh shows experimental and calculated $\psi$ vs $\Delta$ data points representing corrosion of lithium in water vapox. Also in this figure is the curve for bulk LiOH $(n=1.45)$ which deviates markedly from the experimental points. The calculated points were dexived from the multiparameter computer analysis as described in section IV. The fit between experimental and calculated points (Figure 44 ) is only qualitative due to poor reflection caused by the large dimensions of details on the surface.

A film with a final size of $600 \AA(n=4-1.2 i)$ and an underlying roughness layer of $1000 \AA(n=0.7-.501)$ is computed. These layers have a large percentage of metal ( 80 per cent) indicating roughening and perhaps non-stoichiometry which dominate the optical properties of the surface. The evaluated corrosion rate is $0.3 \mathrm{~mA} / \mathrm{cm}^{2}$, which corres ponds to a reaction rate of $3.1 \times 10^{-9}$ moles $/ \mathrm{sec} / \mathrm{cm}^{2}$. Corrosion data obtained at different partial pressures of water did not compare favorably. No consistent trend in the shape of $\psi-\Delta$ curves was found; therefore, only one representative experiment was analyzed giving the qualitative results. 


\section{$50 \%$}

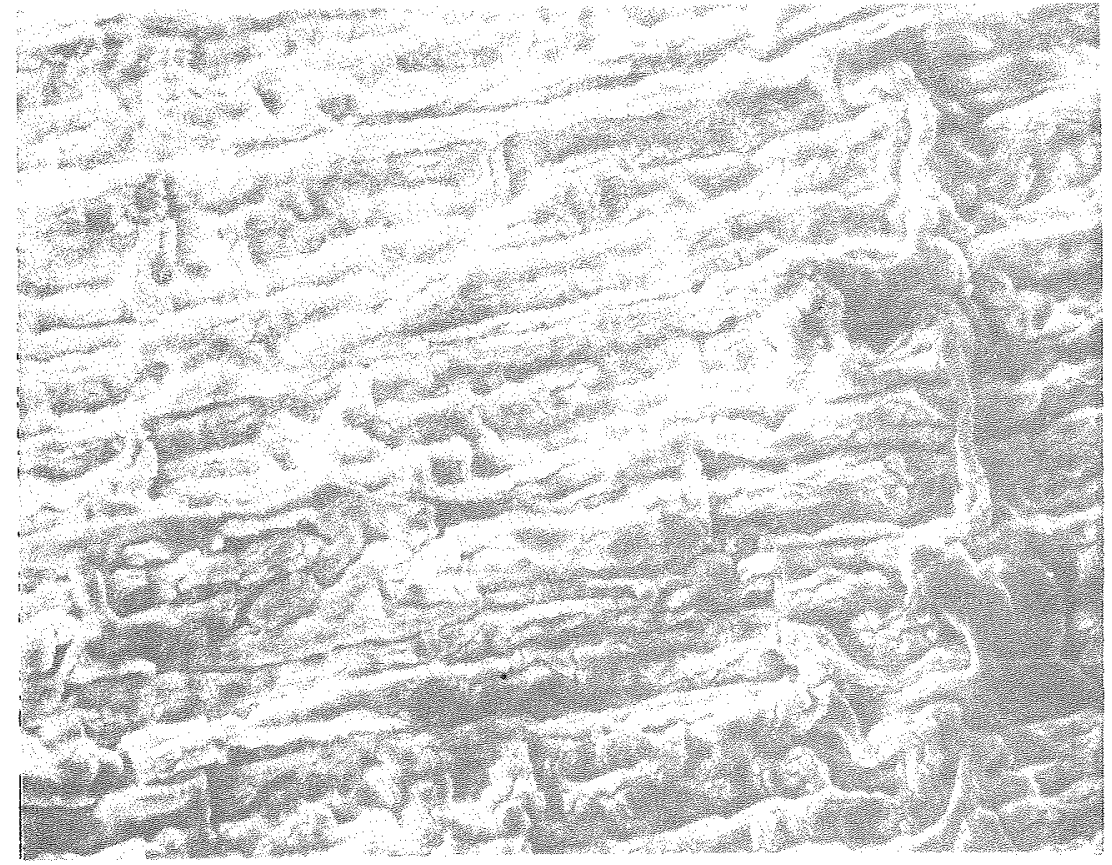

\section{$10 \mu$}

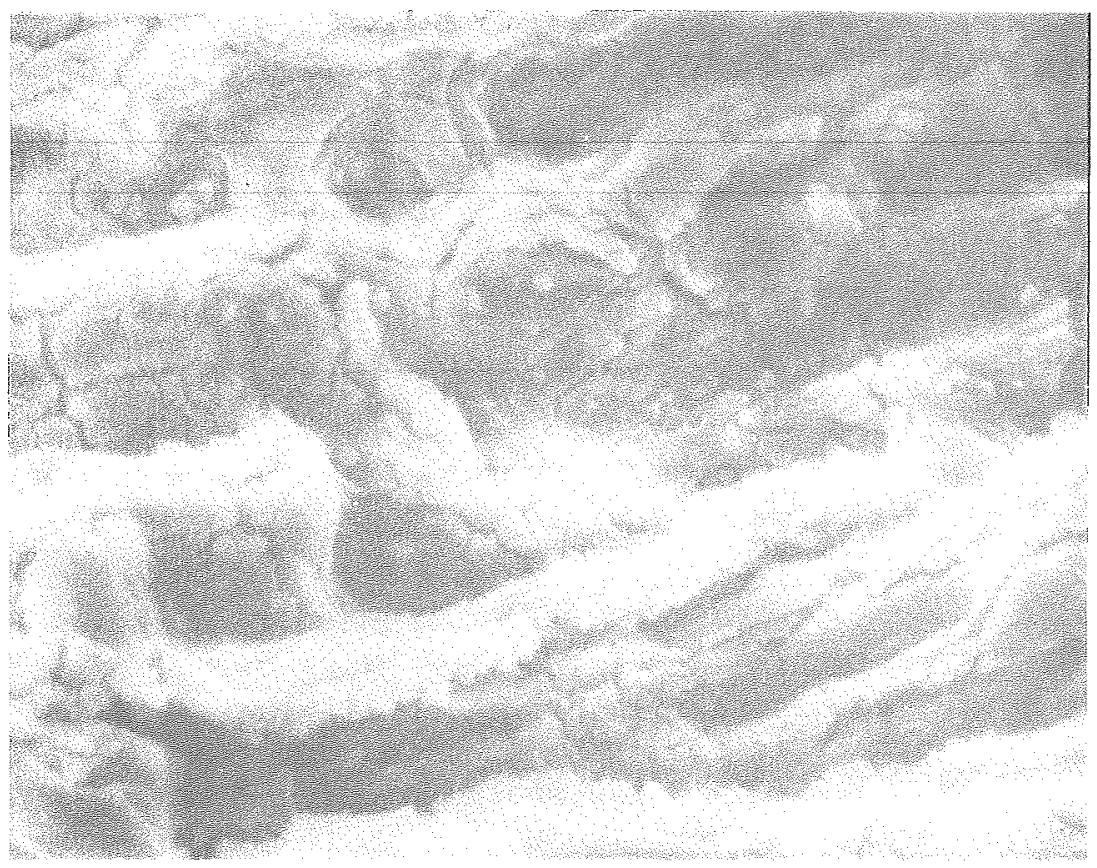

Figure 43. Scanning electron micrograph of tathium sureace exposed to 1.5 torr of water vapor ror 220 gee. Top photograph is at lower magnification than bottom photograph. 


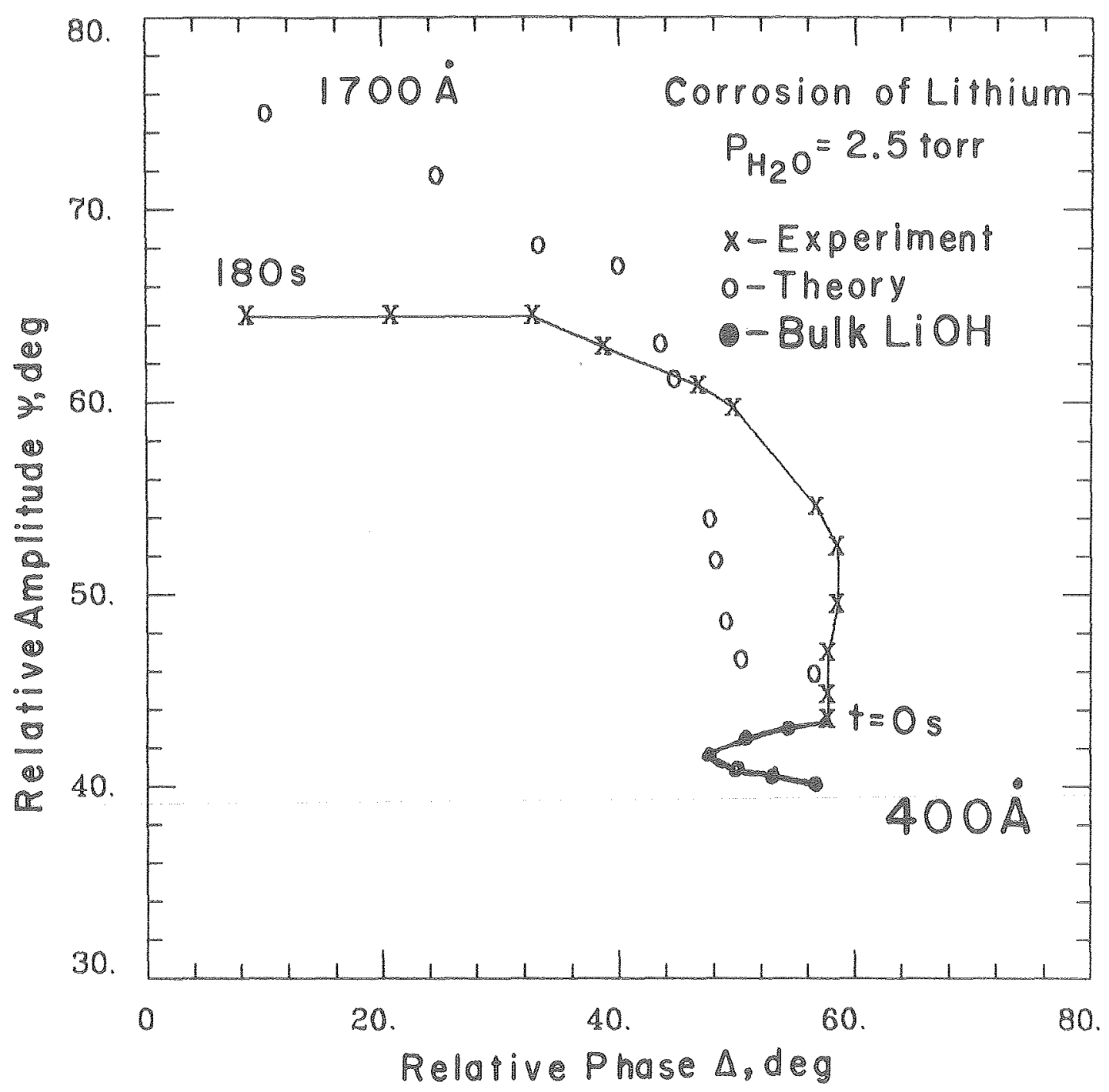

XBL $789-11325$

Figure 44. Experimental and calculated values (Theory) of $\psi$ vs $\Delta$ for corrosive film growth on lithium. Dimension at top left is final thickness of combined roughness and Type I films. Also shown is curve calculated for compact, homogeneous LiOH Eilm ( $\mathrm{n}=1.45$, bulk LiOH). Corrosion product is LiOH, however, experimental points deviate markedly from the compact LiOH film curve. 
VI. Discussion

A. Lead

Anodic PbSO Formation

Film porosity represents the overall vold space between crystals (secondary crystals and Type I layer crystals) on the anodized lead surface. Results described in Section $V$ indicate that apparent film porosity decreases with increasing current density, increasing acid concentration and decreasing convective transport. A higher concentration of dissolved film-forming species is expected under these conditions. This leads to more growth sites per unit area resulting in a less porous deposit.

By the following argument, a relationship can be established between the applied current and supersaturation of dissociated $\mathrm{PbSO}_{4}$ from which secondary crystals are formed. For inorganic crystals, crystal growth has been experimentally found to depend on supersaturam tion as follows (46):

$$
\frac{\mathrm{dL}}{\mathrm{dt}} \alpha \operatorname{In} \frac{\mathrm{C}_{\mathrm{ss}}}{\mathrm{C}_{\mathrm{s}}}
$$

where $\mathrm{C}_{\mathrm{SS}}$ is the supersaturation concentration of ionized $\mathrm{PbSO}_{4}, \mathrm{C}_{\mathrm{S}}$ is $\mathrm{PbSO}_{4}$ solubility and $\frac{\mathrm{dL}}{\mathrm{dt}}$ is the rate of increase of a length of the crystal. The rate $\frac{d L}{d t}$ is linearly related to the current per unit crystal area ${ }^{1}$ CRYS (see equation [A4], Appendix A). Since total current density $i_{\mathrm{T}}$ is linearly related to $i_{C R Y S}$ as discussed in Section V-A (see Figure 37) it follows that $i_{T}$ and $\ln \frac{C_{S s}}{C_{S}}$ are linearly relaced, 


$$
i_{T} \quad \alpha \ln \frac{\mathrm{C}_{S S}}{\mathrm{C}_{\mathrm{S}}}
$$

This describes the relationship between supersaturation of film forming species and applied current during anodic film formation. Interestingly, the overpotential due to supersaturation is also proportional to In $\frac{C_{S S}}{C_{S}}$ (the Nernst equation [40]) so that applied current and concentration overpotential $\mathrm{E}_{\text {conc }}$ are linearly related during anodic crystalIzation as in Eqn. [41].

$$
\begin{aligned}
& E_{\text {conc }}=\frac{\mathrm{RT}}{\mathrm{nF}} \ln \frac{\mathrm{C}_{\mathrm{SS}}}{\mathrm{C}_{\mathrm{S}}} \\
& \mathrm{I}_{\mathrm{T}}=\alpha \mathrm{E}_{\mathrm{cons}}
\end{aligned}
$$

Equation [41] is functionally identical to $\mathrm{Ohm}^{\mathrm{S}} \mathrm{s}$ law. Linear voltagecurrent response during anodic film formation is generally considered due to Ohmic losses through surface layers. However, if films form via crystallization from a supersaturated solution, then the conventional interpretation of i $\mathrm{vs}$. E may be misleading.

Current efficiencies are 70 to 90 per cent for anodic film growth on lead as seen in Table XIV. To account for the balance of current dissolution fluxes of up to $0.1 \mathrm{~mA} / \mathrm{cm}^{2}$ axe required. The ionic concentram tion at the surface required to support such a flux would have to be orders of magnitude higher than the solubility of $\mathrm{PbSO}_{4}$. Potential measurements exclude such supersaturations. In addition, the sensitivity of efficiency to flow condition is not as profound as one would expect assuming ionic transport. In Table XII the free convection experiment 
has an efficiency of 80 per cent, while the forced convection expeximent has an efficiency of 62 per cent, even though the transport condition differs by a factor of 20 or more (relative Nusselt numbers). Solubilized products can conceivably be clusters of colloids consisting of $\mathrm{PbSO}_{4}$. In this case, transport is not as dependent on surface concentration and the Nusselt number, since diffusion coefficients are much lower for colloids than for dissolved ions. Surface concentration of colloids would have to be quite high (.1 M - $1 \mathrm{M}$ ) in order to compensate for lower diffusion coefficients and support large dissolution fluxes. The evaluated refractive index of the solubilized product layer imply that such concentrations are possible. Large well-formed crystals as seen in SEM photographs (Figure 6a,b,c) would be expected to form from ionic species rather than from colloidal material.

Scattering of light from large crystals must be considered when discussing film forming current efficiency. Large crystals (dimensions near the wavelength of 1ight, $1 / 3$ to $1 / 2 \mu$ ) are not "visible" to the ellipsometer since light entering them is scattered in directions other than the specular direction. If anodic material is present in the form of large crystals yet not detected by the ellipsometer, then apparent film forming current may be reduced. However, if this were the only cause of efficiency less than 100 per cent, then efficiency should be lower where larger crystals are found (larger crystals more likely to scatter light) which is the case at lower current densities. However, results in Table XIV show that higher efficiencies are associated with the lower current densities.

The existence of underlying sublayers between large crystals visible in SEM photographs is not directly inferred from the multi- 
parameter computer analysis. Sublayers are calculated for the data at $0.0517 \mathrm{~mA} / \mathrm{cm}^{2}$, but paxameters describing then are not accurately determined. At high current, essentially a single film composed of the Type I film and secondary crystals is used in calculations. Sublayers (the Type II film) are not usually necessary to obtain solutions. However, the high porosity at which passivation occurs in Experiment 98 (see Figure 36), Experiment 147 (Figure 30) and Experiment 73 (Figure 28) suggests a less porous sublayer which inhibits transport of reactants.

\section{Open Circuit Corrosion}

Computed corrosion rates derived from ellipsometer data agree surprisingly well with those of Lander considering the optical approximations applied to $\mathrm{PbSO}_{4}$ deposits (treatment of discrete $\mathrm{PbSO}_{4}$ particles as a homogeneous film). The dependence on water activity suggests this molecule as the attacking component. According to Reaction [3] the rate limiting step would be the fomation of $\mathrm{HPbO}_{2}{ }^{-}$. However, no such intermediate has been detected on a corroding lead surface to date. The Iinearity between $\dot{d}_{\mathrm{corr}}$ and $\mathrm{C}_{\mathrm{H}_{2} \mathrm{O}}^{2}$ suggest a second order dependence on water concentration as in Eqn. [37].

Corrosion films are optically similar to anodic films formed at low current density $\left(0.01\right.$ and $\left.0.05 \mathrm{~mA} / \mathrm{cm}^{2}\right)$. Film growth at $0.01 \mathrm{~mA} / \mathrm{cm}^{2}$ was enhanced by corrosion by approximately $0.009 \mathrm{~mA} / \mathrm{cm}^{2}$.

\section{Transients During Oxidation}

Anodic products which have a rest potential at $-.6 \mathrm{~V}$ (vs $\mathrm{Hg}_{2} / \mathrm{Hg}_{2} \mathrm{SO}_{4}$ ) protect the lead surface from corrosion as seen in Figure 16 (points b 
to c). This is based on the observed arrest in changes of $\psi$ and $\Delta$ which corresponds exactly to the plateau at $-.6 \mathrm{~V}$. Such observations are consistent with the theory that basic lead sulfates are produced (in small amounts not necessarily detectible by ellipsometry) by high potential oxidation and temporarily protect the lead from corrosion when current is interrupted (passivation). Pavlov and others $(5,15,23)$ have postulated that such compounds act by blocking small incercrystalline spaces. The electrode "depassivates" when basic sulfates dissolve, thus initiating corrosion of lead and formation of $\mathrm{PbSO}_{4}$ which is observed by the elipsometer.

Reduction of Anodic Films

The reduction of $\mathrm{PbSO}_{4}$ apparently terminates with the onset of $\mathrm{H}_{2}$ evolution even though a large fraction of anodically formed sulfate remains on the surface (see Figure 27). This $\mathrm{PbSO}_{4}$ evidently is unavailable for conversion back to lead, all of the current being consumed by $\mathrm{H}_{2}$ evolution. Changes in the $\mathrm{H}_{2}$ overpotential on lead sites may occur which result in preferential $\mathrm{H}_{2}$ evolution.

Loss of rechargability (conversion to lead) of the discharged lead battery negative is usually considered due to sulfation (formation of "hard" lead sulfate) as described in Reference 1. Sulfation is caused by recrystallization of $\mathrm{PbSO}_{4}$ deposits which occurs after many cycles over periods of weeks or months. This does not explain the loss of reduction capability observed here. The present findings suggest that reduced material utilization may also be due to changes on the lead surface which affect kinetic parameters. 


\section{B. Lithium}

\section{Aqueous Electrolyte}

The spontaneity with which lithium and water (in concentrated LiOH and KOH solution) react make measurement of polarized light from the electrode surface extremely difficult. Rapid lioH film growth, metal substrate roughening and vigorous $\mathrm{H}_{2}$ evolution prevent any measurement starting from a clean lithium surface. Only in the case where an initial water vapor formed film is present can measurement in the aqueous liquid phase be made and then only for periods lasting less than five seconds. The initial protective film slows attack by water of underlying lithium. Specular reflection and measurement of polarized light is possible for a short duxation after exposure of the electrode to the electrolyte.

Passivating and protective films on the 1ithium anode in the aqueous battery are on the order of $300 \mu$ thick (30). When the LiOH film reaches this dimension (mostly due to corrosion) the parasitic $\mathrm{H}_{2}$ evolution can subside if certain discharge current conditions are applied. Films of this nature cannot be analyzed using ellipsometxy due to their rough non-reflectant appearance.

\section{Corrosion in Water Vapor}

Measurement of polarized light reflected from the lithium surface during corrosion with water vapor is possible. Application of the computer model to the data gives only qualitative results. A great deal of roughness or non-stoichiometry in the layer is indicated from the analysis. Computed film refractive indices are complex suggescing electronic conductivity. The thickness of the layer is roughly $2000 \mathrm{~A}$, 
smal1 compared to protective films in the case of aqueous solutions. Littauer proposes that a thin conducting layer may exist at the base of pores in LioH anodic films in aqueous electrolyte. The layer observed here resembles this film since it is thin and conducting. 
VII. Conclusions

Ellipsometry is sensitive to events occurring on the $\mathrm{Pb} / \mathrm{PbSO}_{4}$ electrode and on corroding lithium surfaces. Characterization of surface layers using this technique is possible. Analysis of ellipsometer data using a multiparameter computer implemented model provides information as to the thickness and porosity of deposited anodic films and corrosion films.

Lead

At anodic current densities below $0.130 \mathrm{~mA} / \mathrm{cm}^{2}$ ellipsometer measurements from film-covered surfaces are difficult to analyze due to large crystals which scatcer light. Computed results are more accurate at higher current densities since the morphology of deposited $\mathrm{PbSO}_{4}$ more closely resembles continuous films assumed in the optical theory. As time proceeds anodic $\mathrm{PbSO}_{4}$ deposits become less poxous due to crystals growing together and perhaps nucleation of new cryscals. At film porosities of 0.3 to 0.4 and thicknesses of $600-1000 \AA$ the transport of reactants through surface layers is impeded for current densities above $0.258 \mathrm{~mA} / \mathrm{cm}^{2}$. This results in anodic oxidacion at potentials above 0.0 volts (vs $\mathrm{Hg} / \mathrm{Hg}_{2} \mathrm{SO}_{4}$ ) with the formation of $\alpha-\mathrm{PbO}_{2}$ and basic lead sulfates. Upon interruption of current the potential falls to a stable basic sulfate plateau of $-0.6 \mathrm{~V}$ and the electrode is passivated (i.e. there is no corrosion in the electrolyte). Depassivation of the electrode is signaled by anothex drop in potential to the $\mathrm{Pb} / \mathrm{PbSO}_{4}$ reversible value and a simultaneous increase in $\Delta$ and decrease in $\psi$ indicating $\mathrm{PbSO}_{4}$ film growth. 
Porosity of anodic films was found to depend on current density, acid concentration and electrolyte transport condition implying a solution side mechanism. Conditions leading to a high concentration of solubilized anodic products result in more compact film suggesting more $\mathrm{PbSO}_{4}$ nucleation sites. Current efficiency computed for high current density experiments are between 75 and $85 \%$. In this case material must be transported in solution away from the surface at high fluxes (corresponding to current densities up to $0.2 \mathrm{~mA} / \mathrm{cm}^{2}$ ) in order to maintain a mass balance. This suggests interfacial concentration of film-forming species $3-5$ orders of magnitude higher than the solubility of $\mathrm{PbSO}_{4}$. Only colloldally aggregated $\mathrm{PbSO}_{4}$ would exist at such high effective concentrations since ionically dissolved material is ruled out. Interfacial refractive index is usually higher than in the bulk solution supporting this possibility. Large crystals on the surface are probably still formed from ionically dissolved $\mathrm{PbSO}_{4}$, their growth rate being proportional to applied current density. This suggests a linear relationship between applied current and the $\log _{\text {of }} \mathrm{PbSO}_{4}$ supersaturation. Sublayers between crystals visible in SEM photographs are not directly indicated from the analysis of ellipsometer data. At low currents a sublayer is used to theoretically reproduce data but parameters describing it are uncextain. For an expeximent at $1.33 \mathrm{~mA} / \mathrm{cm}^{2}$ the rapid jump (to $\mathrm{O}_{2}$ potential) was found to occur at such high porosity $(0.6$ ) that a compact sublayer is thought to exist.

Termination of the reduction of $\mathrm{PbSO}_{4}$ deposits is marked by the onset of $\mathrm{H}_{2}$ evolution. This implies that the surface structure of deposited lead (and not the structure of $\mathrm{PbSO}_{4}$ crystals) changes at this 
point making reduction of $\mathrm{Pb}^{2+}$ unfavorable.

The ellipsometex provides a means to study the initial stages of growth of $\mathrm{PbSO}_{4}$ films at open circuit. The similarity in kinetics between this work and Lander's work confirms the ability of ellipsometry to measure film formation rates even from surfaces with large (3000 $\AA$ and up) product crystals. Anodic film growth at low current densities $\left(0.01 \mathrm{~mA} / \mathrm{cm}^{2}\right)$ is influenced by corrosion of lead in the electrolyte.

\section{Lithium}

Ellipsometer measurement from a clean lithium surface during reaction with water vapor is possible. A corroded sample was found to have a surface layer about $2000 \AA$ thick with a complex refractive index suggesting non-stoichiometry.

Measurement of polarized light starting from a clean Iithium surface in contact with aqueous alkaline electrolyte is not feasible. Rapid film growth, surface roughening and $\mathrm{H}_{2}$ evolution cause incident light to be scattered. When an initial protective film is present to due reaction with water vapor, ellipsometer measurements in aqueous alkaline electrolyte are possible for several seconds since transport of liquid water through the protective film is limited. 
ACKNOWLEDGEMENTS

I am indebted to Dr. Rolf Muller for his direction and inspiration and to Walter Giba and Lee Johnson for their technical and mechanical assistance. I express special appreciation to Dr. Craig Smith who has advanced the interpretation of ellipsometer data and provided many useful discussions. I also thank Carol Payne and my wife, Janice, for their diligent manuscript preparation. My wife also deserves special thanks for her support and inspiration.

This work was supported by the Division of Solar, Geothermal, Electric and Storage Systems office of the Assistant Secretary of Energy Technology, U. S. Department of Energy. 
Appendix A

Relationship Between $1_{\mathrm{CRYS}}$ and $\mathrm{dL} / \mathrm{dt}$

For cubes the volue of the crystal is $L^{3}$ ( $L$ is the length of an edge) so that

$$
\frac{d m}{d t}=\frac{d}{d t}\left(L^{3} \rho\right)
$$

where $m$ is the mass of the crystal and $\rho$ is its density. The rate of mass gain $\dot{m}$ per unit crystal area is

$$
\dot{\mathrm{m}}=3 \rho \frac{\mathrm{dL}}{\mathrm{dt}}
$$

The mass gain and $i_{\text {CRYS }}$ can be related using Faraday's law:

$$
\dot{\mathrm{m}}=\frac{\dot{M}_{\mathrm{CRYS}}}{\mathrm{nF}}
$$

where $M$ is the molecular weight. Eliminating $\mathrm{m}$ from [A2] and [A3] gives

$$
i_{\text {CRYS }}=\frac{3 \rho n F}{M} \frac{d L}{d t}
$$

Since $\frac{d L}{d t}$ is proportional to in $\frac{C_{S S}}{C_{S}}$ and $i_{C R Y S}$ is proportional to $i_{T}$ (see Discussion, Lead, we have

$$
i_{\mathrm{T}}=\frac{3 n F \rho}{\mathrm{M}} \quad K \operatorname{In} \frac{\mathrm{C}_{\mathrm{SS}}}{\mathrm{C}_{\mathrm{S}}}
$$

where $\mathrm{K}$ is a proportionality constant. 
Appendix B

Computer Output

Presented here are reproductions of computer output from the programm RUFF, The following quantities which appear in the printout are not used: LIMITING COVERAGE, TTME TO REACH COMPACT FILM I, PASSIVATION TIME, TYPE 2 EFFECTIVE REFRACTIVE INDEX and VOLTS. other parameters in the printout are described in Table III. Codes at the top of the output specify which model in the program is to be applied to the data. Porosity of the Type I film at the top represents initial porosity. At the bottom are given experimentally measured $\psi, \Delta$ and times, Computed values of $\psi, \Delta$ and dimension of layers are also given. At the top left of the output are experiment numbers which correspond to experiments analyzed in Chapter $V$. 


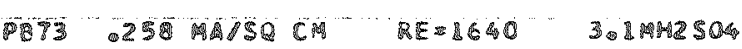

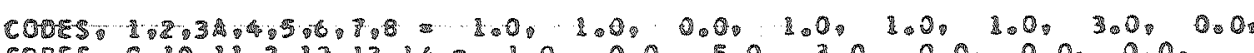

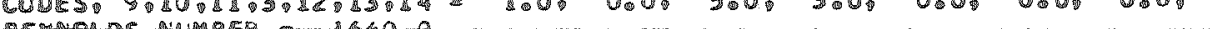

RETECTIVE REFRATIVE INOICES ANO PUROSITIES.

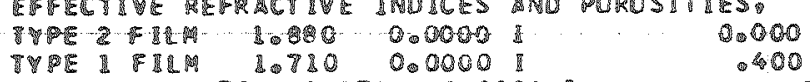

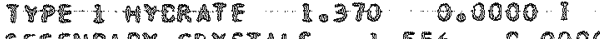

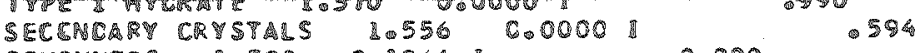

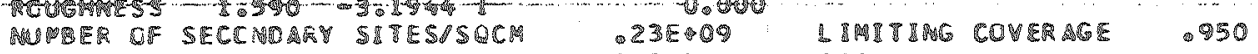

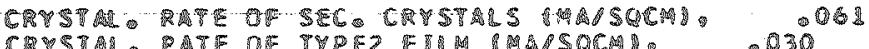

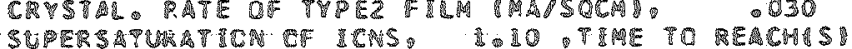

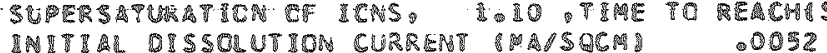

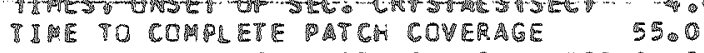

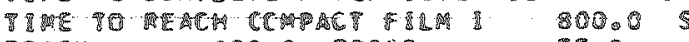

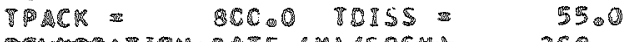

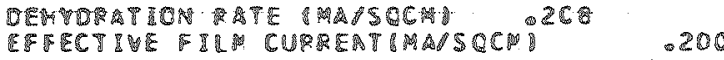

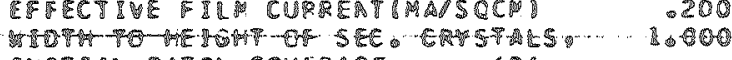

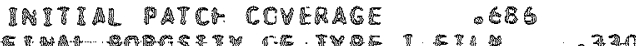

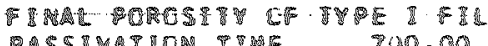

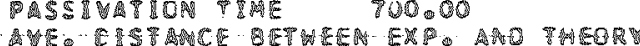

2. BOST

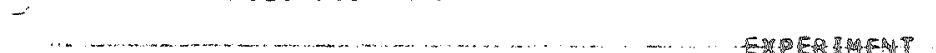

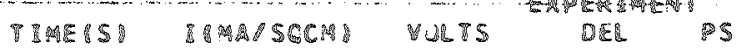

DER PMEORP PI

THEC

TES

$\begin{array}{cccc}1000 & .258 & 10000 & 720300 \\ 20.0 & .258 & 3000 & 730260\end{array}$

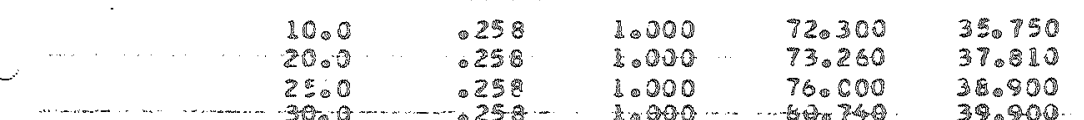

$\begin{array}{llll}3500 & 0258 & 10000 & 85.600\end{array}$

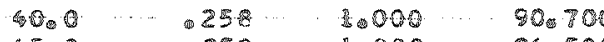

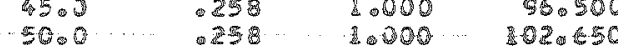

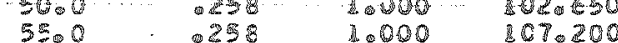

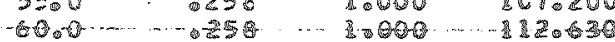

$65.0 \quad 0258 \quad 20000 \quad \mathbb{1 1 6 0 3 0 0}$

$70.0 \quad-25 \%-1.000 \quad 120.50$

$0258 \quad 20000 \quad 1240400$

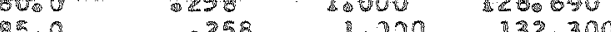

की

30.000

48000

49090

420200

4. 20360

40100

35.200

370450

350300

330240 35.92

$73.940 \quad 370.30$

75.769

39.135

85.

2004.

Q11. 503

5702

$\begin{array}{ll}1020109 & 40.303 \\ 108.051 & 40.127\end{array}$

42,78

$4 \mathbb{B} 108$

40.436 .3009

21006

38.572

125.778037098

35.62

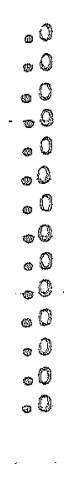

T)

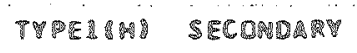

Cov

22.80

\begin{tabular}{|c|c|c|}
\hline 27.0 & $=0$ & 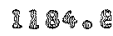 \\
\hline 133.0 & $\infty$. & MSE. \\
\hline 37806 & $=0$ & 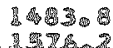 \\
\hline $\begin{array}{l}287.5 \\
250.2\end{array}$ & $\begin{array}{l}-\infty \\
-\infty\end{array}$ & $\begin{array}{l}1578.2 \\
16060.5\end{array}$ \\
\hline 2760 & $\infty 0$ & 1838.7 \\
\hline $297 \cdot 7$ & -0 & M \\
\hline $323 \cdot 2$ & $-\infty$ & 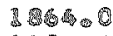 \\
\hline 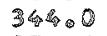 & $=0$ & 195606 \\
\hline 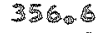 & -.0 & 200501 \\
\hline 387.5 & $\pi_{\infty} 0$ & 20000 \\
\hline 9.2 & -.0 & 2876. \\
\hline 50. & -0 & 280209 \\
\hline 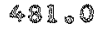 & -0 & (2345. \\
\hline
\end{tabular}




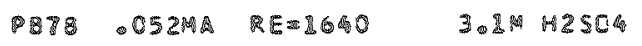

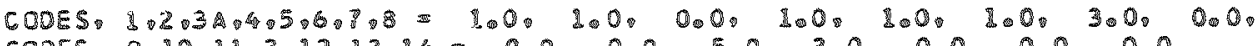

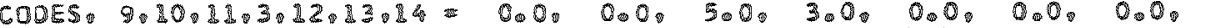

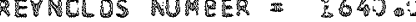

EFFECTIVE REFKACTIUE RNOICES MNG OCRCSITIES.

THP 2 FILA 10880 0.0000 II

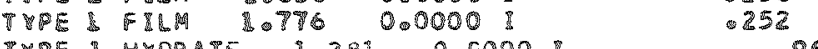

TYPE \& MTORATE \$O3\%\$ 0.0000 I

SECCNDARY CRYSTALS D.73E 0.0000 I 0.000 . 300

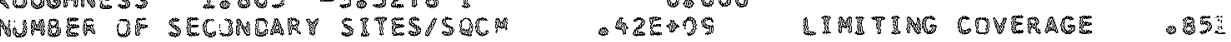

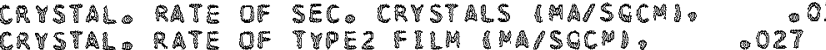

SUPERSATURATION OF IOWSO ZOBO TIME TO REACHSS

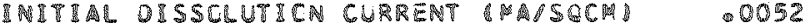

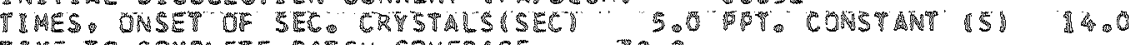

TIME TO COMPLETE PATEM CONERAGE TOOO

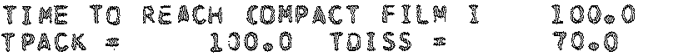

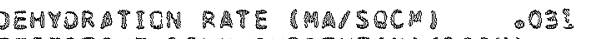

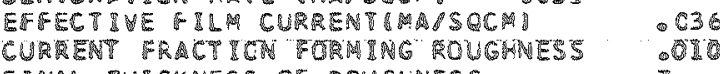

FIMAL TMICKNESS OF ROUGWNESS TT

WOTW TO HETGHT DF SECO CRYSTALSO

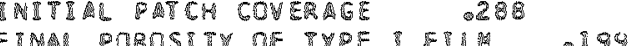

MVE. DISTARE E T

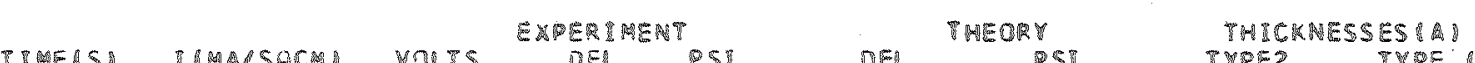

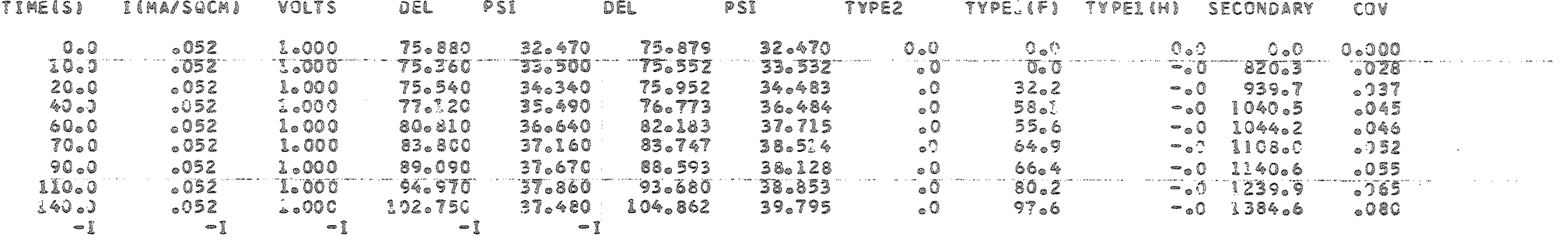




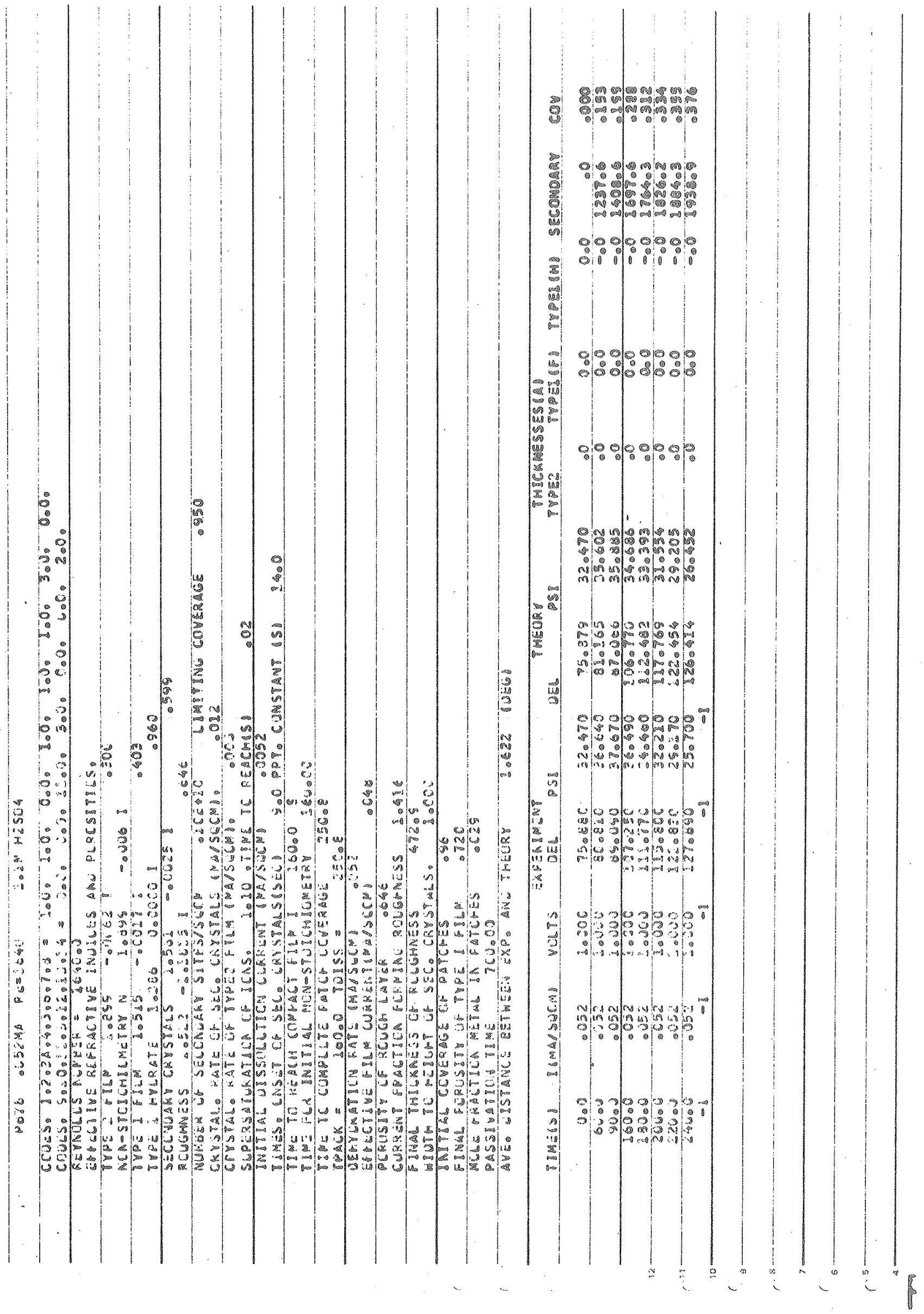




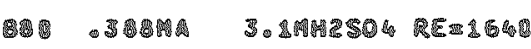

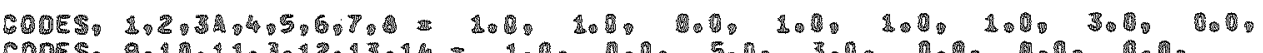

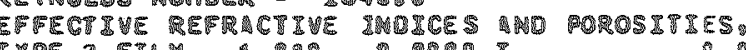

PVE

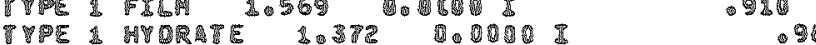

SECOM MV

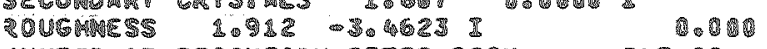

U.

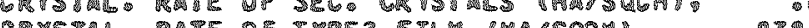

DUP

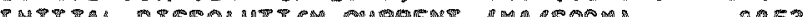

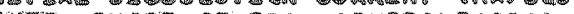

I

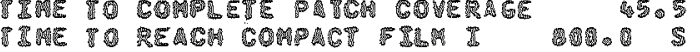

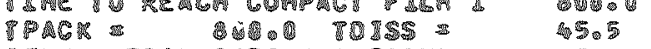

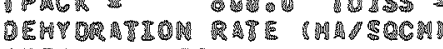
307

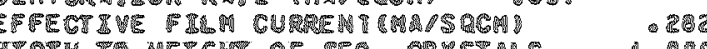

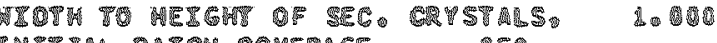

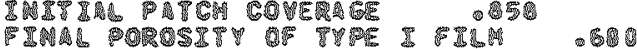

Pa

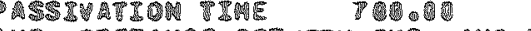

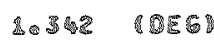

\begin{tabular}{|c|c|c|c|c|c|c|c|c|c|c|c|}
\hline \multirow[b]{2}{*}{ 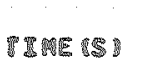 } & \multirow[b]{2}{*}{ 品 } & \multicolumn{3}{|c|}{ 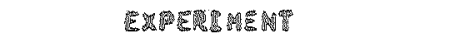 } & \multicolumn{2}{|c|}{ 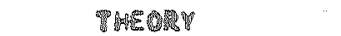 } & \multicolumn{2}{|c|}{ 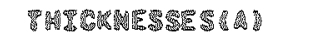 } & \multirow[b]{2}{*}{ 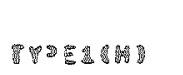 } & \multirow[b]{2}{*}{ 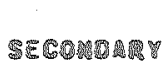 } & \multirow[b]{2}{*}{28} \\
\hline & & 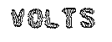 & DE: & PS & DES & & 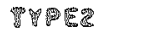 & Topd & & & \\
\hline . & . 38 & 1.8 & 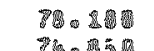 & 3. & 78 . 18 & 3201 & 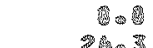 & 的。雨 & 8 & 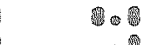 & 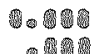 \\
\hline 50 & - 138 & 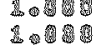 & 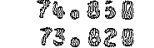 & 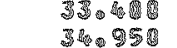 & 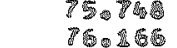 & 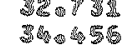 & 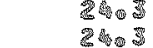 & 28. & $\rightarrow$ & 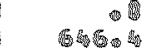 & 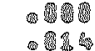 \\
\hline 15 & 032 & 10 & 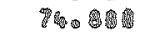 & 36.28 & 72 - & 36。1 & 24 & 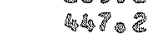 & $-\infty$ & 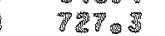 & 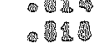 \\
\hline 20.9 & - 32 & 1028 & 780970 & 37.78 & 770096 & 37078 & 2403 & $57 Z_{0}$ & - 辰 & Mg 81 & 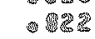 \\
\hline E5. & 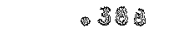 & 28. & 920128 & 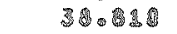 & 18. & 390.6 & 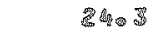 & 䡚要。露 & $\infty$ & 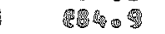 & - $42 \pi$ \\
\hline 30.0 & - 3 & 1.20 & 36.359 & 39.83 & 105.798 & 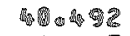 & 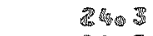 & 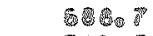 & 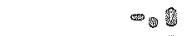 & 9610.60. & 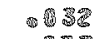 \\
\hline 350 & 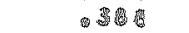 & 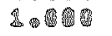 & 94.53 & 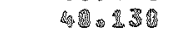 & 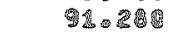 & 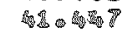 & 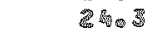 & 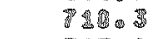 & $\infty$ & 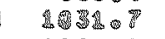 & - 由 8 \\
\hline 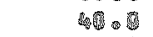 & -3 & 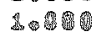 & 26. & 96510 & 96.98 & 4. & 照的事 & FPA & $\infty$ & 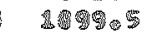 & - 0 \\
\hline 60.0 & (3) & 1000 & 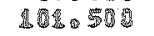 & 40.28 & 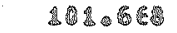 & 60. & 留跑 & P的电 & - $x^{2}$ & 1283 & 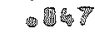 \\
\hline 50. & 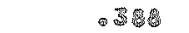 & 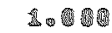 & 29. & 3.9.6.9. & & & & & & & \\
\hline 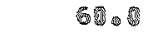 & 0.38 & 1. & 118.13 & 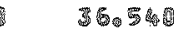 & & & & & & & \\
\hline 80 & - 33 & 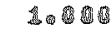 & 826.398 & 33555 & & & & & & & \\
\hline 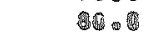 & 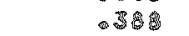 & Sand & 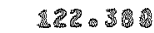 & 30.030 & & & & & & & \\
\hline 90 & - 382 & \&० & 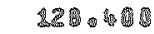 & 38.98 & & & & & & & \\
\hline 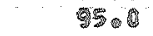 & - 3 & Loy & $\triangle 350$ & 27, & & & & & & & \\
\hline 200.6. & - 3 & 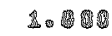 & 84055 & 26.3 3 & & & & & & & \\
\hline
\end{tabular}




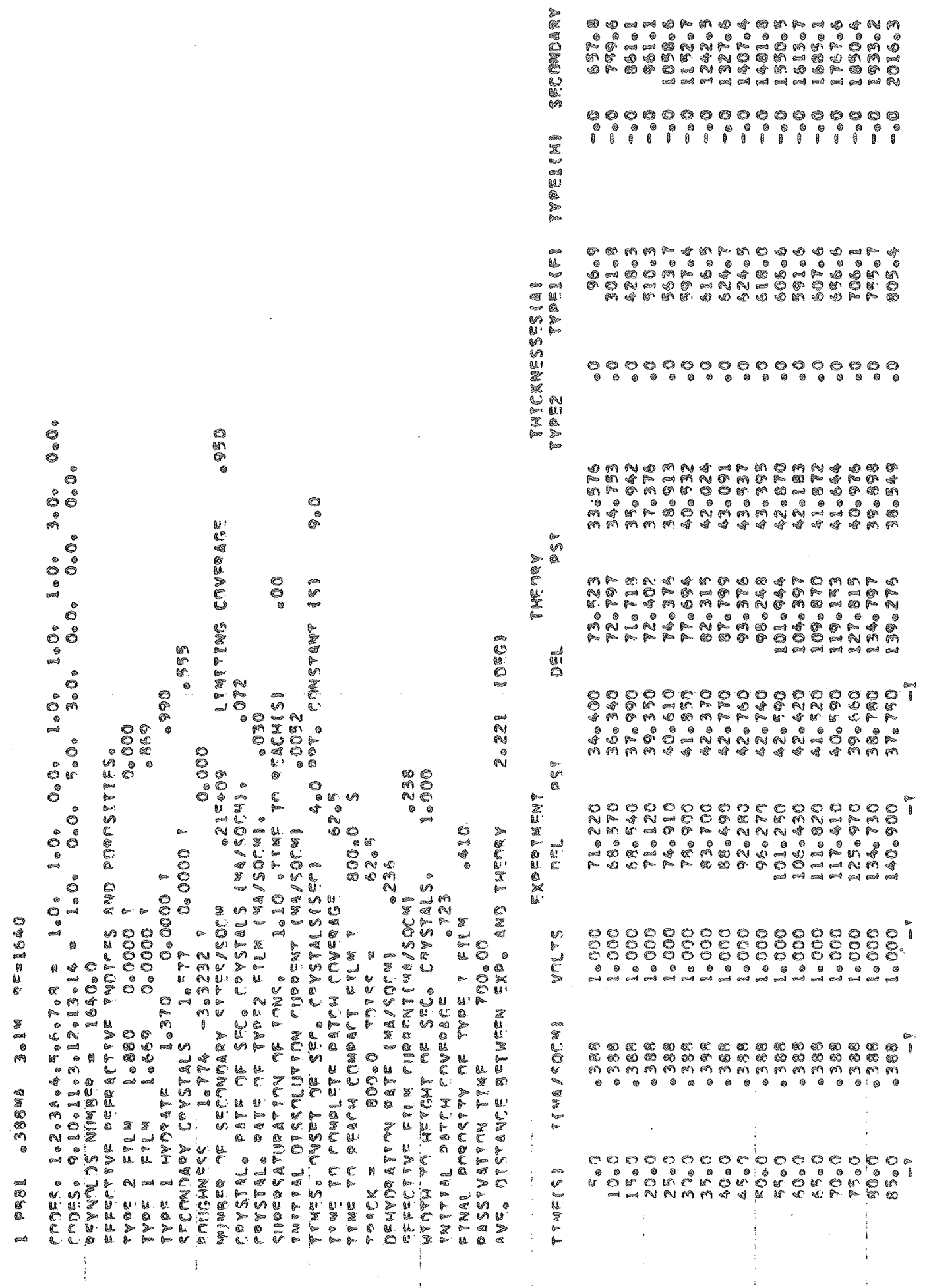

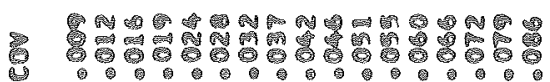




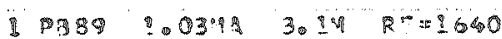

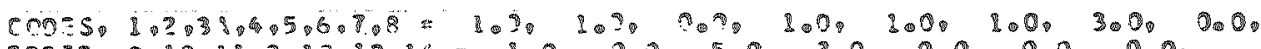

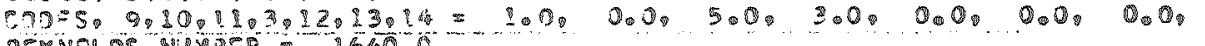
RETNCLDS NUMA

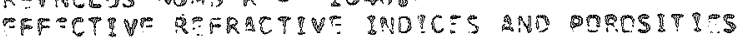

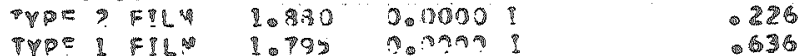

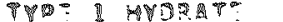

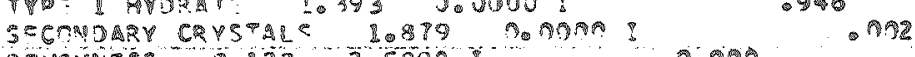

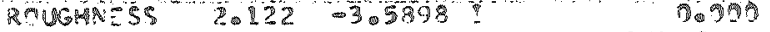

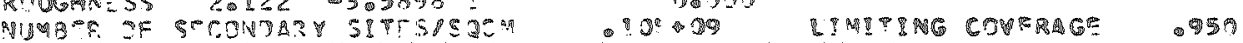

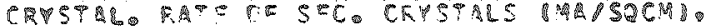

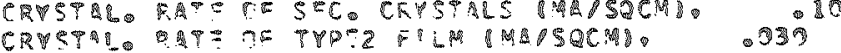

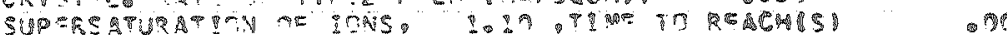

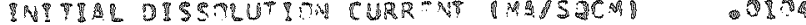

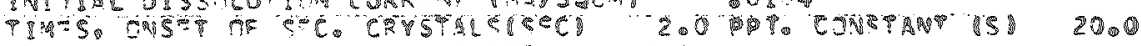

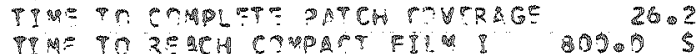

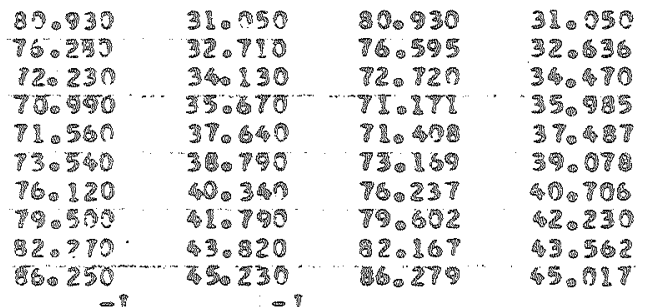

0.9
0
0
0
0
0
0
0

0.3
-0.0
$=0$
$=0$
$=0$
$=0$
$=0$
$=0$
$=0$
$=0$

\begin{tabular}{|c|}
\hline 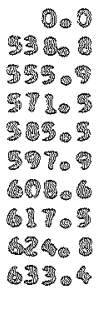 \\
\hline
\end{tabular}


P 898 1.33H RE=3260 3.1M

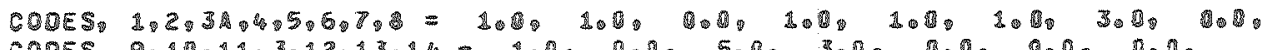

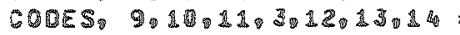

TEYMOLOS MUMOER = 3200.0

EFFECTIVE REFRROTIVE ZNOLCES BMO POROJITIES

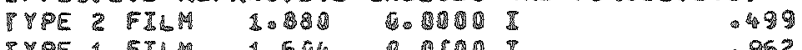

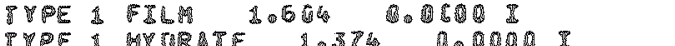

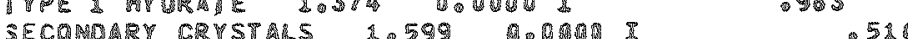

ROUGHESS $2.059-304036$ I

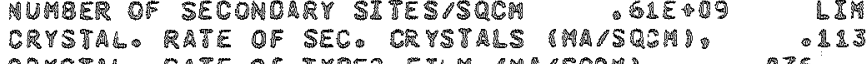

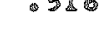

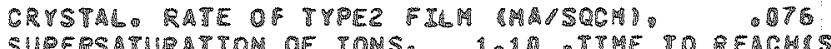

$\rightarrow 0$

0
0

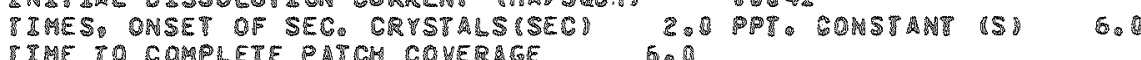

TIAE TO COMPLETE PATCH GOMERAGE

SPCK = OOR. TOTSS = 800

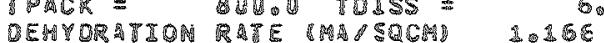

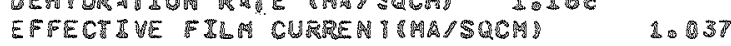

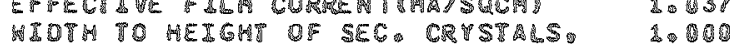

IMITIAL PATCM COVER

PINAL POROSITY OF TYPE IFIMM . F36

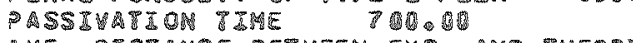

AVE. DISTHAE BETWEE EXP. MNO TMEORY

- 421 $28 E G$

\begin{tabular}{|c|c|c|c|c|c|c|c|c|c|c|c|}
\hline \multirow[b]{2}{*}{ PRAESS } & \multirow[b]{2}{*}{ IUMASOCW } & \multicolumn{3}{|c|}{ EXPER } & \multicolumn{2}{|c|}{ TMEORY } & \multicolumn{2}{|c|}{ THICKNESSESA } & \multirow[b]{2}{*}{ Ty } & \multirow[b]{2}{*}{ 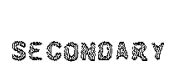 } & \multirow[b]{2}{*}{ Cov } \\
\hline & & VOMTS & $\mathbb{B E}$ & PSI & QES & PSP & PPPEL & PYPESRFB & & & \\
\hline 0,0 & $B \in 30$ & 1.028 & 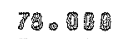 & \$1.000 & 78. 0020 & 31.0000 & 翻。 & B. & $\mathbb{2}, \mathbb{0}$ & 電的象 & 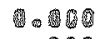 \\
\hline 200 & 20300 & 2080 & 76.060 & 32000 & 75.724 & 31.703 & 23.8 & Q0 & $\rightarrow \infty$ & 0 & -300 \\
\hline 200 & 1. 300 & 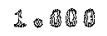 & 76000 & 330000 & 73.995 & 32.512 & 23.7 & 573.4 & -00 & 00 & - \\
\hline 300 & 10 305 & 20000 & 72.600 & 33.800 & 72034 & 33.633 & $23 . \pi$ & 3.5 .4 & -0 & 2 & - 20 \\
\hline$\$ 00$ & $\mathbb{2 0} 300$ & 20000 & $7 D Q 000$ & 340500 & 740051 & 34. 556 & 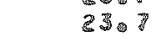 & 346. & $\sin \theta$ & 8. & 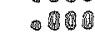 \\
\hline 500 & 1. 300 & 10000 & 69.600 & 35.503 & $78 \cdot 136$ & 35.375 & 23.7 & 312.9 & $-\infty$ & 6.1 & - 120 \\
\hline 600 & 10 उही & 1 & 68.200 & 36.000 & 69.400 & 35.980 & $230 \pi$ & 314 4 . & $\infty$ & 20.7 & 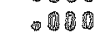 \\
\hline 7.0 & 20300 & 10200 & 68.600 & $\$ 6000$ & 60.58 & 36.910 & 2307 & 350.3 & $\infty 0$ & 460.6 & - 田留 \\
\hline 280 & 2. 3 政边 & 1006 & 68.40 & 37. 300 & 68.152 & 37.649 & $23_{0} 7$ & 4220 & $\infty$ & 13.19 & 2035 \\
\hline 9.0 & 10300 & 2.000 & 68.40 & $3 \mathbb{Z} 800$ & 68.255 & 38.34 & 23.7 & 48505 & $=0 \mathbb{1}$ & 127.5 & (1001 1 \\
\hline
\end{tabular}




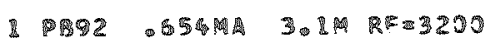

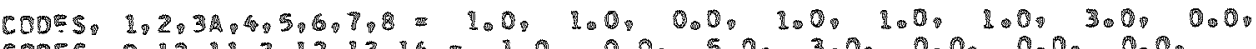

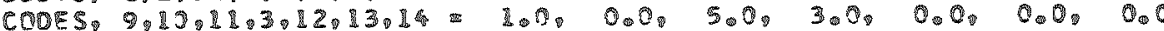

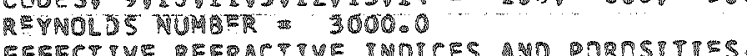

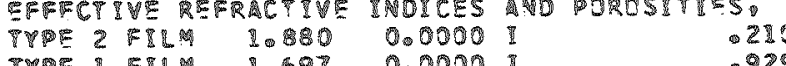

$0.0000 \mathbb{1 1}$

980

SONDARY CRPSTALS 1.83000000

(5ITES

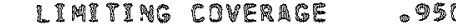

CRYSTRE RATE OF SEC. CRVSTALS MMASTOCMD

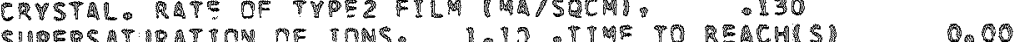

RRAT

Thine

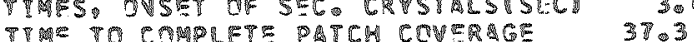

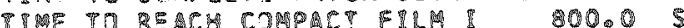

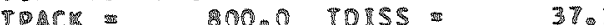

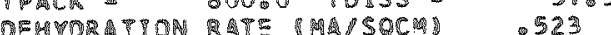

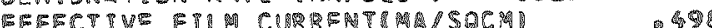

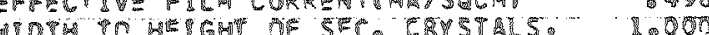

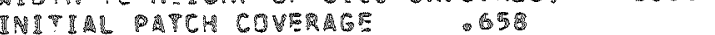

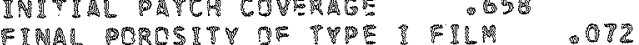

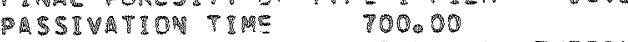

A P

10333 VDEC

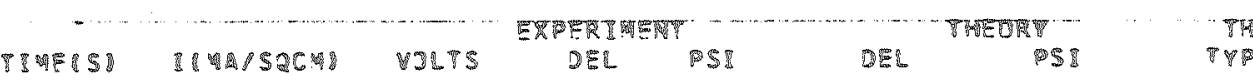

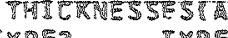

\begin{tabular}{|c|c|c|c|c|c|c|c|c|c|c|c|}
\hline 0.0 & 0654 & 2.000 & 73.820 & 34.90 & 73.220 & 34.60 & 0.0 & 0.0 & 0.0 & 0.0 & 0.000 \\
\hline 200 & .654 & 20000 & 70.180 & 36.210 & 720615 & 35.03 & 20. & 0.0 & -.0 & 0 & 2000 \\
\hline 40 & -659 & 20000 & 69.740 & 37.750 & 69.070 & 36.397 & 20.8 & 253.6 & -.0 & 35.0 & 0230 \\
\hline 6.0 & .6540 & 50000 & 69.050 & उद्य & Bह & -37.103 & 20.8 & 636 & $-\infty$ & 6280 & .012 \\
\hline 8.0 & 065 解 & 2.000 & 80.10 & 19.000 & $89-750$ & 30.253 & 20.8 & $522 \times 3$ & $=\infty$ & 602 & 0.013 \\
\hline 100 & .650 & 2000 & 71.500 & 40.30 & 70.795 & 38.04 & 20.8 & 507.6 & -00 & 706.9 & 010 \\
\hline 2.0 & .654 & 1.000 & 720610 & 420170 & 72.274 & 40.905 & 200.8 & 50304 & $-\infty$ & 705.3 & .006 \\
\hline 1. 9 & .656 & 20050 & 7060 & 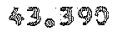 & 72500 & 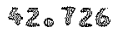 & 20.6 & 606.8 & $-\infty 0$ & $7 x^{2}$ & 0017 \\
\hline 100 & 0.54 & 80000 & 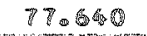 & 44.920 & 77.870 & 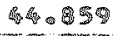 & 20.8 & 62.8 & $-\infty 0$ & 217.8 & 0019 \\
\hline 180 & .85 & 20800 & 6. 60 & 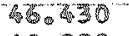 & '81.65 & 7.6035 & e & 620.9 & $=0$ & 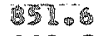 & 022 \\
\hline 20.0 & 065 & 30000 & 85.190 & 40220 & 85.820 & . 8.823 & 20.8 & 605.5 & -.0 & 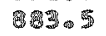 & .022 \\
\hline 22.0 & $.65 g^{2}$ & 10000 & 8.560 & 90010 & 90.328 & 30.307 & 20.8 & 50907 & $-\infty$ & 43.5 & .024 \\
\hline 240 & 0654 & 1.000 & 96.500 & 32.670 & 94092 & 51034 & 200 & 385.3 & $-\infty 0$ & 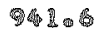 & 0225 \\
\hline 26.0 & $.6 g^{2} \mathbb{S}_{0}$ & 1.000 & 100.000 & 530300 & 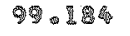 & 51.80 & 20.8 & 981.99 & $=0$ & 97.8 & 0028 \\
\hline 28.0 & (6) $5 \sin ^{2}$ & 2.000 & 104.20 & 5.230 & & & & & & & \\
\hline
\end{tabular}




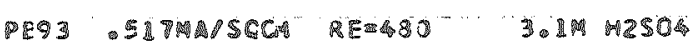

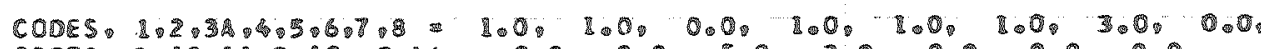

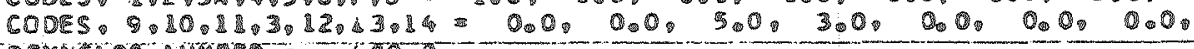

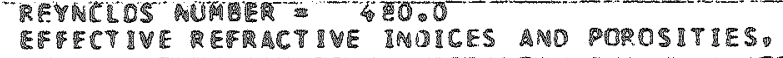

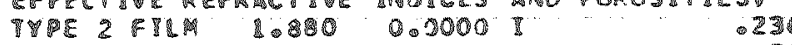

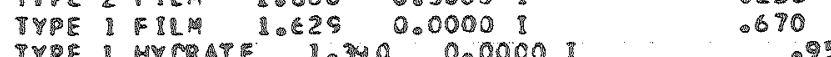

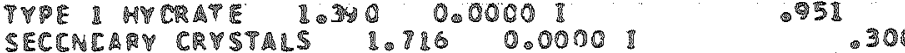

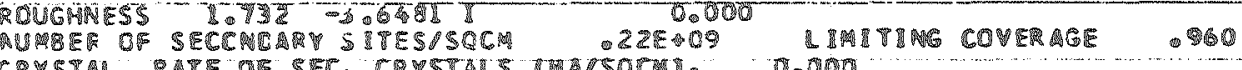

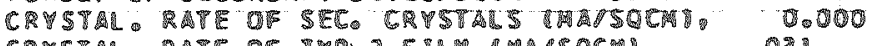

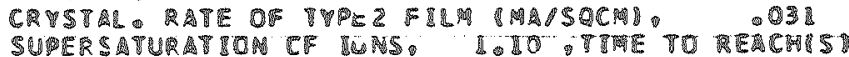

TNITIAR DISSOLUTICM GURRENT IMAISOCM

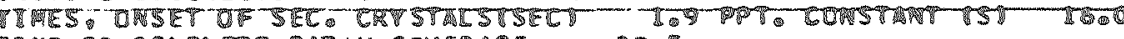

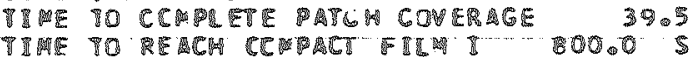

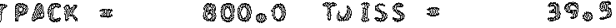

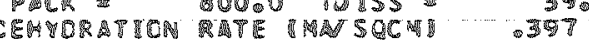

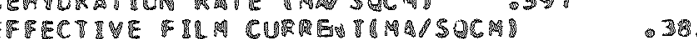

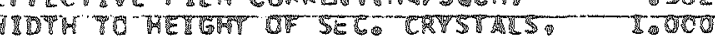

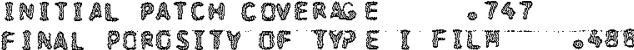

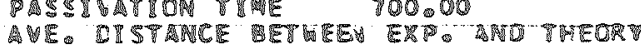

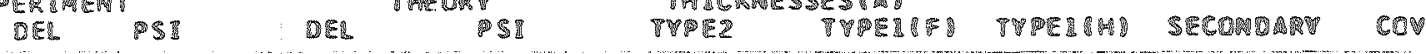

\begin{tabular}{|c|c|}
\hline 0.0 & (4) \\
\hline 200 & 0 \\
\hline 400 & \\
\hline$\$ 0.0$ & 4 \\
\hline $\begin{array}{l}12.0 \\
18.0\end{array}$ & \\
\hline 20.0 & \\
\hline 2400 & \\
\hline 22.0 & 051 \\
\hline $3210^{\circ}$ & \\
\hline 3600 & \\
\hline 40.0 & \\
\hline
\end{tabular}

\begin{tabular}{|c|c|}
\hline $\begin{array}{l}\$ 0000 \\
\$ .000\end{array}$ & $\begin{array}{l}79.870 \\
78.040\end{array}$ \\
\hline 10000 & 76.820 \\
\hline $\begin{array}{l}1.000 \\
1.000\end{array}$ & \\
\hline 1.0000 & 77.930 \\
\hline & $\begin{array}{l}82.520 \\
88.290\end{array}$ \\
\hline 1.000 & 96000 \\
\hline 500 & \\
\hline 1000 & 183350 \\
\hline 10000 & 1220900 \\
\hline
\end{tabular}

33.50

\begin{tabular}{|c|c|c|c|c|c|c|}
\hline 79.870 & 33.310 & 0.0 & 0.0 & 0.0 & 0.0 & 0.000 \\
\hline 78.321 & 34007 & -60 & 79 & $-\infty$ & $\cdots \cdot 0$. & $\cdots 900$ \\
\hline 16.38 & 3409 & 0 & 260.8 & -0 & 0 & .000 \\
\hline 75.2 . & 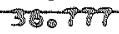 & 0 & 40 & एक & 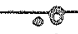 & - 20 \\
\hline 76.182 & $3 P_{0} 390$ & .0 & $331 \cdot 3$ & $-\infty$ & 00 & 0000 \\
\hline 7. & 360 & -0 & 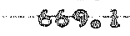 & - खण & 2 & 020 \\
\hline 82.527 & 40.312 & 0 & 790.0 & $=_{\infty} 0$ & .0 & .00 \\
\hline 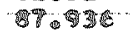 & 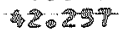 & -0 & $-882 \cdot 5$ & $=0$ & . & . \\
\hline 95.80 & 4283 & 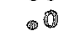 & 96000 & -0 & 0 & .000 \\
\hline 340 & 45030 & 50 & $-2024 \times 4$ & -6 & 웅- & \\
\hline 13.650 & 46.16 & 0 & 8050.4 & $-\infty 0$ & . & .000 \\
\hline 320096 & 4. 13 & .0 & 날 & $-\pi$ & (2) & (2100안 \\
\hline
\end{tabular}
35,330 376690 33.30 35.760 42.290 42. 210 4. 4. 4 उ. 60 


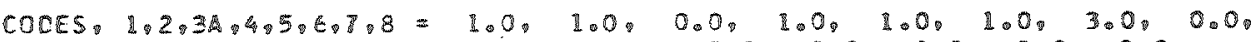

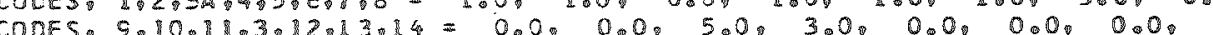

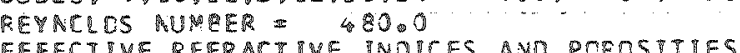

TYPE 2 FE REPRACTIVE INDICES ANO PONOSITIESD

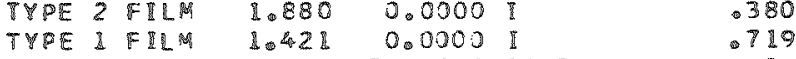

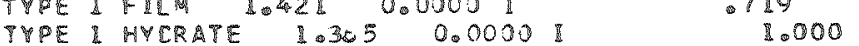

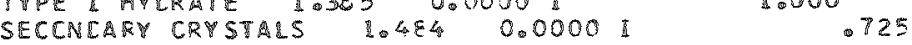

RCLGHAESS 1.333 -3.8818 I C.0DO

NUMBER DF SECCNDAR. DITESRSECM $55 E$ OHOO

CRYSTALO RATE OF SECO CRYSTALM PMAOSECMV 900

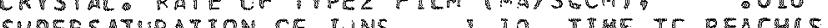

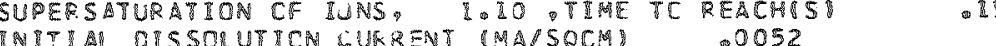

TITES. ORSET OF SEC CRYSTALSTSECT T.O PPT. CCHSTANT TS

TINE TO COMPLETE PATLM COVERAGE $299 \%$

TRME TO REACA CCMPACR FILA I

TPACK = 33.0 TUISS $=2890$

EFFECTIYE FIRM CURREATIMARSCCM I OOR6

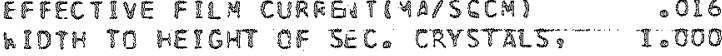

DNITIAL PATCM COVERAE OEZI

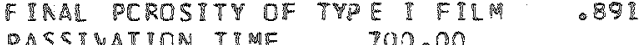

AVE CISTANCE OETEEY EXP. ANO THEDRY OT31 ROEG

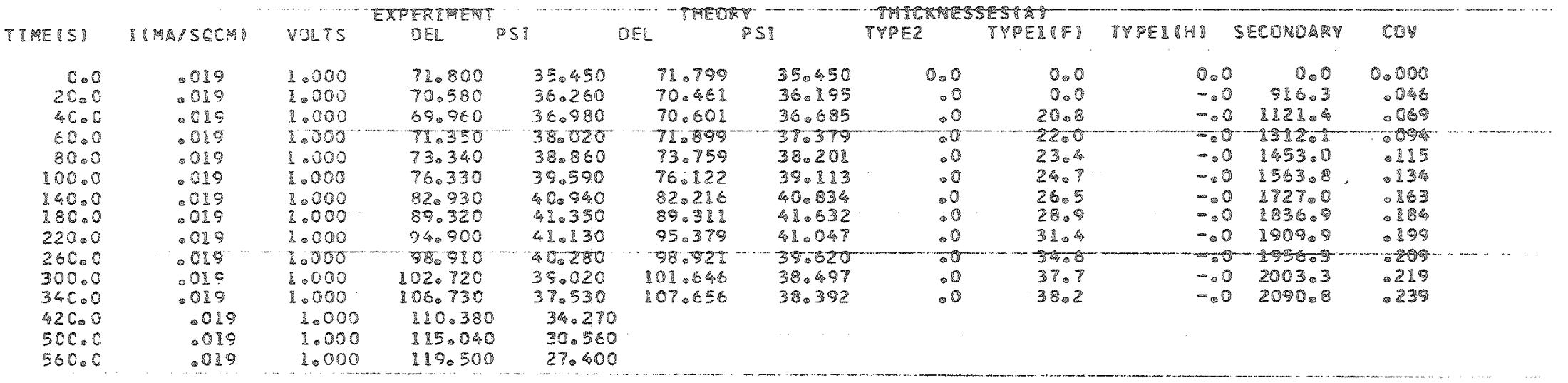




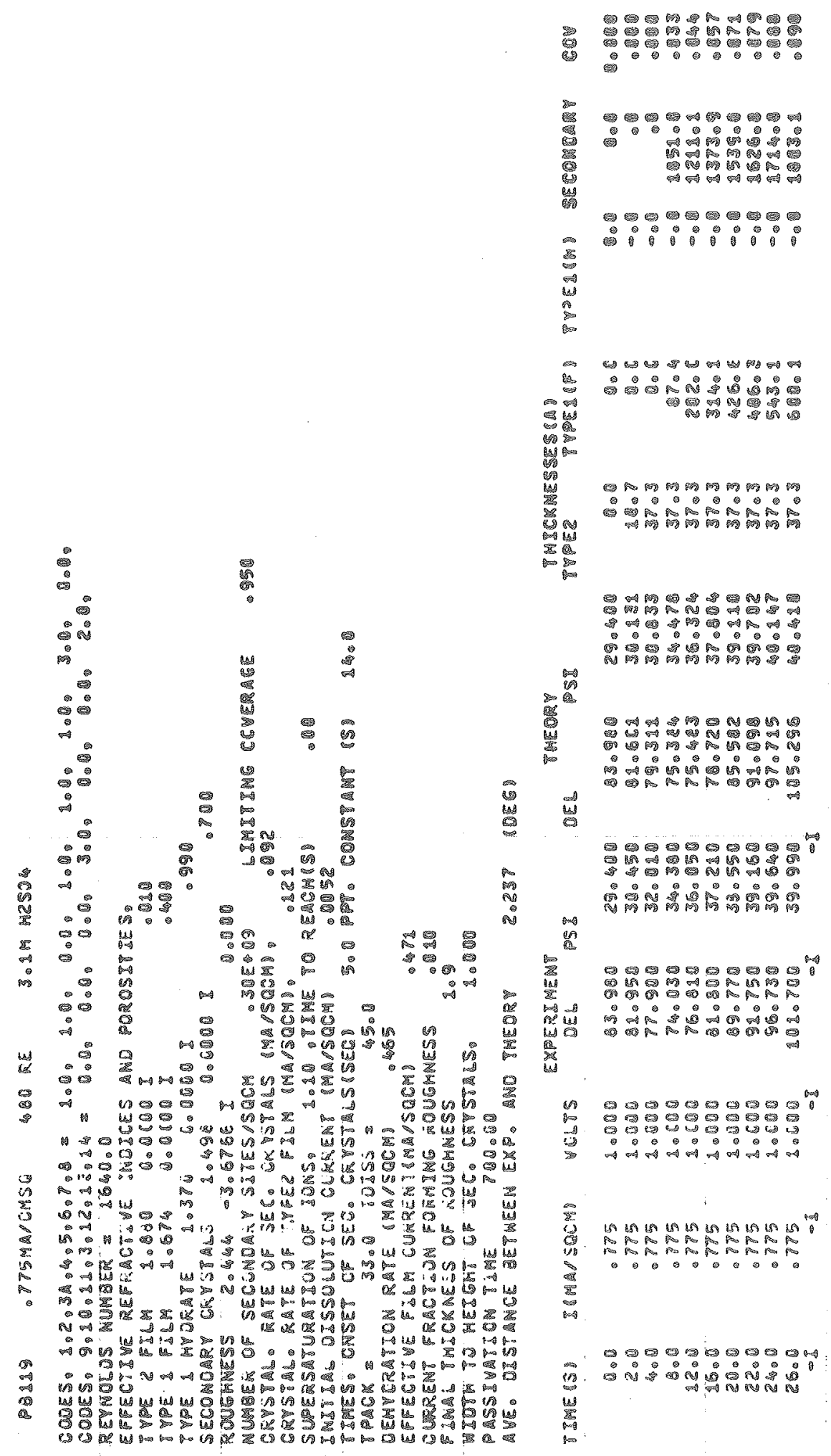




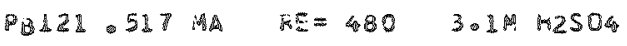

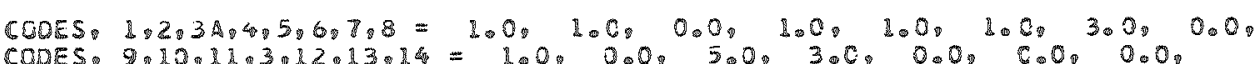

CODES. $9010.180301213 .14=100,0.0,5.0,3.0,0.0,0.0 .0 .0$.

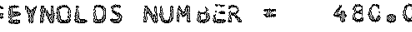

EFFECTIVE REFRACTIUE INCICES ARC PCRCSITIES.

$\begin{array}{llll}\text { IYPE } 2 \text { FILM } & 1.680 & 0.0000 \text { I } & .800 \\ \text { TYPE I FILM } & 1.791 & 0.0000 \text { I } & 0910\end{array}$

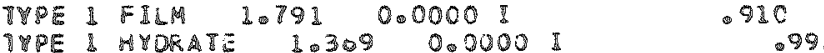

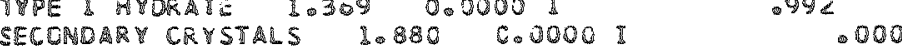

GUGHAESS $1.085-3.5217$ I 0.000

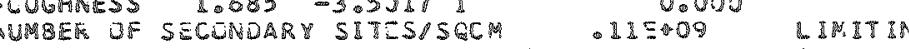

GRYSTALO RATE UF SEC. CRYSTALS IMAASGCMDO DOSA

CRYSTALORATE OF TYPEZ FILM IMASGCPIA -OSO

SUPERSATURATION OF IUAS, 1 O 16 TIIME TO REACHSS

SGCMI 0.0018 .00

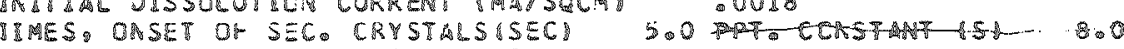

TIME TO COMPLETE PATCH COVERAGE
SRPE TO REACH COMPACT FILM I

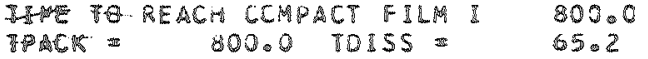

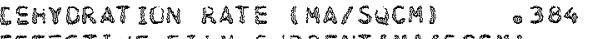

EFFECTIUE FIIM CURRENTIMASSCCM

WOOTH TO MEI I OHT JF SEC. CRYSTALS. 1000

INITIAL PATCH COYERAGE DOTD

FINAL POLESITY OF TYPE I FIL DL DOU

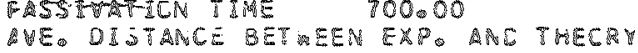

$20109 \cdot$ DDES

\begin{tabular}{|c|c|c|c|c|c|c|c|c|c|c|c|}
\hline \multirow{2}{*}{ TIMUE } & \multirow[b]{2}{*}{ 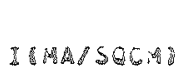 } & \multicolumn{3}{|c|}{ ZXPERIMENT } & \multicolumn{2}{|c|}{ THECRY } & \multicolumn{2}{|c|}{ THICKNESSESH B } & \multirow[b]{2}{*}{ TYPENAH } & \multirow[b]{2}{*}{ SECONEARY } & \multirow[b]{2}{*}{$\cos \sin ^{\circ}(x)$} \\
\hline & & VOLTS & DEL & & DEL & & TYPE2 & TYPESUED & & & \\
\hline $\begin{array}{r}500 \\
1000\end{array}$ & $\begin{array}{r}517 \\
-517\end{array}$ & $\begin{array}{l}1.000 \\
1.000\end{array}$ & $\begin{array}{l}75.210 \\
72.570\end{array}$ & $\begin{array}{l}35.340 \\
30.870\end{array}$ & $\begin{array}{l}75.574 \\
73.799\end{array}$ & $\begin{array}{l}34.122 \\
37.071\end{array}$ & $\begin{array}{l}22.1 \\
22.1\end{array}$ & $\begin{array}{r}0.0 \\
32505\end{array}$ & $\begin{array}{l}-2 \\
=-2\end{array}$ & $\begin{array}{r}.0 \\
876.0\end{array}$ & .000 \\
\hline 3300 & .527 & 1.000 & 73.840 & 38.420 & 73.67 & 38.498 & 250. & 4600 & -00 & 90.67 & .000 \\
\hline 20.0 & .217 & 1.000 & 75,110 & 400480 & 74.703 & 39.835 & 2101 & 54502 & -0.8 & $932 \cdot 1$ & .010 \\
\hline 25.0 & -537 & 20000 & 78.200 & 60.300 & 70.720 & 41 on 193 & $21 \cdot \mathbb{1}$ & 591.7 & $-\infty$ & 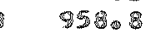 & .010 \\
\hline 3000 & $\cos 7$ & $\$ 000$ & 860680 & 43040 & 790690 & 42.616 & $2 \$ 2$ & 620.6 & -0 & 9846 & 021 \\
\hline 35.0 & 0518 & 10000 & 8.500 & 450000 & 83.623 & 40.12 & $2 \pi \cdot \hat{4}$ & 53802 & -00 & $1009 \cdot 6$ & .038 \\
\hline 4000 & .527 & 10000 & 870620 & 46.560 & 88.454 & 45.662 & $23 \cdot 1$ & 650.1 & -0 & 1033. & .012 \\
\hline 50.0 & 517 & 10000 & 98.550 & 48.510 & $100.20 \%$ & 48.702 & $2 \pi 0$ & 657.1 & -0 & 107706 & .013 \\
\hline 5500 & .518 & 10000 & 107.000 & 50.000 & 106.946 & 50.102 & 22.8 & 65509 & $-0,0$ & 2098.6 & .013 \\
\hline 6000 & .517 & 1.000 & 114 \& 20 & 51.440 & 183.720 & $51 \cdot 326$ & 21.1 & 651.8 & $=0$ & 111805 & .016 \\
\hline-1 & -1 & -1 & -1 & - & & & & & & & \\
\hline
\end{tabular}




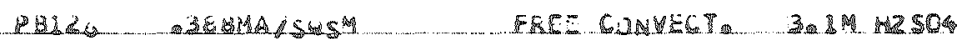

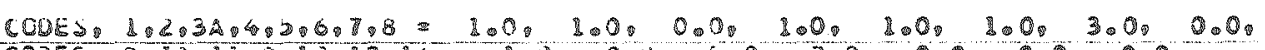

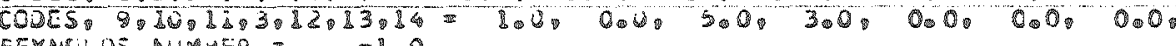

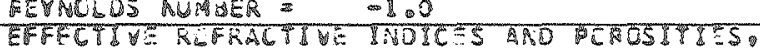

TPPE \& FILA 10880 0.0000?

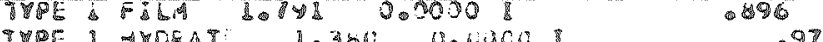

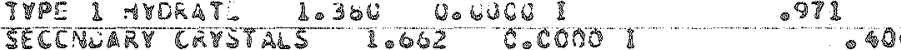

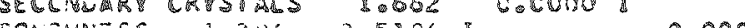

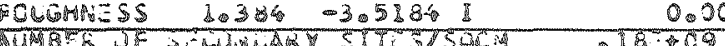

CUN

GRYSIAGO RATE UE SECO CRYSTALS RMABCCN

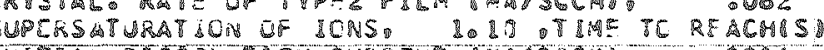

TIMES. UNSET OP SLE. CRYSTALSISEG B B.

TIAE TD REAGH COMPACT FISM I 800.0

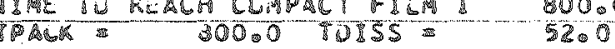

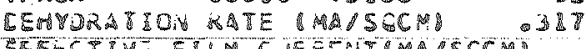

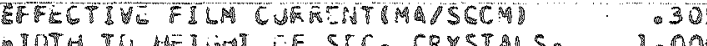

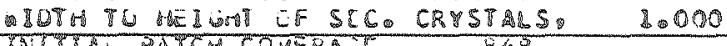

GIMAL POROSTTY OF TYPE: I FBIM

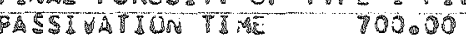

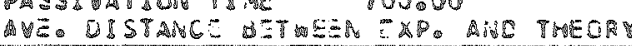

DXMTHE GEVRMEE - 950

PPT. CCASPAM ISO

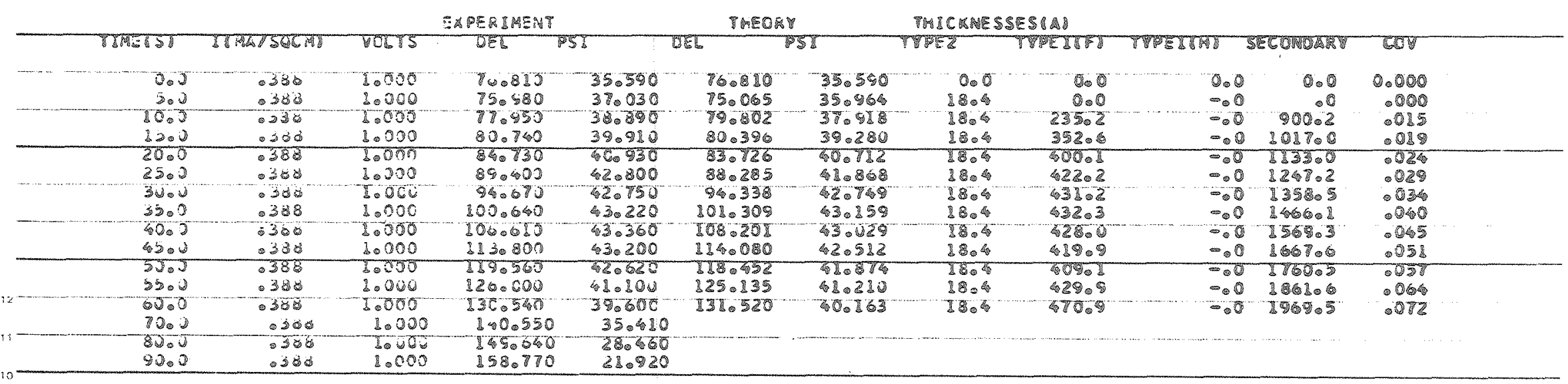

10

$8-$

5 


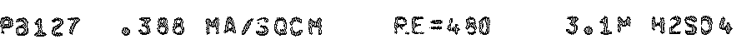

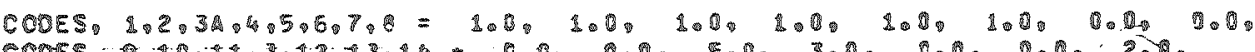

CODEs

EFPECTIVE REFRACPIVE INDICES ARO ONROSTPTES

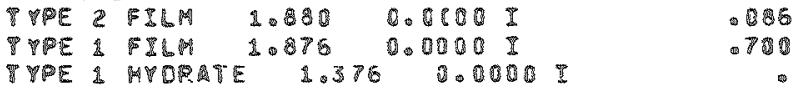

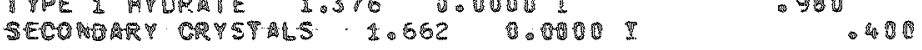

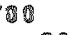

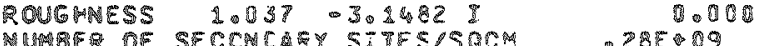

DUNB

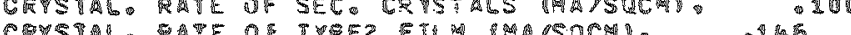

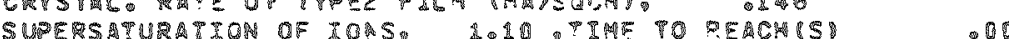

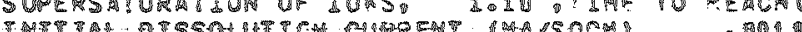

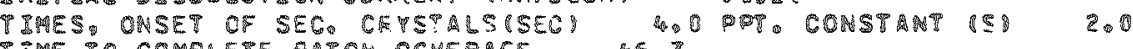

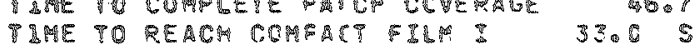

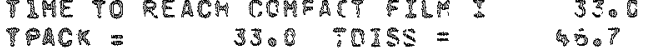

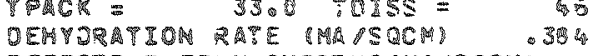

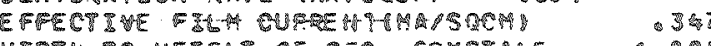

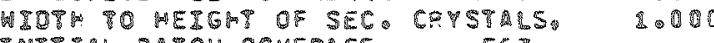

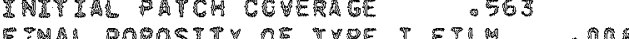

FIMA POROSII OF THPE I FILA

PASS IUR LON TIME

MUE. DISTANCE XETWEEN EXR。 MNE WHEDR

20243 QOEG

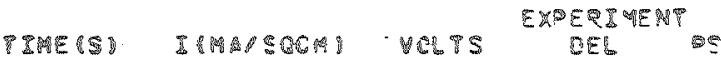

\begin{tabular}{|c|c|c|c|c|c|}
\hline 5.9 & .385 & 1020 & 89.32 . & 39.550 & 81.58 \\
\hline 20.48 & 032 & 10000 & 70.98 & 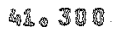 & 72.339 \\
\hline 850 & . & 1080 & 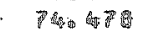 & 蛏, 5 & 74.845 \\
\hline 29.0 & .38 & 1.380 & 82.45 & (4) 380 & 78.298 \\
\hline 25.0 & 358 & 5000 & 350 多象 & 65080 & 96.206 \\
\hline 30. & .39 & 1.000 & 99.570 & 47.350 & 96.818 \\
\hline 350 & - 38 & 2.000 & 108.32 & 4. 0.950 & 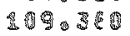 \\
\hline 4 & - उ28 & 1.000 & 213.20 & 48.250 & 1221519 \\
\hline $45+9$ & 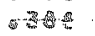 & 2.80 & .28.25 & 45.30 & 125.78 \\
\hline 50.0 & प 38 है & 1.008 & 133.250 & 43.158 & 133.274 \\
\hline 68.8 & .386 & 1. & 140320 & 35.360 & \\
\hline 85.0 & - 388 & 200000 & 144.350 & 33.850 & \\
\hline 70.0 & 388 & 1.30 & 145.780 & 38.260 & \\
\hline
\end{tabular}

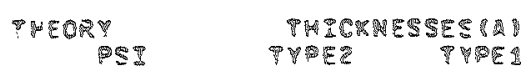

PYT

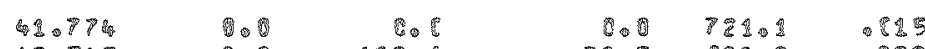

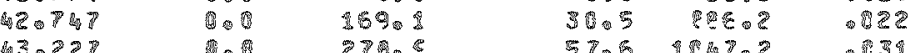

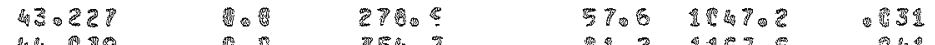
4.

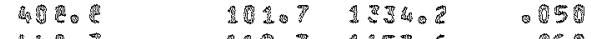

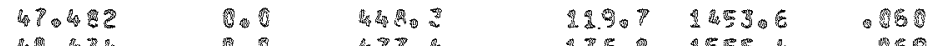

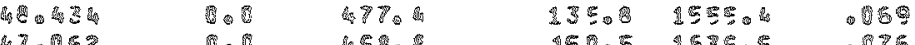
48.082 4.

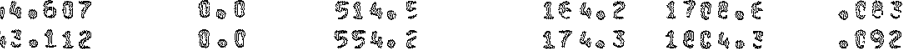




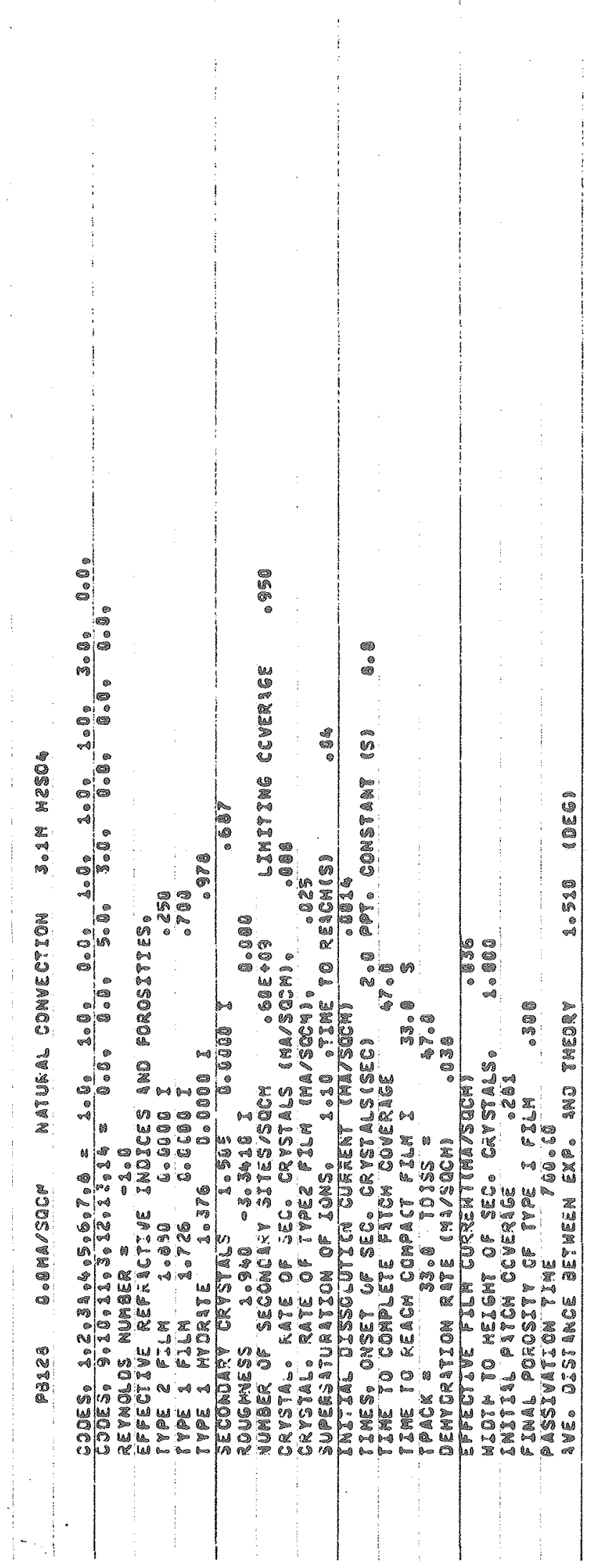

通

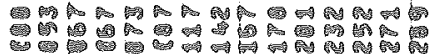
ㅂ.

窟

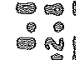

\%

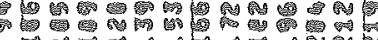

$\Leftrightarrow 0$ -

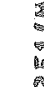

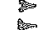

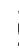

.

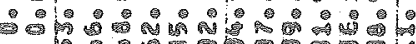

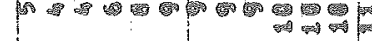



跑

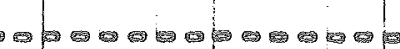

$\because 00000000000000$

a

管照

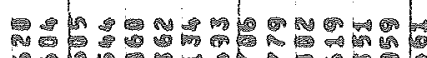

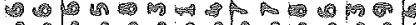

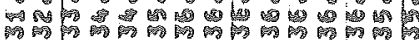

象

.

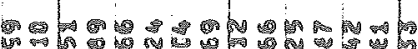

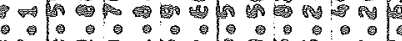

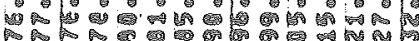

迹

두의

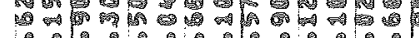

月ำ

紫

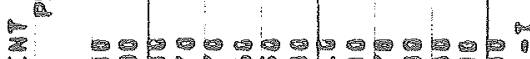

‥

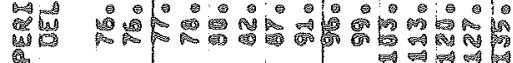

政

n

부의

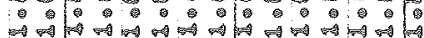

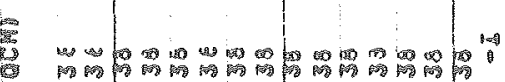

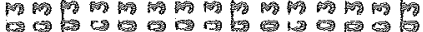

a

蛋

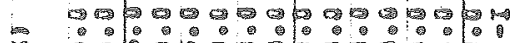

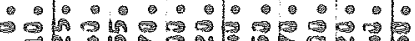

两 


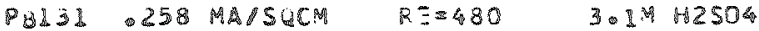

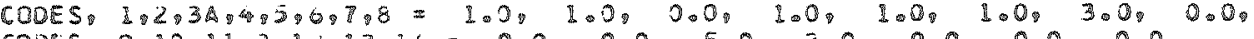

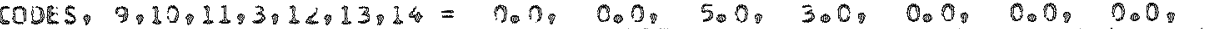

REYNCLDS NUMABR $=480.0$

EFECTIYE REFRACTIVE IRDICES HW PCRESITICS,

TYPE 2 FILA I.8\%0 $0.0000 \mathbb{1}$.

TYPE I MYOEATE

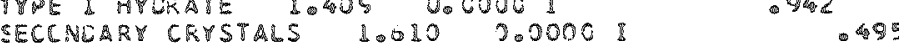

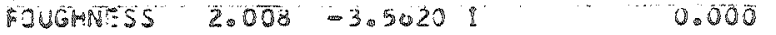

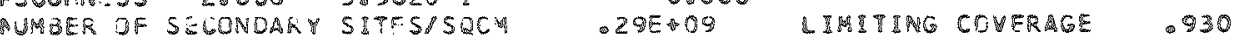

CBYSTAL. RATE OF SEC. CRYSTALS MMASQCHA

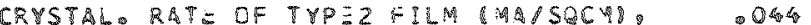

SUPERSAT JRATBON OF IORS. 1010 TIIME TO REAGMSS

IMUTIAL DISSOLUTICN CURRENT RMASSGCMI .0052

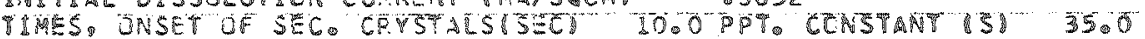

IIPE TO CEMPLETE PATCH COVERAGE 10000

TIME TO REACH COMPACT FILM I 100.0

CEMYOTRTBOA RATE (MB $150 C$ MY

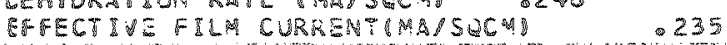

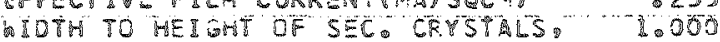

DNTTIAL PATCH COVERAGT CRYSTBS O

EINAL PURCSITY OF TRPE I FILM O165

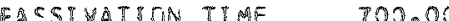

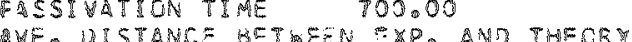

5.3796088

\begin{tabular}{|c|c|c|c|c|c|c|c|c|c|c|c|c|}
\hline PIMEISB & 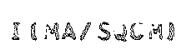 & VOLTS & DEL & PSI & DEL & PSI & TYPEZ & STPEIRFA & TYPEI 18 & & SE CONDARV & $\cos 4$ \\
\hline 502 & .258 & 1.000 & 76.060 & 33.590 & 78.324 & $32 \cdot 295$ & 22.9 & 0.0 & & -.0 & .0 & .000 \\
\hline 10.0 & .238 & 10000 & 740020 & 340930 & 70.430 & 330193 & 21.9 & 70.5 & & $-\infty$ & 0 & .000 \\
\hline 20.0 & .258 & 2.000 & P2.860 & 37.610 & 83.012 & 35.083 & 2209 & 337.2 & & $=-\infty$ & 2 & .000 \\
\hline 3000 & .258 & 2.000 & 74.200 & 60.790 & 75.802 & $3 \% .232$ & 2109 & 524 & & -0 & 20 & .000 \\
\hline 40.0 & .258 & 1.000 & 79.760 & 43.760 & 79.967 & 39.596 & 21.9 & 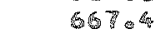 & & $-\infty 0$ & 15.0 & .000 \\
\hline 5000 & 0250 & 1.000 & 83.610 & 48.280 & 86.610 & 43.064 & 2809 & 780.7 & & $=0$ & $57{ }_{\infty} 3$ & 2000 \\
\hline 6000 & .258 & 20000 & 980510 & 50.690 & 99.020 & 47.709 & 2809 & 36400 & & $-\infty$ & 80805 & .002 \\
\hline 70.0 & .250 & $\$ 0000$ & 116.360 & 540050 & 117.608 & 520369 & 210 & 922.5 & & -0 & 263.8 & .002 \\
\hline 80.0 & .258 & 10000 & 136.090 & 55.730 & 138.510 & $5 \cdot 793$ & 21.9 & $\$ 60.5$ & & $-\infty$ & 4207 & .005 \\
\hline 8503 & .258 & 1.000 & 146.160 & 35.260 & 127.901 & 54.882 & 21.4 & 9701 & & -0 & $507 \cdot 5$ & $.000 \%$ \\
\hline 95.0 & .258 & 1.000 & 1600000 & 520640 & 1610026 & 53.763 & 21.9 & 886.3 & & -.0 & 67401 & .013 \\
\hline 10500 & .238 & 10000 & 185.080 & 490210 & 179.864 & 51.666 & 21.9 & 104201 & & $-\infty$ & 84.2 & 0023 \\
\hline $2 \$ 3.0$ & .258 & 1.000 & 192.190 & 400.350 & 197.958 & 48.509 & 21.9 & 122709 & & -0 & 1003.1 & .029 \\
\hline 13000 & .238 & 1.000 & 190.200 & 060540 & 199.929 & 35.467 & 21.9 & 1295.7 & & $-\infty$ & 1298.0 & 0048 \\
\hline 13500 & -258 & 20000 & 149.500 & 43.770 & $192 \cdot 164$ & 33.516 & 21.9 & 136307 & & -0 & 140308 & .056 \\
\hline
\end{tabular}




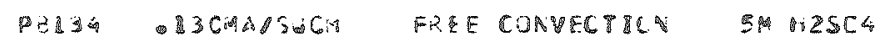

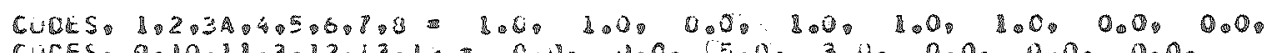

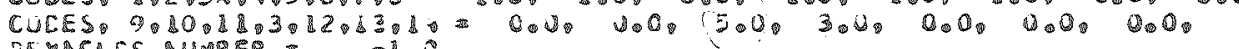

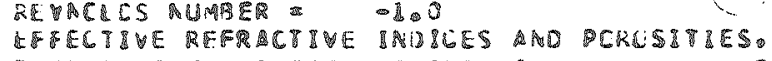

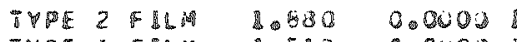

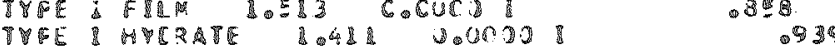

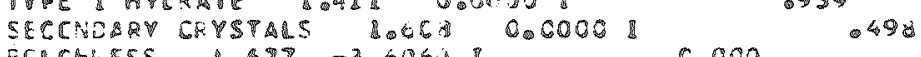

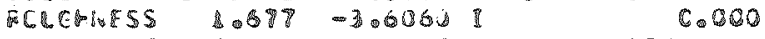

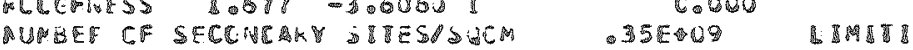

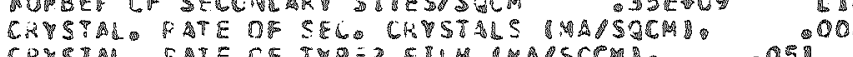

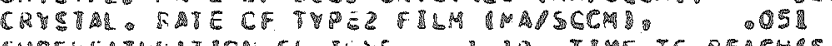

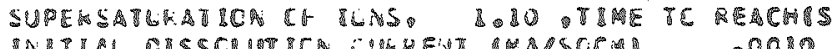

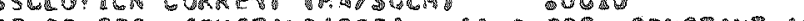

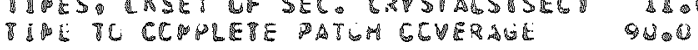

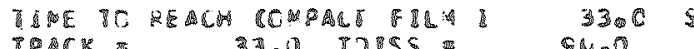

TPRCK 33.0 PDISS

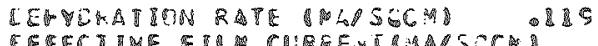

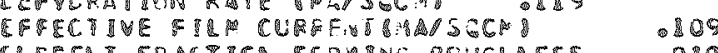

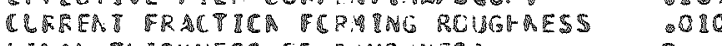

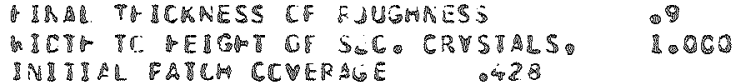

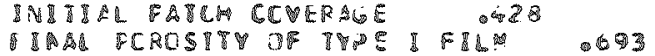

FAE IOATICA IIAGE POD.DO

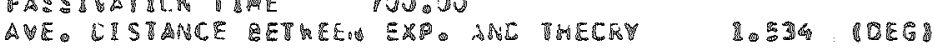

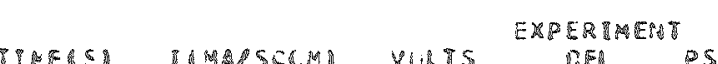

TMEORT

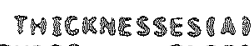

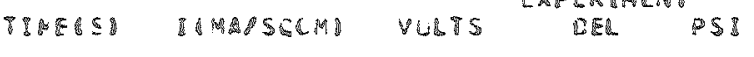

DER

Q 58

TYP

7.

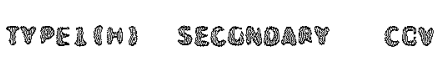

\begin{tabular}{|c|c|c|c|c|}
\hline $\begin{array}{r}C .0 \\
\mathbb{1} .00\end{array}$ & $\begin{array}{r}-830 \\
-130\end{array}$ & $\begin{array}{l}1.000 \\
2.000\end{array}$ & $\begin{array}{l}78.860 \\
76.810\end{array}$ & $\begin{array}{l}33.806 \\
35.840\end{array}$ \\
\hline 26.0 & .830 & 10003 & 77.186 & 39.290 \\
\hline 30.0 & .820 & 2.060 & $? 8_{0} 560$ & 38.530 \\
\hline 4600 & .230 & 10000 & $x C_{0} \rightarrow 00$ & 350800 \\
\hline 5000 & .130 & 3000 & 84.720 & 410350 \\
\hline 66.4 & .830 & $\$ 0000$ & 550080 & 42020 \\
\hline 76.0 & .830 & $\$ .000$ & 940050 & 40320 \\
\hline$E C_{0} 0$ & - 135 & 10000 & 160200 & 450780 \\
\hline 50.0 & 020 & 20000 & 108.50 & 47.250 \\
\hline 100000 & 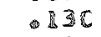 & 20000 & $12008<0$ & 40.510 \\
\hline 1860 & 1830 & 80000 & 4250896 & 99.270 \\
\hline$\triangle 2 C D$ & .830 & 80000 & 134030 & 49.280 \\
\hline 130.0 & .230 & 2.000 & 1430670 & 480460 \\
\hline
\end{tabular}

$78.455 \quad 33.080$

76078 340 36

79. 30 36.760

00.08

30206
\& 325

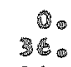

0.0

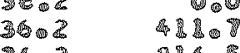

II.

30.2305

$36.2 \quad 187808$

36.2120309

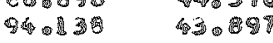

36.2

管露。

\begin{tabular}{|c|c|c|}
\hline 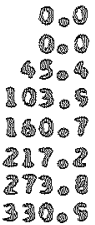 & 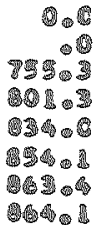 & 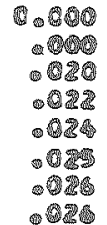 \\
\hline
\end{tabular}




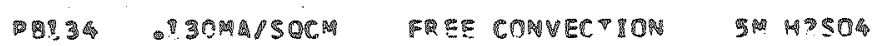

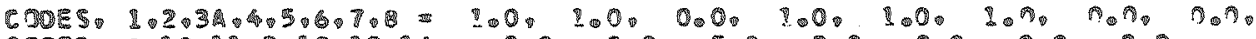

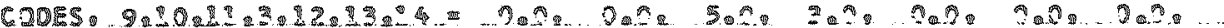

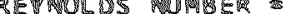

EFHECTIVE RERACTIVE INDICES RNO OROSTIIES.

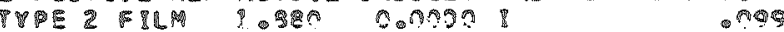

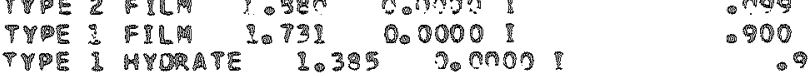

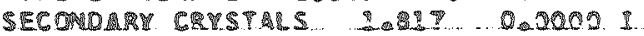

QOUGMARSS $2.677-3.6060$ I

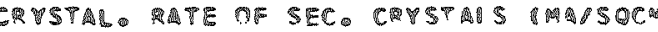

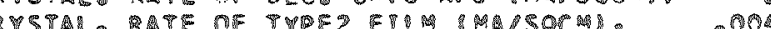

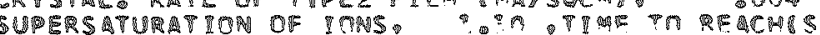

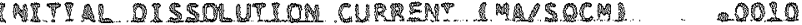

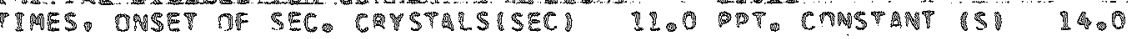

TIMET TO COA ETE RTCM CNUERGE 186.6

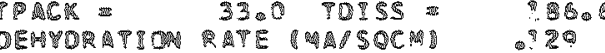

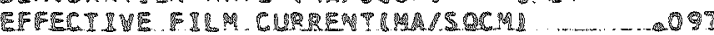

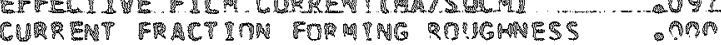

TINAL TWICKNESS DF ROUGHNES

TMTPI

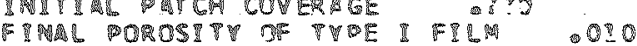

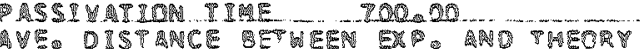




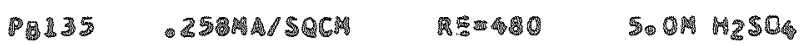

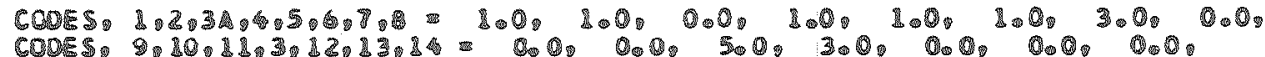

REVMOLOS MUMB

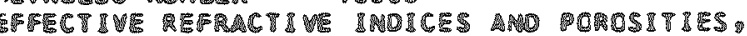

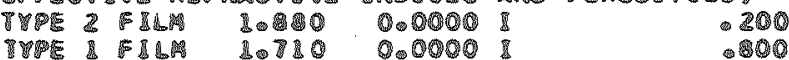

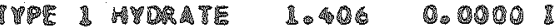

SECONOA CAVSTALS 3.5530 .0000

ROUGHASS $10325-3.3590$ \& -3.000

.900

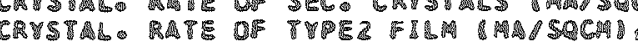

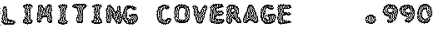

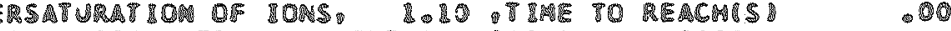

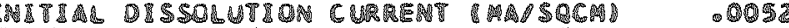

MMES ONSET OF SEG CR OSTMSISECL

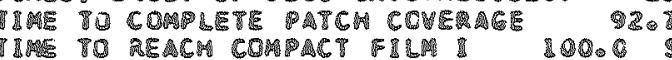

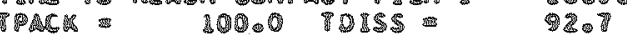

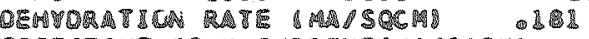

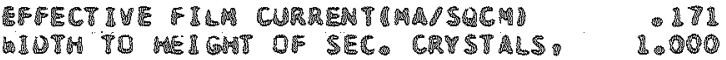

SNDTS PATC CONERAGE

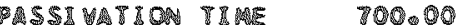

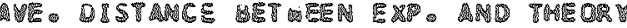

8.769. $10 E B$

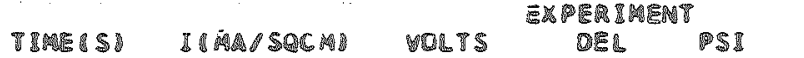

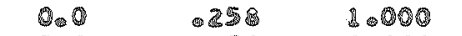

OEd PS

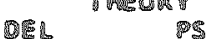

SI TYPE

TPEC

Ses

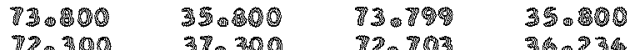

3. 300

82803

7103

$71.973 \quad 38.73$

710200

39.600

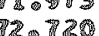

30.100

30000

1000

43000

720.33

25.00000

3000 - 35

$35.0 \quad 255000$

15.0 ....... 15000

270

73071 .

15000

46.100

408

7.290

48090

47.45

10000

230

51.750

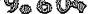

50.570

$55.0 \quad 258 \quad 20000$

60.0258000

65.0 $\quad 258230000$

320

0.

0.0
.0
.0
.0
.0
.0
.0
.0
.0
.0
.0

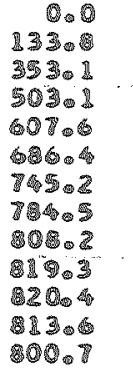

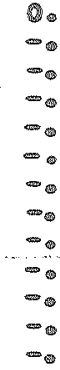

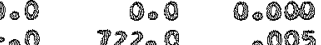

-0 T.

2020025.900

G1.310

530.

75.0 - 3.5800

80. $\quad 258.10000$

$9000-252-1.000$

23532000

820.00195000

1040

82.360

$98.400 \quad 51950$

5 粮 20 


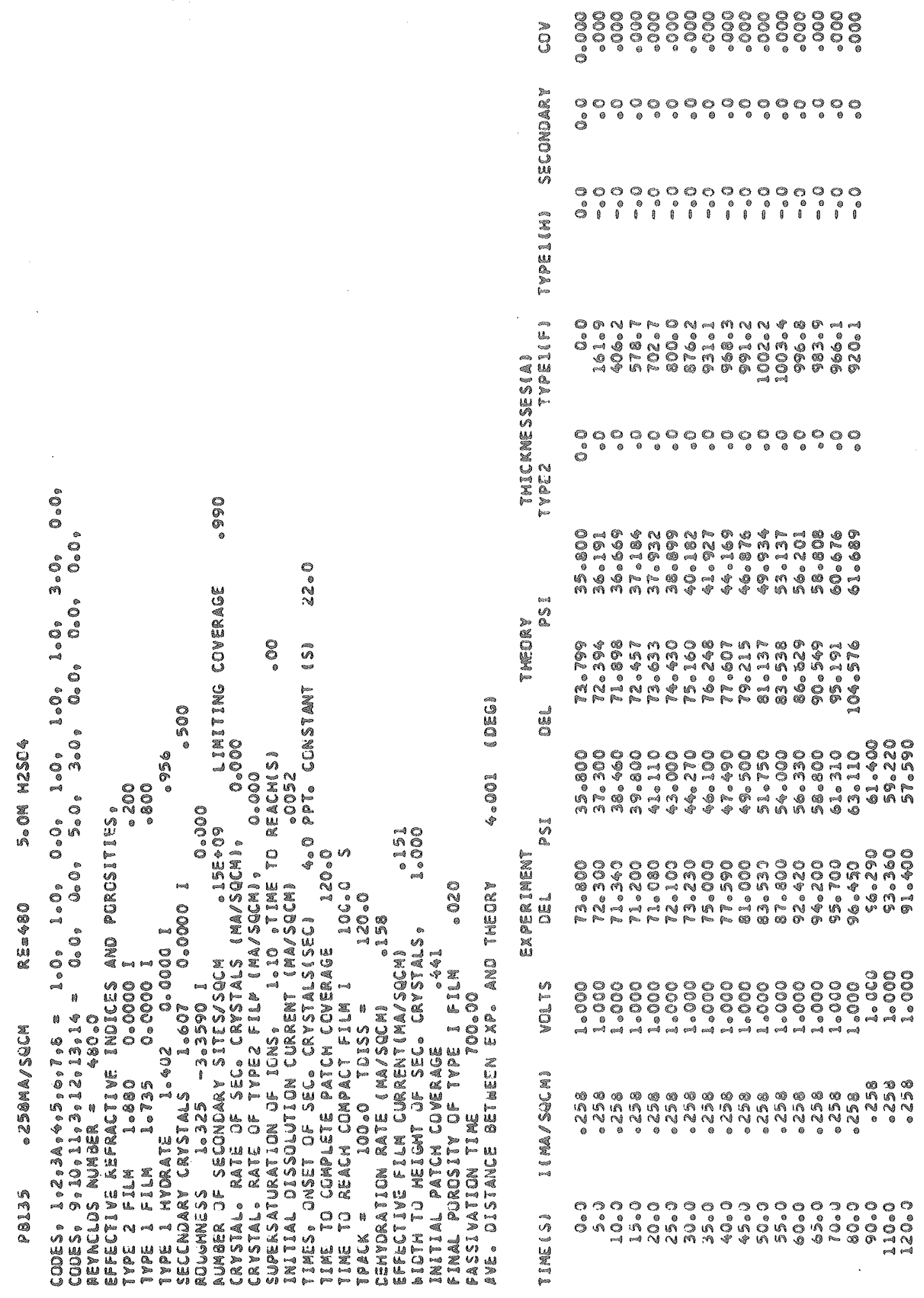




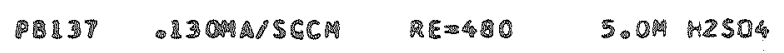

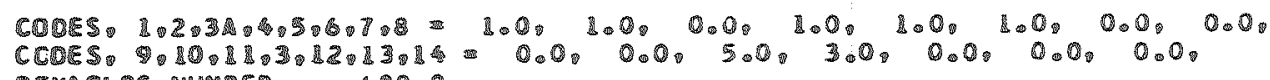

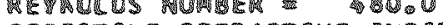

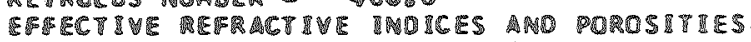

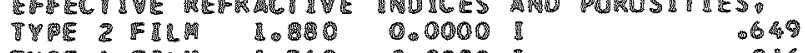

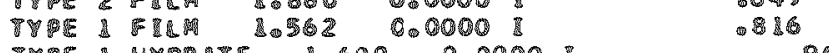

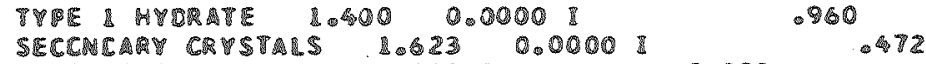

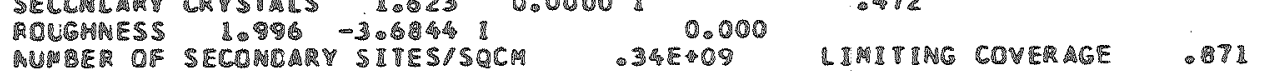

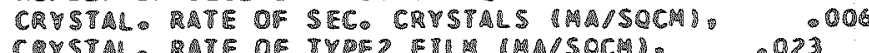

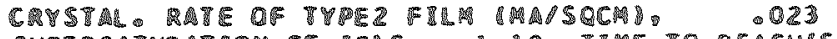

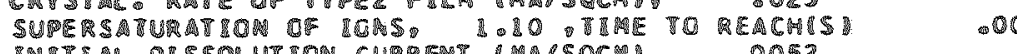

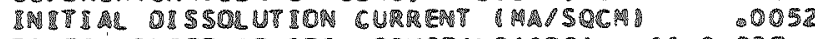

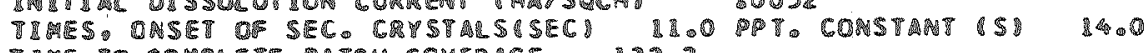

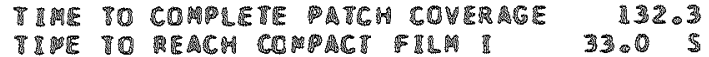

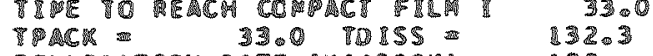

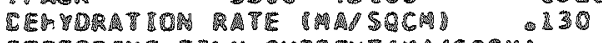

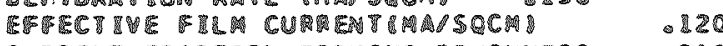

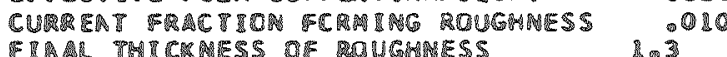

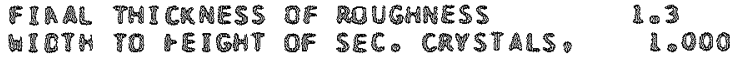

gavinalso

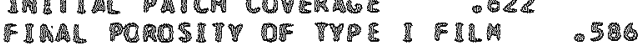

PASEIMATION RBWE 10000

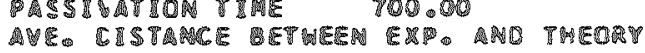

20242086

\begin{tabular}{|c|c|c|c|c|c|c|c|c|c|c|c|}
\hline \multirow[b]{2}{*}{ TII } & \multirow[b]{2}{*}{18025060} & \multicolumn{3}{|c|}{ EXPEDART } & \multicolumn{2}{|c|}{ TMEORY } & \multicolumn{2}{|c|}{ THICKNESSESW } & \multirow[b]{2}{*}{ TYPERAMI } & \multirow[b]{2}{*}{ SECONDARY } & \multirow[b]{2}{*}{$\cos$} \\
\hline & & VOBTS & DES & & DEL & & THPEZ & PYPEA OFI & & & \\
\hline $\begin{array}{r}0.0 \\
10.0 \\
20.0 \\
30.0 \\
30.0 \\
50.0 \\
60.0\end{array}$ & $\begin{array}{l}-130 \\
-130 \\
-130 \\
-130 \\
-130 \\
-130 \\
-130\end{array}$ & $\begin{array}{l}1.000 \\
1.000 \\
1.000 \\
1.000 \\
\$ .000 \\
1.000 \\
1.000\end{array}$ & 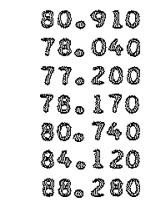 & 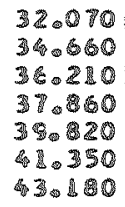 & $\begin{array}{l}90.909 \\
71.574 \\
79.671 \\
78.092 \\
79.002 \\
81.897 \\
87.816\end{array}$ & $\begin{array}{l}32.070 \\
32.925 \\
34.533 \\
36.815 \\
36.569 \\
38.665 \\
42.642\end{array}$ & $\begin{array}{r}0.9 \\
45.9 \\
45.9 \\
45.9 \\
45.9 \\
45.9 \\
45.9\end{array}$ & $\begin{array}{r}0.0 \\
0.0 \\
305.3 \\
600.5 \\
836.0 \\
1022.0 \\
113.8\end{array}$ & $\begin{array}{l}0.0 \\
0.0 \\
.2 \\
.2 \\
.6 \\
.8 \\
0.8\end{array}$ & $\begin{array}{r}0.0 \\
587.0 \\
603.4 \\
626.5 \\
64.8 .2 \\
66.2\end{array}$ & $\begin{array}{l}0.000 \\
.000 \\
.011 \\
.012 \\
.013 \\
.014 \\
.015\end{array}$ \\
\hline $\begin{array}{r}70.0 \\
20.0 \\
90.0 \\
100.0 \\
103.0 \\
100.0\end{array}$ & $\begin{array}{l}130 \\
-130 \\
-130 \\
-130 \\
-130 \\
1330\end{array}$ & $\begin{array}{l}1.000 \\
1.000 \\
1.000 \\
1.000 \\
1.000 \\
1.000\end{array}$ & $\begin{array}{l}97.630 \\
104.550 \\
116.40 \\
127.370 \\
130.340 \\
\$ 33.920\end{array}$ & $\begin{array}{l}4.50 \\
47.270 \\
49.40 \\
45.730 \\
50.130 \\
50.010\end{array}$ & $\begin{array}{r}95.44 \\
206.403 \\
120.112 \\
128.79 \\
130.041 \\
138.931\end{array}$ & $\begin{array}{l}45.138 \\
48.129 \\
49.521 \\
49.186 \\
46.859 \\
4.692\end{array}$ & $\begin{array}{l}45.9 \\
45.9 \\
45.9 \\
45.5 \\
45.9 \\
45.9\end{array}$ & $\begin{array}{l}1268.2 \\
1338.4 \\
1300.6 \\
1399.7 \\
1402.0 \\
1402.3\end{array}$ & $\begin{array}{l}1.3 \\
200 \\
1.8 \\
1.9 \\
2.0 \\
2.0\end{array}$ & $\begin{array}{l}683.7 \\
697.8 \\
709.6 \\
719.2 \\
721.7 \\
724.0\end{array}$ & $\begin{array}{l}.016 \\
.017 \\
.018 \\
.018 \\
.028 \\
.028\end{array}$ \\
\hline
\end{tabular}




\section{PHASA DOZZMASQCM FREE CCAVECTICN EOOM KLSUA}

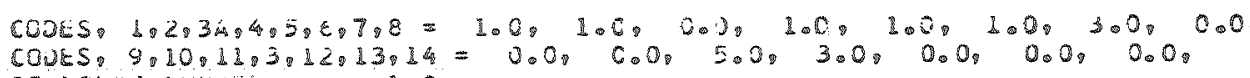

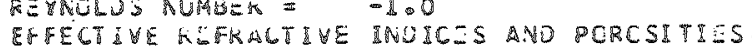

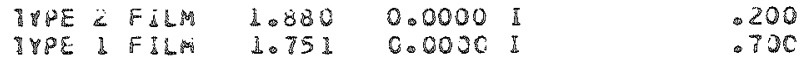

TYFE 1 MYERATE D.368 0.0000 I

SECCNULAY GRYSTALS \$O3\$5 D.0000 I OLII

RCUGHAES AOGL7 -306486 I 0.000

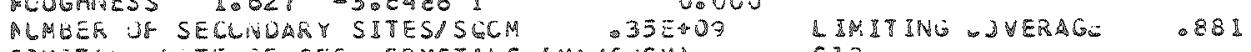

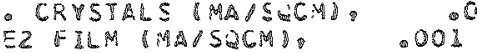

SUPERSATUKATION DF IENS, IOLO TIME TO REACMSS

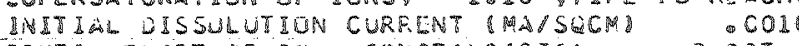

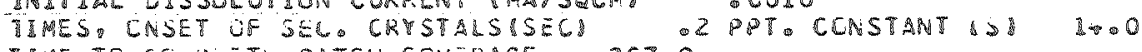

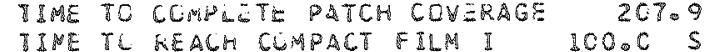

TPACK $=10000$ TOISS $=207.9$

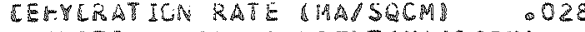

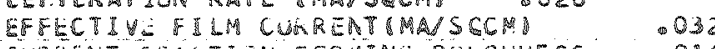

CURACLT FRACTIUN FORAING RULGWINESS OOI

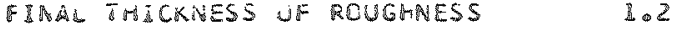

WOTH TU HEI WHT OF SECO GRYSTALS. $\$ .000$

IMITILL PATCM COVERAGE

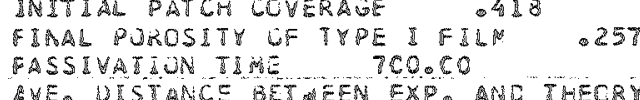

$2.589 .6 E(6)$

LYE. UISTARCE BET EEEN EXP. ANG THECRY

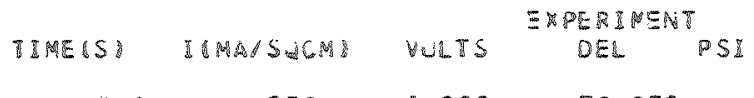

DES THECRY TSI THICKNESSESHA

\begin{tabular}{|c|c|c|}
\hline$\theta 08$. & .052 & 20000 \\
\hline 1000 & .052 & 1.000 \\
\hline 2000 & .052 & 10000 \\
\hline 30.0 & .052 & 10000 \\
\hline 50.0 & .052 & 1.000 \\
\hline 30.2 & .652 & 20.000 \\
\hline 100.0 & .052 & 1.0000 \\
\hline 340.0 & .052 & 2.000 \\
\hline 18000 & .032 & 10000 \\
\hline 21000 & .052 & 1.000 \\
\hline 246.0 & .052 & 10000 \\
\hline 270.0 & .052 & 2.000 \\
\hline 29000 & .052 & 10000 \\
\hline 30000 & .0052 & 3.000 \\
\hline 320.0 & .052 & 30000 \\
\hline 34000 & & 10000 \\
\hline
\end{tabular}

78.850
74.990
73.300

73.060

72.500

13.330

75.510

8400

89.680

94.270

98.670

107.0830

217.600

1220580

$\begin{array}{lll}1.000 & 137.220 & 38.070 \\ 1.000 & 151.470 & 34.810\end{array}$

34.270
36.640
37.660
38.370
39.400
40.740
430470
42.890
42.990
42.980
42.450
42.050
40.960
40.230
38.090
34.810

THPELFI THPEAMA SECONDAMY

cov

\subsection{9}

70.328

340270
$\$ 2.221$

$\$ 2.221$
$\$ 5.543$

750.94

35.792
36.579

28.809

$760622+0.965$

83.250 \$ 4134

$89.553 \quad 43.544$

3.54
2.222

0.0
$\vdots$
$\vdots$
$\vdots$
$\vdots$
$\vdots$
$\vdots$

202
7.2
72.0
3,70

$\begin{array}{rrr}0.0 & 0.0 & 0.000 \\ -0 & 736.0 & 0.019\end{array}$

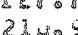

28005

2980

$2930=$

$\angle 5405$

$<4$ in

$42.980 \quad 27503$

$-00787$.

.015
.022
.025

$\begin{array}{rr}-0.03502 & 024 \\ -0.018 .8 & .029\end{array}$

- . 1017.6 .03E

$-0.07101 \quad 0040$

$\begin{array}{lll}-.0 & \$ 138.7 & 0045 \\ -.0 & 1372.6 & 048\end{array}$

$-0 \quad 1387.3 \quad 0049$

$10 \log 1$

34.816 
PB138 . CE2MA/SGCM FREE CONVECTICN 5.0M H2SC4

COCES, $1.2,3 A, 4,5.6,7,8=1.0,1.0$, C.0, $1.0,1.0,1.0,3.0,0.0$, CCICES, S, $10,11,3,12,13,14=0.0,1.0,5.003 .0,0.0,0.0,2.0$, EFFECTIVE REFRACTIVE INCICES AND PURCSITIES,

INDICES AND PORCSITIES,

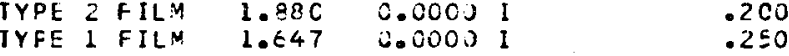

TYFF I HYLRATE 1.400000000 I

SECCNEAFY CRYSTALS 1.7710 .00001000

RCLETAESS $1.627-3.05485$ I $\quad 0.000$

AURBER CF SECCNCARY IITES/SCLM .94E+09 LIMITIN

CRYSTAL. PATE LF TYPEZ FILM (NA/SGCM), .OLE

SLPERSATURATICA CF ILAS, 1.10 ,TIME TC REACH(S) .C2 INITIAL CISSGLUTICN UUREENT (MA/SGCM)

TINES, CNSET OF SFC. CEYSTALSISEC) 22 PPT. CONSTANT (S)

TIME IC CCMPLETE PATCH CCVERAGE 432.5

TIHE TC REACH CCNPACT FILA I 210.0

TPACK $=\quad 21 \mathrm{J.C}$ TJISS $=432.5$

DEFYLFATION RATE (NA/SGCW) 02

EFFECTIVE FILN CURREUTI(1A/S6CM)

CLRREAT FRACTICA FCR.AING RCUGHNESS,

$\begin{array}{lll}\text { FIAAL THICKAESS C.F RULGHNESS } & 1.7 \\ \text { WICTH TO HEIGHT OF SEC. CRYSTALS, } & 1.000\end{array}$

IAITIAL FAICH COVEFAGE

FIAAL FCRCSITY OF TYPE I FILM .524

NCLE FRACTICA METAL IA PATCHES .680

PASSIVATICA TINE SCO.JO

AVE. CISTANCE EETHEE. EXP. AINC THECRY

$3.320(D E G)$

TINE(S) IIVA/SGCM) VCLTS EXLL DS

THICKNESSES(A)

TYPE2

TYPELIFI TYPELEHI SECQNDARY COY

$\begin{array}{rcr}0.0 & .052 & 1.000 \\ 30.0 & .052 & 1.000 \\ 240.0 & .052 & 1.001 \\ 270.0 & .052 & 1.000 \\ 250.0 & .052 & 1.003 \\ 300.0 & .052 & 1.000 \\ 320.0 & .052 & 1.000 \\ 340.0 & .052 & 1.000\end{array}$

$\begin{array}{rrr}78.850 & 34.27 C & 78.850 \\ 72.540 & 38.370 & 78.615 \\ 98.670 & 42.450 & 95.591 \\ 107.830 & 42.050 & 109.500 \\ 117.60 C & 4 C .960 & 115.810 \\ 122.580 & 40.230 & 125.512 \\ 137.120 & 38.070 & 136.474 \\ 151.470 & 34.810 & 147.479\end{array}$

\begin{tabular}{l|l}
$34 .-270$ & 0 \\
38.653 & \\
41.152 & \\
40.703 & \\
39.945 & $\vdots$ \\
39.419 & \\
38.353 & \\
37.285 &
\end{tabular}

0.0
$7 \cdot 3$
$332 \cdot 1$

402.3

461.2

461.2

534.8

0.0
-.0
$=.0$
$=.0$
-.0
$=.0$
$=0$
-.0

0.0
676.8

039.043

102.5

$1142.0 \quad .123$

196.2 ... 127

1228.5 .142 
P314S JPEN CIRCUIT FKEE CONVECTION SM ACIO

SOEES, $1,2,31,4,5,6,7,3=1.0,1.0,0.0,1.0,1.0,1.0,3.0,0.0$,

EUDES, $9,10,1103,12,13_{0} 14=0.0,0.0,5.0,3.6,0.0,0.0,0.0$,

REYHOODS NUMBER = -

EFFETIVE F.EFRICTIVE INOICES TNE FOROEITIES,

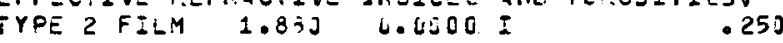

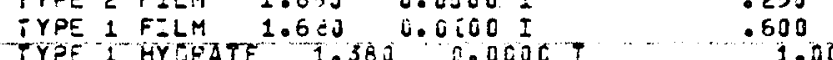

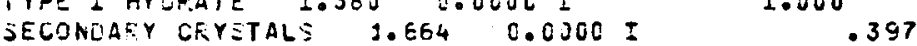

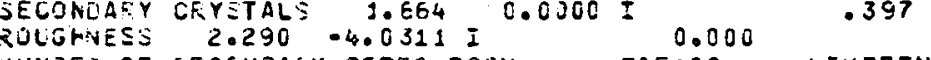

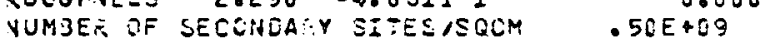

CRYSTAL. RATE OF SECO CEYSTALS (MASSOZM), .0.026

SUPEFSATLAATCN OF IONS, 1.10 TIME YS TEAGM(S)

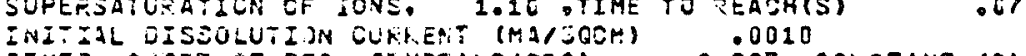

D DPT. CCNSTANT (S) 10.0

TIME TO ODMPLETE PATCR CCVERAGE 100.0000

IPACK $=\quad 120.0$ TOISS $=$ 60.0

JERYOPATION RATE

EFFECI TVE FILM CUAREN (MA/SOCM) .02\%

WDTH TU HEILHT CUFEEL. EYSTALS, 1.060

FINIL POROSIOY CF TYFE I FILM .400

OASS IVATEDNTEME 7 OL. DO

\section{.400}

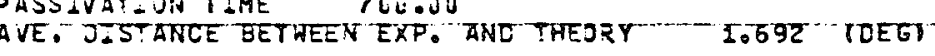

TIME S) I(MA/SQLY) VOLTS EXPERIMENT DEL DS DEL THEORY PSI THICKHESSESIA

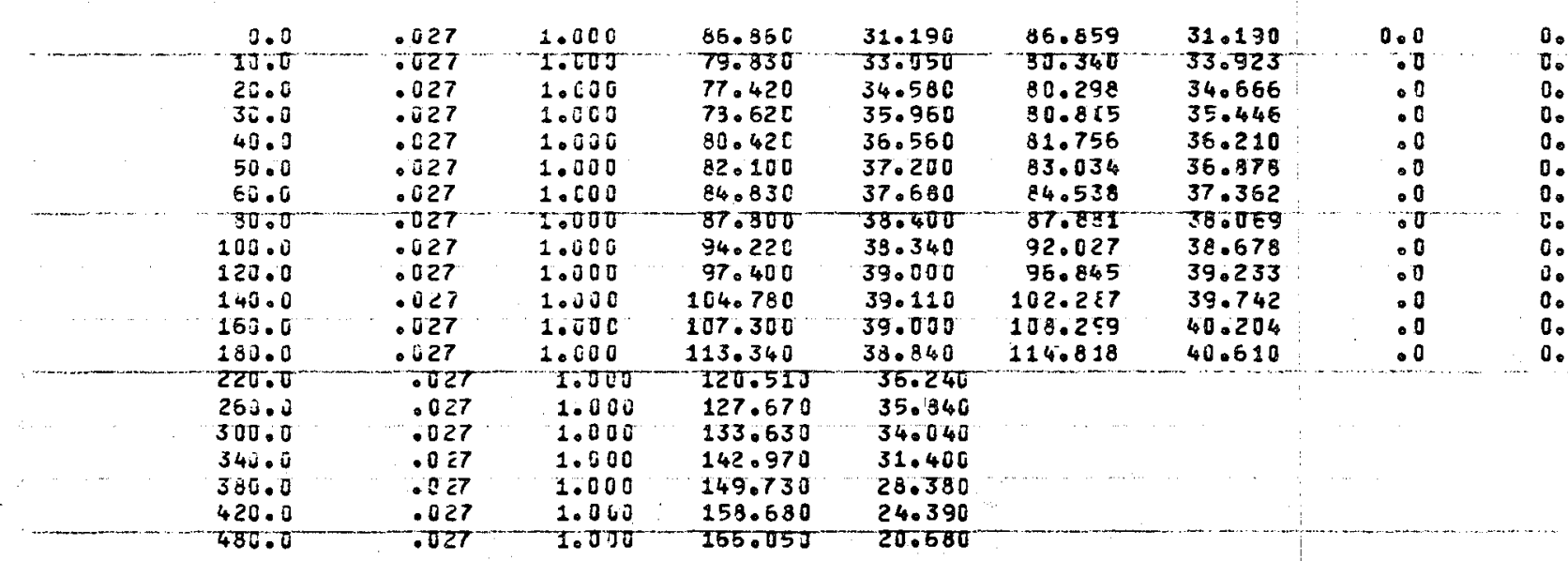

$1(F)$ TYOEI(H) SECCNCARY COV 
PBLAJ CPEN CIPCUII FREE CORHECTION EM ACIO

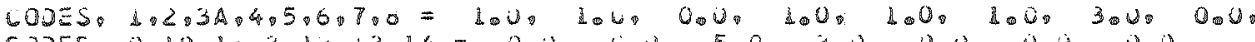

$\begin{array}{llll} & \end{array}$

CFFECTIVE REFRACTIVE INUTCES AMU PCRESITTES

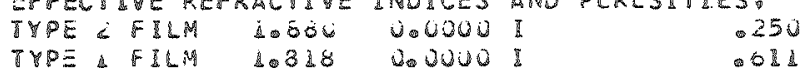

TYPE A HYJKATE S0.385 0.0000 I

SECENUARY CRYSTALS LO579 0.0000 10.952

ROUGMVEDS $20016-2081821$

CRPSTAL KATE UF SEC. CRYSTALS MAISGLUD. .019

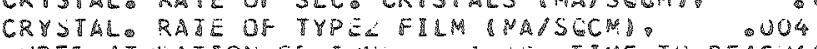

SUPERDATUKATION OF IUNDO DOLU TIME TU REACHBSI OIS

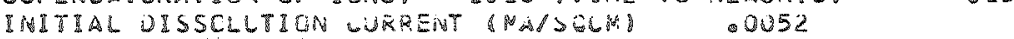

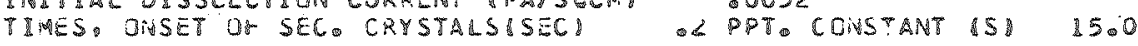

TARE TO COAPAETE HATCH COVERAGE 60.O

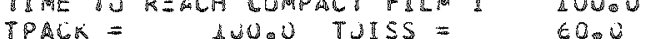

UEHYORATION RATE IMASSUCMI DOST

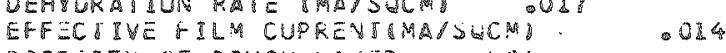

PUROSITY OF ROUGH LAYER OJUL

WURREN FRALTICN FORMIAG RIUGHAESS 2400

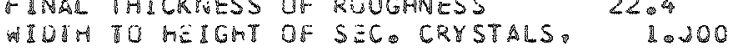

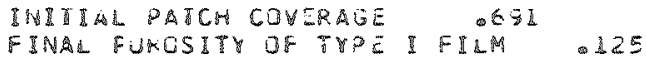

FINAL FUKCSITY OF TYPE I FILM

AVË UIDIANCE BET REEV EXP. ARJ THECRY

60108 10EG

\begin{tabular}{|c|c|c|c|c|c|c|c|c|c|c|c|}
\hline \multirow{2}{*}{ TIMEC $D$ S } & \multirow[b]{2}{*}{ I $190 / \sec 4$} & \multicolumn{3}{|c|}{ EXPERTAEN } & \multicolumn{2}{|c|}{ THEURY } & \multicolumn{2}{|c|}{ THIGKAESSESAAO } & \multirow[b]{2}{*}{ TYPENOHI } & \multirow[b]{2}{*}{ SECONDARY } & \multirow[b]{2}{*}{$\operatorname{cov}$} \\
\hline & & YOLTS & WEL & $P \gg \mathbb{I}$ & $\nu \subseteq L$ & $P \$ \mathbb{I}$ & TYPEL & TYPE $18 F$ & & & \\
\hline 1200 & 0.049 & bojou & 86.860 & $31 \cdot 190$ & 85.372 & $31 \cdot 355$ & 0,0 & 0.0 & 0.0 & 0.0 & 0.000 \\
\hline 22000 & 0.649 & 1.000 & 1200520 & 20040 & $1<309<3$ & 35.720 & 00 & 0.0 & -.0 & $2277_{\oplus} 9$ & .012 \\
\hline 260.0 & .019 & 20000 & $12 \pi \cdot 67 \mathrm{C}$ & 350840 & 120.908 & 350490 & - 0 & $70_{0}^{4}$ & $-\infty$ & 2390.7 & .079 \\
\hline 30600 & 014 & 20000 & 133.630 & 34040 & 130.952 & 35.011 & .0 & 13.0 & -0 & $2503-8$ & .086 \\
\hline Denow & 0409 & Lovios & $44<0570$ & 31.400 & 144.890 & 34.295 & .0 & 16.7 & -00 & $2617 \cdot \mathbb{1}$ & .054 \\
\hline 530.0 & 0043 & 10000 & 149.736 & 28.380 & 1540946 & 33.356 & 0 & $\Delta a_{\infty} 3$ & $-\infty 0$ & 2730.6 & 103 \\
\hline 42000 & $\cos 8$ & 20000 & 258.680 & $24 \cdot 390$ & 455.624 & 32,461 & 0 & 1804 & $-\infty$ & $284 \mathbb{1}$ & - $1 \mathbb{2}$ \\
\hline किष्य & 0019 & 20000 & $\mathbb{L} \in E_{0} 056$ & 26.680 & 4590257 & 30.553 & .0 & 18.6 & -0 & 2992.2 & 0123 \\
\hline
\end{tabular}




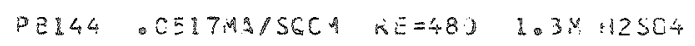

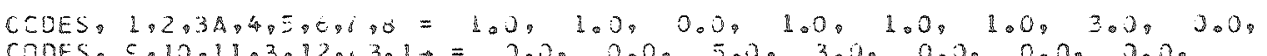
YCLOS AUMBSER =

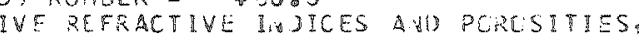

TYPE Z FILN $1.890 \quad 0.3200$ I

YPE 1 FILA 10422 j.0000 I

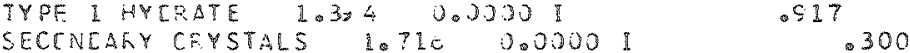

KEUGHRESS $1.002-0.4333$ I D.00000

CFYSTA UT

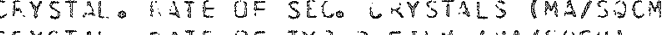

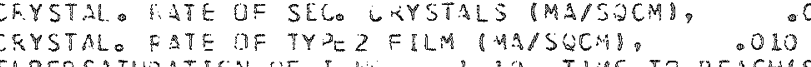

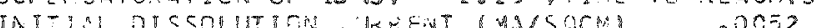

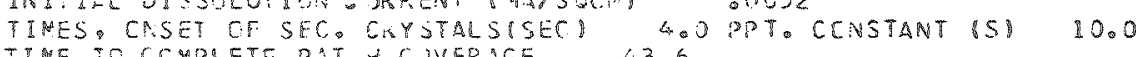

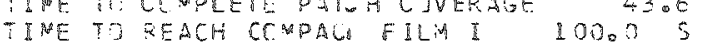

TPACK $=100.3$ TUISS $=$

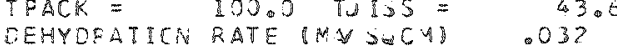

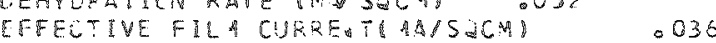

WOTH TU HEIGKT OSF SECOCRYSTALSO 10360

WIOTH TU FEIGWT GF SE CO CRYSTALS

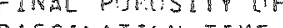

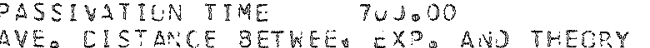

1. $358 \quad 006$

\begin{tabular}{|c|c|c|c|c|c|c|c|c|c|c|c|}
\hline \multirow[b]{2}{*}{ TIMEIS! } & \multirow[b]{2}{*}{$\because 4 A / 5 g C *$} & \multicolumn{3}{|c|}{ EXPERIMERT } & \multicolumn{2}{|c|}{ THEOAY } & \multicolumn{2}{|c|}{ THICKNESSESTAI } & \multirow[b]{2}{*}{ TYPEAYH } & \multirow[b]{2}{*}{ SECONDARY } & \multirow[b]{2}{*}{ COV } \\
\hline & & VILTS & DEL & & DER & 51 & TYPEZ & TYPELUF? & & & \\
\hline 0.0 & .052 & $\mathbb{1} .000$ & 72.390 & 37.740 & 71.389 & 37.740 & 0.0 & 0.0 & 0.0 & 0.0 & 0.000 \\
\hline 1000 & .052 & 1.300 & 70.780 & 38.510 & 72.089 & 38.748 & .0 & 0.0 & -.0 & 889.9 & .070 \\
\hline 20.0 & .052 & 1.003 & 72.550 & 35.740 & 73.083 & 40.24 .4 & .0 & $\$ 4.0$ & -.0 & $920 \cdot 4$ & .075 \\
\hline $2=00$ & .032 & 1.000 & 750500 & $\therefore 0.400$ & 75.064 & 410100 & .0 & 3109 & $-\infty 0$ & 889.6 & .070 \\
\hline 3620 & .052 & 10000 & $78_{0} 050$ & 41.040 & $78.23 ?$ & $\Leftrightarrow 1.644$ & .0 & 59.7 & -.0 & $851 \cdot 1$ & .064 \\
\hline 350.0 & .052 & 1.030 & $8,2.500$ & 41.200 & 82.198 & 42.536 & .0 & 70.7 & $-\infty 0$ & 8110 & .058 \\
\hline 40.0 & .052 & 8.000 & $\$ 5.820$ & 41.300 & 86.216 & 40.602 & .0 & 39.3 & -0 & 77405 & .053 \\
\hline 4000 & .052 & 1.000 & 87.800 & 41.380 & 88.586 & 350.651 & .0 & 118.5 & -.0 & 756.7 & .050 \\
\hline 30.0 & .052 & 1.000 & 99.620 & 41.450 & 89.727 & 39.833 & .0 & 139.5 & -.0 & 778.9 & .053 \\
\hline$\leq C_{0} 0$ & .052 & 1.000 & 83.820 & $\therefore 0.340$ & 920657 & 40.108 & .0 & 180.3 & $-\infty$ & 822.0 & .060 \\
\hline 70.0 & .032 & 1.003 & 92.820 & 35.080 & $\$ 4.228$ & 40.374 & .2 & 218.5 & -0 & 865.2 & .066 \\
\hline 80.3 & .052 & 1.000 & 92.830 & 38.260 & & & & & & & \\
\hline 120.0 & .052 & 1.000 & 950620 & 37.010 & & & & & & & \\
\hline 120.0 & .052 & 1.030 & 100.610 & 35.550 & & & & & & & \\
\hline 140.0 & $.0 \equiv 2$ & 2.000 & 106.790 & 34.150 & & & & & & & \\
\hline 150,0 & .052 & 1.000 & 112.770 & 31.970 & & & & & & & \\
\hline 160.0 & .052 & 1.000 & $1170=60$ & 27.400 & & & & & & & \\
\hline
\end{tabular}




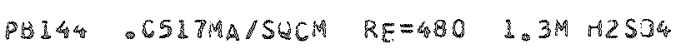

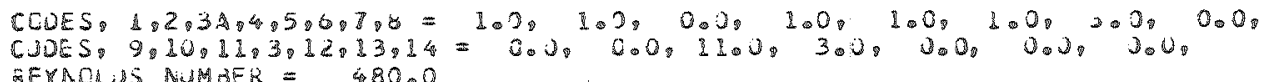

EFFECIIUE REFRACTIVE INOICES AND PCRCSITIES.

TPPE 2 FILM $30490-2.0733$ I

ACA-STOICHICMETNY N $3.479^{\circ}-1.071$ I

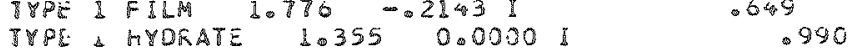

SECENDARY CRYSTALS I.704 - $02147 \mathbb{1} \quad 0.800$

MUCCNDARY CRYSTALS -106145 I

CRYSTAL RATE DF SEC CRYSTALS MATSGOMO

CRYSTAL CATE OF TYPEZ FII I I S SACMB. 005

SUPEXSATURATION OF ICNS IO 13 OTIE TO REACHIS

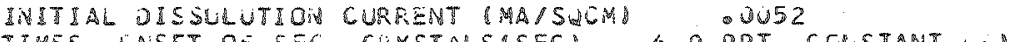

PPTO CCRSTANT I DI LOOO

TIME TO KEACH COMPACT FILTA I 80.05

TAME TU CCMPLETE PATCH CCVERALE 251.7

TPACK $=$ 80.0 TOISS $=231.7$

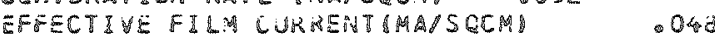

FORUSITY OF RUUGH LAYER 498

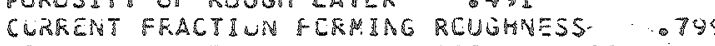

FINAL TAICKNESS GF RQUGNAESS 122.9

WIUTH TO MEI GNT UF SECO CRYSTALS 10000

IRITIAL CUVERAGE OF PATCMES

FINAL POROSITY GF TYPE IFIM 800

WCLE FRACTIUP WETAL IN PATCRES

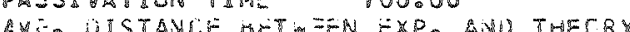

4. 764 (OEG)

\begin{tabular}{|c|c|c|c|c|c|c|c|c|c|c|c|}
\hline \multirow[b]{2}{*}{ TIUE:SD } & \multirow[b]{2}{*}{ I6:4a/SW6.11 } & \multicolumn{3}{|c|}{ EXPERTMENT } & \multicolumn{2}{|c|}{$T H=C B \%$} & \multicolumn{2}{|c|}{ THICKNESDESIAJ } & \multirow[b]{2}{*}{ TYPEDAH } & \multirow[b]{2}{*}{ SECONDARY } & \multirow[b]{2}{*}{$\cos$} \\
\hline & & VOLTS & $D E L$ & & $\partial E L$ & & TYPLZ & TPPED FI & & & \\
\hline 0.0 & .052 & 10000 & 71.390 & 37.740 & $\mathbb{Z} D \rightarrow a \mathbb{Z}$ & 27.740 & .0 & $\psi_{0} 2$ & 0.0 & -0 & .000 \\
\hline 40.0 & .052 & 1.000 & 85.820 & 410300 & $80 .>0$ & 28.460 & .0 & 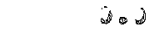 & -.0 & 1784.9 & .134 \\
\hline 70.0 & .002 & 1.000 & -92.823 & $39.080:$ & 90.008 & 57.817 & $=0$ & $\omega_{0}$ & $-0.513 y t h$ & 2861.9 & .197 \\
\hline buou & .052 & 10000 & 92.830 & 38.260 & 840032 & $370 \operatorname{sog} 78$ & .0 & D.2 & -00 & 2262.2 & .215 \\
\hline 11000 & .052 & 1.000 & 90.020 & 37.010 & 1030009 & 26.108 & .0 & Uo 3 & -.0 & 251900 & 02007 \\
\hline 120.0 & .052 & 1.000 & 1000010 & 35.950 & 105.413 & 35.540 & .0 & Dos & -.013101 & 259407 & .283 \\
\hline$\$ 40.0$ & .002 & 20000 & 106.790 & 3400 & $1090 \Delta 01$ & 24.307 & 0 & 203 & -0 & 2733.0 & .324 \\
\hline 150.0 & .052 & 10000 & 112.780 & 31.970 & 1100016 & 230051 & .0 & 0.2 & -0.0 & $2787 \cdot 2$ & .329 \\
\hline 100000 & .632 & 1.000 & 1170500 & 27.400 & 1110200 & 32.985 & .0 & 3.2 & -00 & 285806 & - 34 \\
\hline
\end{tabular}



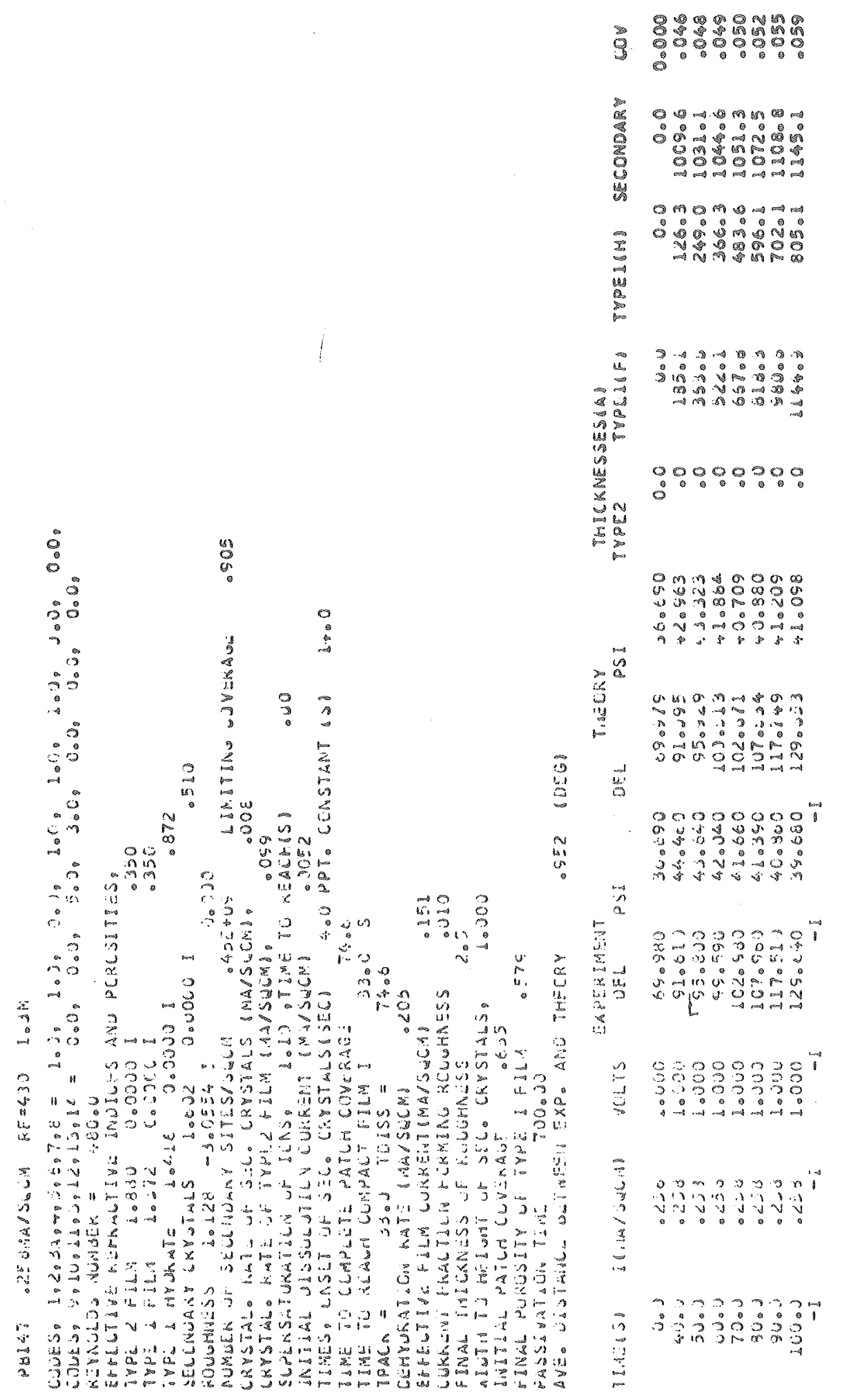


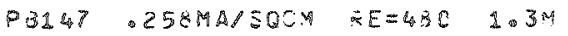

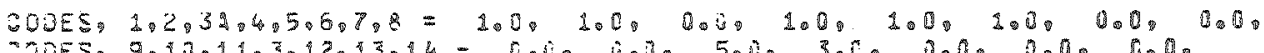

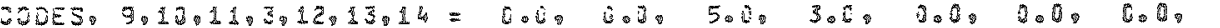
REYNOAS NUMBER $=4 E E_{0}$ \&

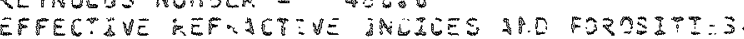

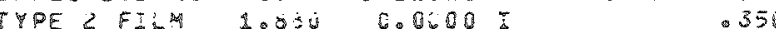

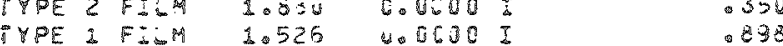

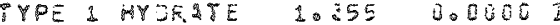

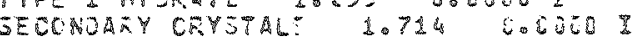

.936

TUUG 0.0000

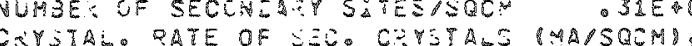

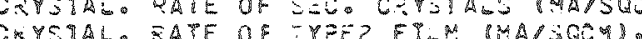

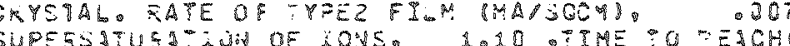

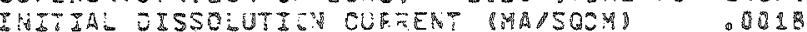

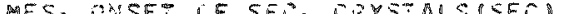

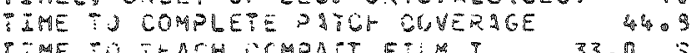

PIAE TO TEACH CCMDACT FLLM I 33.0

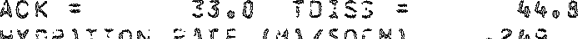

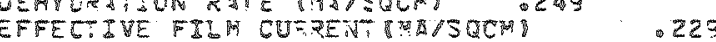

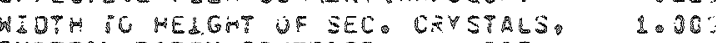

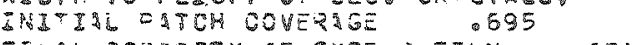

FEUAL POROSITY SF TYPE I FILM

.534

SVE. OTSTARE GETWEET EXF。 AHO IHEORY

.850 TOEG

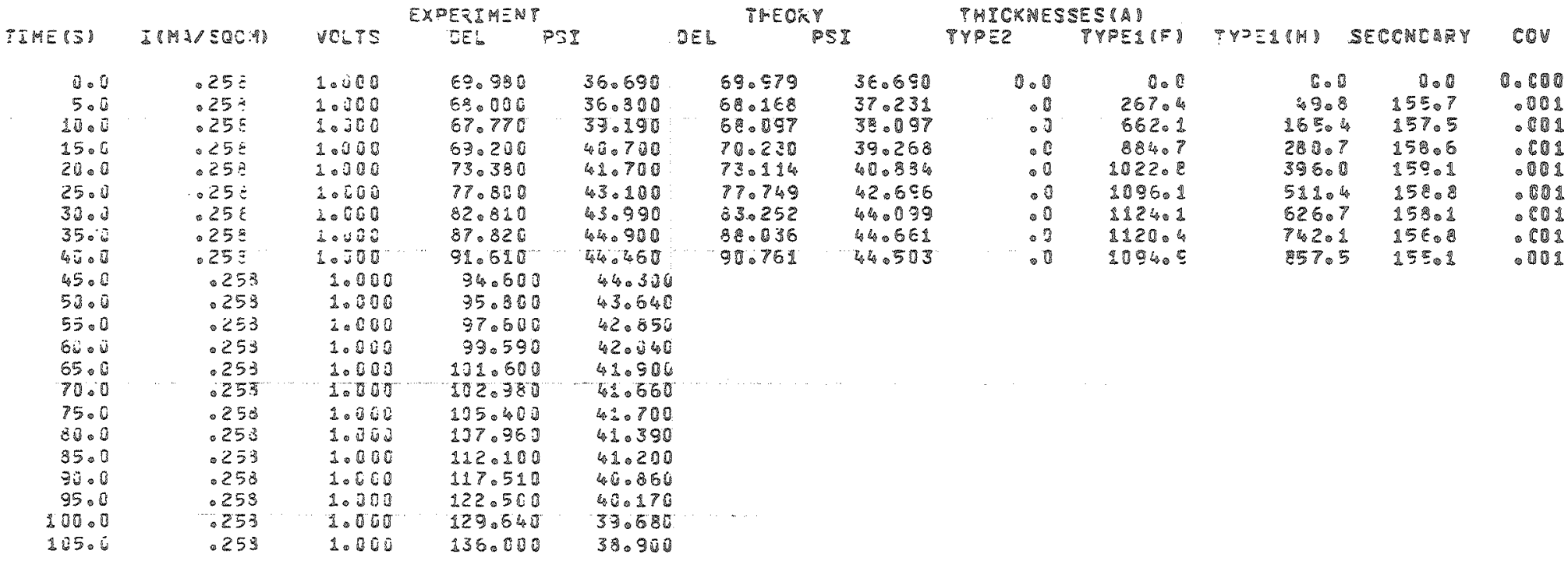




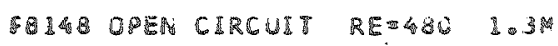

CCOES, 102.38 .

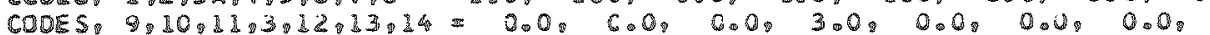

TERNOLOS NUMBER $=480$.

EFFECIIYE RERRACTIVE IRDRCES AND PSRCSITIES

TYPE 2 FILM $\$ 0.86$ C.6000 I

JYPE I 0.0000 T

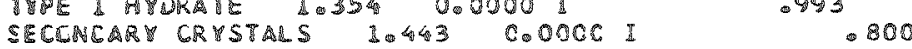

TOLGHAESSS 0.000

RUMBER OF SECONOARY SITESISGCM OUTE HOO

CRUSTAL RATE DF SEC CRYSTALS IMAISQCHA.

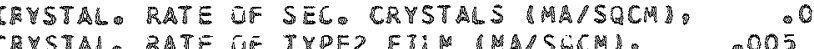

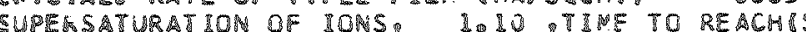

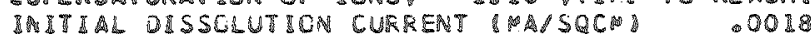

2 PPT CCNSTANT ISI 10.0

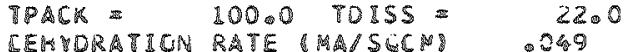

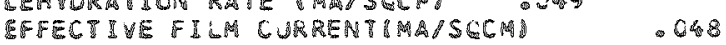

WICTH TO MELWHT OF SEC. CRVSTALS. \$.000

FIMSIYATICAY TIME 700.00

LUE. CTSTANE BETWEEN EXP ANO THECRY 20228 1OEGB

\begin{tabular}{|c|c|c|c|c|}
\hline \multirow[b]{2}{*}{ TIME $15 \%$} & \multirow[b]{2}{*}{ 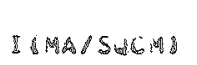 } & \multicolumn{3}{|c|}{ EXPEFIMENT } \\
\hline & & WOLTS & UEL & \\
\hline 0.0 & .050 & 1.200 & 02.030 & 34.150 \\
\hline 5.0 & .050 & 1.000 & 81.000 & 340700 \\
\hline 10.0 & .050 & 10000 & 80.220 & 350050 \\
\hline 25.0 & .050 & 1.000 & 81.100 & 35.300 \\
\hline 20.0 & .050 & 2.000 & 82.032 & 35.590 \\
\hline 3000 & .050 & 10000 & 80.200 & 36.200 \\
\hline 40.00 & .650 & 1.060 & 26.830 & 36.570 \\
\hline 50.0 & .050 & 10000 & 92.000 & 360300 \\
\hline 60.0 & .050 & $\$ .000$ & 55.620 & 35.900 \\
\hline 70.0 & .050 & 10000 & 540000 & 35000 \\
\hline 80.0 & .050 & 20666 & 540030 & 34.25 \\
\hline 10000 & .050 & 1.0000 & 92.320 & 33.80 \\
\hline 240.0 & .050 & $8: 000$ & 92.830 & 33.25 \\
\hline 20000 & .050 & 1.000 & 55.430 & 32.58 \\
\hline 250.0 & $.0>0$ & 1,000 & 58.830 & 29.84 \\
\hline 27000 & .0350 & 10600 & 1020430 & 25.8 \\
\hline
\end{tabular}

THEORY THICKNESSESTAO

$\begin{array}{lllllll}81.029 & 34.150 & 0.0 & 6.6 & 0.0 & 0.6 & 0.000\end{array}$

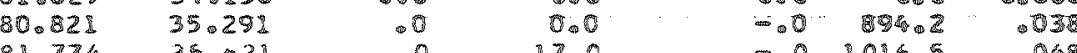

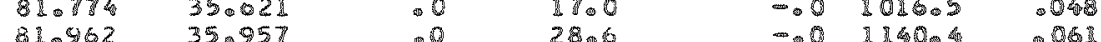

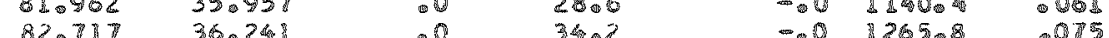

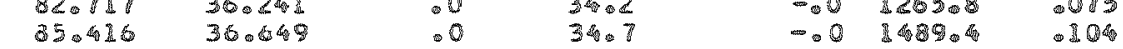

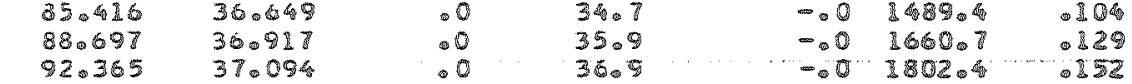

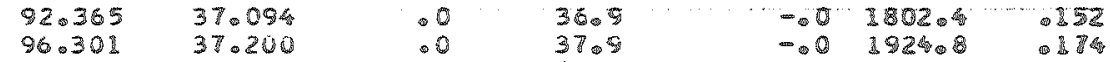




\section{References}

1. Bode, Lead Acid Batteries (Wiley-Interscience 1977), Ch. 2, 4.

2. J. Burbank, A. C. Simon, and E. Willihuganz in "Advances in Electrochemistry and Electrochemical Engineering," Vo. 8 (Wiley 1971), P. Delahay and C. W. Tobias, Eds., p. 157.

3. E, Y.Weissmann in "Batteries," Vo1. 2 (Marcel Dekker, 1977), K。V. Kordesch, Ed., pp 1-181.

4. G. Archdale and J. A. Harrison, Electroan. Chem. and Interfacial Electrochem., 34, 21 (1972).

5. D. Pavlov and R. Popova, Electrochim. Acta, 151483 (1970)。

6. D. A. Vermilyea in "Advances in Electrochemistry and Electrochemical Engineering," Vol. 3 (Wiley 1963), P. Delahay and C.W. Tobias, Eds., p. 211.

7. M. Fleischmaan and H. R. Thirsk, Trans.Faraday Soc., 5171 (1955).

8. B. van't Riet and I. M. Kolthoff, J. Phys. Chem 64 1045 (1960).

9. V. Shaldaev and K. V. Rybalka, Soviet Electrochem. 13223 (1977).

10. D. Pavlov, Electrochim. Acta, 132051 (1968).

11. J. Weininger, J. Electrochem, Soc, 1211454 (1974).

12. T. Chiku and K. Nakajima, J. Electrochem. Soc, 1395 (1971).

13. N, Y. Lyzlov, V. I. Pshenitsyn and I. A. Aguf, Soviet Electrochem. 131201 (1978).

14. C. G. Smith, Effect of Mass Transport Boundary Layers on the Elilipsometry of Surfaces (M.S. Thesis), LBL-3903, 1975.

15. P. Reutschi and R. T. Angstadt, J. Electrochem. Soc, 1111323 (1964).

16. H. F. Harring and U. B. Thomas, Trans, Electrochem. Soc., 68293 (1935)。

17. E. J. Casey and K. N. Campney, J. Electrochem. Soc., 107219 (1954).

18. P. Casson, N. Hampson and K. Peters, J. Electrochem. Soc., 1241655 (1977).

19. J. Burbank, J. Electrochem. Soc., 10387 (1956)。

20. J. Lander, J. Electrochem. Soc., 103 I (1956)。 
21. J.J. Lander, J. Electrochem.Soc, 103 1 (1956).

22. P. Reutschi and B. D. Cahan, J, Electrochem. Soc, 104406 (1957).

23. D. Pavlov and N. Tordanov, J. Electrochem. Soc., 1171103 (1970)。

24. J. Burbank, J. Electrochem.Soc., 104693 (1957).

25. J. J. Lander, J. Electrochem. Soc, 98213 (1951).

26. E. L. Littauer and K. C. Tsai, Proc. 26th Annual Power Sources Conference, p. 57 (1974).

27. E. L. Littauer and K. C. Tsai, J. Electrochem, Soc., 123771 (1976)。

28. E. L. Littauer and K. C. Tsai, J. Electrochem. Soc, 123964 (1976).

29. J. F. Cooper, P.K. Hosmer, R. V. Homsey, J. Electrochem. Soc., 1251 (1978).

30. E. L. Littauer and K. C. Tsai, J. Electrochem. Soc., 124, 850 (1977).

31. B. E. Deal and H, J. Svec, J. Am. Chem. Soc., 756173 (1953).

32. W. R. Irvine and J. A. Lund, J. Electrochem. Soc., 110141 (1963).

33. 0 . Hunderi, Surf. Sci., 57, 451 (1976).

34. H. J. Mathieu, D. E. McClure, R. H. Mullex, Rev. Sci. Instrum.45, 789 (1974)。

35. R. B. Bird, W. E. Stewart, E. N. Lightfoot, Transport Phenomena, John Wiley \& Sons, New York, 1960, Ch. 4.

36. S. Falk, A. Salkind, Alkaline Storage Batteries, Wiley \& Sons, New York, 1969, p. 580.

37. R. C. Weast, CRC Handbook of Chemistry and Physics (Chemical Rubber Co., 1969) p. D171.

38. R. H. Mullex in "Advances in Electrochemistry and Electrochemical Engineering," Vol.9 (Wiley, 1973), R。H.Muller, Ed。, p. 167.

39. C. G. Smith, J. S. Remer and R. H. Muller, Component Imperfections and Azimuth Errors in and Automatic Self-Compensating Ellipsometer, LBL-7303 (1978).

40. H. J. S. Sand, Phil. Mag., 1, (6), 45 (1901).

41. C. R. Wilke, C,W. Tobias and M. Eisenberg, Chem. Engr. Progr. 49 663 (1953). 
42. R. Rosebrugh and W. L. Millex, J. Phys, Chem, 14, 816 (1910)。

43. Program MINUIT, available from Lawrence Berkeley Laboratory, computer program library.

44. C. G. Smith, Ellipsometry of Anodic Film Growth, PhD Thesis, U, C. Berkeley, Dept. of Chem. Engr., 1978.

45. P. Ruetschi, J. Electrochem. Soc, 120, 331 (1973)。

46. C. Y. Tai, W. L. McCabe and R.W. Rousseau, AIChE J., 21, 351 (1975)。

47. C. A. Fenstermaker and F. L. McCrakin, Surf. Sci., 16, 85 (1969).

48. Max Born, Principles of Optics, 4th ed. , Pergaman Press, New York (1969)

49. J.Horkans, B. Cahan and E. Yeager, J. Electrochem. Soc., 1221585 (1975)

50. J.M. Eldridge and D.W.Dong, Surt. Sei., 40512 (1973)

51. P. Delahay, M. Pourbaix and P. Van Rysselberghe, J Electrochem Soc., 9857 (1951). 
This report was done with support from the Department of Energy. Any conclisions or opinions expressed in this report represent solely those of the author(s) and not necessarily those of The Regents of the University of Califorma, the liawrence Berkeley Laboratory or the D) loartment of Pllergy: 


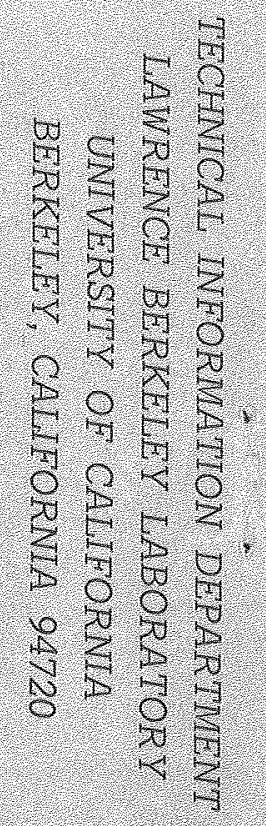

